\title{
Underwater Coatings Testing for INEEL Fuel Basin Applications
}

\author{
Julia Tripp
}

Kip Archibald

Ann Marie Phillips

January 2004

Idaho National Engineering and Environmental Laboratory Bechtel BWXT Idaho, LLC 


\title{
Underwater Coatings Testing for INEEL Fuel Basin Applications
}

\author{
Julia Tripp \\ Kip Archibald \\ Ann Marie Phillips
}

January 2004

Idaho National Engineering and Environmental Laboratory Idaho Falls, Idaho 83415

Prepared for the

U.S. Department of Energy

Office of Nuclear Energy

Under DOE Idaho Operations Office

Contract DE-AC07-99ID13727 


\section{DISCLAIMER}

This information was prepared as an account of work sponsored by an agency of the U.S. Government. Neither the U.S. Government nor any agency thereof, nor any of their employees, makes any warranty, express or implied, or assumes any legal liability or responsibility for the accuracy, completeness, or usefulness of any information, apparatus, product, or process disclosed, or represents that its use would not infringe privately owned rights. References herein to any specific commercial product, process, or service by trade name, trademark, manufacturer, or otherwise, does not necessarily constitute or imply its endorsement, recommendation, or favoring by the U.S. Government or any agency thereof. The views and opinions of authors expressed herein do not necessarily state or reflect those of the U.S. Government or any agency thereof. 


\section{CONTENTS}

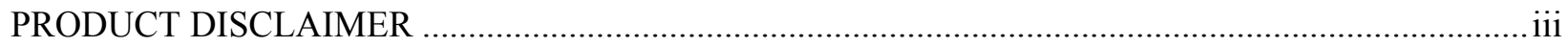

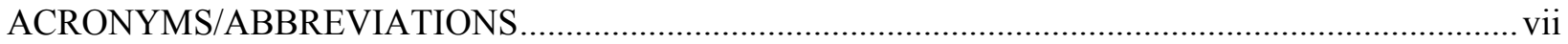

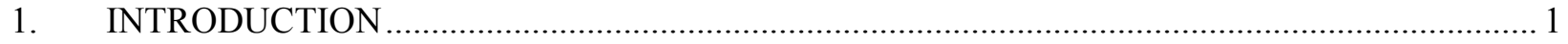

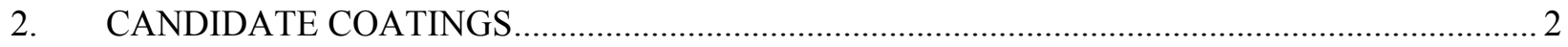

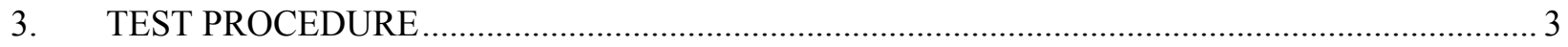

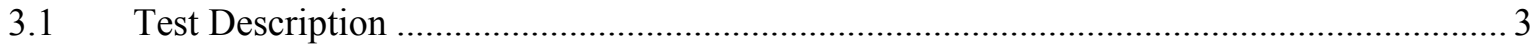

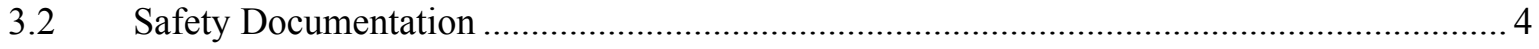

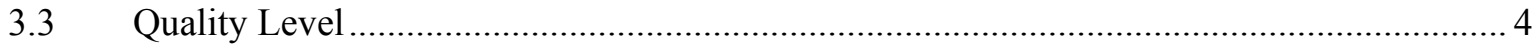

INEEL Personnel Contact Information ................................................................... 5

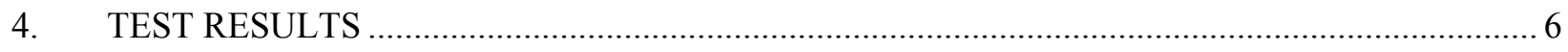

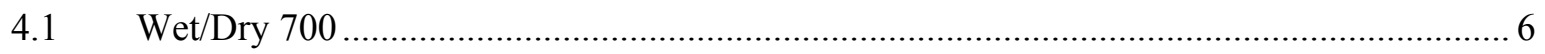

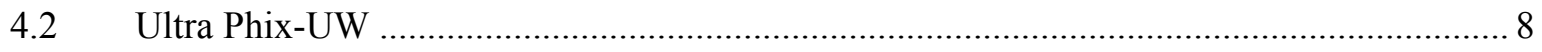

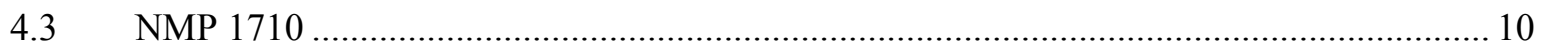

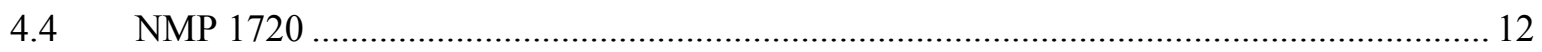

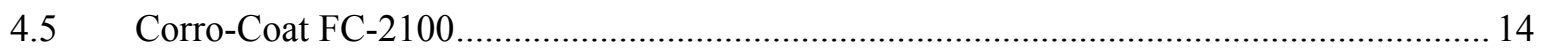

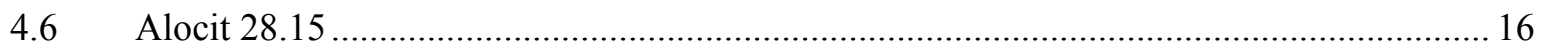

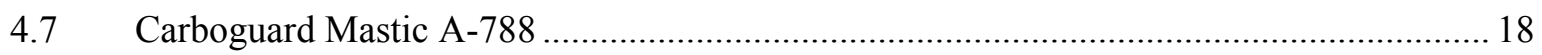

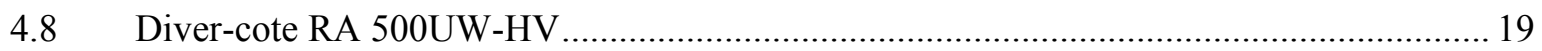

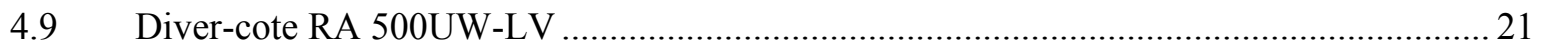

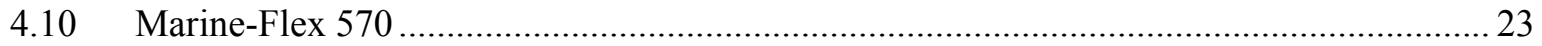

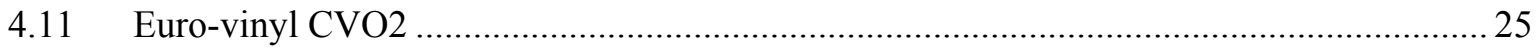

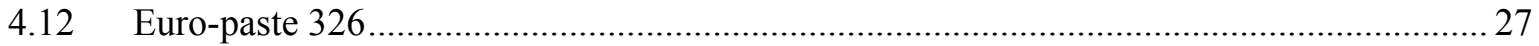

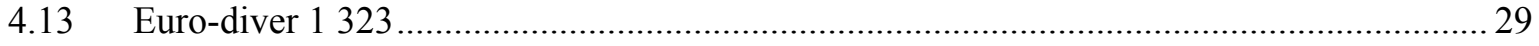

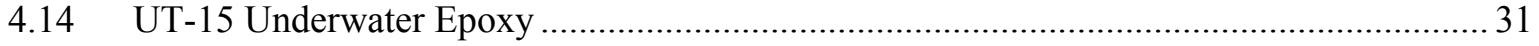

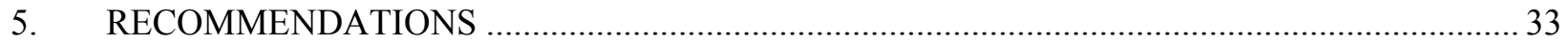


Appendix A-MSDSs and Product Information ....

Appendix B-Quality Assurance Documentation.

Appendix C-Water Sample Analysis .

\section{TABLES}

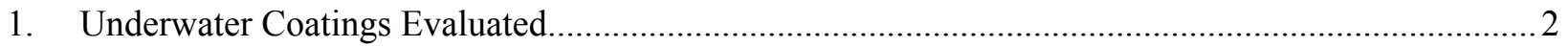

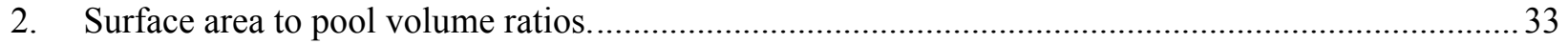




\section{ACRONYMS/ABBREVIATIONS}

$\begin{array}{ll}\text { CFA } & \text { Central Facilities Area } \\ \text { INEEL } & \text { Idaho National Engineering and Environmental Laboratory } \\ \text { INTEC } & \text { Idaho Nuclear Technology and Engineering Center } \\ \text { JSA } & \text { Job Safety Analysis } \\ \text { MSDS } & \text { Material Safety Data Sheet } \\ \text { MTR } & \text { Materials Test Reactor } \\ \text { NBA } & \text { North Boulevard Annex } \\ \text { PBF } & \text { Power Burst Facility } \\ \text { PPE } & \text { Personal Protective Equipment } \\ \text { TAN } & \text { Test Area North }\end{array}$




\section{Underwater Coatings Testing for INEEL Fuel Basin Applications}

\section{INTRODUCTION}

The Idaho National Engineering and Environmental Laboratory (INEEL) is deactivating several fuel storage basins. Airborne contamination is a concern when the sides of the basins are exposed and allowed to dry during water removal. One way of controlling this airborne contamination is to fix the contamination in place while the pool walls are still submerged. There are many underwater coatings available on the market that are used in marine, naval and other applications. A series of tests were run to determine whether the candidate underwater fixatives are easily applied and adhere well to the substrates (pool wall materials) found in INEEL fuel pools.

The four pools considered included 1) Test Area North (TAN-607) with epoxy painted concrete walls; 2) Idaho Nuclear Technology and Engineering Center (INTEC) (CPP-603) with bare concrete walls; 3) Materials Test Reactor (MTR) Canal with stainless steel lined concrete walls; and 4) Power Burst Facility (PBF-620) with stainless steel lined concrete walls on the bottom and epoxy painted carbon steel lined walls on the upper portions. Therefore, the four materials chosen for testing included bare concrete, epoxy painted concrete, epoxy painted carbon steel, and stainless steel. The typical water temperature of the pools varies from $55^{\circ} \mathrm{F}$ to $80^{\circ} \mathrm{F}$ dependent on the pool and the season. These tests were done at room temperature. 


\section{CANDIDATE COATINGS}

Through the use of internet searches, phone calls, and email, thirteen candidate underwater coatings were determined. Originally, EKOR coating (from Eurotech) was going to be tested, however, due to an inability to obtain required information and samples, this test was cancelled. An additional coating (UT-15) was added to the list tested based on a vendor response to a request for proposals for coating the pool walls underwater.

Table 1. Underwater Coatings Evaluated

\begin{tabular}{|l|l|l|}
\hline \multicolumn{1}{|c|}{ Product Name } & \multicolumn{1}{c|}{ Vendor } & \multicolumn{1}{c|}{ Comments } \\
\hline Wet/Dry 700 Epoxy & Progressive Epoxy Polymers, Inc. & www.epoxyproducts.com \\
\hline Ultra Phix-UW & Ultra Polymers, Inc. & www.ultraploymersinc.com \\
\hline NMP 1710 Epoxy & National Maintenance Products & Australia \\
\hline NMP 1720 Epoxy & National Maintenance Products & Australia \\
\hline Corro-Coat FC 2100 Epoxy & Progressive Epoxy Polymers, Inc. & www.epoxyproducts.com \\
\hline Alocit 28.15 Epoxy & Alocit Systems & UK/Europe \\
\hline Carboguard Mastic A-788 & Somay Product & \\
\hline Diver-cote RA 500UW-HV & Chemco International & Scotland \\
\hline Diver-cote RA 500UW-LV & Chemco International & Scotland \\
\hline Marine-Flex 570 & Edison Coatings Inc. & www.edisoncoatings.com \\
\hline Euro-vinyl CV02 & Euronavy & Portugal \\
\hline Euro-paste 326 & Euronavy & Portugal \\
\hline Euro-diver 1 323 Epoxy & Euronavy & Portugal \\
\hline UT-15 Underwater Epoxy & Picco Coatings Co. & Texas \\
\hline
\end{tabular}

The following criteria were used during this evaluation. The underwater coating must:

- $\quad$ Be easy to apply

- Adhere well to the four surfaces of interest

- $\quad$ Not change or have a negative impact on water chemistry or clarity

- Not be hazardous in final applied form

- $\quad$ Be proven in other underwater applications.

In addition, it is desirable for the coating to have a high pigment or high cross-link density to prevent radiation from penetrating. 


\section{TEST PROCEDURE}

\subsection{Test Description}

The coatings were applied underwater in a non-radioactive test at the North Boulevard Annex (NBA). Each coating was applied to four different substrates: epoxy-painted concrete; bare concrete; epoxy-painted carbon steel; and stainless steel. The test equipment included clear plastic containers (1.5 feet deep, 2.5 feet long, 1.5 feet wide), brushes, rollers, trowels, stirring sticks, and small containers for mixing up the coatings. Before use, the test containers were washed with soap to remove any manufacturing residue. Personal protective equipment (PPE) consisting of nitrile gloves and safety glasses, as identified by the Industrial Hygienist, were used for all mixing and application of all coatings. Also per the Industrial Hygienist's recommendations, an eyewash was obtained and installed.

A set of four test coupons was used for each of the coatings. The stainless steel and carbon steel test coupons were cut (8" squares) from stock material. The carbon steel plates were then painted with epoxy paint and allowed to cure according to manufacturer's recommendations. Standard concrete bricks (6000 psi concrete -4 " wide X 8" long X 2" deep) were also used and half of these bricks were coated with epoxy paint. Before placing the steel coupons in the water, they were washed to remove any machine oil residue. The metal test coupons were glued with silicone in a vertical orientation to the sides of the clear plastic containers. A separate container was used for each coating to avoid cross-contamination among different fixatives. Concrete test coupons were placed in water to soak for at least 48 hours before the start of testing then transferred to the test container with the metal samples and the test container was filled with water. To avoid excessive rusting of the carbon steel coupons, the test containers were filled with water on the test day. Before and during testing, the water temperature was monitored with a thermocouple since water temperature can have a significant impact on product performance and on epoxy coating pot life (the length of time between mixing and hardening).

Each coating was mixed according to the supplier's instructions. Careful attention was paid to the expected pot life; to ensure that the coating was applied to all four test coupons before hardening. The coating was applied underwater to the vertical surface of each of four test coupons; one of each type of substrate material. The applicator (brush, roller, trowel) was selected based on the supplier's recommendation and discretion of the person completing the application. During application of the fixatives, observations were recorded, including the following:

- $\quad$ Ease of application

- Viscosity (subjective assessment)

- $\quad$ Effectiveness of application method

- Workability

- $\quad$ Applied thickness

- $\quad$ Product control

- $\quad$ Mixing

- $\quad$ Pot time

- $\quad$ Runny, bubbles, lumpy

- Underwater transport of mixed product

- Impact on water clarity

- Chunks or drops that float or settle to bottom 
- $\quad$ Film on water

- $\quad$ Coverage

- $\quad$ Adhesion

After curing, the samples were analyzed visually for adhesion, surface roughness, cracking, and any other visually notable characteristics. In addition, an attempt to peel the fixative from the test coupon by hand, scratching with a scraper (screwdriver) at about 45 degrees, and striking with a hammer were completed. The results were documented and compared to determine which coatings displayed the best adhesion to the test coupons. This information, combined with the observations taken during application, was analyzed and the three most promising fixatives selected. Still and video photos were taken of test set-up, fixative application, cured fixative, and adhesion testing.

Upon completion of the analysis, the water was disposed of in the floor drain (after straining to remove any chunks of cured coating that could have plugged the drain). The test equipment was disassembled and the test coupons were stored for future reference. The unused fixatives were disposed of or stored in approved locations.

\subsection{Safety Documentation}

All Material Safety Data Sheets (MSDSs) and product descriptions (Appendix A) were obtained from the suppliers. INEEL form 442.10, "Agent Request Hazard Evaluation" was completed and approved for each product. Through this process, the NBA facility chemical custodian (Craig Robb), the Industrial Hygienist (Saul Chessin), Safety (Doug Ardary), and Environmental (Chris Kent) were all informed of the upcoming use of these chemicals. Once these approvals were in place, free samples of each fixative were requested from the suppliers. The fixatives were shipped to the INEEL Central Facilities Area (CFA) warehouse, and then transported to the NBA for storage and use.

The existing Job Safety Analysis (JSA) for the NBA includes mixing and applying epoxy-type materials. An analysis by the Safety Representative and Chemical Custodian showed that the existing JSA encompassed the planned work, so an additional JSA was not required.

\subsection{Quality Level}

A form 414.A06 (Appendix B) was completed to determine and document the Quality Level for this work. The testing at the NBA was a Quality Level 4 as it was a simple scoping test.

Procurement verified that suppliers do not need to be on the Qualified Supplier List to obtain free samples for research and development testing. If the products test successfully and procurement is planned, the supplier will need to be evaluated, based on the Quality Level, for approval as a Qualified Supplier. 


\subsection{INEEL Personnel Contact Information}

\begin{tabular}{|l|l|c|l|}
\hline \multicolumn{4}{|c|}{ INEEL Personnel } \\
\hline \multicolumn{1}{|c|}{ Project Specific Title } & \multicolumn{1}{|c|}{ Name } & Phone Number & \multicolumn{1}{c|}{ E mail } \\
\hline Project Manager & Randy Bargelt & $(208) 526-9304$ & rnl@inel.gov \\
\hline Technical Lead & Julia Tripp & $(208) 526-3876$ & jtri@inel.gov \\
\hline Project Planning & Ann Marie Phillips & $(208) 526-6877$ & aqs@inel.gov \\
\hline Test Engineer & Kip Archibald & $(208) 526-3187$ & archke@inel.gov \\
\hline Test Technician & Craig Robb & $(208) 526-5295$ & car4@,inel.gov \\
\hline
\end{tabular}




\section{TEST RESULTS}

\subsection{Wet/Dry 700}

Color and Apparent Viscosity of Coating: Part A was a lumpy white paste. Part B was tan, smooth and slightly runny. After mixing together in a ratio of 1:1 with a wooden stick it was a cream-colored high viscosity paste.

Application Method Used: Both a gloved hand and a trowel were used to apply the mixed coating. It was too thick for brush application.

\section{Pot Life: 80 minutes at $75^{\circ} \mathrm{F}$}

Applied Thickness: Varied from 1/32 to 1/16 inch.

Impact on Water Clarity: During application, water was clear. After 15 minutes of curing, water turned a faint yellow. The excess fixative settled on the bottom of the container. There was no apparent film on the water during or after curing.

Adhesion during Application: Covered the painted brick and painted carbon steel coupons with ease. However, the coating seemed to tear away from the stainless steel and bare concrete surfaces as it was applied. After application, there was no slumping of the coating.

Cure Time and Temperature: A seven-day cure was used (only 2 days required according to manufacturer's information) at about $57^{\circ} \mathrm{F}$.

Appearance after Curing: The surface was cream-colored and rough but no cracking was observed. 100\% of the surfaces were covered.

Adhesion after Curing: The coating was very well adhered to all surfaces. The material overhanging the edge of the coupon could be broken off (taking the epoxy paint with it on the painted coupons).

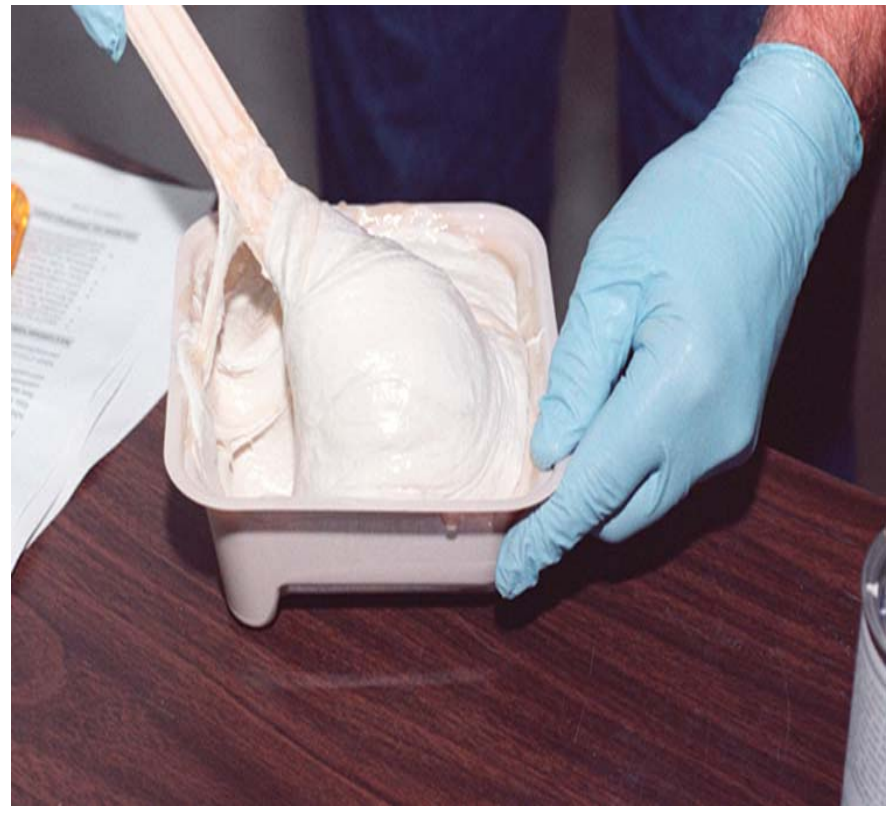

Mixing Wet-Dry 700 resulted in thick white paste.

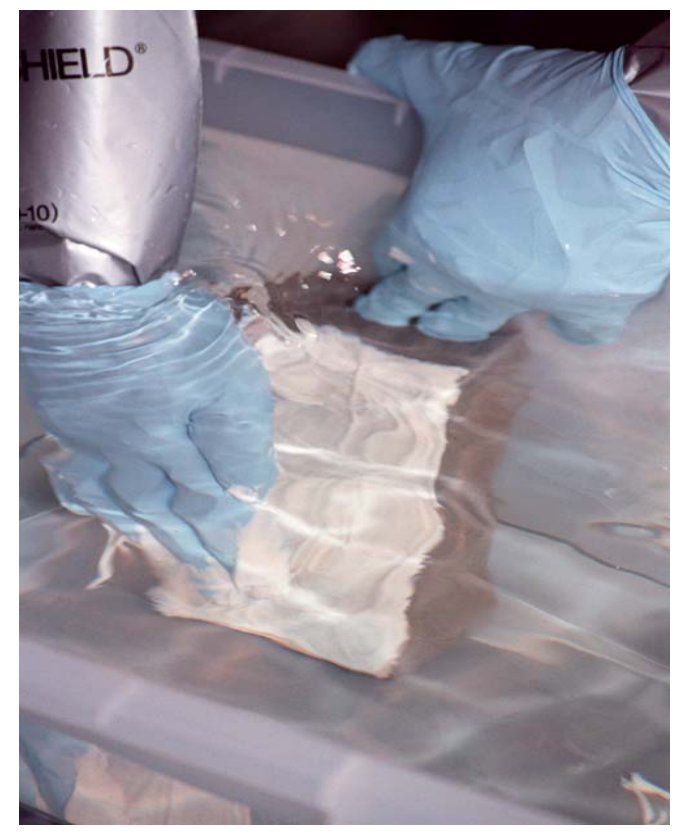

Applying Wet-Dry 700 to brick with gloved hand. 

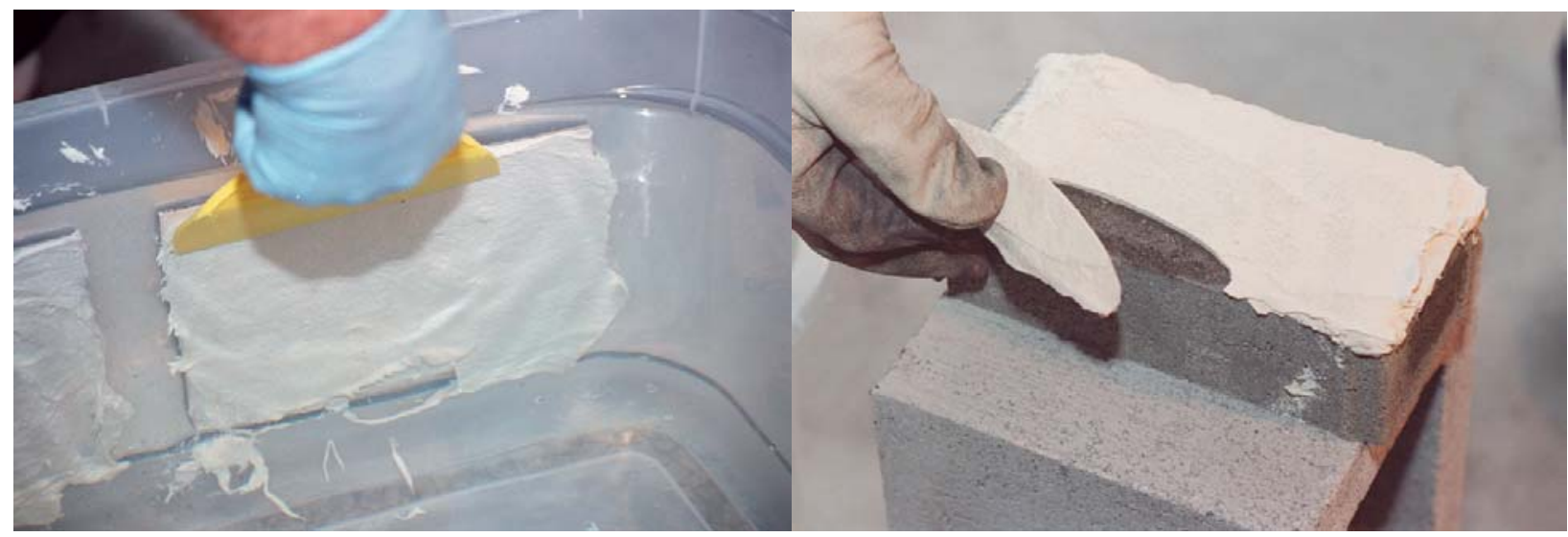

Applying Wet-Dry 700 to stainless steel with trowel.

Overhanging edge of Wet-Dry 700 can be broken off brick.

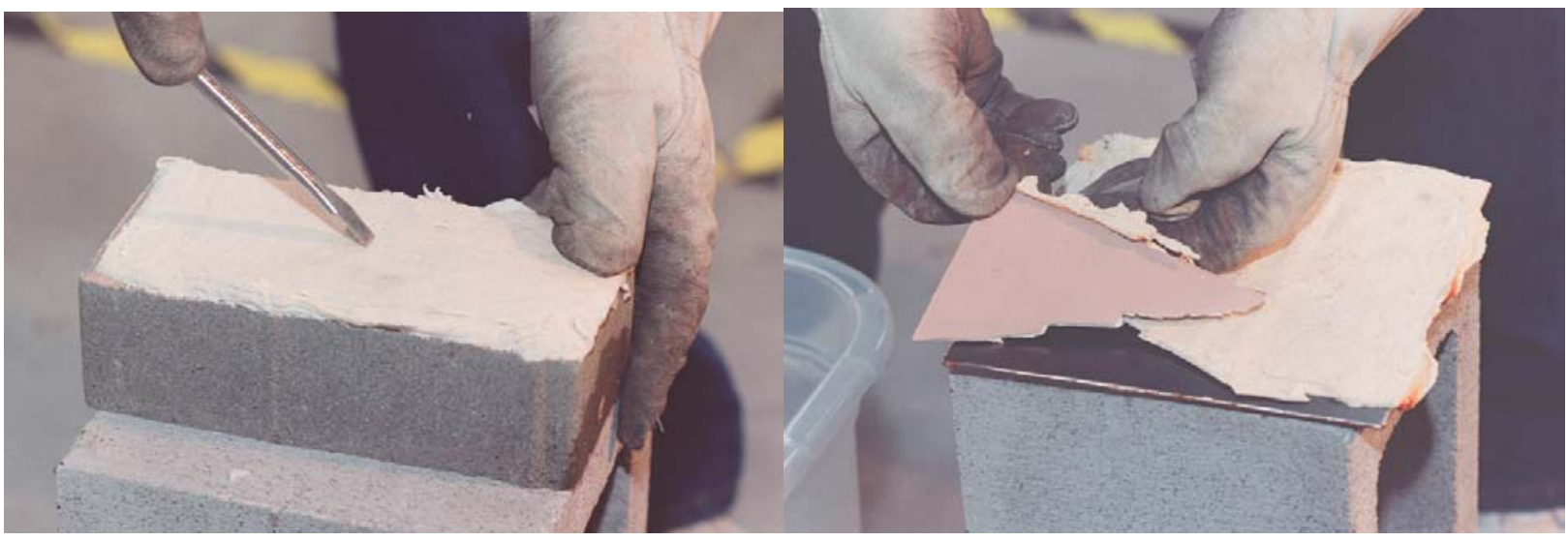

Scrapping Wet-Dry 700 has no affect.

Overhanging edge of Wet-Dry 700 can be broken off of carbon steel plate taking epoxy paint with it. 


\subsection{Ultra Phix-UW}

Color and Apparent Viscosity of Coating: Both parts of the coating were contained inside a caulking type tube. After application, in a ratio of 2:1 as automatically fed through an in line mixing tube with the caulking gun it was a cream-colored high viscosity paste.

Application Method Used: The vendor provided the caulking gun with a mixing tip was used to squirt the coating out on the coupons surfaces underwater. Then a trowel was used to smooth the coating over the entire surface. This was very time consuming as each squeeze provided just a little coating and the resulting coating was not well mixed (in full scale application it is assumed this would not be an issue).

Pot Life: Since the coating is mixed as it is applied, pot life is not an issue.

\section{Applied Thickness: Varied from 1/32 to $1 / 16$ inch}

Impact on Water Clarity: During application, water was clear. After 15 minutes of curing, water turned a faint yellow. A small amount of coating floated on the water surface (probably due to the application method). There was no apparent film on the water during or after curing.

Adhesion during Application: Covered the painted brick and painted carbon steel coupons with ease. However, the coating seemed to tear away from the stainless steel and bare concrete surfaces as it was applied. After application there was no slumping of the coating.

Cure Time and Temperature: A seven-day cure was used (only 3 days required according to manufacturer's information) at about $57^{\circ} \mathrm{F}$.

Appearance after Curing: The surface was cream-colored and rough but no cracking was observed. 100\% of the surfaces were covered.

Adhesion after Curing: The coating would not peel away from the coupon surfaces but it could be scratched off with a screwdriver held at a $45^{\circ}$ angle. The material overhanging the edge of the coupon could be broken off (taking the epoxy paint with it on the painted coupons).

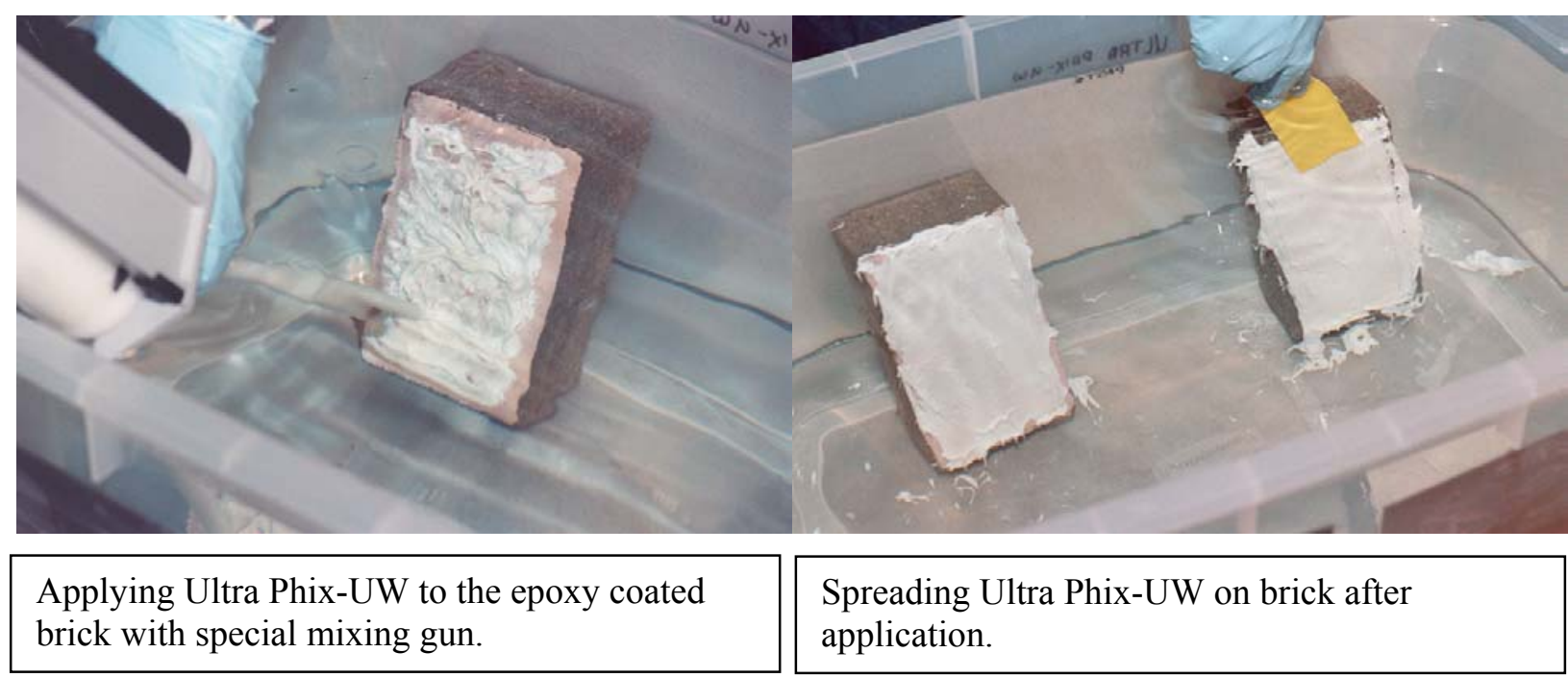




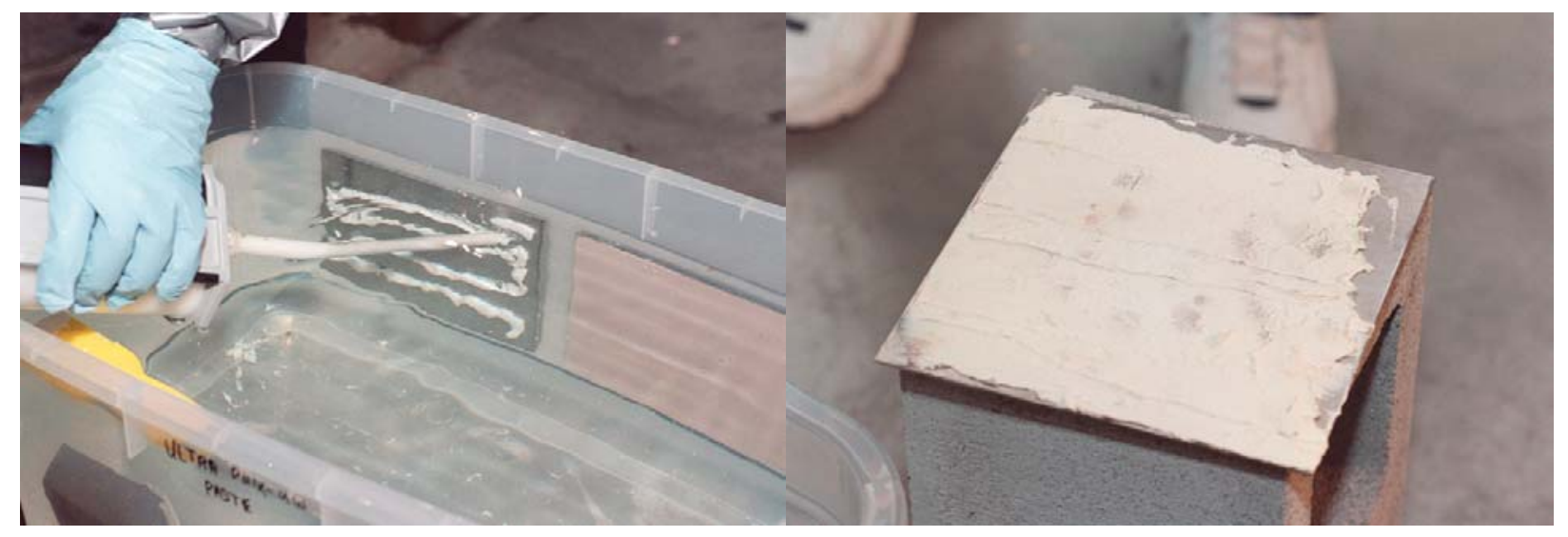

Applying Ultra Phix-UW to the stainless steel with special mixing gun.

Overhanging edges of Ultra Phix-UW will break off.

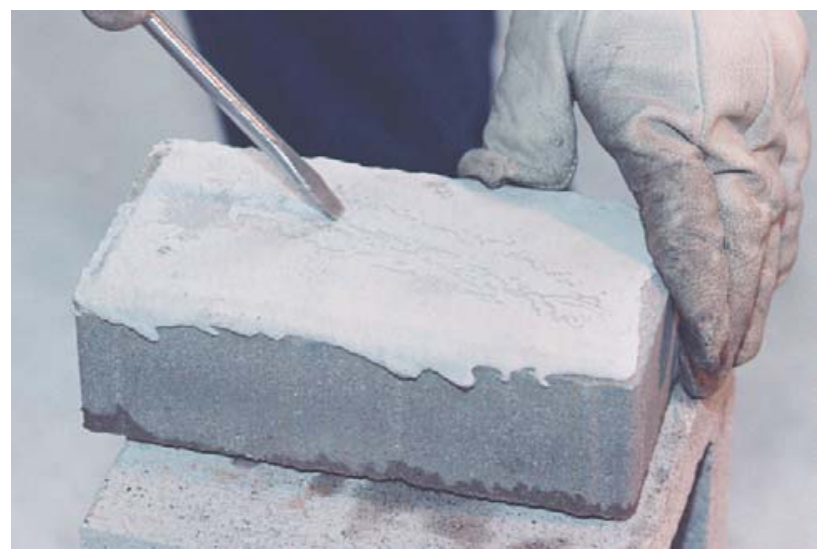

Scrapping Ultra Phix-UW will remove some coating. 


\subsection{NMP 1710}

Color and Apparent Viscosity of Coating: Part A was a white and runny. Part B was grey and a sticky paste. After mixing together in a ratio of 1:1 with a wooden stick, it was a grey-colored medium viscosity paste.

Application Method Used: This material was applied using a plastic trowel.

Pot Life: 45 minutes at $75^{\circ} \mathrm{F}$

Applied Thickness: Varied from 1/32 to $1 / 16$ inch

Impact on Water Clarity: Water remained clear at all times. No visible effects.

Adhesion during Application: Easily covered all coupon surfaces with no tearing and no slumping.

Cure Time and Temperature: A seven-day cure was used (only 2 days required according to manufacturer's information) at about $57^{\circ} \mathrm{F}$.

Appearance after Curing: The surface was light grey-colored and semi rough but no cracking was observed. $100 \%$ of the surfaces were covered.

Adhesion after Curing: The coating was very well adhered to all surfaces. The material overhanging the edge of the coupon could be broken off.

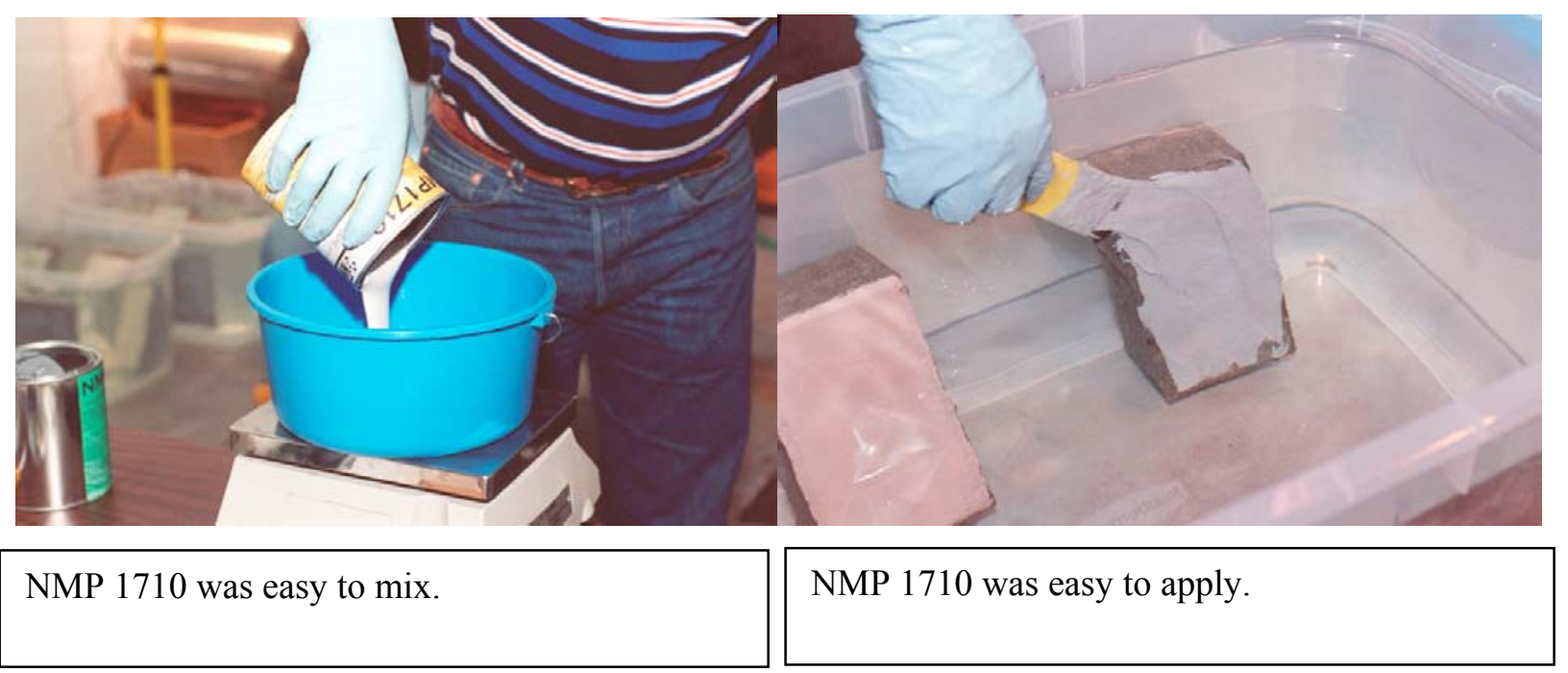




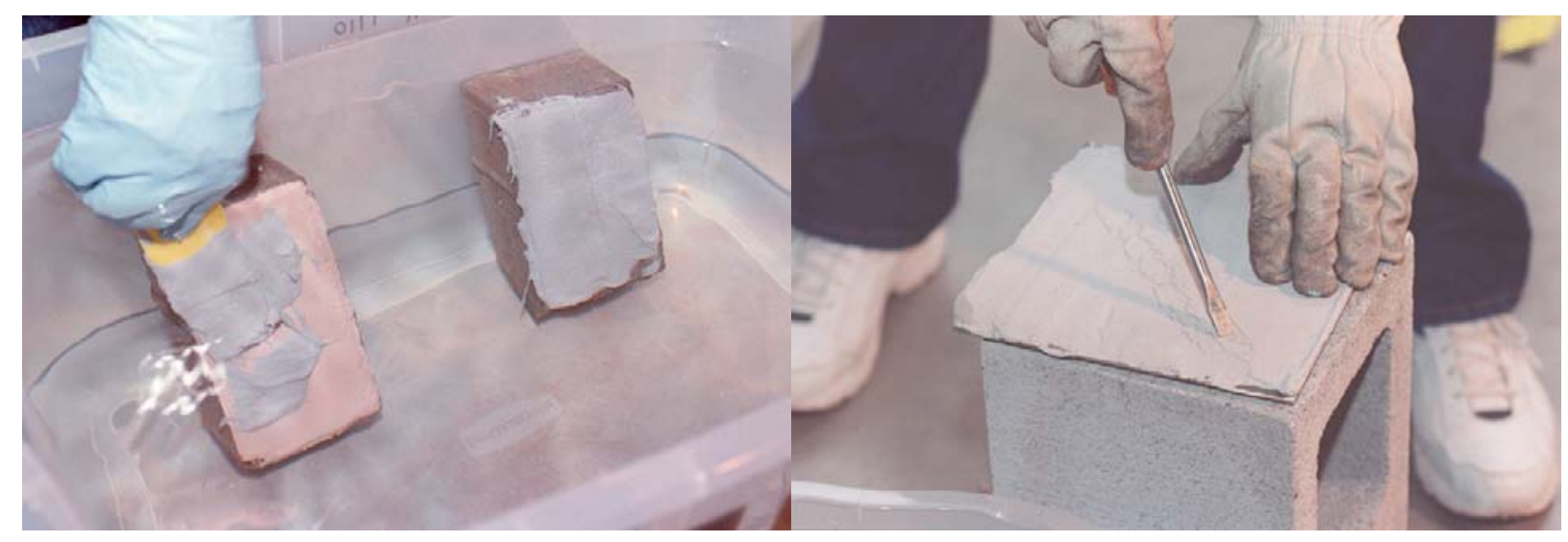

NMP 1710 application on epoxy coated brick.

A little of the overhanging edge of NMP 1710 could be broken off but coating is well adhered to all surfaces.

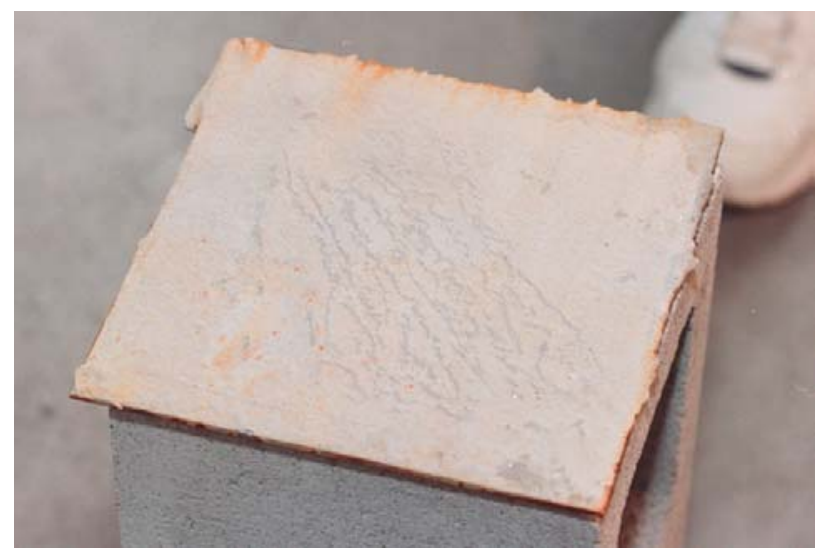




\subsection{NMP 1720}

Color and Apparent Viscosity of Coating: Part A was a white and taffy-like. Part B was tan and pastelike. After mixing together in a ratio of 1:1 with a wooden stick, it was a white-colored high viscosity paste.

Application Method Used: This material was applied using a plastic trowel.

Pot Life: 45 minutes at $75^{\circ} \mathrm{F}$

Applied Thickness: Varied from 1/32 to $1 / 16$ inch

Impact on Water Clarity: Water remained clear at all times. No visible effects.

Adhesion during Application: Easily covered all coupon surfaces. Some tearing was observed when applying the coating to the bare concrete coupon. No slumping of the coating was observed.

Cure Time and Temperature: A seven-day cure was used (only 2 days required according to manufacturer's information) at about $59^{\circ} \mathrm{F}$.

Appearance after Curing: The surface was white-colored and rough but no cracking was observed. 100\% of the surfaces were covered.

Adhesion after Curing: The coating was very well adhered to all surfaces. The material overhanging the edge of the coupon could be broken off.
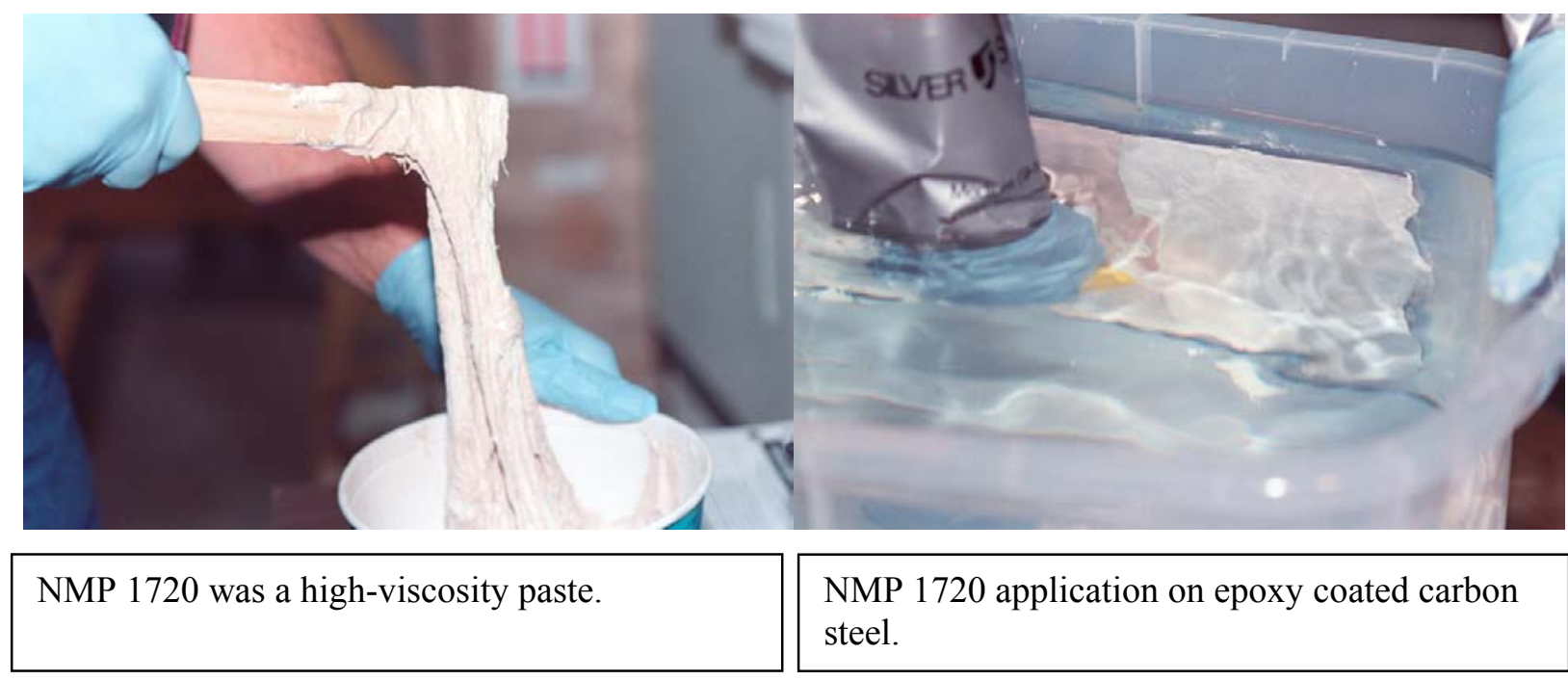

NMP 1720 application on epoxy coated carbon steel. 


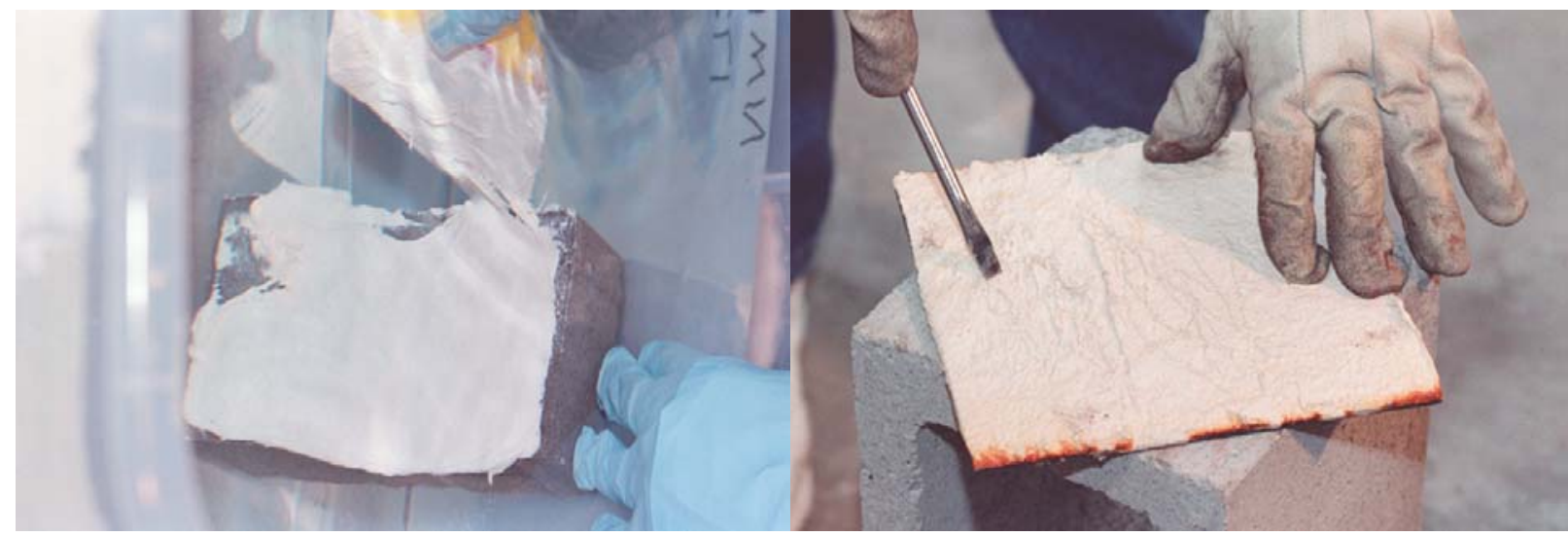

Some tearing occurred when applying NMP 1720 application to bare brick.

A little of the overhanging edge of NMP 1720 could be broken off but coating is well adhered to all surfaces.

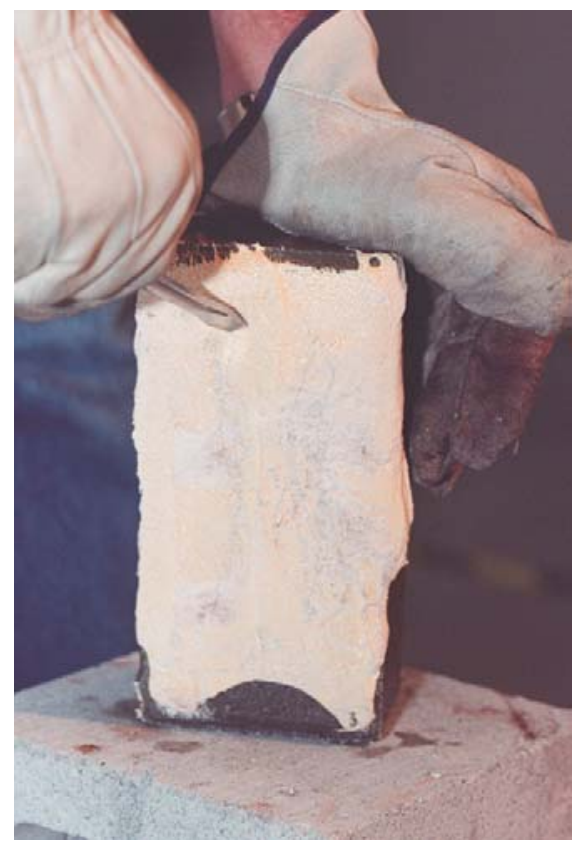

NMP 1720 could not be scrapped off the bare brick. 


\subsection{Corro-Coat FC-2100}

Color and Apparent Viscosity of Coating: Part A was a silver paste. Part B was gold with a varnish-like consistency. After mixing together in a ratio of 2:1 with a wooden stick, it was a grey-colored honey-like consistency (low-medium viscosity).

Application Method Used: This material was applied using a paintbrush.

Pot Life: $55-75$ minutes at $75^{\circ} \mathrm{F}$

Applied Thickness: Varied from 1/32 to 1/16 inch. It was easier to control the thickness and apply an even coating with this coating than with most of the others.

Impact on Water Clarity: Water remained clear at all times. No visible effects.

Adhesion during Application: Easily covered all coupon surfaces with no tearing and no slumping.

Cure Time and Temperature: A seven-day cure was used (only 8-10 hrs required according to manufacturer's information) at about $56^{\circ} \mathrm{F}$.

Appearance after Curing: The surface was grey-colored with a light roughness but no cracking was observed. $100 \%$ of the surfaces were covered with a thin coat.

Adhesion after Curing: The coating was very well adhered to all surfaces. The material overhanging the edge of the coupon could be broken off. When scrapping with a screwdriver and applying higher pressure the outer surface of the fixative can be removed. Several weeks after the original adhesion test, some of the coating on the stainless steel coupon had fallen off, but was still tightly adhered to the other coupons (these coupons had been transported around to allow others to observe them).
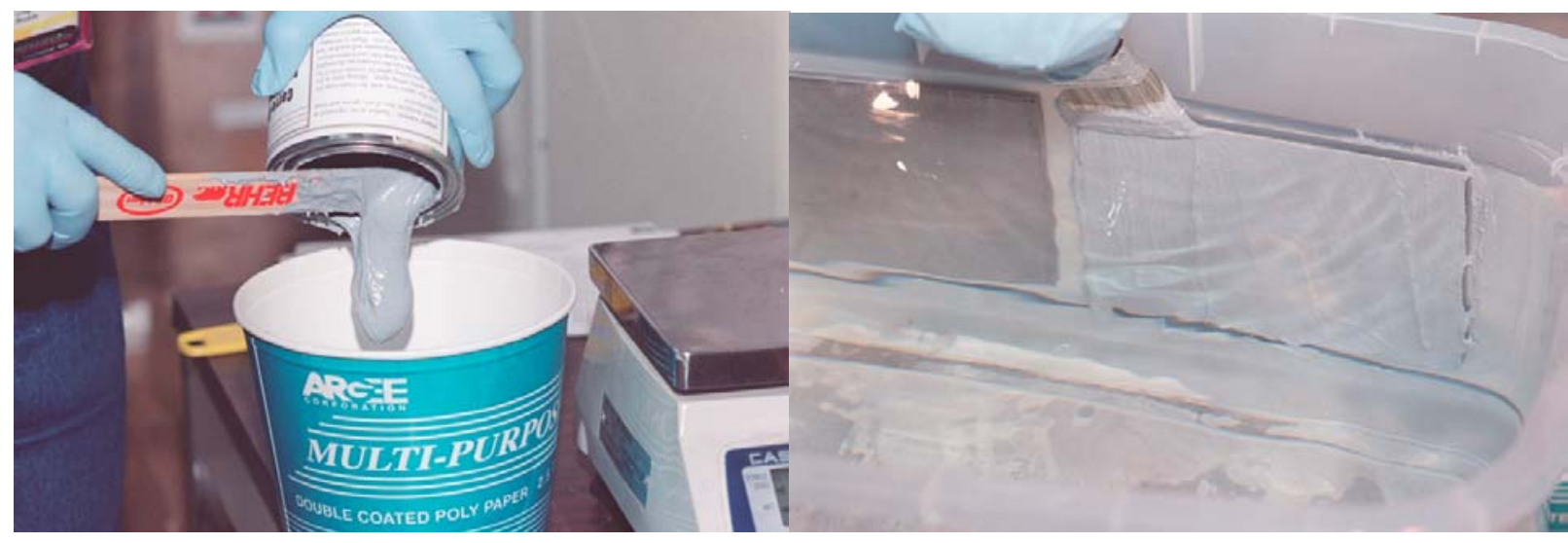

Corro-Coat FC 2100 was relatively easy to mix.

Corro-Coat FC 2100 was applied with a brush. 

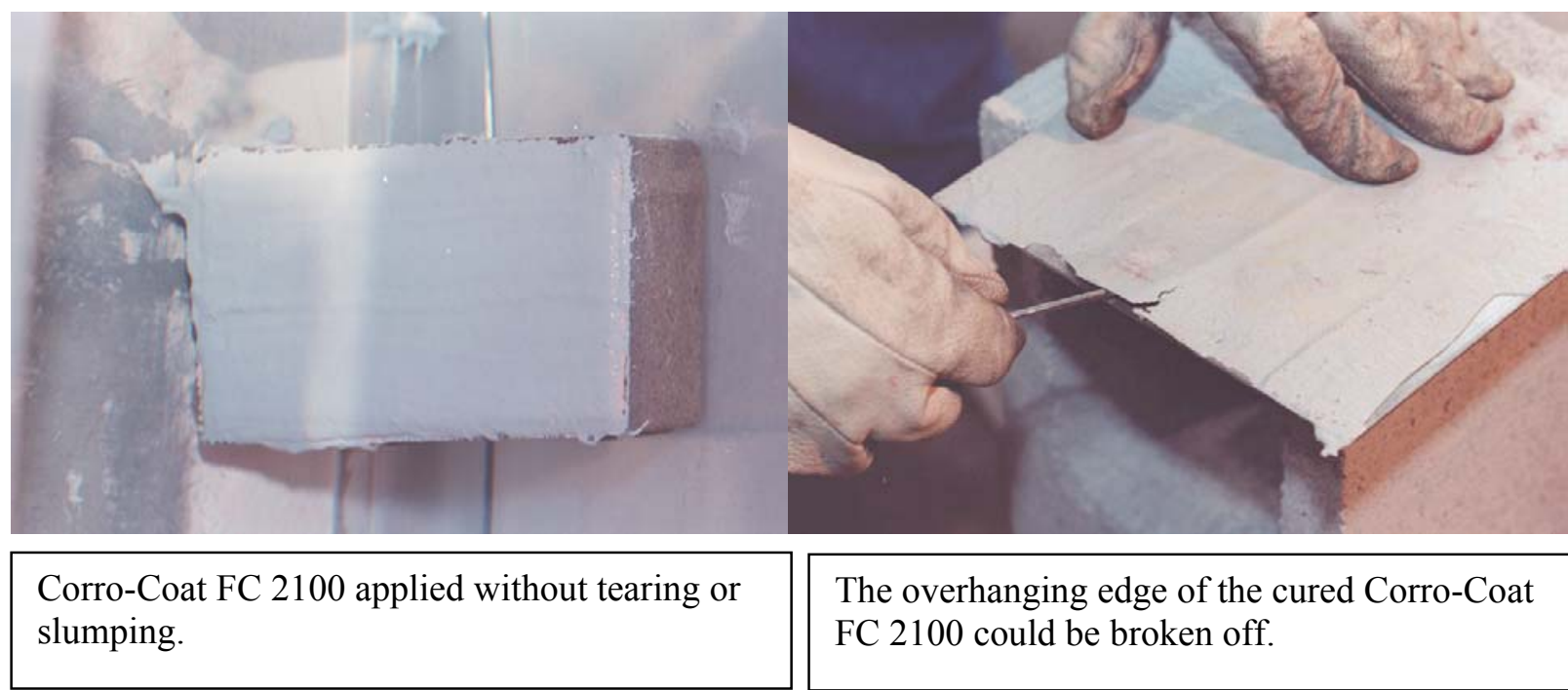

Corro-Coat FC 2100 applied without tearing or

The overhanging edge of the cured Corro-Coat FC 2100 could be broken off.

Corro-Coat FC 2100 adhered well to all surfaces during initial adhesion testing but later came off the stainless steel coupon.
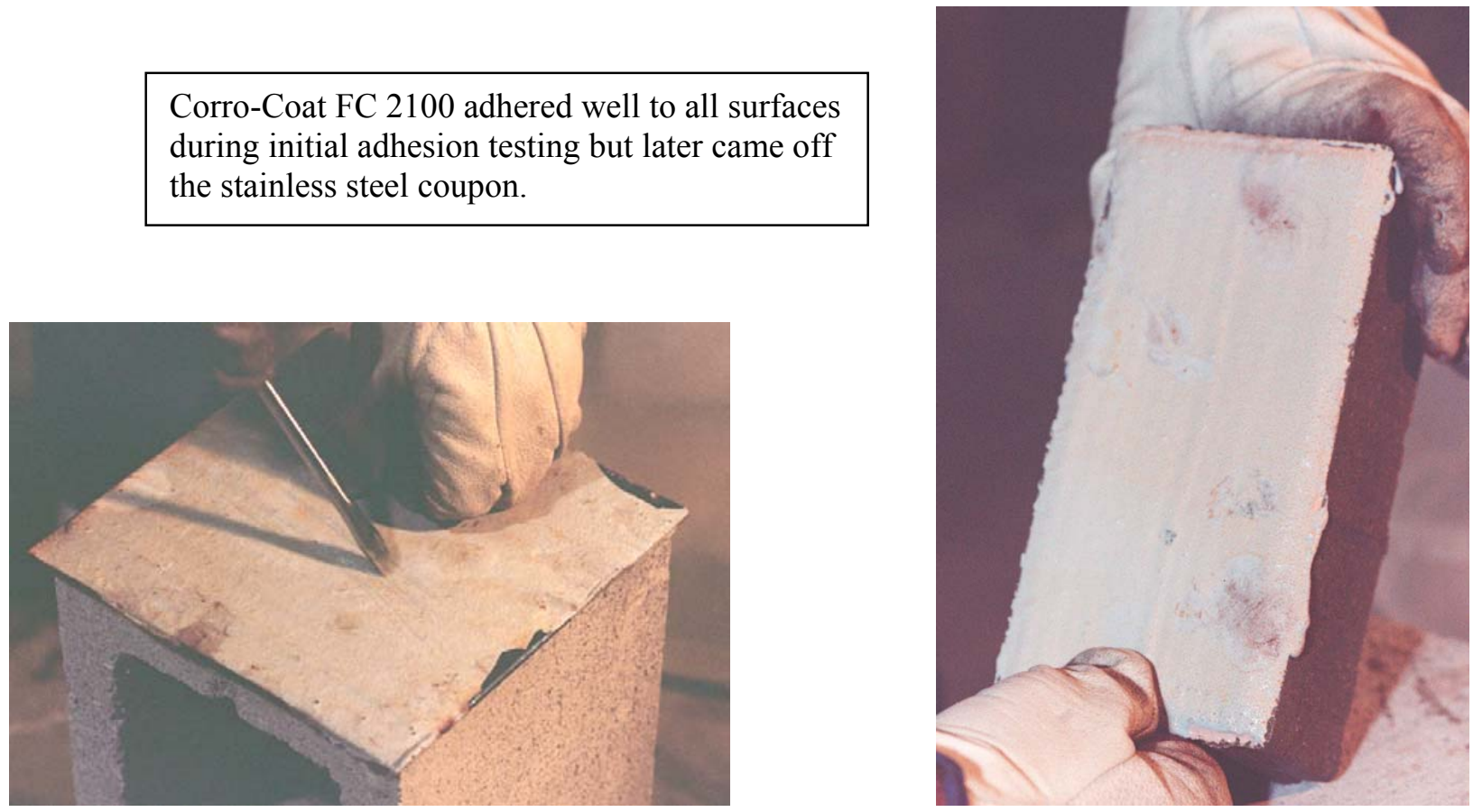


\subsection{Alocit 28.15}

Color and Apparent Viscosity of Coating: Part A was a brown paint-like material. Part B was clear with a consistency of varnish. After mixing together in a ratio of 5:1 with a wooden stick, it was tan-colored with a low-medium viscosity (like latex paint).

Application Method Used: This material was applied using a paintbrush.

Pot Life: $45 / 60$ minutes to one hour at $68^{\circ} \mathrm{F}$.

Applied Thickness: Varied from 1/32 to $1 / 16$ inch. It was easier to control the thickness and apply an even coating with this coating than with most of the others.

Impact on Water Clarity: Water remained clear during application. A small amount of floating coating was observed. After curing, a small amount of oil-like film appeared on the water surface.

Adhesion during Application: Easily covered all but the unpainted brick. It would tear away from the unpainted brick making it extremely hard to cover. Thirty minutes after the coating had been applied to the unpainted brick only about $60 \%$ of the coating remained on the brick with the rest slumping off onto the bottom of the container. After one hour of cure time, some slumping had occurred on all of the different coupons.

Cure Time and Temperature: A seven-day cure was used at about $57^{\circ} \mathrm{F}$.

Appearance after Curing: The surface was brown and smooth with no cracking was observed. 100\% of the surfaces of the stainless steel, painted carbon steel and painted concrete were covered with a thin coat. Only $60 \%$ of the bare concrete was coated.

Adhesion after Curing: The coating was very well adhered to all surfaces. The material overhanging the edge of the coupon could be broken off. When scrapping with a screwdriver and applying pressure greater than 5 psi the outer surface of the fixative can be removed.
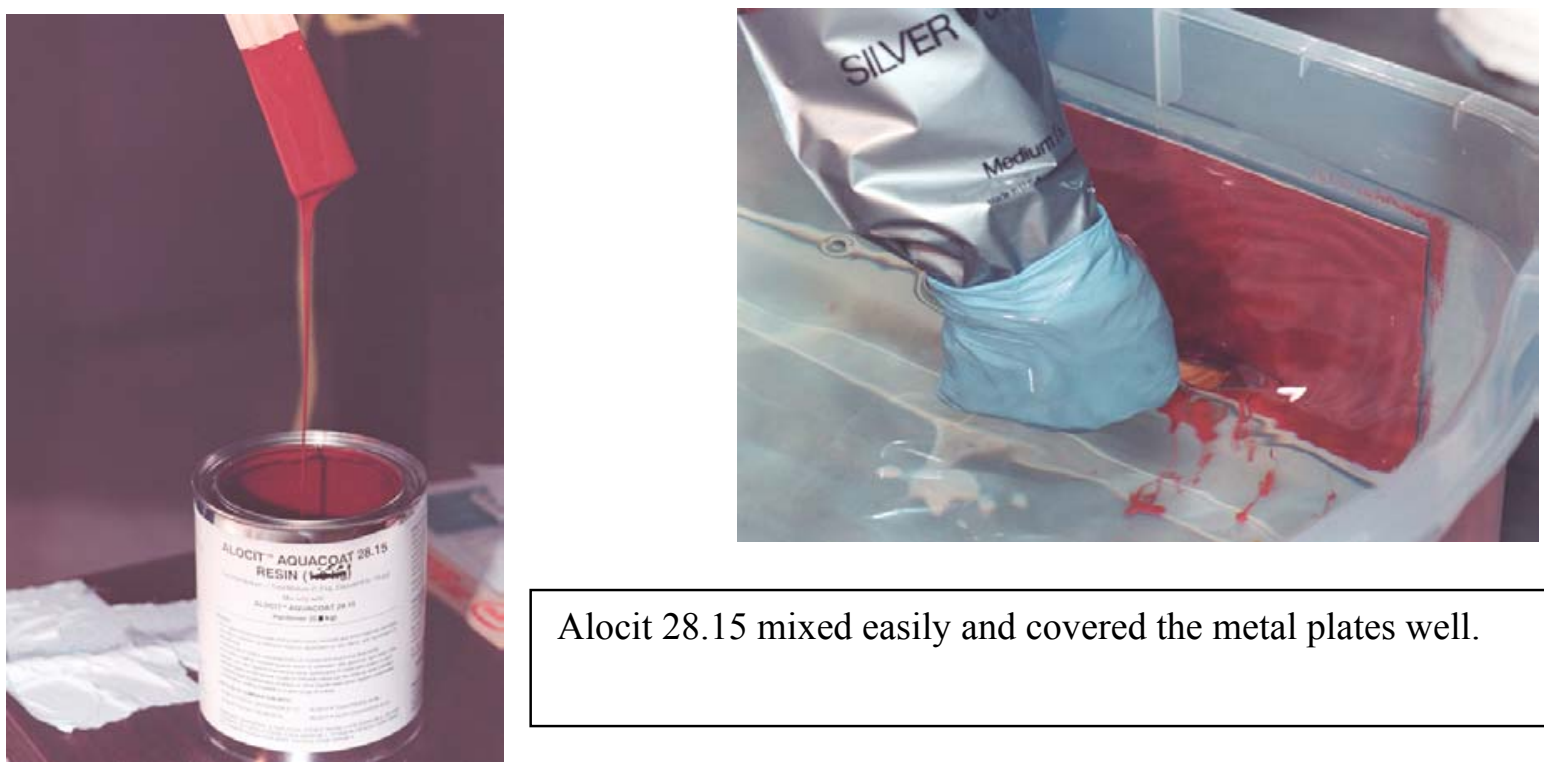

Alocit 28.15 mixed easily and covered the metal plates well. 

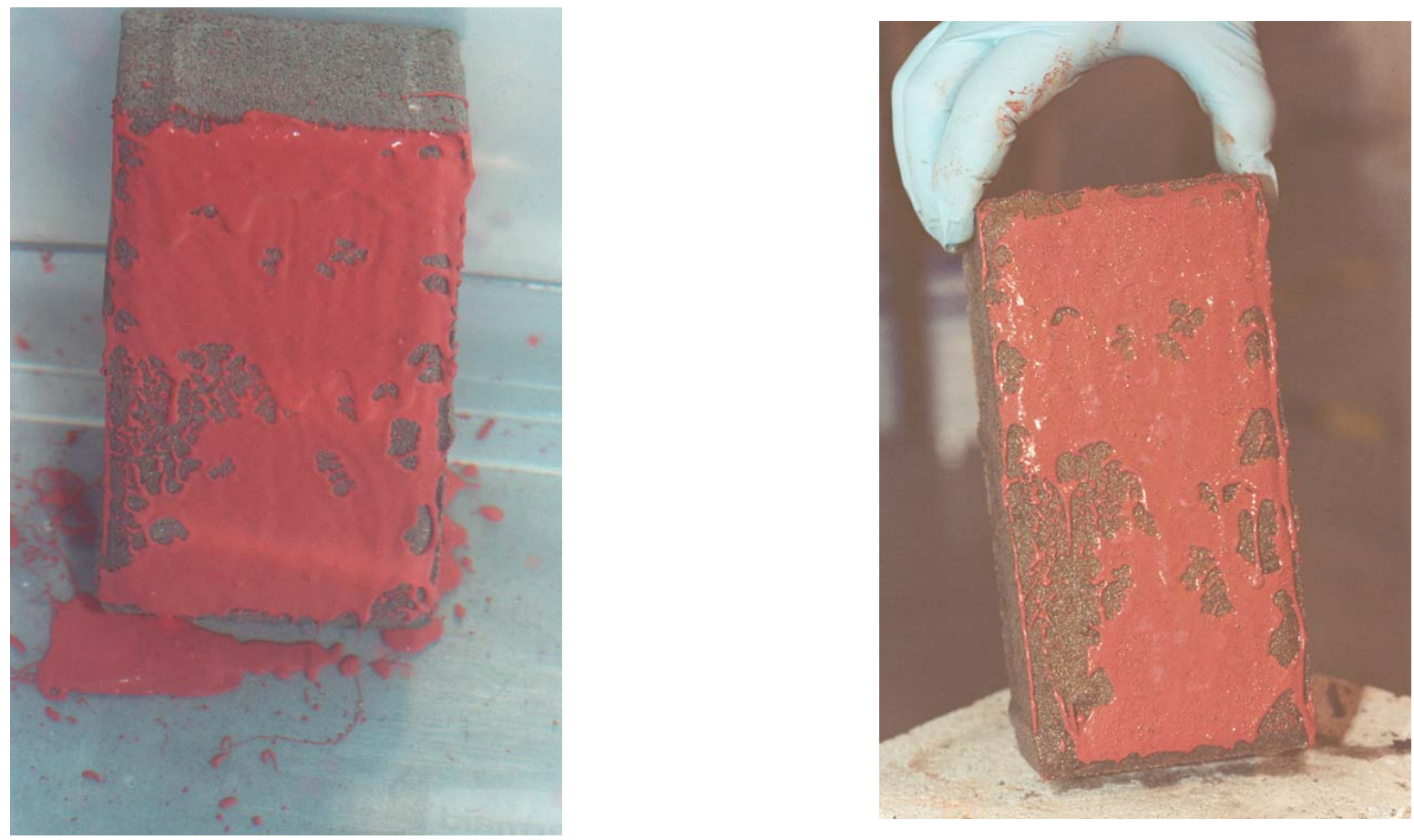

Alocit 28.15 did not adhere well to the bare brick when coating but the coating that did cure on the surface was well adhered..

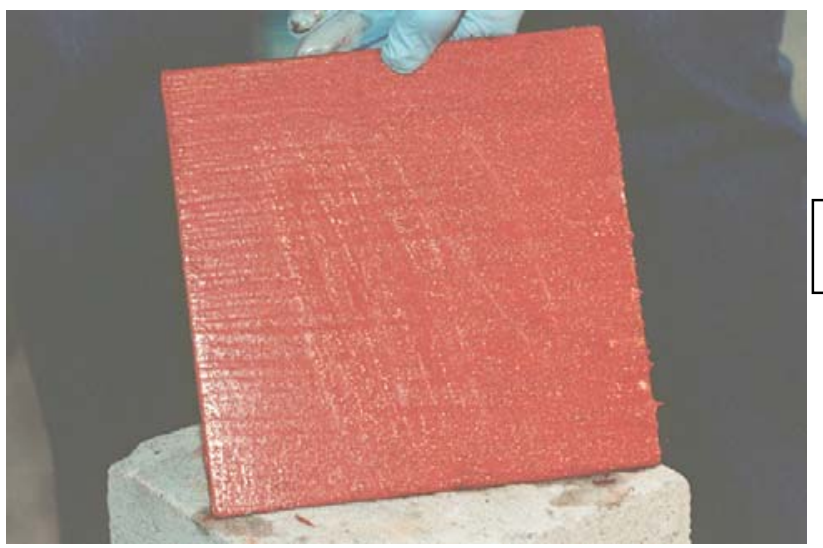

Alocit 28.15 adhered well to the metal coupons. 


\subsection{Carboguard Mastic A-788}

Color and Apparent Viscosity of Coating: Hard paste that was too difficult to mix by hand (broke two wooden sticks trying to mix).

Application Method Used: Unable to apply due to mixing difficulties and short pot life.

Pot Life: 40 minutes at $75^{\circ} \mathrm{F}$ for golf ball size amount, 15 minutes for $1 / 2$ gallon

Applied Thickness: Not applicable

Impact on Water Clarity Not applicable

Adhesion during Application: Not applicable

Cure Time and Temperature: Not applicable

Appearance after Curing: Not applicable

Adhesion after Curing: Not applicable

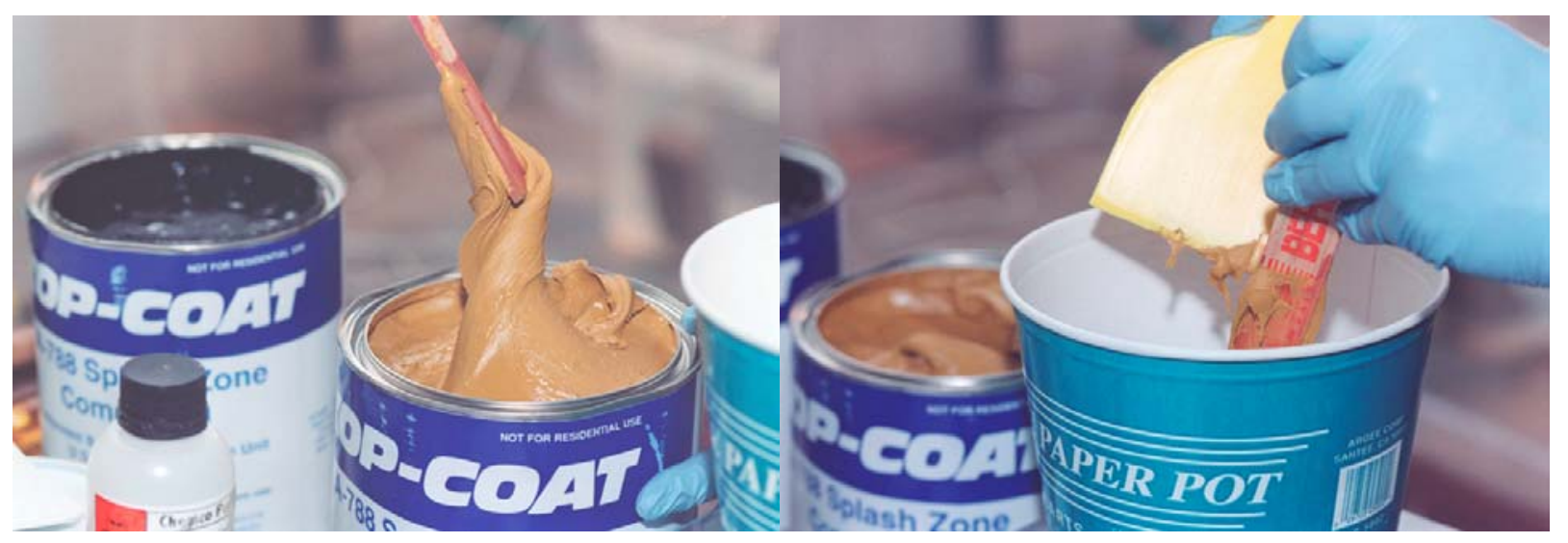

Carboguard Mastic A-788 was not tested as it was too difficult to mix and had a very short pot life.. 


\subsection{Diver-cote RA 500UW-HV}

Color and Apparent Viscosity of Coating: Part A was a clear and runny. Part B was black and lumpy paste. After mixing together in a ratio of 3:1 with a wooden stick, it was a black-colored high-viscosity paste.

Application Method Used: This material was applied using a putty knife to the painted carbon steel and half the stainless steel coupons. Application method was changed to a paintbrush after noting ease of application.

Pot Life: 80 minutes at $68^{\circ} \mathrm{F}$

Applied Thickness: Varied from 1/32 to $1 / 16$ inch.

Impact on Water Clarity: Water remained clear with a small amount of floating coating. Some excess coating settled to the bottom of the container. No film on the water when it was first applied but after application complete a small amount of oil-like film appeared on the water surface.

Adhesion during Application: Easily covered the painted brick, stainless steel and painted carbon steel. Did not adhere well to the bare concrete - tearing away from the surface. When smoothing out the coating on all surfaces the coating was stringy (thus the floating and settling coating noted above).

Cure Time and Temperature: A seven-day cure was used (only 3 days required according to manufacturer's information) at about $56^{\circ} \mathrm{F}$.

Appearance after Curing: The surface was black and smooth with no cracking observed. $100 \%$ of the surfaces were covered with a thin coat.

Adhesion after Curing: The coating was adhered to the epoxy coated brick and epoxy coated carbon steel. The coating on the bare brick and the stainless steel could be peeled off. The material overhanging the edge of the coupons could be broken off and much of the stringy material remained adhered to the coupons. When scrapping with a screwdriver and applying pressure greater than 5 psi the outer surface of the fixative can be removed.

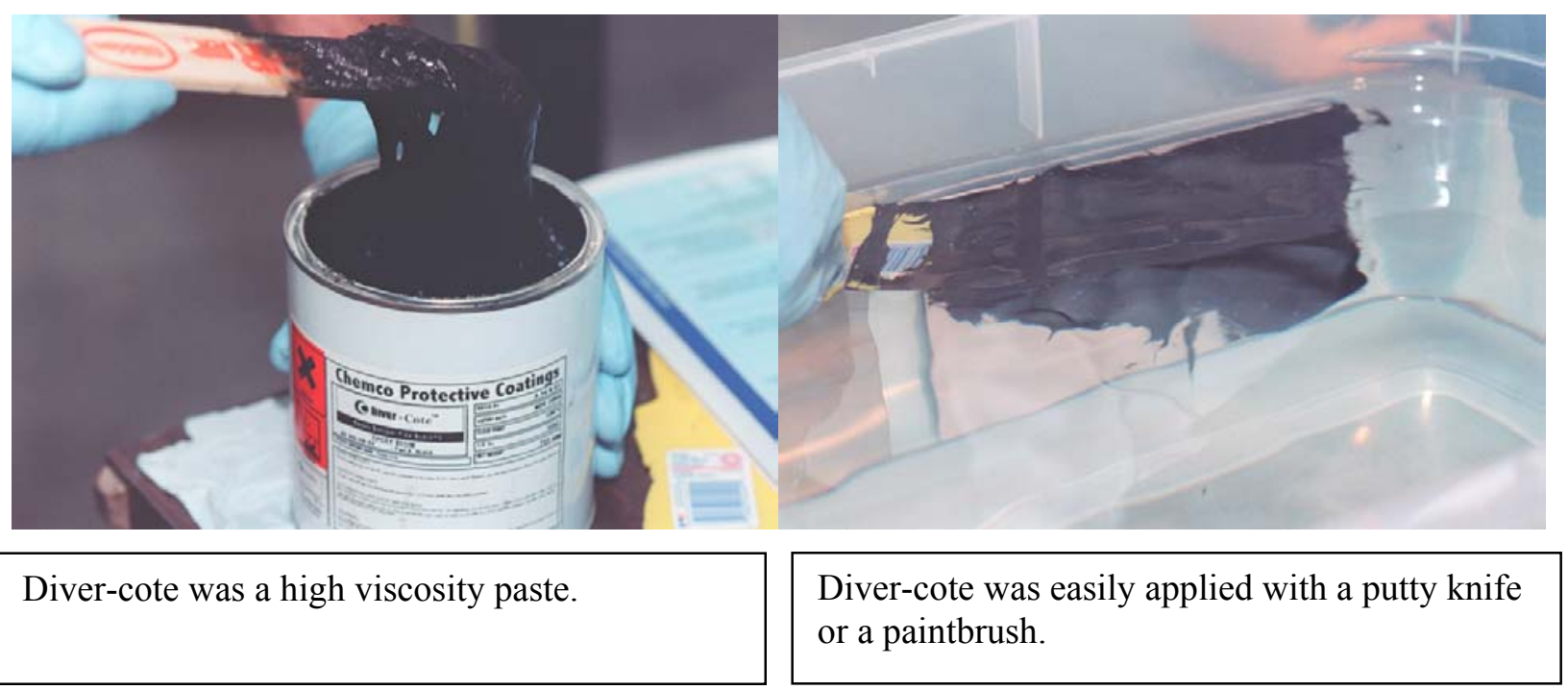




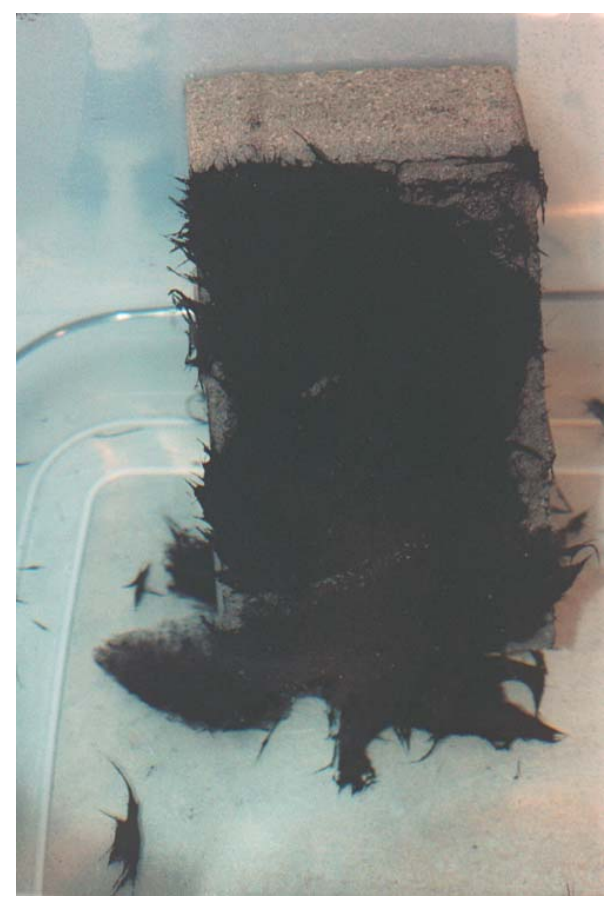

Diver cote formed "strings" in the water.

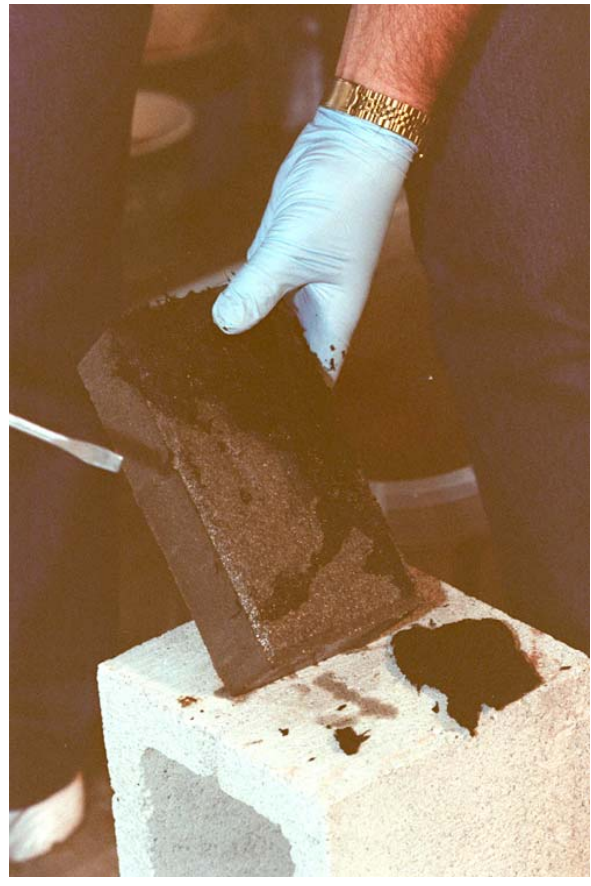

Diver-cote peeled off the bare brick after curing.

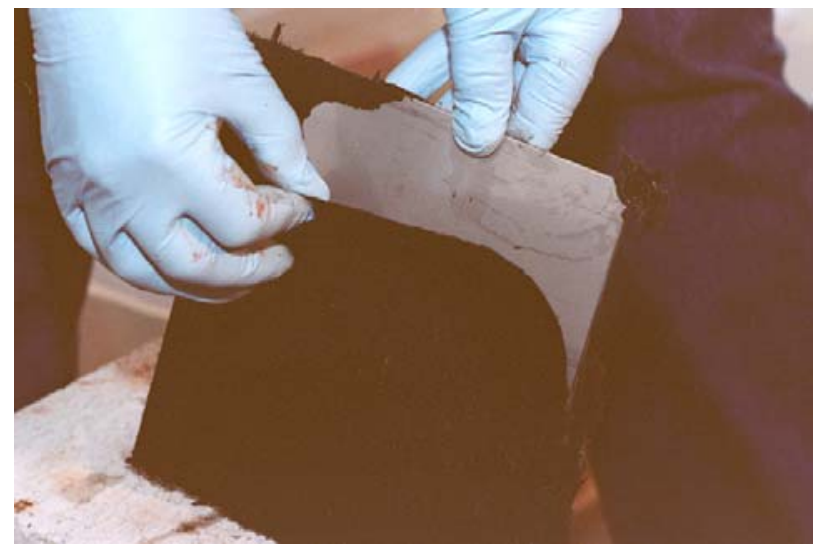

Diver-cote peeled off the stainless steel after curing. 


\subsection{Diver-cote RA 500UW-LV}

Color and Apparent Viscosity of Coating: Part A was a silver paste. Part B was gold with a varnish like consistency. After mixing together in a ratio of 3:1 with a wooden stick, it was a grey-colored honey-like consistency (low-medium viscosity).

Application Method Used: This material was applied using a paintbrush.

Pot Life: 80 minutes at $68^{\circ} \mathrm{F}$

Applied Thickness: Varied from 1/32 to $1 / 16$ inch. It was easier to control the thickness and apply an even coating with this coating than with most of the others.

Impact on Water Clarity: Water remained clear at all times. No visible effects.

Adhesion during Application: Easily covered all coupon surfaces except the unpainted brick where a larger amount of pressure had to be applied to make it adhere. The fixative slumped off all surfaces but on all but the bare brick the slumping still left a coating on the coupon.

Cure Time and Temperature: A seven-day cure was used (only 3 days required according to manufacturer's information) at about $56^{\circ} \mathrm{F}$.

Appearance after Curing: The surface was blue with a light roughness and very porous (popped air bubbles). $100 \%$ of the surfaces were covered with a thin coat except for the bare brick which was only about $1 / 8$ covered.

Adhesion after Curing: On the painted carbon steel the coating could not be peeled off but a small amount could be scrapped off with a screwdriver. The coating easily peel away from the surface of the stainless steel and the bare brick. On the painted brick small pieces of coating would peel from the edge but the majority was well adhered.
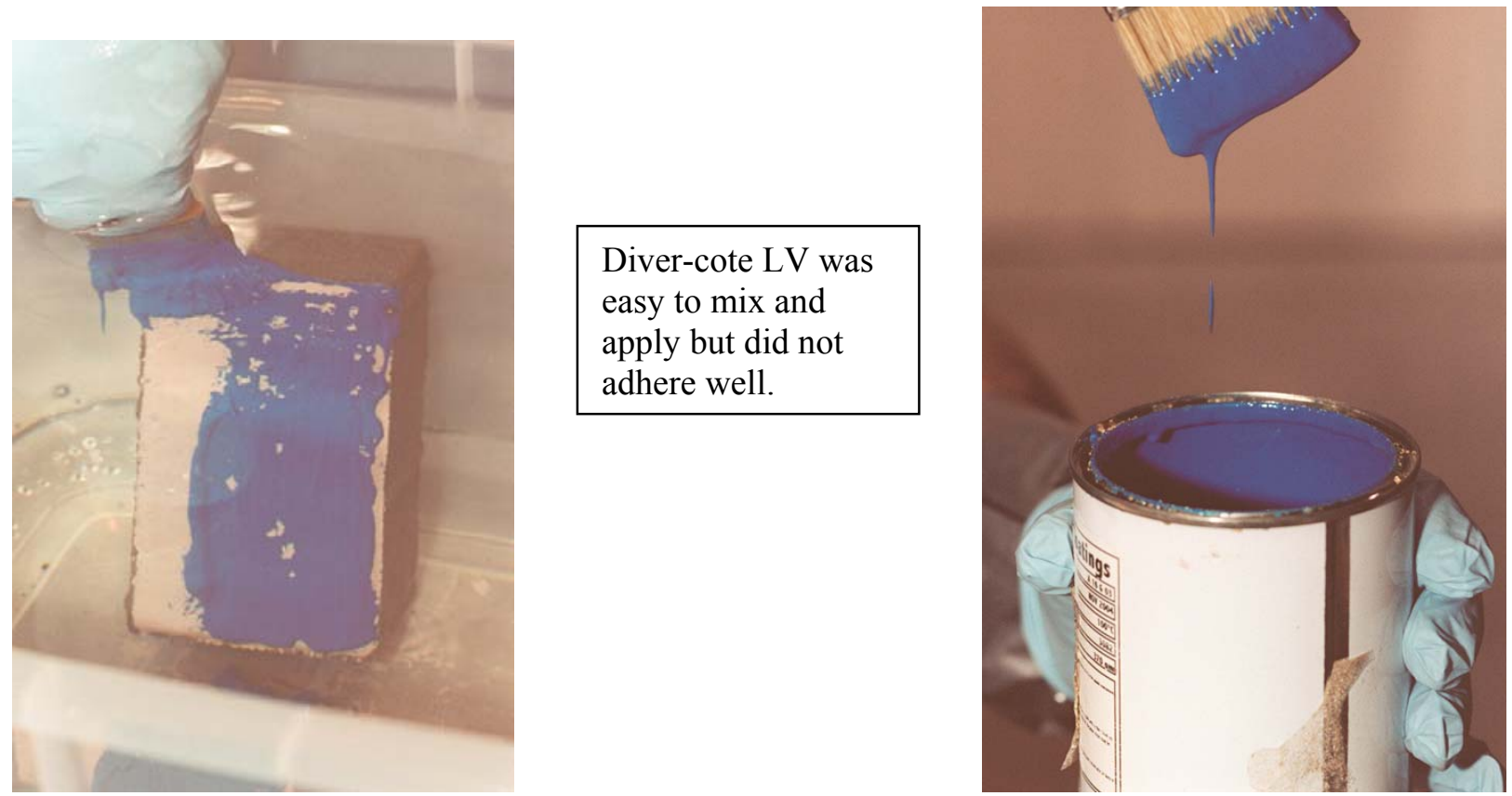

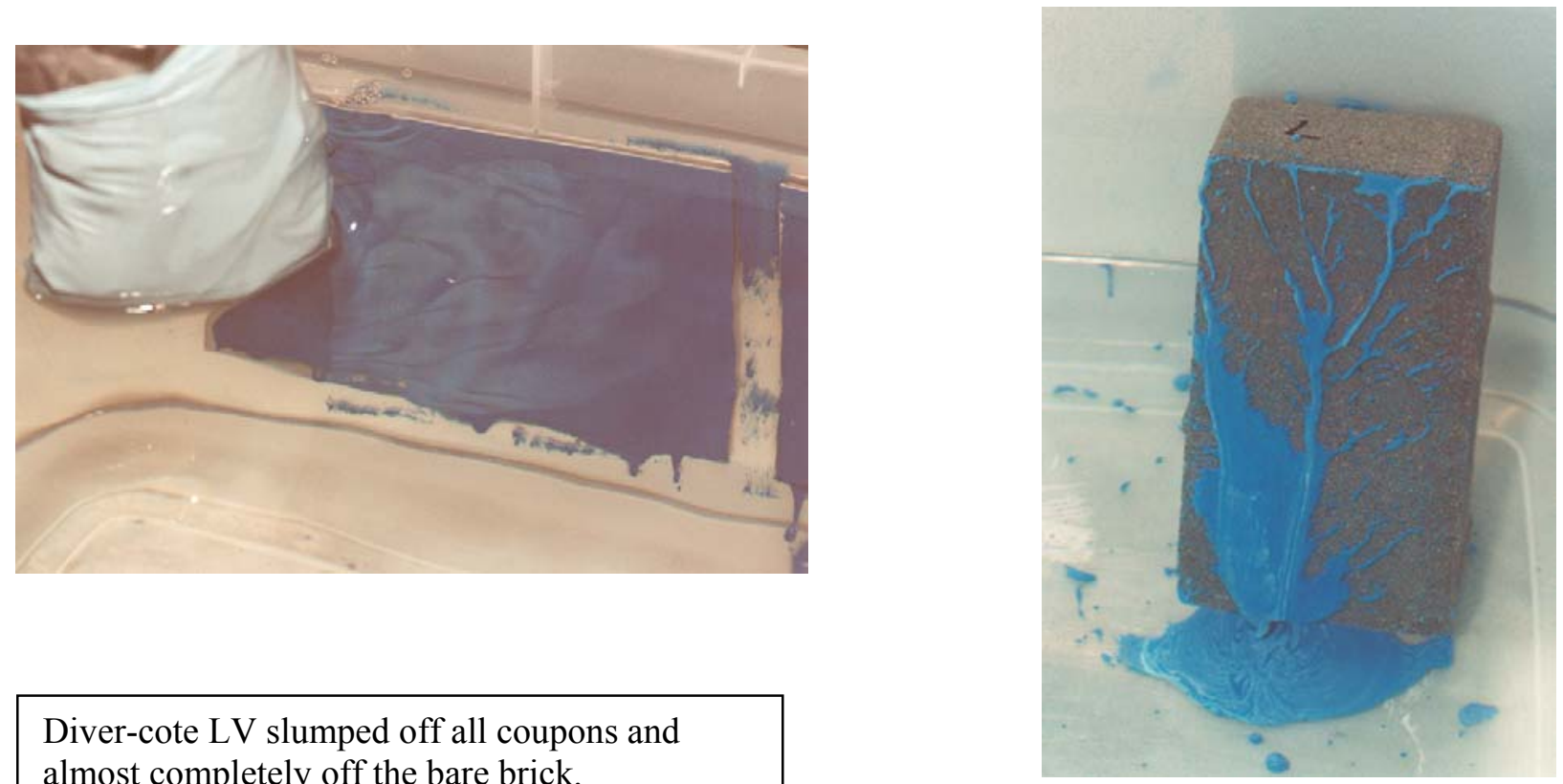

Diver-cote LV slumped off all coupons and almost completely off the bare brick.
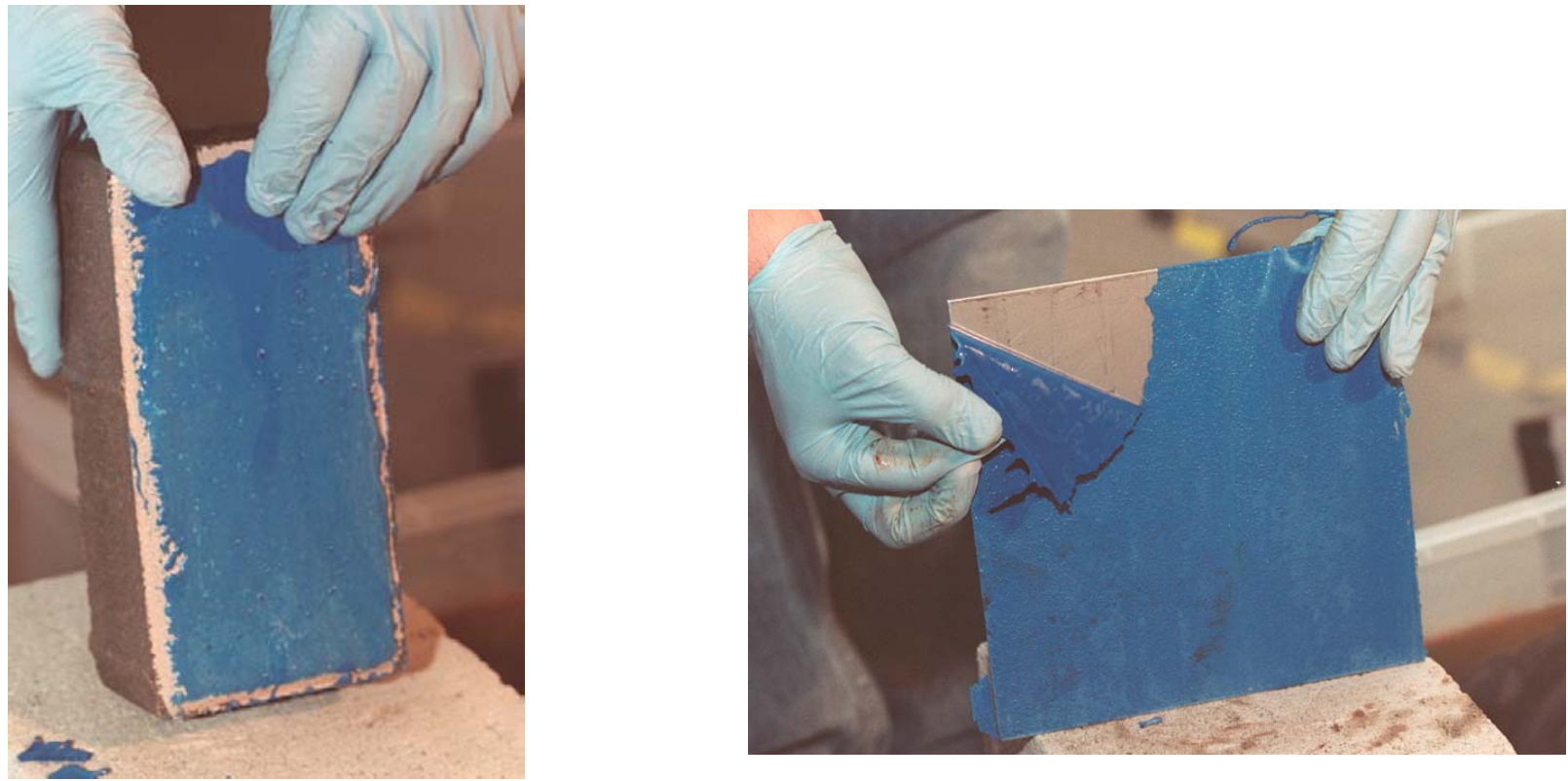

Diver-cote LV was adhered to the epoxy coated brick.

Diver-cote LV peeled off the stainless steel after curing. 


\subsection{Marine-Flex 570}

Color and Apparent Viscosity of Coating: Part A was grey with a consistency of latex paint. Part B was yellow-brown with a honey-like consistency. After mixing together in a ratio of 1.5:1 with a wooden stick, it was a grey paint-like consistency (low-medium viscosity).

Application Method Used: This material was applied using a paintbrush.

Pot Life: 20 minutes at $77^{\circ} \mathrm{F}$

Applied Thickness: Varied from 1/32 to $1 / 16$ inch.

Impact on Water Clarity: Water remained clear at all times. No visible effects.

Adhesion during Application: Easily covered all coupon surfaces with no tearing and no slumping. However, more pressure was required when applying to the painted brick to get it to adhere.

Cure Time and Temperature: A four-day cure was used at about $56^{\circ} \mathrm{F}$.

Appearance after Curing: The surface was grey-colored and smooth but no cracking was observed. 100\% of the surfaces were covered.

Adhesion after Curing: The coating was not well adhered to any surfaces and was easily peeled or scrapped off. On the epoxy coated carbon steel the epoxy paint peeled off with the coating.

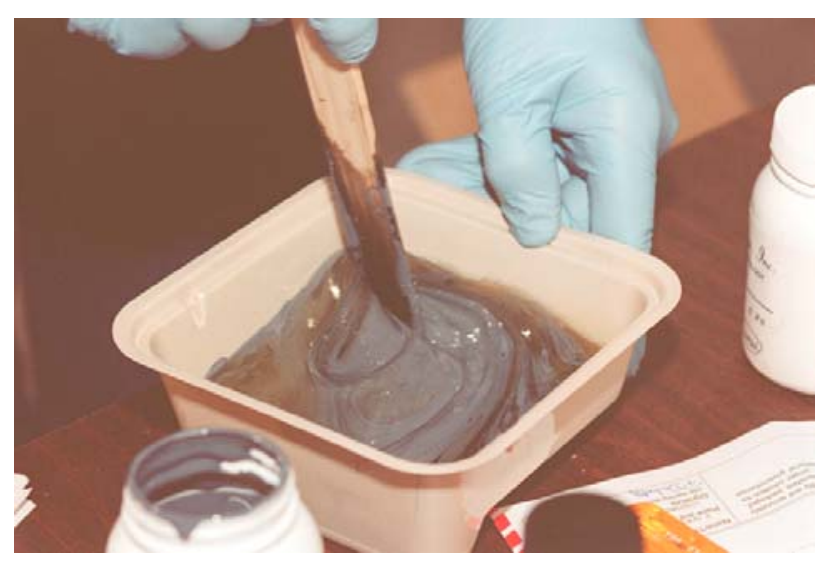

Marine Flex 570 mixed easily and was applied with a paintbrush.

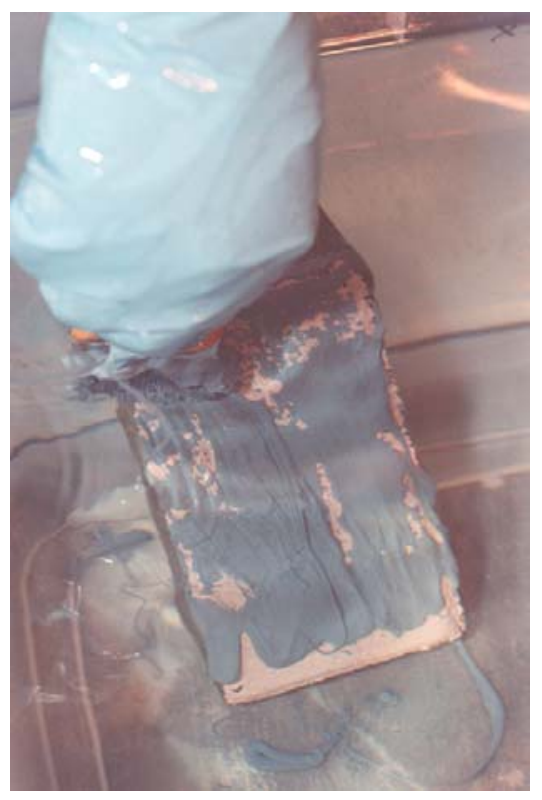




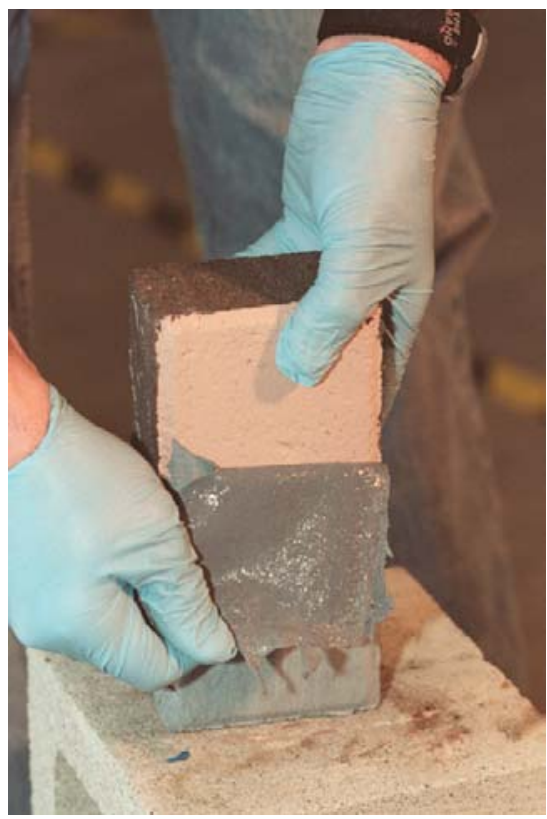

Marine Flex 570 was easily peeled from all surfaces after curing.

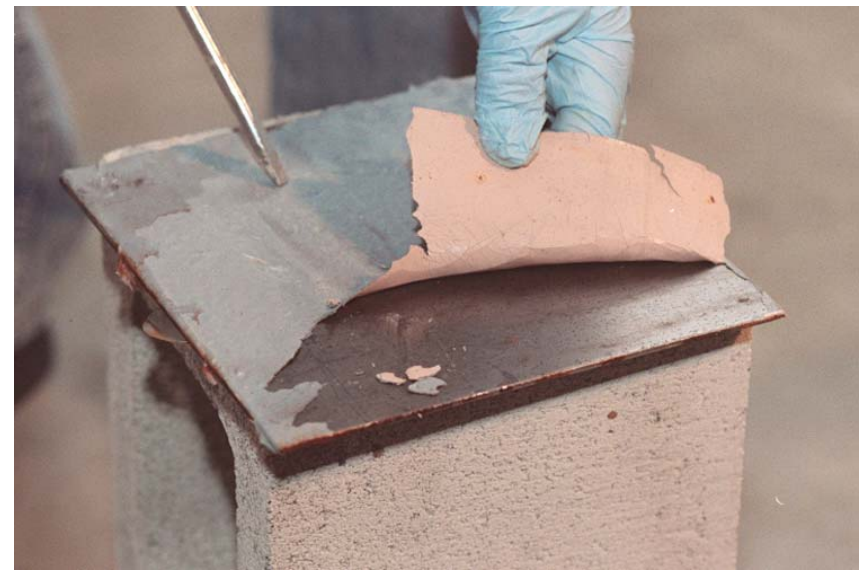

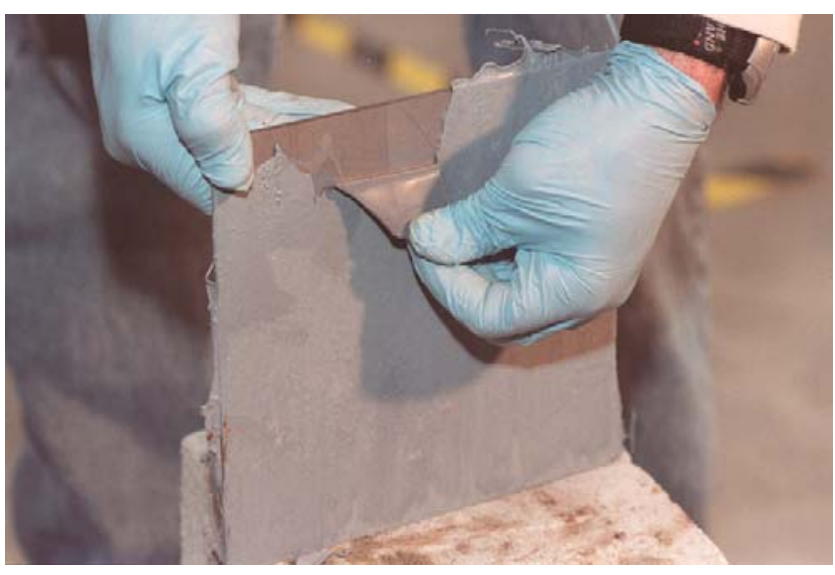

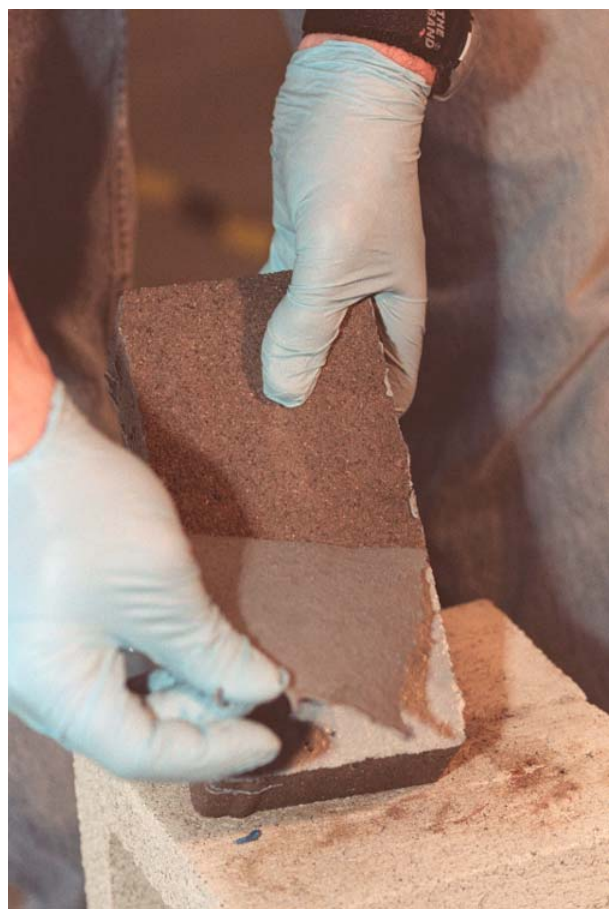




\subsection{Euro-vinyl CVO2}

Color and Apparent Viscosity of Coating: All in one container, stirred with wooden stick to a white medium viscosity paste.

Application Method Used: This material was applied to the painted carbon steel and the stainless steel using a paintbrush and to the painted concrete and bare concrete using a plastic trowel.

\section{Pot Life: NA}

Applied Thickness: Varied from 1/32 to 1/16 inch.

Impact on Water Clarity: Water remained clear with a small amount of floating coating pieces.

Adhesion during Application: Easily covered all coupon surfaces, however some tearing occurred when applying with the paintbrush to the concrete bricks. Therefore, a trowel was used on these bricks with no tearing. More pressure needed to get coating to adhere to the bare brick.

Cure Time and Temperature: A four-day cure was used at about $56^{\circ} \mathrm{F}$ (only 16 hours required to overcoat at $73^{\circ} \mathrm{F}$ according to manufacturer's information).

Appearance after Curing: The surface was white with a non-uniform application but no cracking was observed. $100 \%$ of the surfaces were covered.

Adhesion after Curing: The coating was not well adhered to any surfaces and was easily peeled or scrapped off, it appeared very glue-like (seemed like uncured).
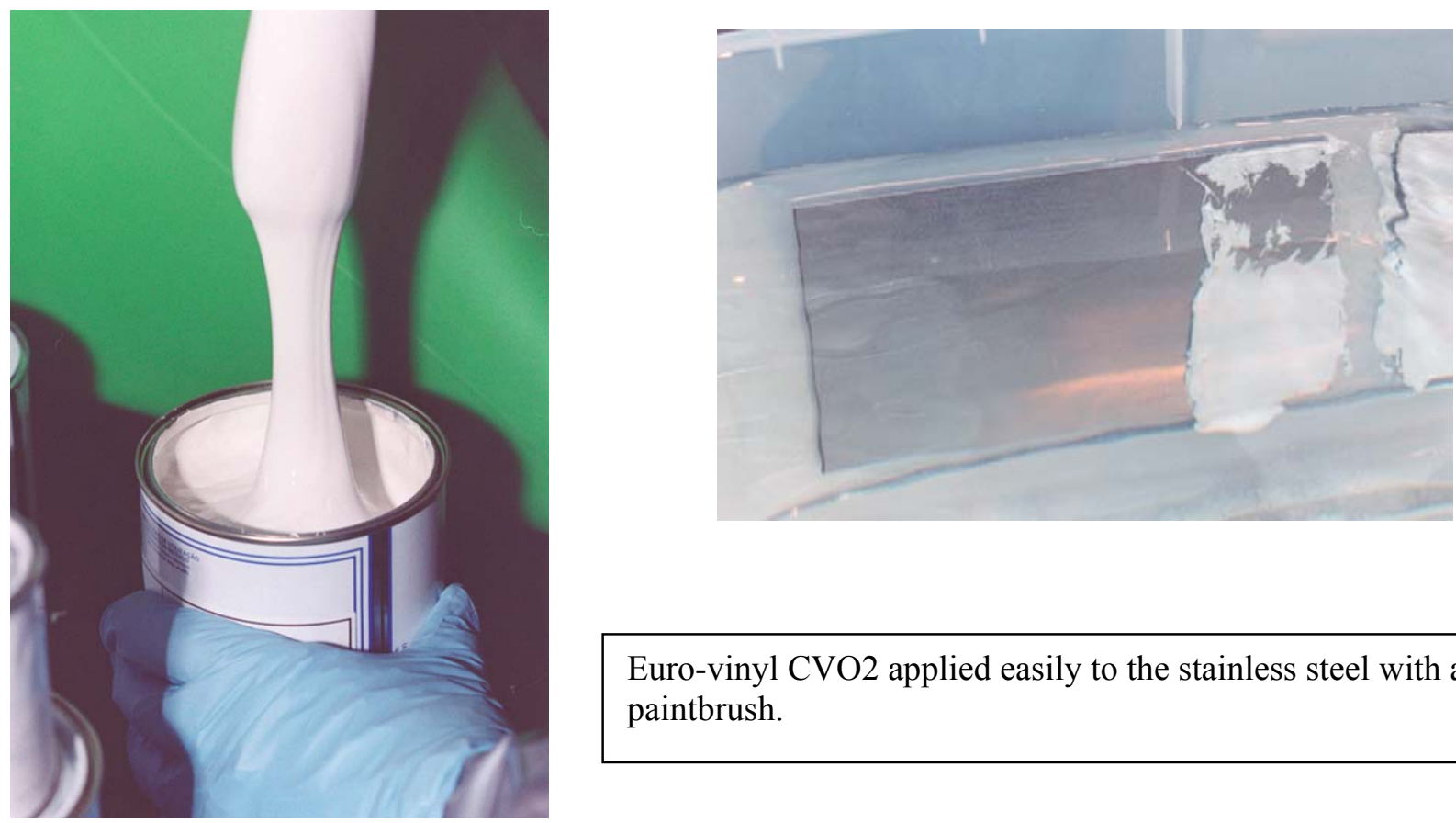

Euro-vinyl CVO2 applied easily to the stainless steel with a paintbrush. 


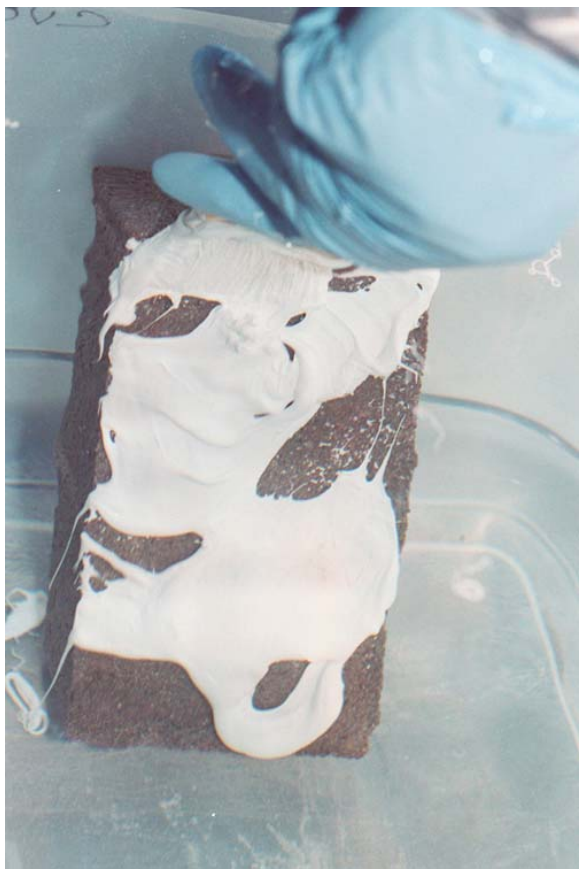

Euro-vinyl CVO2 was more difficult to apply to the bare brick and a trowel was used to apply more pressure.

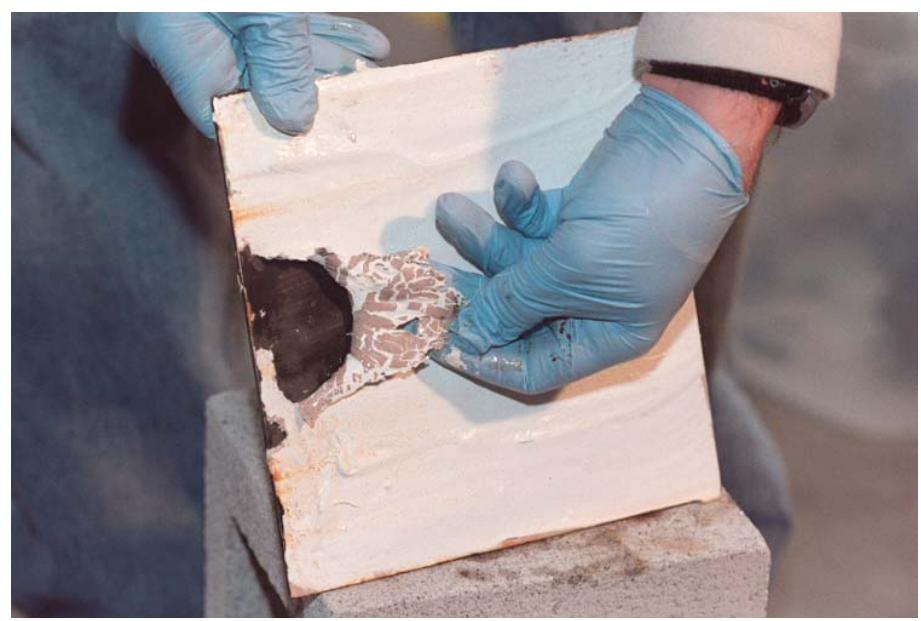

Euro-vinyl CVO2 did not adhere well to any surfaces after curing and in some cases did not seem to be fully cured despite adequate lapsed time.

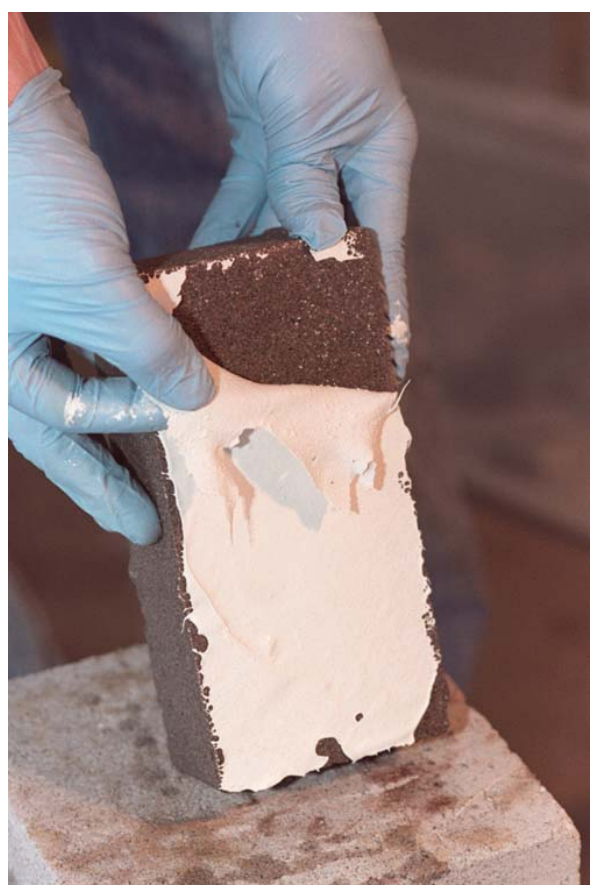




\subsection{Euro-paste 326}

Color and Apparent Viscosity of Coating: Part A was a white paste. Part B was white with a latex paintlike consistency. After mixing together in a ratio of 5:1 with a wooden stick, it was a white paste (medium viscosity).

Application Method Used: This material was applied using a plastic trowel.

Pot Life: 30 minutes at $73^{\circ} \mathrm{F}$.

Applied Thickness: Varied from 1/32 to $1 / 16$ inch.

Impact on Water Clarity: Water remained clear at all times. Some coating pieces floated on the surface of the water.

Adhesion during Application: Easily covered all coupon surfaces with no tearing and no slumping. However, more pressure was required when applying to the unpainted brick to get it to adhere.

Cure Time and Temperature: A four-day cure was used at about $56^{\circ} \mathrm{F}$ (only 1 day required at $73^{\circ} \mathrm{F}$ according to manufacturer's information).

Appearance after Curing: The surface was off-white with non-uniform thickness of coating. $100 \%$ of the surfaces were covered.

Adhesion after Curing: The coating was very well adhered to the painted carbon steel and the stainless steel. On the stainless steel, when putting a screwdriver under the edge could peel a small amount off. On the painted brick, the entire coating could be peeled off (taking $50 \%$ of the paint with it) by pulling on the overhanging edge. However, a screwdriver could not break through the coating surface. On the unpainted brick, the coating easily peeled off the entire brick surface in one big piece.

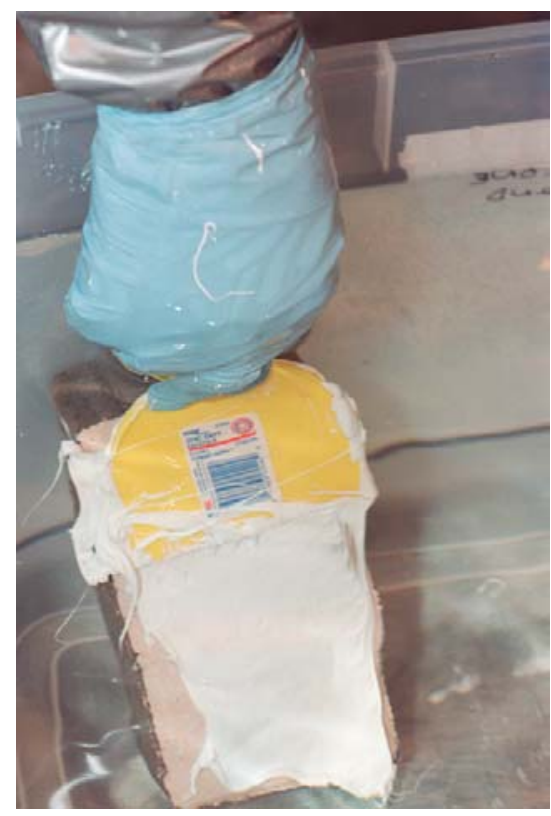

Euro-paste 326 was easily applied with a trowel.

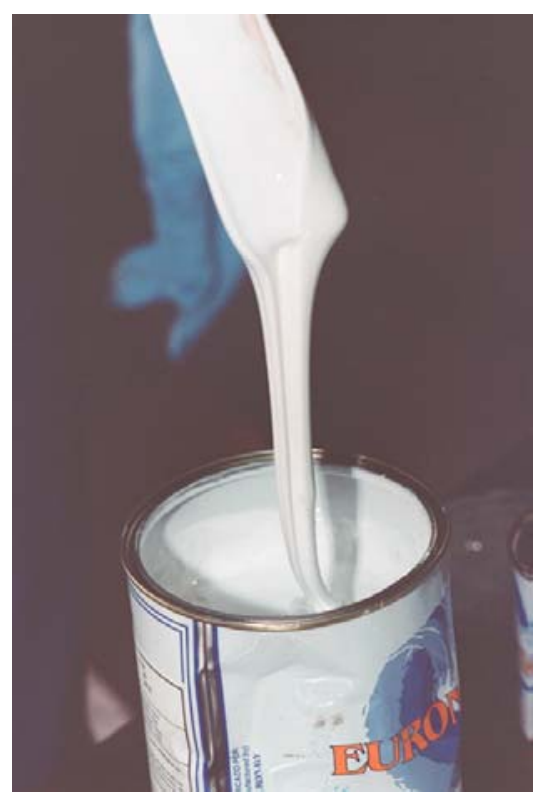




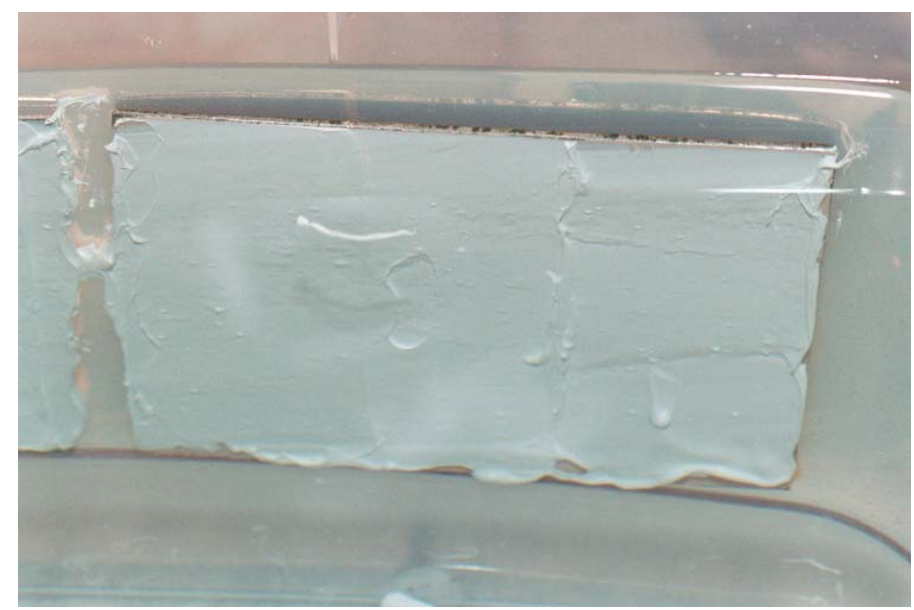

Euro-paste 326 applied easily to the stainless steel.

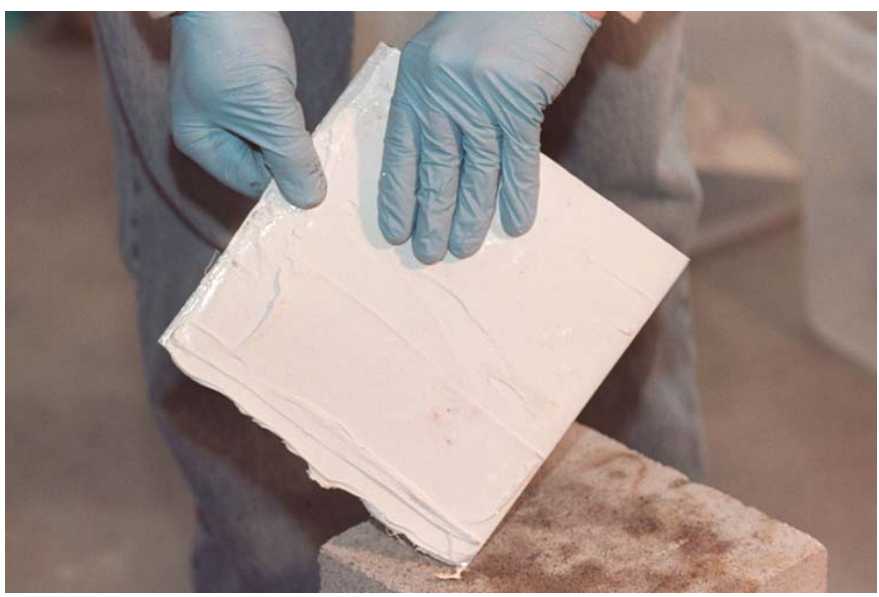

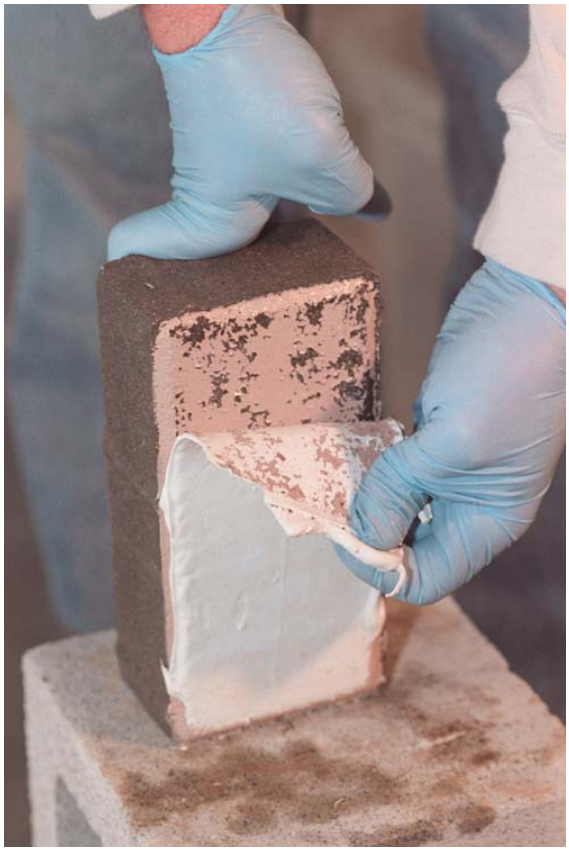

Euro-paste 326 adhered well to the stainless steel and painted carbon steel but not to the bricks.

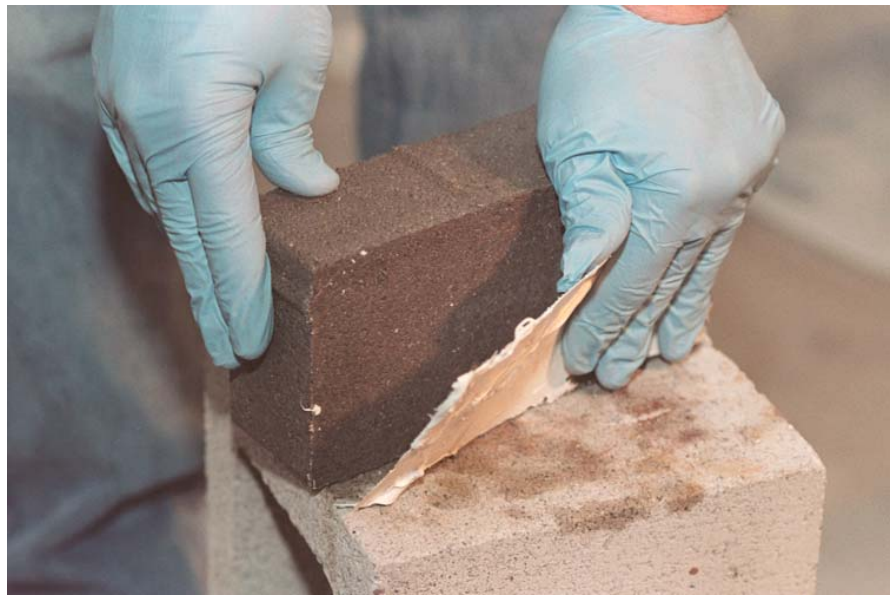




\subsection{Euro-diver 1323}

Color and Apparent Viscosity of Coating: Part A was a white paste. Part B was clear with a honey-like consistency. After mixing together in a ratio of 5:1 with a wooden stick, it was a white with a latex paint consistency (low viscosity).

Application Method Used: This material was applied using a paintbrush and a trowel.

Pot Life: 40 minutes at $73^{\circ} \mathrm{F}$.

Applied Thickness: Varied from 1/32 to $1 / 16$ inch.

Impact on Water Clarity: Water remained clear at all times. Some coating pieces floated on the water surface.

Adhesion during Application: Easily applied to all metal surfaces (stainless steel and painted carbon steel). However, a large amount of pressure was required when applying to the unpainted brick to get it to adhere. The painted brick was extremely hard to cover. Approximately 10 minutes after applying, the coating began to slump off the unpainted and painted brick.

Cure Time and Temperature: A four-day cure was used at about $56^{\circ} \mathrm{F}$ (only 1 day required at $73^{\circ} \mathrm{F}$ according to manufacturer's information).

Appearance after Curing: The surface was off-white colored with an uneven texture. All surfaces were covered except for the unpainted brick, which was only $30 \%$, covered. There was significant rusting of the carbon steel.

Adhesion after Curing: The coating was easily peeled off the painted carbon steel taking the paint with it. It also peeled easily off of the stainless steel. It was more difficult to remove from the painted brick. The remaining fixative on the unpainted brick peeled off very easily (still had an odor).
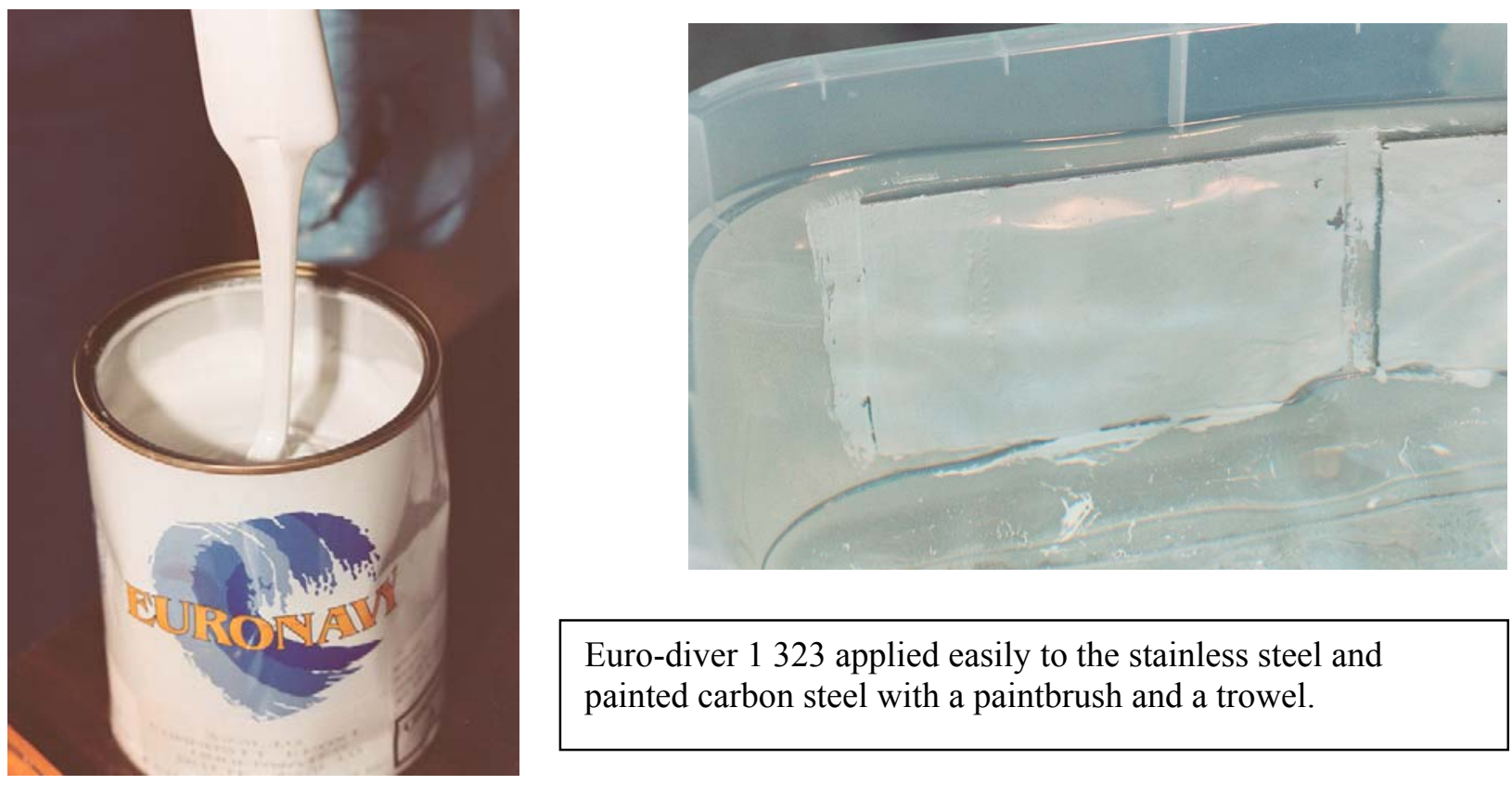

Euro-diver 1323 applied easily to the stainless steel and painted carbon steel with a paintbrush and a trowel. 


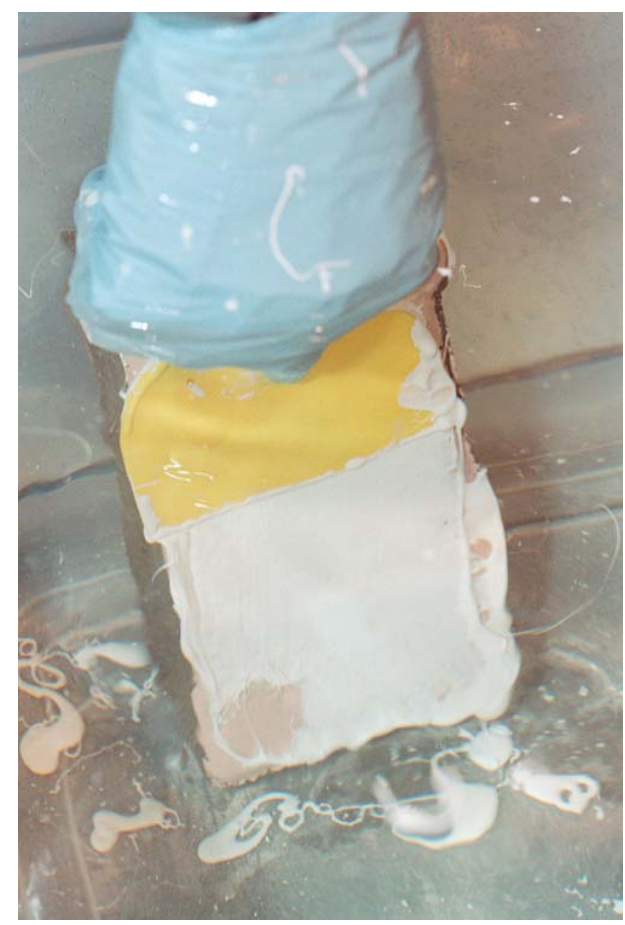

Euro-diver 1323 did not stick to the painted and bare bricks well when applying.
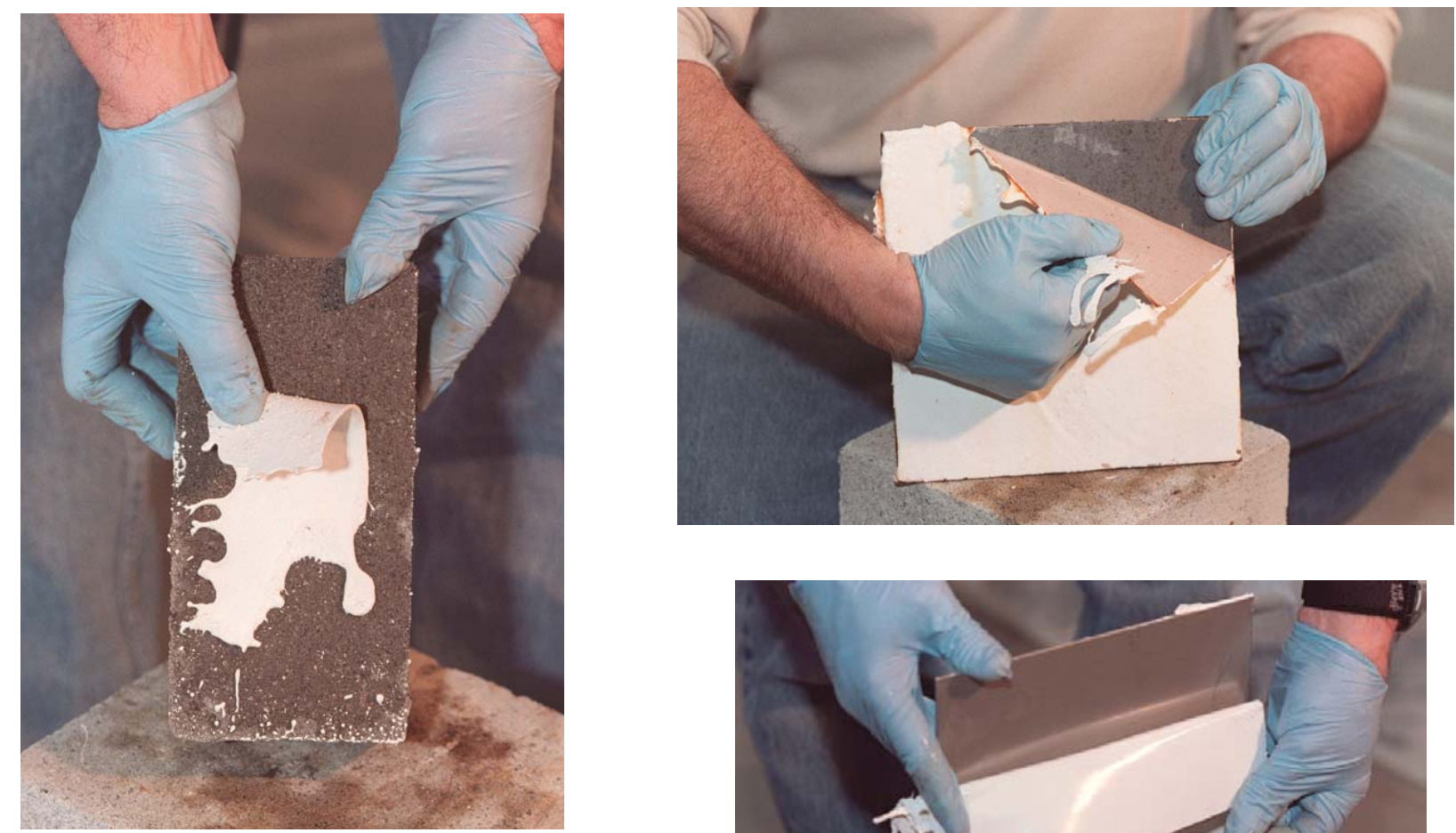

Euro-diver 1323 peeled off of all surfaces after curing.

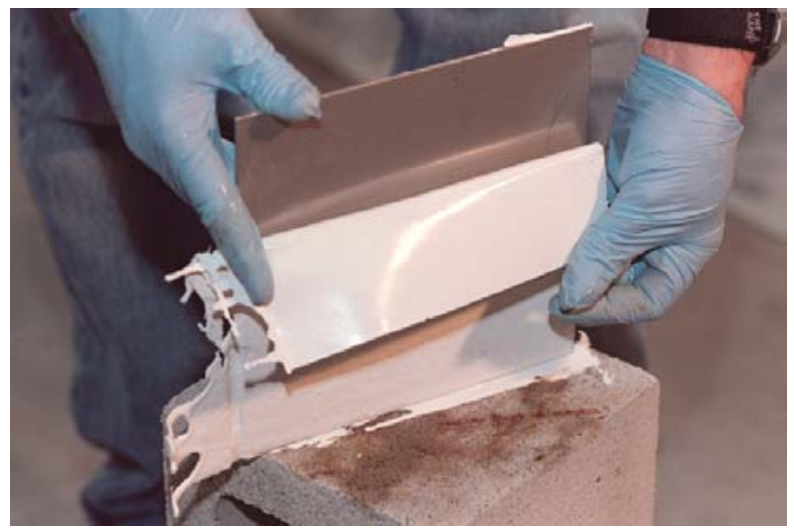




\subsection{UT-15 Underwater Epoxy}

Color and Apparent Viscosity of Coating: Part A was a clear syrup. Part B was tan and paint-like. After mixing together in a ratio of 1:1 with a wooden stick, it was off-white with a latex paint consistency (lowmedium viscosity).

Application Method Used: This material was applied using a paintbrush.

Pot Life: 65 minutes at $77^{\circ} \mathrm{F}$.

Applied Thickness: Varied from 1/32 to $1 / 16$ inch.

Impact on Water Clarity: Water remained clear during application but turned a yellowish green the day after the coating was applied. A light film appeared on the surface of the water (could be due to incomplete cure of the silicon holding the coupons to the container wall). Analysis of the water found no chemicals of concern.

Adhesion during Application: Very easily covered all coupon surfaces with no tearing and no slumping.

Cure Time and Temperature: A four-day cure was used at about $56-67^{\circ} \mathrm{F}$ ( 1.5 days required at $70^{\circ} \mathrm{F}$ and 4 days required at $33^{\circ} \mathrm{F}$ according to manufacturer's information).

Appearance after Curing: The surface was pale green-colored, uniform and smooth with no cracking observed. $100 \%$ of the surfaces were covered.

Adhesion after Curing: The coating was very well adhered to all surfaces and could not be removed. If there is an overhang of the coating on the edge it could be broken off but did not take it off the coupon surface.

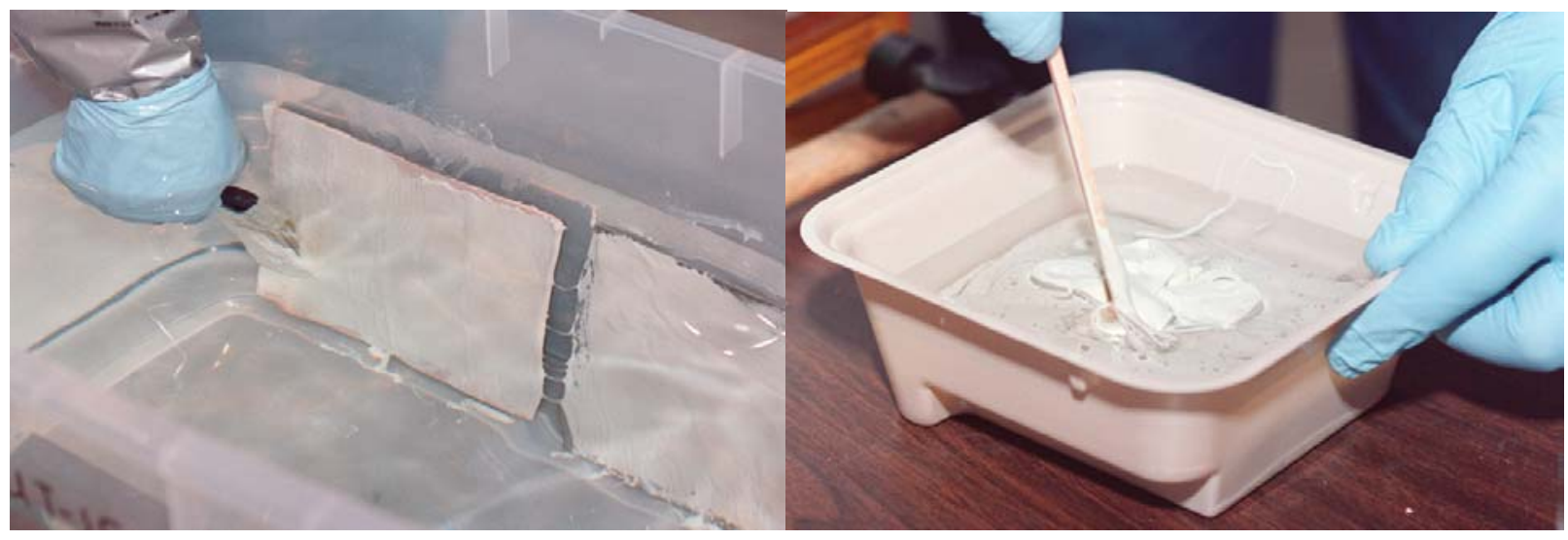

UT-15 applied easily to all surfaces using a paintbrush. 

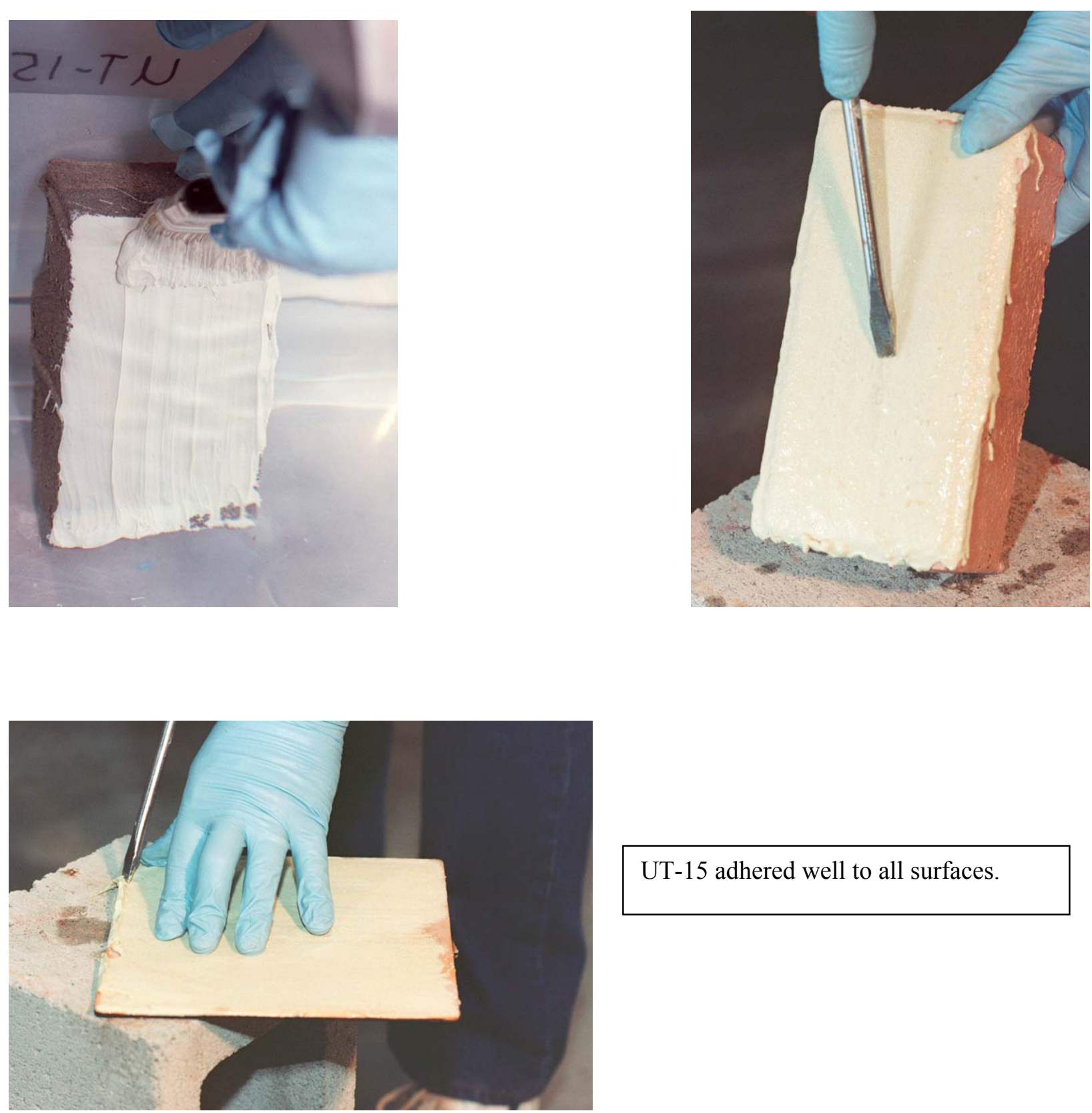

UT-15 adhered well to all surfaces. 


\section{RECOMMENDATIONS}

The three coatings that were the easiest to apply and adhered well were the NMP 1710, Corro-Coat FC 2100 Epoxy, and the UT-15 Underwater Epoxy. However, there is some concern on the Corro-Coat FC 2100 since after several weeks it broke off the stainless steel surface. Many of these coatings require a roughed up surface to adhere well according to manufacturers instructions and this may be why this coating came off.

In several cases, applied coatings bonded well to the epoxy painted surfaces but caused the bond of the epoxy paint to the surface of the coupon to weaken. Some literature suggests that the coating over the epoxy paint actually softens the paint to allow this to happen.

Water samples were analyzed for the UT-15 coating and the Corro-coat FC 2100 coating to determine the presence of any undesirable organic compounds. The samples were analyzed using a carboxen SPME (solid phase micro extraction) technique. The SPME is sensitive to organics in the part per billion and high range. The SPME was adsorbed in the sample for approximately 15 minutes. The SPMEs were then desorbed in the injector of a Shimadzu GCMS. The results for both samples (Appendix C) indicated that there were no hazardous agents present. The compounds that were picked up were not hazardous.

The ratio of surface area to pool volume was calculated for the test coupons (Table 2). This showed that the concentration of any chemicals coming from the coating as it cures should have been higher in the test case than it will be in any of the actual pools.

Table 2. Surface area to pool volume ratios.

\begin{tabular}{|l|c|c|c|}
\hline & $\begin{array}{c}\text { Surface area covered } \\
\text { (ft2) }\end{array}$ & $\begin{array}{c}\text { Volume } \\
\text { (gallons) }\end{array}$ & $\begin{array}{c}\text { Ratio } \\
\text { (gallons/ft2) }\end{array}$ \\
\hline Test & 1.33 & 15.7 & 11.8 \\
\hline TAN & 13,000 & 750,000 & 57.7 \\
\hline CPP-603 & 26,600 & $1,400,000$ & 52.6 \\
\hline MTR & 5,100 & 118,000 & 23.1 \\
\hline PBF & 2,100 & 25,000 & 11.9 \\
\hline
\end{tabular}

Based on these results, use of the UT-15 and the NMP 1710 coatings are recommended for larger scale testing in the actual fuel basins. 
Appendix A

MSDS's and Product Information 
Appendix B

Quality Assurance Documentation 
Date Prepared: $11-11-2003$

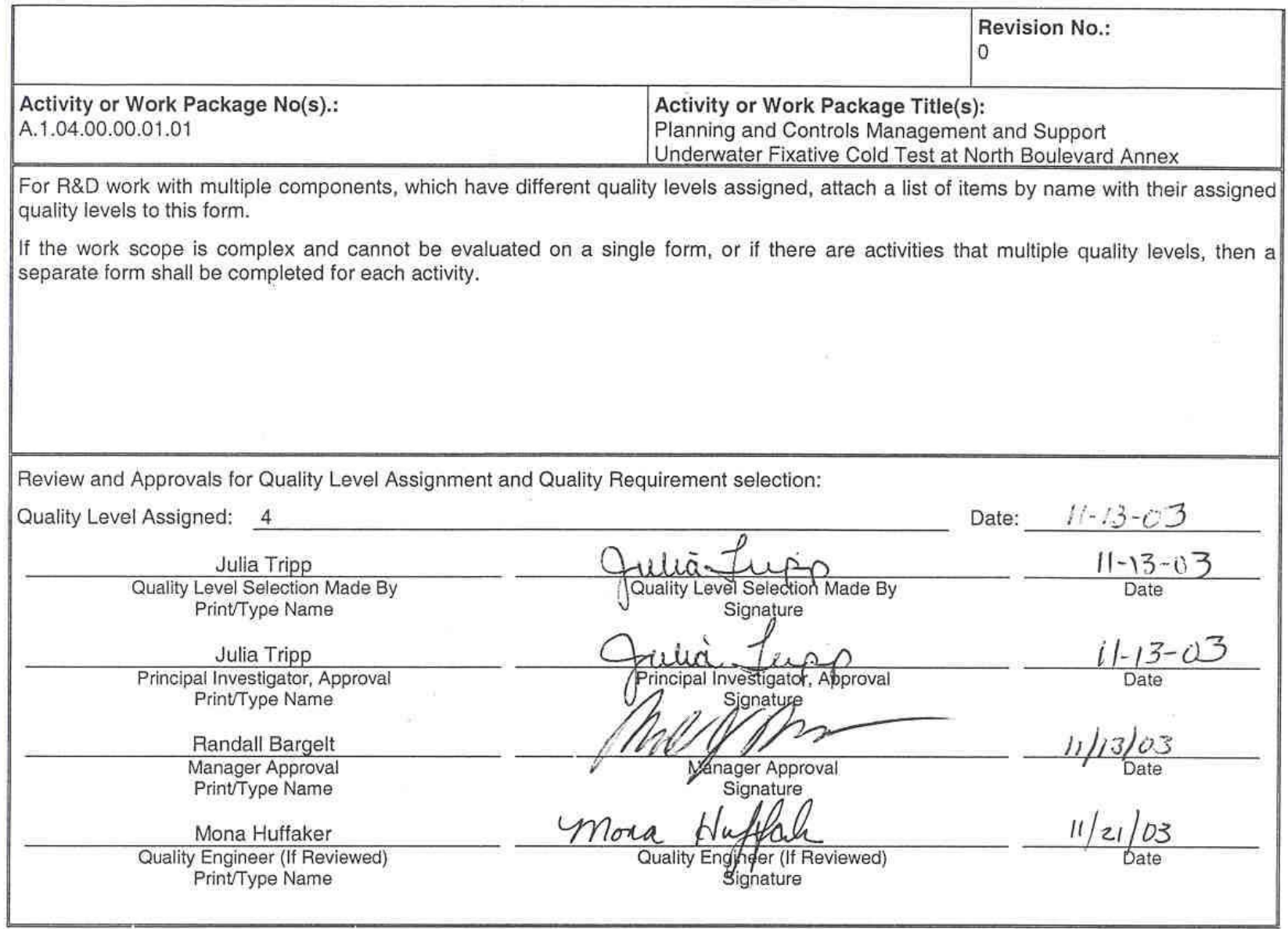

\section{CONVERSION TABLE}

This table shall be used to convert a safety category to an equivalent quality level.

\begin{tabular}{|c|c|}
\hline QUALITY LEVEL & SAFETY CATEGORY \\
\hline 1 & Safety Class - SC \\
\hline 2 & Safety Significant - SS \\
\hline 3 & Low Safety Consequence - LSC \\
\hline 4 & Consumer Grade - CG \\
\hline
\end{tabular}

Note 1: Quality Level may be applied to each individual item or activity and can vary based on the material or process verification requirements. For example an overall process may be assigned Quality Level 2, while some subcomponents of the process may be considered Quality Level 3 or Quality Level 4.

Note 2: Quality requirements are additives as you go from Quality Level 4 to Quality Level 1. 


\begin{tabular}{|c|c|c|c|c|}
\hline Quality Level & Quality Level 4 & Quality Level 3 & Quality Level 2 & Quality Level 1 \\
\hline $\begin{array}{l}\text { Quality } \\
\text { Requirements } \\
\text { To Be Applied }\end{array}$ & 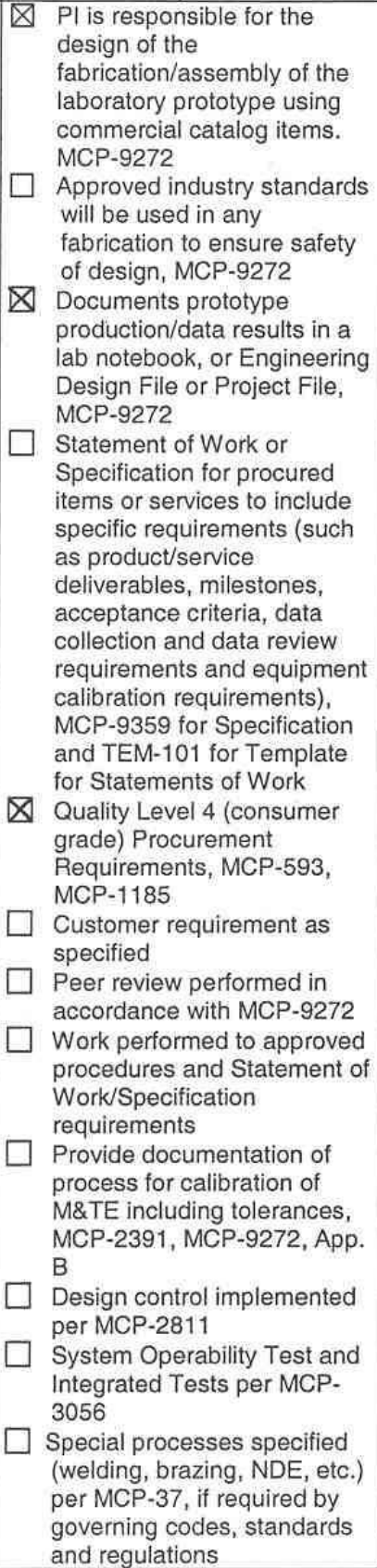 & $\begin{array}{l}\square \text { Document inspections per } \\
\text { MCP-195 and selected test } \\
\text { TPR } \\
\square \text { Special processes specified } \\
\text { (welding, brazing, NDE, etc.) } \\
\text { per MCP-37 } \\
\square \text { Quality Level } 3 \text { Procurement } \\
\text { Requirements specified } \\
\text { (vendor qualification, receipt } \\
\text { inspections, etc.) MCP-590, } \\
\text { MCP-591, MCP-1185 } \\
\text { Documented } \\
\text { training/certification of } \\
\text { personnel performing special } \\
\text { processes and inspections as } \\
\text { per MCP-37 } \\
\text { Documents prototype } \\
\text { production/data results in a } \\
\text { lab notebook, or Engineering } \\
\text { Design File or Project File, } \\
\text { MCP-2875. }\end{array}$ & $\begin{array}{l}\square \text { Quality Level } 2 \\
\text { Procurement } \\
\text { Requirements } \\
\text { specified (vendor } \\
\text { qualification, } \\
\text { receipt } \\
\text { inspections, etc.) } \\
\text { MCP-590, } \\
\text { MCP-591, MCP- } \\
1185, \text { MCP-3512, } \\
\text { MCP-3513 } \\
\text { Software Control } \\
\text { per MCP-3039. }\end{array}$ & $\begin{array}{l}\text { Quality Level 1 } \\
\text { Procurement } \\
\text { Requirements } \\
\text { specified (vendor } \\
\text { qualification, } \\
\text { receipt } \\
\text { inspections, etc.) } \\
\text { MCP-590, } \\
\text { MCP-591, } \\
\text { MCP-1185, } \\
\text { MCP-3512, MCP. } \\
3513 \text {. }\end{array}$ \\
\hline
\end{tabular}

Note 1: Quality Level may be applied to each individual item or activity and can vary based on the material or process verification requirements. For example an overall process may be assigned Quality Level 2, while some subcomponents of the process may be considered Quality Level 3 or Quality Level 4.

Note 2: Quality requirements are additives as you go from Quality Level 4 to Quality Level 1. 
Appendix C

Water Sample Analysis 

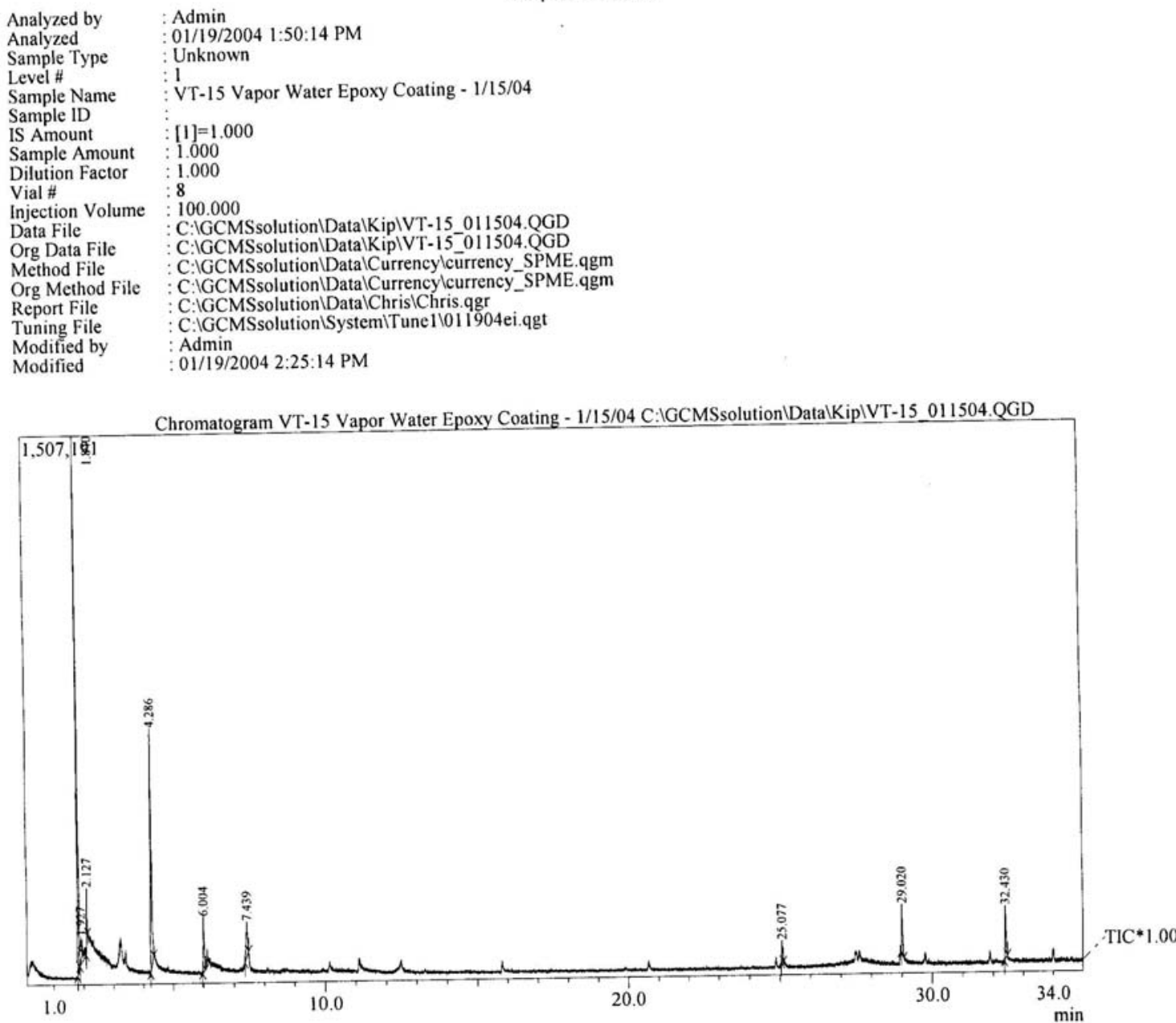

$\begin{array}{rrrrrr}\text { Peak\# } & \text { R.Time } & \text { I.Time } & \text { F.Time } & \text { Area } & \text { Area\% } \\ 1 & 1.840 & 1.802 & 1.875 & 2475175 & 41.76 \\ 2 & 1.927 & 1.875 & 1.972 & 219874 & 3.71 \\ 3 & 2.127 & 2.105 & 2.156 & 174914 & 2.95 \\ 4 & 4.286 & 4.244 & 4.357 & 1607767 & 27.13 \\ 5 & 6.004 & 5.969 & 6.063 & 368999 & 6.23 \\ 6 & 7.439 & 7.366 & 7.488 & 330553 & 5.58 \\ 7 & 25.077 & 25.043 & 25.117 & 128579 & 2.17 \\ 8 & 29.020 & 28.985 & 29.070 & 278234 & 4.69 \\ 9 & 32.430 & 32.379 & 32.481 & 343040 & 5.79 \\ & & & & 5927135 & 100.00\end{array}$

Peak Report TIC Height leight $\%$ $1470065 \quad 50.07$ $62404 \quad 2.13$ $\begin{array}{ll}653598 & 22.26\end{array}$ $153123 \quad 5.22$ $95038 \quad 3.24$ $60260 \quad 2.05$

$\begin{array}{llll}38403 & 4.71 & 2.01\end{array}$

$144703 \quad 4.93$ $2935727 \quad 100.00$ 


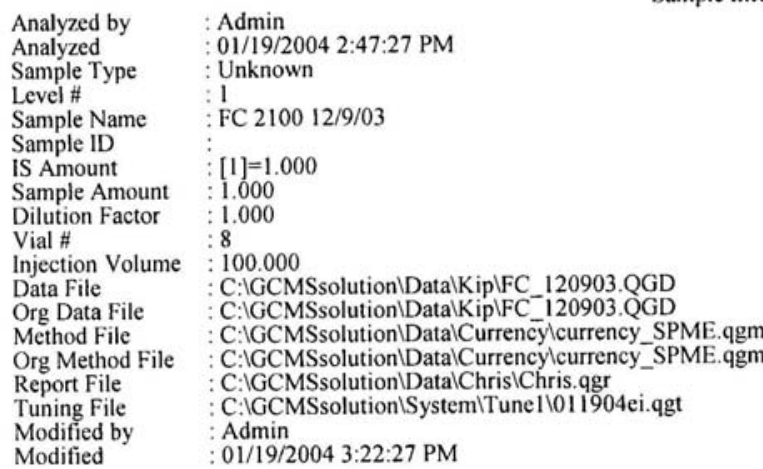

Chromatogram FC 2100 12/9/03 C:IGCMSsolution\DatalKip\FC_120903.QGD

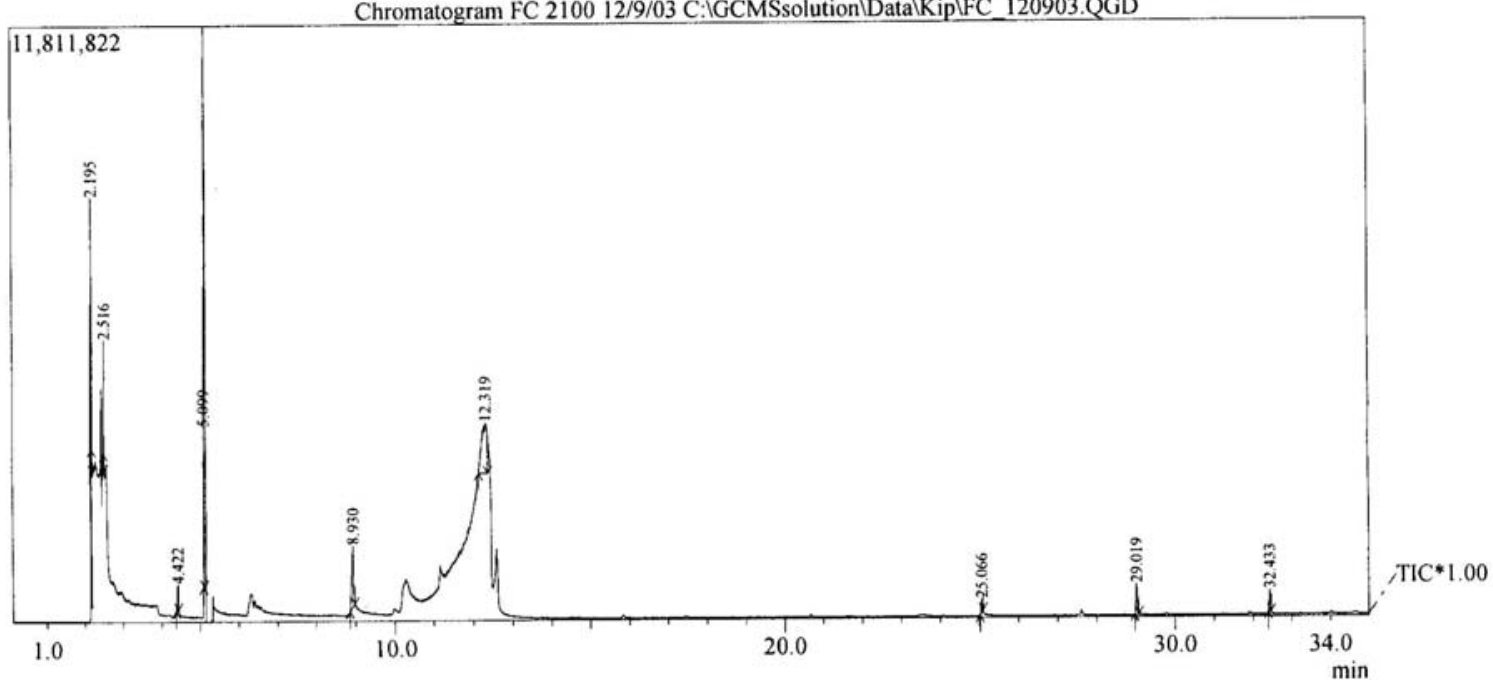

$\begin{array}{rrrrrr}\text { Peak\# } & \text { R.Time } & \text { I.Time } & \text { F.Time } & \text { Area } & \text { Area\% } \\ 1 & 2.195 & 2.192 & 2.221 & 2495281 & 11.30 \\ 2 & 2.516 & 2.510 & 2.521 & 704882 & 3.19 \\ 3 & 4.422 & 4.383 & 4.439 & 874309 & 3.96 \\ 4 & 5.099 & 5.080 & 5.099 & 2107831 & 9.55 \\ 5 & 8.930 & 8.857 & 8.978 & 3577963 & 16.21 \\ 6 & 12.319 & 12.143 & 12.373 & 9433885 & 42.73 \\ 7 & 25.066 & 25.015 & 25.094 & 555812 & 2.52 \\ 8 & 29.019 & 28.970 & 29.078 & 1366092 & 6.19 \\ 9 & 32.433 & 32.396 & 32.470 & 960525 & 4.35 \\ & & & & 22076580 & 100.00\end{array}$

Peak Report TIC Height leight\% A/H Mark Name $\begin{array}{lllll}5032206 & 34.35 & 0.50 & \text { MI } & \text { (S)-(+)-1-Cyclohexylethylamine }\end{array}$ $\begin{array}{lllll}2414968 & 16.48 & 0.29 & \text { MI Silane, fluorotrimethyl- }\end{array}$ $\begin{array}{lllll}524001 & 3.58 & 1.67 & \text { MI Acetic acid }\end{array}$

$\begin{array}{lll}3168732 & 21.63 & 0.67\end{array}$ $\begin{array}{llll}3168732 & 21.63 & 0.67 & \mathrm{MI}\end{array}$

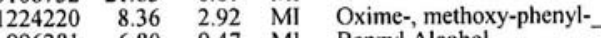

$\begin{array}{lllll}996281 & 6.80 & 9.47 & \mathrm{Ml} & \text { Benzyl Alcohol }\end{array}$

$\begin{array}{lll}255160 & 1.74 & 2.18 \\ 2\end{array}$

$\begin{array}{llll}601042 & 4.10 & 2.27 & \text { MI Benzeneethanamine, } \mathrm{N}-[\text { (pentafluoropl }\end{array}$

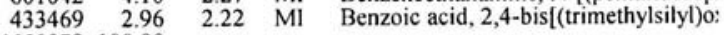
$14650079 \quad 100.00$ 
Appendix 1

MSDS's and Product Information 


\section{- material safety data sheet}

\section{Produet Information}

Praduct Name: Wet-Ory 700 Hardener Part $\mathrm{B}$

.

. Composition/Information on Ingredients

\section{Chemleal Name}

Cyclophatic Amines

Product Code: ER160-B

Chemical Family: Amines

$\begin{array}{ll}\text { Exposure LImlis } \\ \text { ACGIH. } & \text { OSHA } \\ \text { TLV.TWA } & \text { PEL } \\ \text { NEE } & \text { NE (Not estadlishod) }\end{array}$

\section{Health Hazards}

Eye Contact: Corrosive liquid. Cause severe irritation and may cause bum. sensitization. Symptoms can be immediate or delayed several hours.

Skin Coneact: Corroslve llquid. Cause irritation ano

\section{First Aid Measures}

Eyes: Flush eyes thoroughly with water for at least 15 minutes whlle holding eyellds open. Seek medical attention, Skin: Remove contaminated clothing. Wipe excess from skin and wash the affected area thoroughly with soap and water. Wash contaminated clothing thoroughly before reuse. Inhalation: Remove to fesh alr, and provide oxygen or artificial respiration if needed. Obtain medical attentlon; symptorns can be delayed up to several hours. Ingestion: DO NOT induce vorniting. Give 1-2 cups of water or milk unless the person is drowsy, convulsing, or unconscious. Get medical attention.

\section{Fira Figheing Measurea}

\section{Flash Point: $>200^{\circ} \mathrm{F}$ (PMCC) Explosive Umits: Nol applicable Auto-ignition Temperature: Not appllcable}

Hazardous Decompositlon Products: Oxides of nitrogen, amon monoxide, carbon dioxide and other oroenic materials media: Use carbon dioxide, dy chemical, or appropriate foam.

\section{Accidental Release Measures}

Ventilate the spill area and evacuate if necessary. Remove all ignition sources. Dike and contain large spllls. Flush area with water spray. Cleanup personnel should use adequate prolective equipment.

\section{Handling and Storage}

Store in a cool; iny place, in closed containers at room lemperature. Avoid contact with incompalible malenals. Wear protective eyewear. jemical-resistant gloves, and other prolective clothing as appropriate.

\section{Exposure Control and Personal Protection}

EnglneerlngNentllation Controls: Elfective engineering controls should be used whenever possible to eliminate and/or reduce worker exposure to all resplratory hazards. General ventilation, local ventilation, or isolation may prove adequate to keep alrbome concentrations below exposure limits. Resplratony Protection: If exposure limits are exceeded and local ventlation Is unavallable, a supplied-air respirator or a selfcontained breathing apparatus is required. Skin Protection: Impervious gloves and protectlve dothing should be wom as necessary. Eye Protection: Chemical splash goggles or safely glasses with side shields should be worn as appropriate.

\section{Stabllity and Reactivity}

Chemical Stabilly: Stable under normal conditions and use. agents. Hazandous Polymarlzation: Will not occur

Conditions and Materlals to Avold: Reacts with epoxy and strong oxidlzing

10. Physical and Chemical Propenies

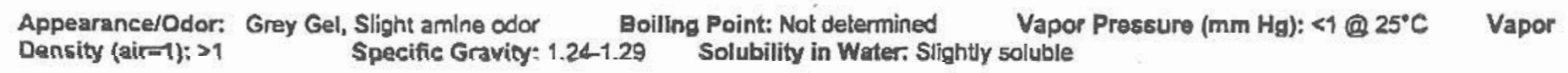

\section{Toxicological Information}

Acure Toxicity Data: Not available

Chronic Toxidty Data: Not avallable

\section{Disposal Considerations}

Keep oul of surface waters, sewers, and walerways entering or leading lo sufface waters. Notify authorities if any exposure to the environment occurs or is likely to occur. Utilize an appropriate disposal facility, in compliance with applicable federal, state, and local environmental control regulations.

\section{Transportation and Regulatory Information}

DOT/ATA Proper Shipping Name: Non Corrosive, Not Regulated Hazardous Labal: NON-CORROSIVE

\section{Regulatory Information}

SDCA: The chemical components of this producl are included in the TSCA Chemical Substance Inventory, as requlred. SARA TITLE III: ection 313 - Toxic Chemlcals: None Section 311/312 - Hazard Categories: Fire Hazard - No, Reactivity Hazard - No. Sudden Releae of fessure Hazard - No, Immediate (Acute) Health Hazard - Yes, Delayed (Chronic) Health Hazard - No. standard Hazard Classes: Corrosive NFPA Mazards: Health - 2, Flammability - 0, Reactivlty - 0 HiMIS hazards: Health - 2, Flammability 0 . Reactivity - 0 
MATERLAL SAFETY DATA SHEET

\section{Product Information}

Sroduct Name: Wet-Dry 700 A Resin

2. Composition/Information on Ingredients

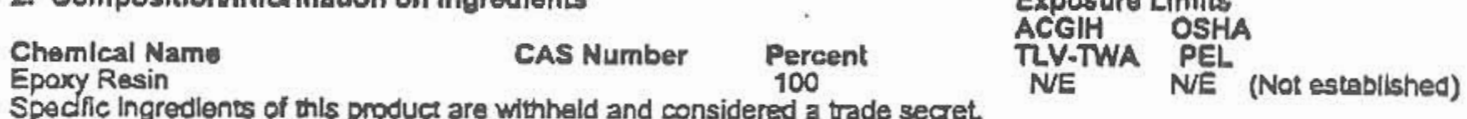

Spedfic ingredlents of this product are withheld and considered a trade secret.

\section{Health Hazards}

delayed several hours. Inhalation: May cause iritation and temporary or permanent sensitzatlon.

mptoms can be immediate or irritation. Other. Preexisting skin sensitization may be aggravated by exposure to this product.

\section{First Ald Measures}

Eyes: Flush eyes thoroughly with water for at least 15 minutes while holding eyelids open. Seek medlcal attenton. or anificial respleatlon if needed. Obtain medical attentuan: drowsy, convulsing. or unconscious. Get medical attention.

\section{Fire Flghing Measures}

\section{Flammable Propertes: Flash Polnt: $>300^{\circ} \mathrm{F}$ (closed cup) Exploslve Limits: Not avallable Auto-lgnition Temperature:} Not available Hazardous Decomposition Products: Carbon monoxlde, carbon dioxide, widehydes, and other organic substancess Exringulshing Medla and Fire Fighting Instructions: When sufficiently large quantlies are present, nirefightsers should be equipped with full bunker gear. Including a Dositive pressura, NIOSH approved, self-contalned breathing apparatus. Extreme heat or water contaminatlon may cause closed containers to explode. Extinguishing Media: Use carbon dloxlde, dry chemical, or appropriate foam

\section{Accidental Release Measures}

Ventilate the splll area and evacuate if necassary. Remove all ignition sources. Dlke and contaln large spills. Clean-up personnel should use adequate protective equipment.

\section{Handling and Storage}

tore In a cool; dry place, in dosed containers at room temperature. Avoid contact with incompatible materlals. Wear protective eyewear, inemical-resistant gloves, and other protective clothing as appropriate.

\section{Exposure Contral and Personal Protection}

Engineering/Ventilation Controls: Effective engineering controls should be used whenever posslble to eliminate and/or reduce worker expesure to all respiratory hazards. General ventilation, local ventilation, or isolaton may prove adequate to keep airbome concentrations below exposure limits. Respiratory Protection: If exposure limits are exceeded and local ventllation is unavailable, a supplied-air resplrator or a selfcontained breathing apparalus is required. Skin Protection: Impervlous gloves and protective dothing should be wom as necessary, Eyo Protection: Chemical Splash goggles or safety glasses with side shlelds should be wom as appropriate.

\section{Stability and Reacrivity}

Chemical Stability: Stable under normal conditlons and use. Conditions and Materials to Avold: Reacts with amines and stong oxidizing agents. Hazardous Polymerlzatlon: Will not occur.

\section{Physical and Chemical Properties}

Appearanee/Odor. Thixotropic gel, slight ether odor Vapor Density (air-1): >1

11. Toxicologlcal information

This section provides loxicological information with regard $t 0$ the pure form of the component indicated. It is suggested that persons trained In Its evaluation interpret this information. Epoxy Resins: Acute Oral LD50 (Ras): $11.4 \mathrm{~g} / \mathrm{kg}$ Aaute Dermal LDSO (rabbit): >20 g/kg

\section{Disposal Considerations}

Keep out of surface waters, sewers, and waterways entering or leading to surface waters. Notfify authorities if any exposure to the environment occurs or is likely to occur. Ublize an approprlate disposal facility, in compliance with applicable federal, state, and local environmental control regulations.

\section{Transportation Information and Regulatory Information}

VOT/LATA Proper Shlpping Name: Not Regulated. TSCA: The chemical components of this product are included In the TSCA Chemical ibstance Inventory, as required. SARA TITLE III: Section 313 - Toxlc Chemicals: None Secton 311/312-Hazand Categones: Flre azard: No Raactivity Hazard: No Sudden Release of Pressure Hazard: No Immediate (Acute) Health Hazard: Yes Delayed (Chronic)

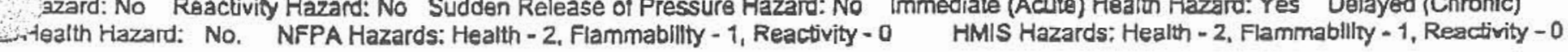




\section{Wet/Dry 700 EpOXy TECHNICAL DATA}

\section{SOLVENT-FREE EPOXY COATING}

\begin{tabular}{r|l} 
Protective Coating & $\begin{array}{l}\text { Solvent-Free } \\
\text { Easy 1:1 Mixing Ratio } \\
\text { Sealant } \\
\text { Works Underwater } \\
\text { Pevlar }\end{array}$ Patching Reinforced
\end{tabular}

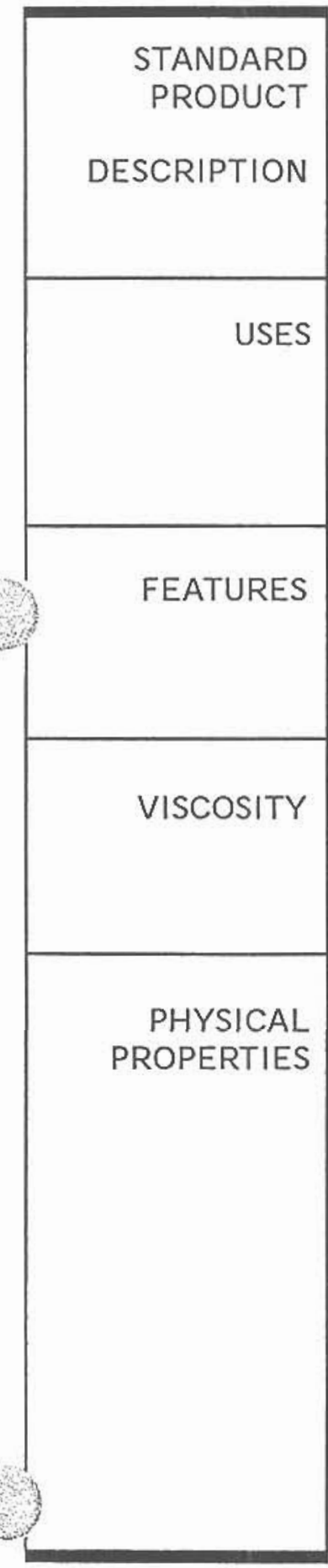

Wet/Dry 700 epoxy is a $100 \%$ solids, non-regulated, non-hazmat, Kevlar ${ }^{\mathrm{TM}}$ reinforced epoxy coating system designed for coating surfaces that may be subjected to constant immersion in water. Wet/Dry 700 will bond to water saturated concrete, and is resistant to sewer gasses, sulfur based chemicals, dilute acids and most caustics.

Marine environments

Docks, fiberglass and wood boats

Sewers, tunnels, dams, spillways

Underground concrete structures

Steel and concrete piping

Excellent chemical resistance

Convenient $1: 1$ ratio by volume or 1:0.83 by weight (base/cure)

Superior adhesion to cold, damp surfaces

Nonhazmat to ship

Viscosity at $72^{\circ} \mathrm{F}$ :

Part A: gel

Part B: $\quad$ gel

Mixed: gel

$\begin{array}{ll}\text { COMPRESSIVE STRENGTH ............. ASTM D695 } & 10,500 \mathrm{psi} \\ \text { TENSILESTRENGTH ....................ASTM D638 } & 5,200 \mathrm{psi}\end{array}$

ABRASION RESISTANCE ...............

CS-17 WHEEL, $1 \mathrm{~kg}$ LOAD ............. ASTM D4060 $0.20 \mathrm{gm}$ loss

WATERABSORPTION ....................ASTM D570 ， $0.19 \%$

(2 hour boil)

FLEXURAL STRENGTH .................ASTM D790 4,900 psi

SHORE D HARDNESS ...................ASTM D2240 88

HEAT DISTORTION ........................ASTM D649 $122^{\circ} \mathrm{F}$

TEMPERATURE

BONDSTRENGTHTOCONCRETE $\quad 100 \%$ concrete failure 


\section{Wet/Dry 700 Epoxy TECHNICAL DATA}

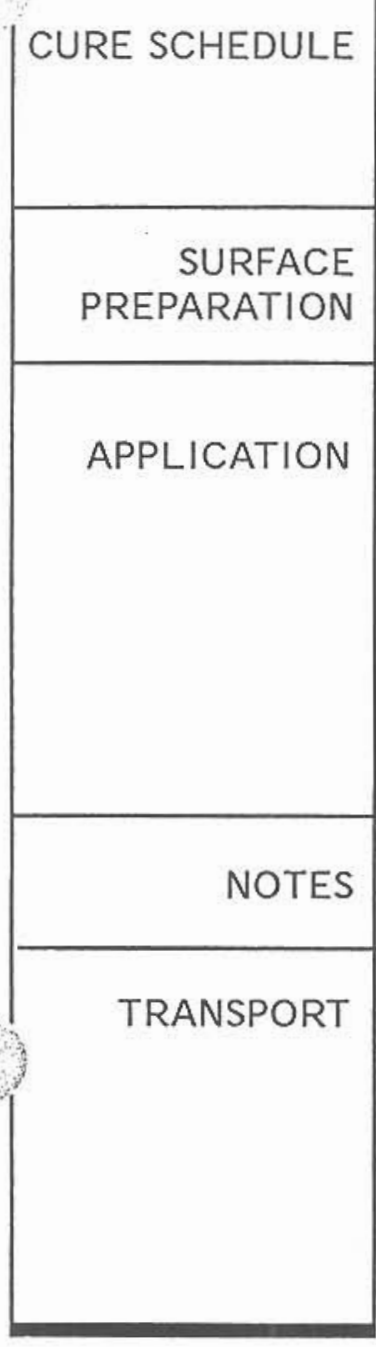

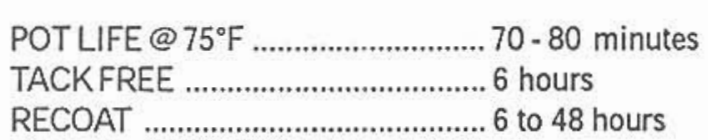

Surface to be topcoated must be clean and free of oils, grease and loose contamination.

Mix Wet/Dry 700 epoxy base with the Wet/Dry 700 curing agent. Use a mechanical mixer if possible to ensure thorough mixing. The mixing ratio is $1 / 1$ (base/curing agent) by volume or $1 / 0.83$ by weight. Wet/ Dry 700 does not require a 'sweat-in' or induction time and the mixed components should be used immediately.

Potlife is approximately $70-80$ minutes at $75^{\circ} \mathrm{F}$, so mix only the amount of epoxy that can be easily applied within that time limit. Apply using a squeegee.

Wet/Dry 700 is suitable for horizontal surfaces and vertical surfaces.

Unless top-coated with a UV absorber, this epoxy will yellow in sunlight.

Nonregulated by USDOT, IATA \& IMO.

SAFETY: This is a hazardous material if misused. Read and understand the Material Safety Data Sheet (MSDS) before use.

WARRANTY DISCLAIMER: The technical data given herein has been compiled for your help and guidance and is based upon our experience and knowledge. However, as we have no control over the use to which this information is put, no warranty, express or implied is intended or given except that these goods shall be of merchantable quality and buyer assumes all risk and liability for results obtained by the use of the materials covered in this data sheet, whether used singly or in combination with other products. We assume no responsibility whatsoever for coverage, performance or damages, including injuries resulting from use of this information or of products recommended herein. The sale and use of this product is governed by Progressive Products, Inc.'s Warranty Disclaimer and Return Policy.

\begin{tabular}{lll} 
Manufactured by: & Distributed by: & Tel: $603-435-7199$ \\
ERC in RI & Progressive Epoxy Polymers, Inc. & Fax: 603-435-7182 \\
& 48 Wildwood Dr. & www.epoxyproducts.com \\
& Pittsfield, NH 03263-3406 & info@epoxyproducts.com \\
\hline
\end{tabular}


This material asfety dstz sheat (MSDS) be becn preparoo in compliance with the FEDERAL OSHA COMMUNICATION STANDARD 29 CFR 1910. 1200.

$\begin{array}{ll}\text { UL.TRA POLYMERS, INC. } & \text { PHONE: (724) 449-2123 } \\ \text { OX } 1376 & \text { 36 Hour Emergency Phone (412) 487.5560 } \\ \text { UNTA, PA 15044 } & \text { Reviston Dater March 1, 2000 }\end{array}$

MATERIAL SAFETY DATA SHEET

SECTION I: IDENTITY INFORMATION

DENTITY (TRADENAME): ULTRA PHIX UW - PART A

FAMILY/CHEMICAL NAME: EPOXWE Resin

PRODUCT TYPE: Coating/patching

SECTION II: HAZARDOUS INGREDIENTS

SPECIFIC CHEMICAL NAME: Propietary

CAS \#:na

EXPOSURE LIMITS:

OSHA PEL: Not established

ACGIH TLV: Not established

CARCINOGENICITY:

IARC: NO NTP: NO OSHAA:NO ACGIH: NO OTHER: NO

SPECIFIC CAIEMICAL NAME: Titanium dioxide (TiO2)

CAS \#: 1363-67-1

EXPOSURE LIMITS:

OSHA PEL: $15 \mathrm{mg} / \mathrm{m}$ (total dust)

ACGLH/ TLV: $15 \mathrm{mg} / \mathrm{m}$ (total dust)Not established

CARCINOGENICTTY:

IARC: NO NTP: NO OSHA:NO ACGIH: NO OTHER: NO

C.

CAS \#: 1344-28-1

EXPOSURE LIMTTS:

OSHA PEL: $15 \mathrm{mg} / \mathrm{m} 3$ (total dust)

ACGIH TLV: Not established

CARCINOGENICITY:

LARC: NO NTP: NO OSHA:NO ACGIH: NO OTHER: NO

SECTION III : PHYSICAL DATA

APPEARANCE AND ODOR: Thick. No odor. SPECIFIC GRAVITY: 1.15

SOLUBILITY IN WATER: Insoluble FREEZING POINT: N/A

BOILING POINT $(760 \mathrm{~mm}$ Hg): N/A \% VOLATILE BY VOL.: N/A

MELTING POINT: Not Applicable VISCOSITY: Paste

SECTION IV : FIRE AND EXPLOSION HAZARD DATA

FLASH POINT: $>300 \mathrm{~F}$

EXTINGUISHING MEDIA: Water spray, $\mathrm{CO} 2$, dry chemical, foam.

FIRE FIGHTENG PROCEDURES - SPECIAL: Firefighters should wear goggles and self-contained breathing app: atus to svo. inhalation of smoke or vapors.

UNUSUAL FIRE AND EXPLOSION HAZARDS: None known.

\section{SECTION V : REACTIVITY DATA}

STABILITY: Stable

CONDITIONS TO AVOID: Elevated temperatures.

INCOMPATIBLITY: Strong oxidizing agents.

ZARDOUS DECOMPOSITION PRODUCTS: Silica will dissolve in Hydrofluoric acid and produce a corrosive gas silicon ffluoride.

HAZARDOUS POLYMERIZATION: None known. 


\section{SECTION VI : HEALTH HAZARD DATA}

PRIMARY ROUTES OF EXPOSURE: Inhalation, ingestion, skin and eye contact.

EXE: May cause slight transient (temporary) eye irritation. Corneal injury is unlikely.

V CONTACT: Prolonged exposure is not likely to cause significant skin irritation. Repeated exposure may cause skin irritation.

iaused allergic skin reaction in humans.

SKIN ABSORPTION: A single prolonged exposure is not likely to result in the material being absorbed through skin in harmful amounts. The LD50 for skin absorption in rabbits is $20,000 \mathrm{mg} / \mathrm{kg}$.

DNGESTION: Single dose oral toxicity is low. The oral LDS0 for rats is $>5,000 \mathrm{mg} / \mathrm{kg}$. No hazards anticipated from swallowing small amounts incidental to normal handling operations.

INHALATION: Vapors are unlikely due to physical properties.

SYSTEMATIC (OTHER TARGET ORGANS) EFFECTS: Except for skin sensitization, repeated exposures to low molecular weight diglycidyl ether of bisphenol $\mathrm{A}$ are not anticipated to cause any significant adverse affects.

CANCER INFORMATION: A poorly characterized sample of low molecular weight diglycidyl ether of bisphenol A has been reported to produce skin cancer in a highly sensitive strain of mice. However, high levels of impurities (including a known animal skin carcinogen) compromise the validity of the findings. Diglycidyl ether of bisphenol A that is representative of current manufacturing processes is not to believed to be a cancer hazard to humans.

TERATOLOGY (BIRTH DEFECTS): Did not cause birth defects or other adverse effects on the fetus when pregnant rabbits were exposed by skin contact, the most likely route of exposure.

\section{EMERGENCY AND FIRST AID PROCEDURES:}

EYES: Immediately flush eyes with water for $10 \mathrm{~min}$.

SKIN: Wash with mild soap and water.

INGESTION: If conscious, give large quantities of water.

Induce vomiting.

INHALATION: Remove to fresh air.

OTHER: Remove contaminating clothing.

\section{SECTION VII : SPILL OR LEAK PROCEDURES}

SPILL PROCEDURES: Avoid all personal contact. Take up with absorbent material. Use closable containers. Flush area with y.m.r.

FTE DISPOSAL METHODS: Dispose in accordance with federal, state, and local regulations.

\section{SECTION VII : SPECIAL PROTECTION INFORMATION}

VENTILATION: Good general mechanical ventilation and local exhaust.

PROTECTIVE GLOVES: Wear impervious gloves.

EYE PROTECTION: Wear splash-proof chemical goggles.

RESPIRATORY PROTECTION: Use NIOSH approved respirator for organic vapors. IF REQUIRED.

OTHER PROTECTIVE EQUIPMENT: It is preferable to use disposable protective clothing and gloves. Use equipment necessary to prevent skin or eye contact.

\section{SECTION DX : SPECIAI PRECAUTIONS AND PROTECTION}

HANDLING, SHIPPING AND STORING PRECAUTIONS:

Avoid contact with skin, eyes, and clothing.

Store above freezing $(32 \mathrm{~F})$

Do not taste. Avoid breathing mists or vapors.

Wash thoroughly after handling.

Keep containers closed when not in use.

Use with adequate ventilation.

\section{SECTION X : REGULATORY INFORMATION}

DOT CLASS: Not regulated.

SARA: Health: 1 Fire: 1 Reactivity: 1

RCRA STATUS: Not a hazardous waste.

CERCLA STATUS: Not listed

POR MURTHER INFORMATTON, PLEASE CONTACT LEO A. ANNA

TTR DNFORMATION AND RECOMMENDATIONS IN THS DATA SHEPT ARE BASHD UPON DATA BELIEVED TO BE CORRECT. NO GUARANTER OR WARRANTY OF ANY KRND IS EXPRESSED OR DFORMATION AND RECOMMENDATIONS NN TIIS DATA SH 


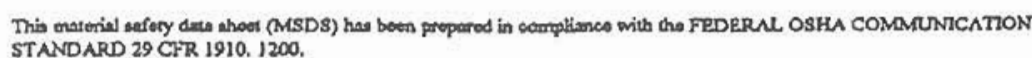

I POLYMRRS, INC.

OX 1376

GIBSONTA, PA 15044
PHONE: (720) 49.2123

26 Hour Emorgency Phooe (412) 487-5560

Revision Dato: March 1, 2000

\section{MATERIAL SAFETY DATA SHEET}

\section{SECTION I: IDENTITY INFORMATION}

IDENTITY (TRADENAME): ULTRA PHIX UW - PART B

FAMTY/CHEMRCAL NAME: ALIPHATIC POLYAMINES/AMIDO POLYAMINES

PRODUCT TYPE: COATINGS - CONCRETE REPAIR

\section{SECTION II: HAZARDOUS INGREDIENTS}

SPECIFIC CHEMICAL NAME: Aliphatic polyamine

CAS \#: Not available

EXPOSURE LIMITS:

OSHA PEL: Not established

ACGIH TLV: Not established

CARCINOGENICITY:

IARC: NO NTP: NO OSHA:NO ACGIH: NO OTHER: NO

SPECIFIC CHEMICAL NAME: Amidopolyamine

CAS \#: 68410231

EXPOSURE LIMITS:

OSHA PEL: Not established

ACGIH TLV: Not established

CARCINOGENICITY:

TARC: NO NTP: NO OSHA:NO ACGIH: NO OTHER: NO

$+3$

U- - TION III : PHYSICAL DATA

APPEARANCE AND ODOR: Amber liquid SPECIFIC GRAVITY: 1.10

SOLUBILITY IN WATER: Slightly

BOILING POINT $(760 \mathrm{~mm} \mathrm{Hg})$ : Not available \% VOLATLES BY VOL: Zero

MELTING POINT: Not applicable

SECTION IV : FIRE AND EXPLOSION HAZARD DATA

FLASH POINT: Not available

EXTINGUISHING MEDIA: Water spray, $\mathrm{CO} 2$, dry chemical

FIRE FIGHTING PROCEDURES - SPECIAL: Cool exposed containers with water spray. Self-contained breathing apparatus in contained areas.

UNUSUAL FIRE AND EXPLOSION HAZARDS: None

\section{SECTION V : REACTIVITY DATA}

STABILITY: Stable

CONDITIONS TO AVOI: High temperatures

INCOMPATIBILITY: Strong oxidizing agents

HAZARDOUS DECOMPOSITION PRODUCTS: None known

HAZARDOUS POLYMERIZATION: None known

\section{SECTION VI : HEALTH HAZARD DATA}

PRIMARY ROUTES OF EXPOSURE: Inhalation, ingestion, skin and eye contact.

EYE: May cause slight transient (temporary) eye irritation. Comeal injury is unlikely.

SKIN CONTACT: Prolonged exposure is not likely to cause significant skin irritation. Repeated exposure may cause skin irritation. ros caused allergic skin reaction in humans.

N ABSORPTION: A single prolonged exposure is not likely to result in the material being absorbed through skin in harmful initurnts. The LD50 for skin absorption in rabbits is $20,000 \mathrm{mg} / \mathrm{kg}$. 
INGESTION: Single dose oral toxicity is low. The oral LD50 for rats is $>5,000 \mathrm{mg} / \mathrm{kg}$. No hazards anticipated from swallowing small amounts incidental to normal handling operations.

INHALATION: Vapors are unlikely due to physical properties.

TEMATIC (OTHER TARGET ORGANS) EFFECTS: Except for skin sensitization, repeated exposures to low molecular

it diglycidyl ether of bisphenol $\mathrm{A}$ are not anticipated to cause any significant adverse affects.

CnNCER INFORMATION: A poorly characterized sample of low molecular weight diglycidyl ether of bisphenol A has been reported to produce skin cancer in a highly sensitive strain of mice. However, high levels of impurities (including a known animal skin carcinogen) compromise the validity of the findings. Diglycidyl ether of bisphenol A that is representative of current manufacturing processes is not to believed to be a cancer hazard to humans.

TERATOLOGY (BIRTH DEFECTS): Did not cause birth defects or other adverse effects on the fetus when pregnant rabbits were exposed by skin contact, the most likely route of exposure.

\section{EMERGENCY AND FIRST AID PROCEDURES:}

EYES: Immediately flush eyes with water for $10 \mathrm{~min}$.

SKIN: Wash with mild soap and water.

INGESTION: If conscious, give large quantities of water.

Induce vomiting.

INEALATION: Remove to fresh air.

OTHER: Remove contaminating clothing.

\section{SECTION VII : SPILL OR LEAK PROCEDURES}

SPILL PROCEDURES: Avoid all personal contact. Take up with absorbent material. Use closable containers, Flush area with water. For large spills, contain material, take up with absorbent material. Avoid use of water.

WASTE DISPOSAL METHODS: Dispose in accordance with federal, state and local regulations.

\section{SECTION VII : SPECIAL PROTECTION INFORMATION}

VENTLATION: Good general mechanical ventilation and local exhaust.

PROTECTIVE GLOVES: Wear impervious gloves, such as nitrile rubber gloves.

EYE PROTECTION: Wear splash-proof chemical goggles RESPIRATORY PROTECTION: Use NIOSH approved respirator for organic vapors, IF REQUIRED.

ER PROTECTIVE EQUIPMENT: It is suggested that disposable protective gloves and clothing are used. Use equipment . W. sussary to prevent skin or eye contact. Wash before eating, smoking or using the toilet.

\section{SECTION IX : SPECIAL PRECAUTIONS AND PROTECTION}

HANDLING, SHIPPING AND STORING PRECAUTJONS: Avoid contact with skin, eyes and clothing. Do not taste. Avoid breathing mists or vapors. Wash thoroughly after handling. Keep containers closed when not in use. Use with adequate ventilation.

\section{SECTION X : REGULATORY INFORMATION}

DOT CLASS: Not regulated

OSHA: Corrosive

Reportable Quantities: NA

Shipping Class: Corrosive liquid

SARA: No toxic chemicals subject to reporting requirements.

Health: 2 Fire: 1 Reactivity: 0

RCRA STATUS: Not a hazardous waste

CERCLA STATUS: Not listed

\section{FOR FURTHER INFORMATION, PLEASE CONTACT LEO A. ANNA}

THE INFORMATION AND RECOMMENDATIONS IN THIS DATA SHEET ARE BASED UPON DATA BELIEVED TO BE CORRECT, NO GUARANTEE OR WARRANTY OF ANY KIND IS EXPRESSED OR IMPLIED IS MADE WITH RESPECT TO THE ABOVE INFORMATION 


\section{ULTRA POLYMERS, INC.}

230 Laurel Avenue - P.O.Box 1376 - Gibsonia - PA - 15044 - Phone: 724 - 449 - 2122 - Fax: 724 - 449 - 1044

NEW PRODUCTS! STELLAR with KEVLAR now available. Ultracoat Underwater for under water mi

Contents

Search

Email Us!

Our Commitment

\section{Resistance Char}

Started in 1976 as the maker of specialized epoxy solutions for a variety of industries. Ultra Polymers, Inc. now offers a full line of coatings. Our coatings are formulated based on experience in commercial and industrial applications.

\section{遇 965}

About Ultra Polymers, Inc.

Ultra Polymers, Inc. is the manufacturer and distributor of a superior line of $100 \%$ solids high-performance epoxy coatings and liners.

Our coatings are customized to provide high wear resistance, chemical resistance, flexibility, superior adhesion and dimensional stability.
We offer products that are proven to solve problems. Our coatings are ideal for steel and other metals, concrete. fiberglass, PVC and rubber.

\section{Products}

- STELLAR with KEVLAR now available for the ultimate in wear resistance!!

- ULTRACOAT UNDERWATER now available for commercial and industrial use. Mix underwater! Apply underwater! Create strong bonds and permanent repairs while completely submerged.

- ULTRACOAT Create a chemical and abrasive resistant barrier for metal, steel, wood and concrete.

- ULTRAGRIP For anti-slip surfaces

- ULTRALINER Superior wear resistance

- ULTRATHANE Flexible epoxy

- ULTRACRETE 4-12 times stronger than concrete

- ULTRAPHIX Superior coating performance in a premeasured cartridge and easy-to-use applicator.

\section{Services}

- APPLICATIONS

\section{Ultracoat} Underwater

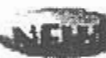

STELLAR

with

KEVLAR 


\section{Ultracoat Undenwater

\section{Home \\ - ULTRACOAT UNDERWATER}

Contents

\section{Search}

Our Commitment

Resistance Chart

\section{Email Us!}

A breakthrough in epoxy coating, ULTRACOAT UNDERWATER lets you apply our superior epoxy coating to surfaces that are completely submerged. Add impact and chemical resistance to damp, wet or even submerged areas in an easy, inexpensive way.

\section{UNDER WATER!}

Using cartridges of pre-measured material and a hands-off mixing system, (see the ULTRAPHIX system) ULTRACOAT LNDERWATER is mixed and dispensed right where you want it. NO MESS!

There are some materials that can be applied under water, but they nust be mixed in a dry environment first. This limits the time you have to complete repairs and results in expensive wasted material.

\section{APPLY TO WET SURFACES}

\section{ULTRACOAT UNDERWATER is specially}

formulated to adhere directly to wet surfaces without floating awray.

Thorough surface preparation yields optimum performance, but surfaces that are corroded or othervise compromised also can be coated or repaired with excellent results!

\section{- SAVE MONEY! SAVE TIME!}

Because you only mix exactly the amount you need, when you need it, waste is aroided entirely. It won't cure before you can use it. Unlike most epoxies, small amounts can be used without mixing an entire kit.

ATTENTION DIVERS - it won't ruin your wetsuit!
ULTRACOAT

UNDERWATER works in dry environments too! Use it for all your repairs.

Pipes

Boats

Docks

Sump pumps

Gutters

Drains

Pools

Shower rooms

Tanks

Containment areas

More! 
MATERIAL SAFETY DATA SHEE'T

NMP 1710 EPOXY BASE AND CURE

NATIONAL MAINTENANCE PRODUCTS Pty Ltd

Page I of Total: -2

STATEMENT OF HAZARDOUS NATURE

Date of Issue: - Feb 03

Considered toxic according to criteria of Worksafe Australia. Not considered hazardous if used as per instructions. DOES NOT CONTAIN CARCINOGENS

\section{COMPANY DETAILS}

$\begin{array}{ll}\text { Company: } & \text { National Maintenance Products Pty Ltd. ACN 097 } 487637 \\ \text { Address: } & \text { Unit 19, 10 Miltiadis St, Acacia Ridge Qld 4110 } \\ & \text { PO Box 8149, Woolloongabba, Qld 4102 } \\ \text { Phone/Fax: } & \text { Ph+61 732167388: Fax +61 7 3216 7488 } \\ \text { Emergency Telephone No: } & +61732167388\end{array}$

Emergency Telephone No: $\quad+61732167388$

\begin{tabular}{llll}
\hline IDENTIFICATION & & \\
\hline & NMP 1710 (Base and Cure) & UN Number: & None Allocated \\
Product Name: & NMP 1710 & Dangerous Goods Class \& Subsidiary Risk: None Allocated \\
Other Names: & NMP1710 & Hazchem Code: & None Allocated \\
Manufacturers Product Code: & 8L Pack & Poisons Schedule Number: None Allocated \\
Pack Size: & &
\end{tabular}

PHYSICAL DESCRIPTION/PROPERTIES:

BASE:

Appearance:

Packaging:

Boiling Point:

Melting Point:

Vapour Density:

Density @2 $20^{\circ} \mathrm{C}$ :

CURE:

Appearance:

Packaging:

Boiling Point:

Melting Point:

Vapour Density:

Solubility in Water:

Density @ $20^{\circ} \mathrm{C}$ :

Coloured paste with characteristic epoxy odour.

Packaged in it's own metal or plastic container with press fit lid.

Not applicable. $\quad$ Flashpoint: $>121^{\circ} \mathrm{C}$.

Not applicable. $\quad$ Freezing Point: Not applicable.

$\begin{array}{ll}\text { Not applicable. } & \text { Freezing Point: } \\ \text { Not applicable. } & \text { Flammability Limits: Not applicable. }\end{array}$

$\begin{array}{lll}\text { Not applicable. } & \text { Flammability Limits: Not applic } \\ \text { Negligible. } & \text { Specific Gravity: } 1.34 .\end{array}$

$\begin{array}{ll}\text { Negligible. } & \text { Specific Gravity: } \\ 1.36 \mathrm{~kg} / \mathrm{L} \text {. } & \text { Auto ignition Temp: Not applicable. }\end{array}$

OTHER PROPERTIES:

Curing Time:

Storage Life:

Spread Rate:

Pot Life:

Minimum Cure Temperature:

Corrosiveness:

VOC:

White paste with very slight ammoniac odour.

Packaged in it's own metal or plastic container with press fit lid.

Not applicable. $\quad$ Flashpoint: $\quad>93^{\circ} \mathrm{C}$

Not applicable. $\quad$ Freezing Point: Not applicable.

Not applicable. $\quad$ Flammability Limits: Not applicable.

Negligible. Specific Gravity: 1.69.

$1.69 \mathrm{~kg} / \mathrm{L}$. Auto ignition Temp: Not applicable.

INGREDIENTS:

BASE:

Touch dry 4hrs@2 $27^{\circ} \mathrm{C}$. Hard 14hrs@2 $27^{\circ} \mathrm{C}$. Variations of temperature up or down will by rule of thumb half or double these times per approx each $10^{\circ} \mathrm{C}$ variation.

Minimum 24 months.

15sq. m/kit @ $0.5 \mathrm{~mm}$.

Approx 40mins @ $27^{\circ} \mathrm{C}$.

$5^{\circ} \mathrm{C}$.

Non-Corrosive.

$0.5 \% \max$.

\begin{tabular}{|c|c|c|c|}
\hline & INGREDIENT & CAS NUMBER & PROPORTION \% \\
\hline & Epoxy resin liquid polymer & $25068-38-6$ & $50-75$ \\
\hline & p-tertbutylphenyl glycidyl ether & $31101-60-8$ & $5-10$ \\
\hline & Poly terephthaloylchloride p-phenylenediamine & $26125-61-1$ & $2-5$ \\
\hline & Micronised silica & $7631-86-9$ & $5-10$ \\
\hline & Products determined not to be hazardous & & to 100 \\
\hline \multirow[t]{4}{*}{ CURE: } & & & \\
\hline & INGREDIENT & CAS NUMBER & PROPORTION \% \\
\hline & Benzyl Alcohol & $100-51-6$ & $12-24$ \\
\hline & Products determined not to be hazardous & & to 100 \\
\hline
\end{tabular}

HEALTH HAZARD INFORMATION

\section{HEALTH EFFECTS:}

BASE:

Skin Irritation - Slight irritant, possible sensitiser

Dot. Corrosivity - Not corrosive.

Oral Toxicity - Unknown - Do not ingest.
Inhalation Toxicity - Unknown, see below.

Eye Irritation - Slight irritant.

Dermal Toxicity - Unknown 
Skin and Eye Contact - Slightly irritating, possible sensitiser.

Ingestion-Considered slightly toxic.

Inhalation - Overexposure to mist may cause irritation of respiratory tract. Prolonged or repeated exposure may cause an asthmatic reaction.

First Aid Recommendations:

Skin and Eye Contact - Immediately flush eyes with fresh water holding lids apart for 15 minutes, washing within one minute is essential to achieve maximum effectiveness. Remove from skin using soap and water. Remove contaminated shoes and clothing. Call a physician.

Ingestion - Do not induce vomiting. Prevent aspiration (breathing) liquid into lungs. Get medical attention.

Inhalation - Immediately move to fresh air. If breathing is difficult, give oxygen. Call a physician.

CURE:

Inhalation - Do not inhale the product. May cause irritation to upper respiratory tract upon prolonged or repeated inhalation. (Note: because of low volatility of product and pasty viscosity it is extremely unlikely that excessive exposure to vapours will be experienced at normal temperature under normal circumstances).

Eye and Skin Contact - May cause skin and eye irritation. May cause permanent visual impairment. Wear protective clothing and goggles.

Caution-Pre-existing eye, skin and respiratory disorders may be aggravated by exposure to this product, exercise caution in handling. Remove from skin using liquid soap or detergent - always avoid using solvents to remove skin contamination.

First Aid Recommendations:

Skin and Eye Contact - Immediately flush eyes with fresh water holding lids apart for 15 minutes, washing within one minute is essential to achieve maximum effectiveness. Remove from skin using soap and water. Remove contaminated shoes and clothing. Call a physician. Victims of a major skin contact should remain under medical observation for at least 24 hours due to possible delayed effects.

Ingestion - Danger! Do not take internally. May cause gastrointestinal irritation or ulceration. May cause burns of mouth and throat. Do not induce vomiting. Give a large quantity of milk or water. Do not give fluids to an unconscious person. Call a physician.

Inhalation - Immediately move to fresh air. If symptoms persist, call a physician.

\section{PRECAUTIONS FOR USE}

$\begin{array}{ll}\text { Exposure Standards: } & \text { None assigned. } \\ \text { Engineering Controls: } & \text { None required during normal use. } \\ \text { Personal Protection: } & \text { Mechanical local exhaust at point of contaminant release if conditions warrant. Wear impervious gloves; wear chemical } \\ & \text { resistant safety goggles if eye contact possible; wear overalls. It is extremely unlikely that harmful concentrations of volatile } \\ \text { materials will be released during normal applications by spreaders, trowels, or similar tools in open areas. Wear organic } \\ \text { vapour cartridge respirator or fresh air hood if working for extended periods in enclosed spaces with minimal ventilation. }\end{array}$

\section{SAFE HANDLING INFORMATION}

\begin{tabular}{|c|c|}
\hline $\begin{array}{l}\text { Storage and Transport: } \\
\text { Spills and Disposal: }\end{array}$ & General good practice required. Store at ambient conditions. Avoid extremes. Transport as non-hazardous. \\
\hline Spills: & Scrape up and place in suitable container for disposal. Wash area with solvent of thinners. \\
\hline Disposal: & Dispose in industrial disposal. Observe local regulations for chemical waste disposal. \\
\hline ire or Exp & ducts. Use water spray, foam or dry chemical to fight fire. Not \\
\hline
\end{tabular}

\section{OTHER INFORMATION}

$\begin{array}{ll}\text { Reactivity: } & \text { No known reactivity. Avoid contact with strong acids, bases and oxidising agents. } \\ \text { Ecotoxicity data: } & \text { None known. } \\ \text { Toxicological information: } & \text { None known. } \\ \text { Stability: } & \text { Stable. } \\ \text { Incompatible Materials: } & \text { None known. } \\ \text { Hazardous Decomposition: } & \mathrm{CO} \text {; CO2; unspecified others. } \\ \text { Hazardous Polymerisation: } & \text { Will not occur. } \\ \text { Conditions to avoid: } & \text { Mixing large volumes of base and cure ... expect a significant exotherm within 20-25 minutes at } 25^{\circ} \mathrm{C} .\end{array}$

\section{CONTACT POINT}

Technical Services Information Officer: +61732167388

DISCLAIMER: To the best of our knowledge, the information contained herein is accurate. However, National Maintenance Products Pty Ltd. assumes no liability for the accuracy and completeness of the information contained herein. Final determination of suitability of this material is the sole responsibility of the user. All materials present unknown hazards and should be used with caution. Although certain hazards are described herein, we cannot guarantee that these are the only hazards that exist. 


\section{NMP 1710 \\ HEAVY DUTY SUPERIOR COATING}

\section{PRODUCT DATA SHEET}

Date of Issue:- Feb 03

NMP 1710 is a brushable version of our superior NMP 1720. It is a premium performance epoxy, especially formulated to provide superior protection to piers, splash zones, tanks, pits, bunds, walls, floors, pipes, hulls and decks, above or below water. This unique protective coating can be likened to "case hardening" the surface it is protecting, with a tensile strength of 5 times, flexural strength of 3 times, and chip and wear resistance up to 6 times other readily available epoxies, even those which are thick film.

It is formulated on the highest quality, pure epoxy polymers and curing agents. Pigmentation is selected for hardness and durability in order to obtain the best possible properties when cured.

Kevlar $^{\mathrm{TM}}$ fibres are also incorporated to enhance the coatings' unique properties. It employs no solvents, is non-hazmat and is so tolerant of wet conditions it makes an excellent anti-corrosive for underwater application to steel, concrete and similar surfaces. Constant immersion in fresh or salt water, sewerage, fuels and oils, hydrocarbons, mineral acids or many other industrial waste products has no detrimental effect on its life span.

NMP 1710 can be applied by brush, spatula or trowel, without the need for a primer. The cured film is hard and glossy with a slight texture resulting from the fibre reinforcement. The solvent-free nature means it is non-corrosive, non-flammable, odourless and is perfectly safe for use in confined spaces, has no shrinkage and is environmentally safe with absolutely no effect on the surrounding plant or marine life.

NMP 1710 is formulated to be "non-regulated", by IATA, IMO, DOT and USDOT for uncomplicated shipment by land, sea or air.

\section{RECOMMENDED USES}

- HEAVY DUTY PROTECTIVE COATING FOR STEEL AND CONCRETE

- EXCELLENT CHEMICAL AND IMPACT RESISTANCE FOR TANKS, PITS, BUND WALLS AND FLOORS, SEA WALLS ETC.

- SUPERIOR PHYSICAL STRENGTH UP TO 6 TIMES STRONGER THAN OTHER EPOXIES - FOR SURFACE REINFORCEMENT

- HEAVY-DUTY MAINTENANCE FOR DECKS AND TANKS

- ANTI-CORROSIVE COATING FOR SWEATING PIPES OR UNDER INSULATION TO NEGATE CUI

- IDEAL FOR POWER GENERATION APPLICATIONS - DRAFT TUBES, PENSTOCKS, WATER BOXES, TUBE SHEETS, DAM WALLS ETC.

- REINFORCEMING, REPAIRING AND PROTECTING CONCRETE AND STEEL TANKS DAMAGED BY EXPOSURE TO CORROSIVE CHEMICAL AND MUNICIPAL WASTE SYTEMS

- ADD CARBOTUNDUM GRIT FOR AN EXTREMELY LONG LIFE NON-SLIP SURFACE FLOORING IN HARSH ENVIRONMENTS

\section{TECHNICAL INFORMATION}

VEHICLE TYPE. PIGMENTATION.. 2-pack epoxy/polyamines.

Colour/inert/fibrous reinforcing. 
COLOURS.

FINISH..

CLEANER

MIXING RATIO

POT SIZE

INDUCTION TIME.

POT LIFE.

FLASH POINT

SOLIDS BY VOLUME

SPREAD RATE.

SURFACE TYPE

DRY TIME

VOC..

LIFE SPAN
Grey, white, other on request.

Glossy with slight texture from the fibre.

MEK or lacquer thinner.

$1: 1$ v:v

$8 \mathrm{~L}$.

Not required.

Approx.40mins @25․

Over $100^{\circ} \mathrm{C}$.

$100 \%$

15 sq.m per kit@600 microns.

Concrete, brick, wood, fibreglass, metal, polystyrene.

6 hours @ $25^{\circ} \mathrm{C}$ touch, 15 hours hard. Full: 7 days.

Zero.

Very long life, even in adverse conditions.

\section{APPLICATION NOTES}

\section{Surface Preparation:}

New Concrete - should be left for 28 days (minimum) before coating. Weak surface laitance must be removed by water blasting, acid etching or abrasive sweeping

Existing Concrete ... coated or bare - sound surfaces should be well cleaned by degreasing, water blasting or grit blasting as appropriate. Small areas can be cleaned by grinder but that is not practical for large areas.

Repair holes or scabbled areas by trowelling in a mix of NMP 1710 and clean fine grain sand at about a 2:1 mix of sand to epoxy. Solvent free - apply over existing well-adhered, clean coatings.

\section{Application:}

Mix desired amount well at a 1:1 ratio. Ensure the two components are well mixed to a uniform colour. You do not need to mix the entire product at once. Shelf life of unused product is almost indefinite. Mix well to ensure complete mixing. NMP products do not require an induction time so you can use immediately. Apply by spatula or trowel at about 600 microns.

Underwater- take the mixed product underwater in a bucket. Apply within 30-40mins of mixing by brush, spatula, trowel or hand mitt on difficult shapes such as risers. It is much easier to apply than traditional "splash zone" compositions, and is substantially less messy than lower viscosity underwater "paints".

CHEMICAL RESISTANCE - Resistant to all fuels, oils, skydrol, hydraulic fluid, alkalies, $50 \%$ caustic soda, $70 \%$ Sulphuric acid. TRANSPORTATION - Unregulated.

THIS INFORMATION SHOULD BE READ IN CONJUNCTION WITH MATERIAL SAFETY DATA SHEETS,

NATIONAL MAINTENANCE PRODUCTS Pty Ltd
Unit 19, 10 Miltiadis St, Acacia Ridge, Q1d 4110, Australia
Ph +61732167388, Fax +61732167488
For Coating Solutions ...askNMP.com

WARRANTY DISCLAIMER The technical data given herein has been complied for your help and guidance and is based upon our experience and knowledge. However as we have no control over the use to which this information is put, no warranty express or implied is intended or given. We assume no responsibility whatsoever for coverage, performance or damages, including injuries resulting from use of this information or of products recommended herein. 
MATERIAL SAFETY DATA SHEET

\begin{tabular}{|c|}
\hline NMP 1720 EPOXY BASE AND CURE \\
NATIONAL MANTENANCE PRODUCTS Pty Ltd \\
\hline \\
STATEMENT OF HAZARDOUS NATURE \\
\hline
\end{tabular}

Considered toxic according to criteria of Worksafe Australia. Not considered hazardous if used as per instructions. DOES NOT CONTAIN CARCINOGENS

\section{COMPANY DETAILS}

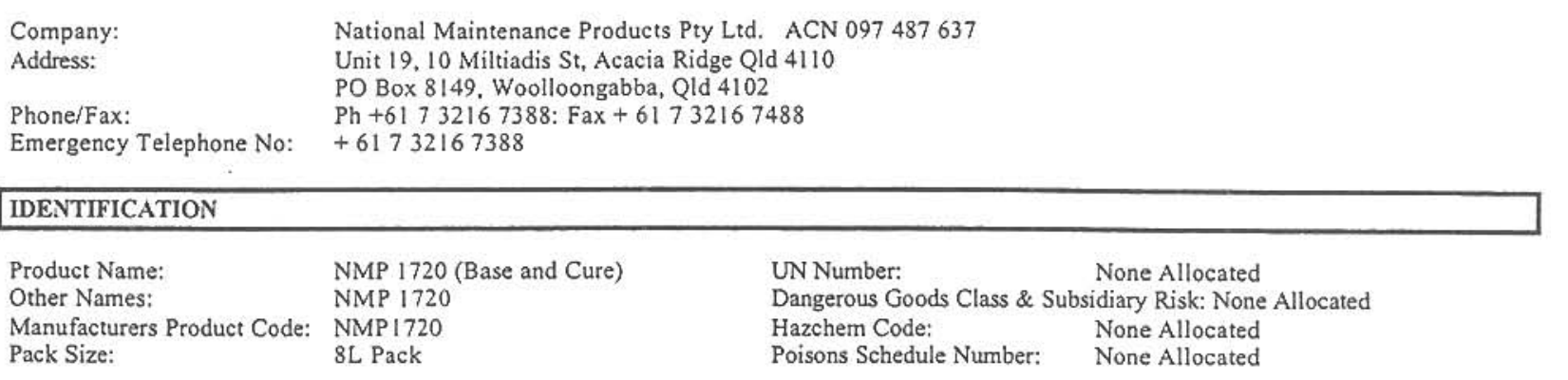

\section{PHYSICAL DESCRIPTION/PROPERTIES:}

BASE:

Appearance:

Appearance:

Boiling Point:

Melting Point:

Vapour Density:

Density@ $20^{\circ} \mathrm{C}$;

Coloured paste with characteristic epoxy odour.

Packaged in it's own metal or plastic container with press fit lid

Not applicable.

Not applicable.

Not applicable.

Flashpoint: $\quad>121^{\circ} \mathrm{C}$

Freezing Point: Not applicable.

Flammability Limits:Not applicable.

Specific Gravity: $\quad 1.34$

CURE:

Appearance:

Packaging:

Boiling Point:

Melting Point:

Vapour Density:

Solubility in Water:

Auto ignition Temp:Not applicable.

Density@ $20^{\circ} \mathrm{C}$ :

Coloured paste with slight ammonia odour.

Packaged in it's own metal or plastic container with press fit lid.

Not applicable.

Negligible. Specific Gravity: 1.69 .

$1.7 \mathrm{~kg} / \mathrm{L}$. Auto ignition Temp:Not applicable.

OTHER PROPERTIES:

Curing Time:

Storage Life:

Spread Rate:

Pot Life:

Minimum Cure Temperature:

Corrosiveness:

VOC:

Touch dry 4 hrs @ $27^{\circ} \mathrm{C}$. Hard $14 \mathrm{hrs} @ 27^{\circ} \mathrm{C}$. Variations of temperature up or down will by rule of thumb half or double these times per approx each $10^{\circ} \mathrm{C}$ variation.

Minimum 24 months.

11 sq. $\mathrm{m} / \mathrm{kit} @ 0.8 \mathrm{~mm}$.

Approx 40mins@2 $27^{\circ} \mathrm{C}$.

Non-Corrosive.

INGREDIENTS:

BASE:

$0.5 \% \max$.

\begin{tabular}{lll}
\multicolumn{1}{c}{ INGREDIENT } & CAS NUMBER & PROPORTION \% \\
Epoxy resin liquid polymer & $25068-38-6$ & $50-75$ \\
p-tertbutylphenyl glycidyl ether & $31101-60-8$ & $5-10$ \\
Poly terephthaloylchloride p-phenylenediamine & $26125-61-1$ & $2-5$ \\
Micronised silica & $7631-86-9$ & $5-10$ \\
Products determined not to be hazardous & & to 100
\end{tabular}

CURE:

\begin{tabular}{lll}
\multicolumn{1}{l}{ INGREDIENT } & CAS NUMBER & PROPORTION \% \\
$\begin{array}{l}\text { Benzyl Alcohol } \\
\text { Products determined not to be hazardous }\end{array}$ & $100-51-6$ & $12-24$ \\
& & to 100
\end{tabular}

HEALTH HAZARD INFORMATION

HEALTH EFFECTS

Skin Irritation - Slight irritant, possible sensitiser

Dot. Corrosivity - Not corrosive.

Oral Toxicity - Unknown - Do not ingest.
Inhalation Toxicity - Unknown, see below.

Eye Irritation - Slight irritant.

Dermal Toxicity - Unknown 
Skin and Eye Contact - Slightly irritating, possible sensitiser.

Ingestion - Considered slightly toxic.

Inhalation - Overexposure to mist may cause irritation of respiratory tract. Prolonged or repeated exposure may cause an asthmatic reaction.

First Aid Recommendations:

Skin and Eye Contact - Immediately flush eyes with fresh water holding lids apart for 15 minutes, washing within one minute is essential to achieve maximum effectiveness. Remove from skin using soap and water. Remove contaminated shoes and clothing. Call a physician.

Ingestion - Do not induce vomiting. Prevent aspiration (breathing) liquid into lungs. Get medical attention.

Inhalation - Immediately move to fresh air. If breathing is difficult, give oxygen. Call a physician.

CURE:

Inhalation - Overexposure to harmful concentrations of vapour is extremely unlikely in normal brush or roller applications. Inhalation of spray mist might cause irritation of the respiratory tract. Prolonged or repeated exposure may cause an asthmatic reaction in susceptible persons.

Eye and Skin Contact - Danger! Causes severe skin and eye irritation or burns. May cause permanent visual impaiment, Not considered toxic by skin absorption but prolonged exposure may cause absorption of harmful amounts. Wear protective clothing and goggles.

Caution - Pre-existing eye, skin and respiratory disorders may be aggravated by exposure to this product, exercise caution in handling. Remove from skin using liquid soap or detergent - always avoid using solvents to remove skin contamination.

First Aid Recommendations:

Skin and Eye Contact - Immediately flush eyes with fresh water holding lids apart for 15 minutes, washing within one minute is essential to achieve maximum effectiveness. Remove from skin using soap and water. Remove contaminated shoes and clothing. Call a physician.

maximum ( Give a large quantity of milk or water. Do not give fluids to an unconscious person. Call a physician.

Inhalation - Immediately move to fresh air. If symptoms persist, call a physician.

\section{PRECAUTIONS FOR USE}

Exposure Standards:

None assigned.

Engineering Controls: $\quad$ None required during normal use.

Personal Protection:

Mechanical local exhaust at point of contaminant release if conditions warrant. Wear impervious gloves; wear chemical. resistant safety goggles if eye contact possible; wear overalls. It is extremely unlikely that harmful concentrations of volatile materials will be released during normal applications by spreaders, trowels, or similar tools in open areas Wear organic vapour cartridge respirator or fresh air hood if working for extended periods in enclosed spaces with minimal ventilation.

\section{SAFE HANDLING INFORMATION}

$\begin{array}{ll}\text { Storage and Transport: } & \text { General good practice required. Store at ambient conditions Avoid extremes. Transport as non-hazardous. } \\ \text { Spills and Disposal: } & \text { Scrape up and place in suitable container for disposal. Wash area with solvent of thinners, } \\ \text { Spills: } & \begin{array}{l}\text { Dispose in industrial disposal. Observe local regulations for chemical wa ste disposal. } \\ \text { Disposal: }\end{array} \\ \text { Fire or Explosion Hazard: } & \text { Generation of toxic products. Use water spray, foam or dry chemical to fight fire. Not susceptible to explosion. }\end{array}$

Fire or Explosion Hazard:

Generation of toxic products. Use water spray, foam or dry chemical to fight fire. Not susceptible to explosion.

\section{OTHER INFORMATION}

Reactivity:

Ecotoxicity data:

Toxicological information:

Stability:

Incompatible Materials:

Hazardous Decomposition:

Hazardous Polyme

Conditions to avoid:
No known reactivity. Avoid contact with strong acids, bases and oxidising agents. None known.

None known.

Stable.

None known.

$\mathrm{CO}$. $\mathrm{CO}$; unspecified others.

Will not occur.

Mixing large volumes of base and cure ... expect a significant exotherm within $20-25$ minutes at $25^{\circ} \mathrm{C}$.

\section{CONTACT POINT}

Technical Services Information Officer: +61732167388

DISCLAIMER: To the best of our knowledge, the information contained herein is accurate. However, National Maintenance Products Pty Ltd assumes no liability for the accuracy and completeness of the information contained herein. Final determination of suitability of this material is the sole responsibility of the user. All materials present unknown hazards and should be used with caution. Although certain hazards are described herein, we cannot guarantee that the use are the only hazards that exist. 


\section{NMP 1720 \\ HEAVY DUTY SUPERIOR COATING}

\section{PRODUCT DATA SHEET}

Date of Issue:- Feb 03

NMP 1720 is the undisputed leader in premium performance epoxy pastes, especially formulated to provide superior protection to piers, splash zones, tanks, pits, bunds, walls, floors, pipes, hulls and decks, above or below water. This unique protective coating can be likened to "case hardening" the surface it is protecting, with a tensile strength of 5 times, flexural strength of 3 times, and chip and wear resistance up to 6 times other readily available epoxies, even thick film.

It is formulated on the highest quality pure epoxy polymers and curing agents. Pigmentation is selected for hardness and durability in order to obtain the best possible properties when cured.

$\operatorname{Kevlar}^{\mathrm{TM}}$ fibres are also incorporated to enhance the coatings' unique properties. It employs no solvents, is non-hazmat and is so tolerant of wet conditions it makes an excellent anti-corrosive for underwater application to steel, concrete and similar surfaces. Constant immersion in fresh or salt water, sewerage, fuels/oils, hydrocarbons, mineral acids has no detrimental effect.

NMP 1720 can be applied under or above water by spatula or trowel, without the need for a primer. The cured film is hard and glossy with a slight texture resulting from the fibre reinforcement. The solventfree nature means it is non-corrosive, non-flammable, odourless and is perfectly safe for use in confined spaces, has no shrinkage and is environmentally safe with absolutely no effect on the surrounding plant or marine life. It is approved for use in potable under AS4020(Int).

NMP 1720 is formulated to be "non-regulated", by IATA, IMO, DOT and USDOT for uncomplicated shipment by land, sea or air.

\section{RECOMMENDED USES}

- APPROVED FOR USE IN ALL DRINKING MATERIAL TANKS

- HEAVY-DUTY ANTI-CORROSIVE PROTECTTVE COATING FOR STEEL AND CONCRETE

- USE IN SPLASH ZONES - PIERS. WONT WASH OFF BY WAVE ACTION, EVEN DURING CURING

- EXCELLENT CHEMICAL AND IMPACT RESISTANCE FOR SECONDARY CONTAINMENT - TANKS, PITS, BUND WALLSAND FLOORS, SEA WALLS ETC.

- SUPERIOR PHYSICAL STRENGTH UP TO 6 TIMES STRONGER THAN OTHER EPOXIES

- HEAVY-DUTY MAINTENANCE FOR MARINE AND OFFSHORE PRODUCTS - DECKS, TANKS.

- ANTI-CORROSIVE COATING FOR USE ON SWEATING PIPES OR UNDER INSULATION TO NEGATE CUI IN PETROCHEMICAL APPLICATIONS

- IDEAL FOR POWER GENERATION APPLICATIONS - DRAFT TUBES, PENSTOCKS, WATER BOXES, TUBE SHEETS, DAM WALLS ETC.

- REINFORCING, REPAIRING AND PROTECTING CONCRETE AND STEEL TANKS DAMAGED BY EXPOSURE TO THE CORROSIVE CHEMICAL AND MUNICIPAL WASTE SYSTEMS

- REPAIR AND FAIRING - PATCHING, LEAK SEALING, ROUGH STEEL, CONCRETE REBUILD

- ADHESIVE MORTAR - ADD SAND TO CREATE MORTAR.

\section{TECHNICAL INFORMATION}

VEHICLE TYPE.

PIGMENTATION. 2-pack epoxy/polyamines.

Colour/inert/fibrous reinforcing. 


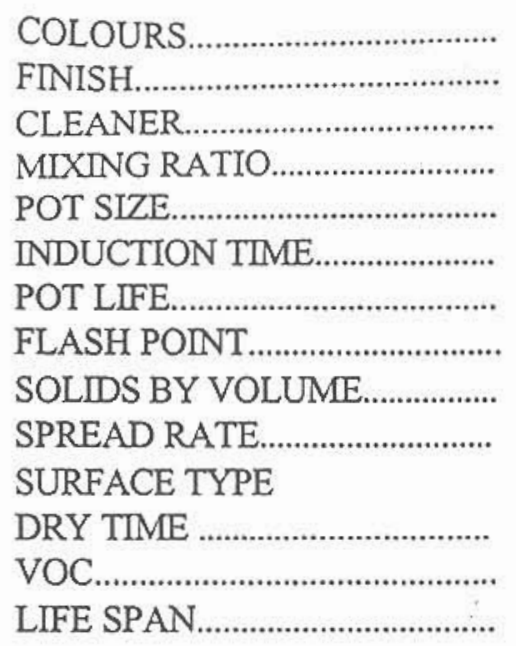

Grey, white, other on request.

Glossy with slight texture from the fibre.

MEK or lacquer thinner.

1:1 v:v

$8 \mathrm{~L}$.

Not required.

Approx 40mins@2 $25^{\circ} \mathrm{C}$.

Over $100^{\circ} \mathrm{C}$

$100 \%$

11sq.m perkit@800 microns.

Concrete, brick, wood, fibreglass, metal, polystyrene 6 hours @ $25^{\circ} \mathrm{C}$ touch, 15 hours hard. Full: 7 days. Zero.

Very long life, even in adverse conditions.

\section{APPLICATION NOTES}

\section{Surface Preparation:}

New Concrete - should be left for 28 days (minimum) before coating. Weak surface laitance must be removed by water blasting, acid etching or abrasive sweeping.

Existing Concrete ... coated or bare - sound surfaces should be well cleaned by degreasing, water blasting or grit blasting. Small areas cleaned by grinder, but not practical for large areas.

Repair holes or scabbled areas by trowelling in a mix of NMP 1720 and clean fine grain sand at about a 1:1 mix of sand to epoxy. Solvent-free - apply over existing well-adhered, clean coatings.

Metal - High-pressure water/abrasive blasting or grinding. Can be applied over tight rust.

Underwater- Remove marine growth/rust by high-pressure water/abrasive blasting or grinding.

\section{Application:}

Mix desired amount well at a 1:1 ratio. Ensure the two components are well mixed to a uniform colour. You do not need to mix the entire product at once. Shelf life of unused product is almost indefinite. Mix well to ensure complete mixing. NMP products do not require an induction time so you can use immediately. Apply by spatula or trowel at about 800 microns.

Underwater - take the mixed product underwater in a bucket. Apply within 30-40mins of mixing by spatula or trowel or hand mitt on difficult shapes such as risers. It is resistant to effects of wave movement during curing. It is much easier to apply than traditional "splash zone" compositions, and is substantially less messy than lower viscosity underwater "paints".

CHEMICAL RESISTANCE - Resistant to all fuels, oils, skydrol, hydraulic fluid, alkalies, 50\% caustic soda, $70 \%$ Sulphuric acid.

TRANSPORTATION - Unregulated.

\section{THIS INFORMATION SHOULD BE READ IN CONJUNCTION WITH MATERIAL SAFETY DATA SHEETS.}

NATIONAL MAINTENANCE PRODUCTS P ty Ltd
Unit 19, 10 Miltiadis St, Acacia Ridge, Qld 4110, Australia
Ph + 61 73216 7388, Fax +61 73216 7488
For Coating Solutions ..... askNMP.com

WARRANTY DISCLAIMER: The technical data given herein has been complied for your help and guidance and is based upon our experience and knowledge. However as we have no control over the use to which this information is put, no warranty express or implied is intended or given. We assume no responsibility whatsoever for coverage, performance or damages, including injuries resulting fromuse of this information or of products recommended herein. 


\section{Product Information}

2. Composition/Information on Ingredients

Chemical Name

CAS Number Percent 50-90

Exposure Limits
ACGIH OSHA
TLV-TWA PEL
N/E

Specific ingredients of this product are withheld and considered a trade secret.

\section{Health Hazards}

\section{Eye Contact: May cause irritation and swelling. SkIn C ontact: May cause irritation and sensitization. Symptoms can be immediate or delayed several hours. Inhalation: May cause irritation and temporary or permanent sensitization. Ingestion: May caus $\theta$ irritation. Other:} Preexisting skin sensitization may be aggravated by exposure to this product.

\section{First Aid Measures}

Eyes: Flush eyes thoroughly with water for at least 15 minutes while holding eyelids open. Seek medical attention. Skin: Remove contaminated clothing. Wipe excess from $\mathrm{skin}$ and wash the affected area thoroughly with soap and water. W ash contaminated clothing thoroughly before reus $\theta$. Inhalation: Remove to fresh air, and provide oxygen or artificial respiration If needed. Obtain medical attention; symptoms can be delayed up to several hours. Ingestion: DO NOT induce vomiting. Give 1.2 cups of water or milk unless the person is drowsy, convulsing, or unconsclous. Get medical attention.

\section{Fire Flghting Measures}

\section{Flammable Propertles: Flash Point: $>300^{\circ} \mathrm{F}$ (closed cup) Explosive LImits: Not available Auto-Ignitlon Temperature: Not} available Hazardous Decomposition Products: Carbon monoxide, carbon dioxide, aldehydes, and other organic substances

Extlnguishing Medla and Fire Fighting Instructions: When sufficiently large quantities are present, firefighters should be equipped with full bunker gear, including a positive pres sure, NIOSH approved, self-contained breathing apparatus. Extreme heat or water contamination may cause closed containers to explode. Extinguishing Medla: Use carbon dioxide, dry chemical, or appropriate foam

\section{Accldental Release Measures}

Ventilate the spill area and evacuate if necess ary. Remove all ignition sources. Dike and contain large spills. Clean-up personnel should use adequate protective equipment.

\section{Handling and Storage}

Store in a cool: dry place, in closed containers at room temperature. Avoid contact with incompatible materials. Wear protective eyewear, chemicalresistant gloves, and other protective clothing as appropriate.

\section{Exposure Control and Personal Protection}

Engineering/Ventllation Controls: Effective engineering controls should be used whenever possible to eliminate and/or reduce worker exposure to all respiratory hazards. General ventilation, local ventilation, or isolation may prove adequate to keep airborne concentrations below exposure limits.

Respiratory Protection: If exposure limits are exceeded and local ventilation is unavailable, a supplled-air respirator or a self-contained breathing apparatus is required. SkIn Protectlon: Impervious gloves and protective clothing should be worn as necess ary. Eye Protectlon: Chemical Splas $h$ goggles or safety glass es with side shields should be worn as approp riate.

\section{Stabillty and Reactlvity}

Chemical Stabllity: Stable under normal conditions and use. agents. Hazardous Polymerization: WIII not occur.

Conditions and Materials to Avoid: Reacts with amines and strong oxidizing

10. Physical and Chemical Propertles

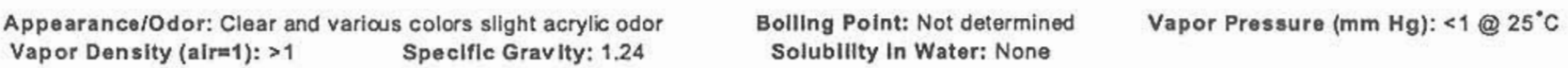

\section{Toxicological Information}

This section provides toxicological information with regard to the pure form of the component indicated. It is suggested that persons trained in its evaluation interpret this information. Epoxy Resins: Acute Oral LD50 (Rat): $11.4 \mathrm{~g} / \mathrm{kg} \quad$ Acute Dermal LD50 (rabbit): >20 g/kg

\section{Disposal Considerations}

Keep out of surface waters, sewers, and waterways en tering or leading to surface waters. Notify authorities if any exposure to the environm ent occurs or is Ikely to occur. Utilize an appropriate disposal facility, in compliance with applicable federal, state, and local environmental control regulations.

\section{Transportation Information and Regulatory Information}

DOT/IATA Proper Shipping Name: Not Regulated. TSCA: The chemical components of this product are included in the TSCA Chemical Substance Inventory, as required. SARA TITLE III: Section 313 - Toxic Chemicals: None Section 311/312 - Hazard Categories: Fire Hazard: No Reactivity Hazard: No Sudden Release of Pressure Hazard: No Immediate (Acute) Health Hazard: Yes Delayed (Chronic) Health Hazard: No. NFPA Hazards: Health - 2, Flammability - 1, Reactivity - 0 HMIS Hazards: Health - 2, Flammability - 1, Reactivity - 0 
1. Product Information

Product Name:Corro Coat FC 2100 Hardener Part B

Chemical Family: Cycloaliphatic Amine Product Code: ER140-B

2. Composition/Information on Ingredients

Chemical Name Cycloaliphatic Amines
The specific ingredients of this product are considered a trade Secret. Exposure Limits
ACGIH

$\begin{array}{ll}\text { TLV-TWA } & \text { PEL } \\ \text { N/E } & \text { NIE }\end{array}$
N/E (Not established)

\section{Health Hazards}

Eye Contact: Corrosive liquid. Cause severe irritation and may cause burn. Skin Contact: Corrosive liquid. Cause irritation and sensitization. Symptoms can be immediate or delayed several hours. Inhalation: Can cause res piratory tract irritation. Ingestlon: Can cause nausea. headache, and gastrointestinal irritation. Other: Preexisting skin sensitization may be aggravated by exposure to this product.

\section{First Ald Measures}

Eyes: Flush eyes thoroughly with water for at least 15 minutes while holding eyelids open. Seek medical attention. Skin: Remove contaminated clothing. Wipe excess from $\mathbf{s}$ kin and wash the affected area thoroughly with soap and water. W ash contaminated clothing thoroughly before reus $e$. Inhalation: Remove to fresh air, and provide oxygen or artificial respiration if needed. Obtain medical attention; symptoms can be delayed up to several hours. Ingestion: DO NOT induce vomiting. Give 1.2 cups of water or milk unless the person is drowsy, convuls ing, or unconscious. Get medical attention.

\section{Flre Flghting Measures} Decomposition Products: Oxides of nitrogen, carbon monoxide, carbon dioxide and other organic materials Extinguishing medla: Use carbon dioxide, dry chemical, or appropriate foam.

\section{Accidental Release Measures}

Ventilate the spill area and evacuate if necessary. Remove all ignition sources. Dike and contain large spills. Flush area with water spray. Clean-up pers onnel should use adequate protective equipment.

\section{Handling and Storage}

Store in a cool; dry place, in clos ed containers at room temperature. Avoid contact with incompatible materials. Wear protective eyewear, chemicalresis tant gloves, and other protective clothing as appropriate.

\section{Exposure Control and Personal Protection}

EngIneering/Ventllation Controls: Effective engineering controls should be used whenever possible to eliminate and/or reduce worker exposure to all respiratory hazards. General ventilation, local ventilation, or isolation may prove adequate to keep airborne concentrations below exposure limits. Respiratory Protection: If exposure limits are exceeded and local ventilation is unavailable, a supplied-air respirator or a self-contained breathing apparatus is required. Skin Protection: Impervious gloves and protective clothing should be worn as necessary. Eye Protection: Chemical splash goggles or safety glasses with side shields should be worn as approp riate.

\section{Stability and Reactivity}

Chemical Stability: Stable under normal conditions and use. Hazardous Polymerization: Will not occur

10. Physical and Chemlcal Properties

Appearance/Odor: Grey Gel, Slight amine odor_Bolling Polnt: Not determined Vapor Pressure (mm $\mathrm{Hg}):<1 @ 25^{\circ} \mathrm{C} \quad$ Vapor Density (air=1): $>1 \quad$ Specific Gravity: $1.18 \quad$ Solubility in Water: Slightly soluble

11. Toxicological Information

Acute Toxicity Data: Not available Chronic Toxicity Data: Not available

12. Disposal Considerations

Keep out of surface waters, sewers, and waterways entering or leading to surface waters. Notify authorities if any exposure to the environment occurs or is likely to occur. Utilize an appropriate disposal facility, in compliance with applicable federal, state, and local environmental control regulations.

\section{Transportation and Regulatory Information}

DOT/IATA Proper Shipping Name: Non-Corrosive, Not Regulated Hazardous Label: NON-CORROSIVE

\section{Regulatory Information}

TSDCA: The chemical components of this product are included in the TSCA Chemical Subs tance Inventory, as required. SARA TITLE III: Section 313- Toxic Chemicals: None Section 311/312- Hazard Categories: Fire Hazard - No, Reactivity Hazard - No. Sudden Releae of Pressure Hazard - No, Immediate (Acute) Health Hazard - Yes, Delayed (Chronic) Health Hazard - No. OSHA Hazard Comm unication Standard Hazard. Classes: Corrosive NFPA Hazards: Health - 2, Flammability - 0 , Reactivity -0 HMIS hazards: Health -2, Flammability -0, Reactivity -0

date of prepn: $12 / 7 / 98$

Distributed by: Progressive Epoxy Polymers - 48 Wildwood Drive - Pittsfield, NH 03263 - Tel: 603-435-7199 - Fax 603-435-7182 


\title{
Corro-Coat FC 2100 Epoxy TECHNICAL DATA
}

\section{SOLVENT-FREE EPOXY COATING SYSTEM}

Mix and Match Corro-Coat FC 2100 Bases and Curing Agents

\section{Protective Coating | Solvent-Free and Non-Hazardous}

Marine Barrier Coat

Corrosion Protection

Apply/Cures Underwater

\author{
Applies and Cures in Water (fresh, salt, brackish) \\ Excellent Chemical and Abrasion Resistance \\ Easy 2:1 Mixing Ratio \\ Feldspar Ceramic and Kevlar ${ }^{\mathrm{TM}}$ Reinforced
}

\begin{tabular}{|c|c|}
\hline $\begin{array}{r}\text { STANDARD } \\
\text { PRODUCT } \\
\text { DESCRIPTION }\end{array}$ & $\begin{array}{l}\text { Corro Coat FC } 2100 \text { is a } 100 \% \text { solids, next generation, epoxy coating featuring } 40 \% \text { tensile elongation, } \\
\text { excellent chemical and abrasion resistance, one coat, no sag, high build glaze finish that will withstand } \\
\text { severe abuse. Bonds to concrete (wet and dry), fiberglass, steel and wood surfaces. Novolac version } \\
\text { available. } \\
\text { Novalac and thicker (nonhazmat) versions available. High temperature (hazmat) version is also available. }\end{array}$ \\
\hline USES & $\begin{array}{l}\text { Most corrosive environments } \\
\text { Marine, chemical, pulp and paper } \\
\text { Spillways, piping, pilings, columns } \\
\text { Excellent as a finish top coat }\end{array}$ \\
\hline FEATURES & $\begin{array}{l}\text { Solvent-Free with long pot life } \\
\text { Non-Sag at thicknesses up to } 30-35 \text { mils } \\
\text { High Gloss } \\
\text { Convenient } 2 \text { to } 1 \text { ratio by volume (1:0.37 by weight) } \\
\text { Non-blushing and non-water spotting } \\
\text { Non-corrosive and Non-hazmat } \\
\text { Kevlar }{ }^{\mathrm{TM}} \text { microfibers reinforce against hairline cracking and chipping } \\
\text { Feldspar (ceramic plates/needles) provides extreme abrasive resistance } \\
\text { Apply by brush, roller (at the upper limits of roller application) or spreader }\end{array}$ \\
\hline VISCOSITY & $\begin{array}{ll}\text { Viscosity at } 72^{\circ} \mathrm{F}: \\
\text { Part A: } & 25,000 \mathrm{cps} \\
\text { Part B: } & 450 \mathrm{cps} \\
\text { Mixed: } & 1,200 \mathrm{cps}\end{array}$ \\
\hline $\begin{array}{r}\text { PHYSICAL } \\
\text { PROPERTIES }\end{array}$ & 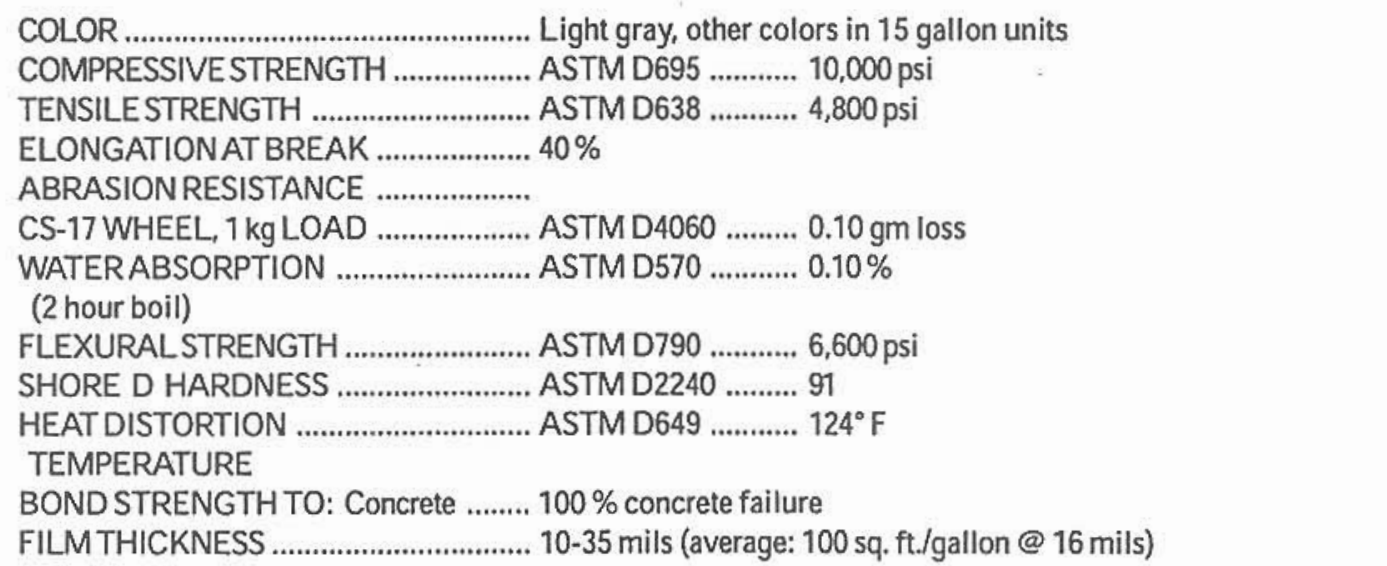 \\
\hline & MULTI-VENDOREPOXY SOLUTIONS \\
\hline
\end{tabular}




\section{Corro Coat FC 2100 Epoxy TECHNICAL DATA}

\begin{tabular}{|c|c|c|c|c|c|}
\hline \multirow{2}{*}{$\begin{array}{l}\text { CURE SCHEDULE } \\
\\
\text { CHEMICAL } \\
\text { RESISTANCE }\end{array}$} & \multicolumn{5}{|c|}{ 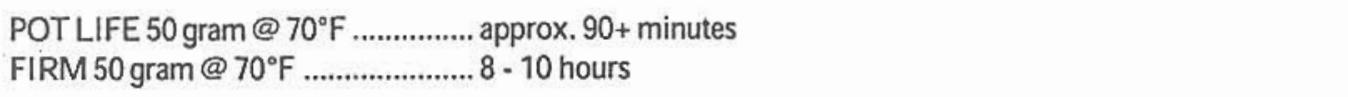 } \\
\hline & $\begin{array}{ll}\text { REAGENTACIDS } \\
\text { Acetic } & 1-5 \% \\
\text { Chromic } & 1-5 \% \\
\text { Citric } & \text { All } \\
\text { Hydrochloric } & \text { All } \\
\text { Lactic } & 1-10 \% \\
\text { Nitric } & 1-5 \% \\
\text { Oxalic } & 1-20 \% \\
\text { Phosphoric } & \text { All } \\
\text { Sulfuric } & 1-75 \% \\
& 2=\text { intermi }\end{array}$ & $\begin{array}{c}: \\
\text { RATING } \\
2 \\
2 \\
2 \\
2 \\
2 \\
2 \\
2 \\
2 \\
2 \\
\text { nt immersi }\end{array}$ & $\begin{array}{l}\text { REAGENT ALKALIES } \\
\text { Ammonium Hydroxide } \\
\text { Calcium Chloride } \\
\text { Calcium Hypochlorite } \\
\text { Caustic Soda } \\
\text { Caustic Potash } \\
\text { Sodium Hydroxide } \\
\text { Sodium Sulfide } \\
\\
\text { hours with } 8 \text { hours dry ti }\end{array}$ & $\begin{array}{l}1-26 \% \\
\text { All } \\
1-15 \% \\
\text { All } \\
1-30 \%\end{array}$ & $\begin{array}{c}\text { RATING } \\
2 \\
2 \\
2 \\
2 \\
2 \\
2 \\
2 \\
\end{array}$ \\
\hline $\begin{array}{r}\text { SURFACE } \\
\text { PREPARATION }\end{array}$ & \multicolumn{5}{|c|}{ Surface to be topcoated must be clean and free of oils, grease and loose contamination. } \\
\hline APPLICATION & \multicolumn{5}{|c|}{$\begin{array}{l}\text { Mix Corro Coat FC } 2100 \text { epoxy base with the Corro Coat FC } 2100 \text { curing agent. Use a mechanical mixer if } \\
\text { possible to ensure thorough mixing. The mixing ratio is } 2 / 1 \text { (base/curing agent) by volume or } 1 / 0.37 \text { by } \\
\text { weight. Corro Coat FC } 2100 \text { does not require a 'sweat-in' or induction time and the mixed components } \\
\text { should be used immediately. } \\
\text { Potlife is approximately } 55-75 \text { minutes at } 75^{\circ} F \text {, so mix only the amount of epoxy that can be easily applied } \\
\text { within that time limit. Apply using a brush, roller (product is at the upper limits of rollability), or squeegee. } \\
\text { This product can be thinned for improved rollability or thickened to paste like viscosity. }\end{array}$} \\
\hline TEMPERATURE & \multicolumn{5}{|c|}{$\begin{array}{l}\text { Corro Coat-FC2100 may be applied in temperatures as low as } 45^{\circ}\left(7^{\circ} \mathrm{C}\right) \text {-curing will be slow, however the } \\
\text { viscosity of the material will still be workable. Temperature will exert a considerable influence on the rate } \\
\text { of curing. In broad terms expect each } 10^{\circ} \mathrm{C},\left(18^{\circ} \mathrm{F}\right) \text {, rise or fall in temperature to half or double dry times and } \\
\text { pot lives. }\end{array}$} \\
\hline TRANSPORT & \multicolumn{5}{|c|}{$\begin{array}{l}\text { Corro-Coat FC2100 and Novalac version is nonregulated by USDOT, IATA \& IMO. } \\
\text { Corro-Coat FC2100 HT (High Temperature) is hazardous for shipping: } \\
\text { UN2735, Packing Group III, Class } 8 \text {, Corrosive. }\end{array}$} \\
\hline
\end{tabular}

SAFETY: This is a hazardous material if misused. Read and understand the Material Safety Data Sheet (MSDS) before use.

WARRANTY DISCLAIMER: The technical data given herein has been compiled for your help and guidance and is based upon our experience and knowledge. However, as we have no control over the use to which this information is put, no warranty, express or implied is intended or given except that these goods shall be of merchantable quality and buyer assumes all risk and liability for results obtained by the use of the materials covered in this data sheet, whether used singly or in combination with other products. We assume no responsibility whatsoever for coverage, performance or damages, including injuries resulting from use of this information or of products recommended herein. The sale and use of this product is governed by Progressive Products, Inc.'s Warranty Disclaimer and Return Policy.

$\begin{array}{lll}\text { Manufactured by: } & \text { Distributed by: } & \text { Tel: 603-435-7199 } \\ \text { ERC in RI } & \text { Progressive Epoxy Polymers, Inc. } & \text { Fax: 603-435-7182 } \\ & \text { 48Wildwood Dr. } & \text { www.epoxyproducts.com } \\ & \text { Pittsfield, NH 03263-3406 } & \text { info@epoxyproducts.com }\end{array}$



STANDARD

\section{IDENTIFICATION OF THE PREPARATION, SUBSTANCE AND COMPANY}

\section{Product name: Alocit 28.15 Standard Grade}

Alocit Systems Limited, Milltown Street, Radcliffe, Manchester, United Kingdom, M26 IWE. Tel: +44 (0)1362694916 Fax: +44 (0)1362696360 Email: hq@alocit.co.uk

\section{COMPOSITION/INFORMATION ONINGREDIENTS}

Chemical characterization : preparation

Bisphenol A epoxy resin containing reactive diluent

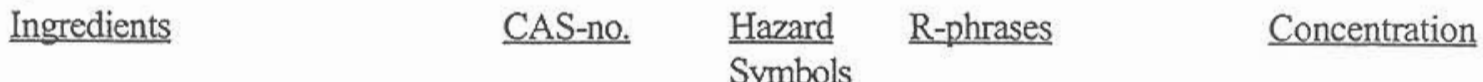

Reaction product: Bisphenol A-(epichlorhydrin); epoxy resin (number average molecular weight $<700$ )

$$
\text { 25068-38-6 Xi, N R36/38, R43, R51/53, R68 } \quad 30-35 \%
$$

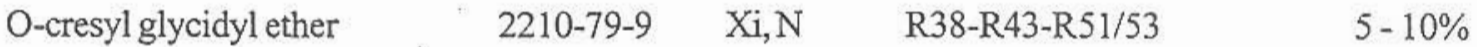

(See full text of phrases under chapter 15)

\section{HAZARDSIDENTIFICATION}

Most important hazards: Irritating to eyes and skin. May cause sensitization by skin contact.

\section{FIRST AID MEASURES}

General In all cases of doubt, or when symptoms persist, seek medical attention. Information: Never give anything by mouth to an unconscious person.

Inhalation: Consult a physician if necessary.

Skin Contact: Wash off with soap and plenty of water. Do not use organic solvents.

Eye contact: Rinse thoroughly with plenty of water for at least 15 minutes and consult a physician.

Ingestion: Drink plenty of water. Do not induce vomiting without medical advice. Consult a physician. 


\section{FIRE-FIGHTINGMEASURES}

Suitable extinguishing media: Extinguish with carbon dioxide, dry chemical, foam or waterspray

Extinguishing media which must not be used for safety reasons:

Do not use water jet

Specific hazards:

Do not allow material to contaminate ground water system. Dispose of rinse water in accordance with local and national regulations.

Special protective

equipmentfor firefighters: $\quad$ Self-contained breathing apparatus

\section{ACCIDENTAL RELEASE MEASURES}

Environmental precautions: $\quad$ Do not contaminate surface water. If this does occur, contact authorities immediately.

Methods for cleaning up: $\quad$ Soak up with inert absorbent material (e.g. sand, silica gel, acid binder, universal binder, sawdust). Dispose of as special waste in compliance with local and national regulations.

\section{HANDLING AND STORAGE}

Handling:

Avoid contact with skin, eyes and clothing. Keep away from food and drink. Wash hands and face before breaks and immediately after handling the product.

Storage:

Keep container tightly closed in a dry and well-ventilated place. If stored in plastic containers, stack no more than 2 high.

\section{EXPOSURE CONTROLS/PERSONAL PROTECTION}

Personal protection equipment:

- Respiratory protection:

Provide adequate ventilation

- Hand protection:

PVC or other plastic material gloves

- Eye protection:

- Skin and body protection:

Safety glasses with side-shields

Protective suit

\section{PHYSICAL AND CHEMICAL PROPERTIES}

Odour: Slight

\section{STABILITYAND REACTIVITY}

Stability:

This product is chemically stable and generally compatible with other substances

Materials to avoid: Avoid contact with strong acids and bases and strong oxidizing agents. 


\section{TOXICOLOGICAL INFORMATION}

Acute toxicity: $\quad \mathrm{LD} 50 / \mathrm{oral} / \mathrm{rat}=5000 \mathrm{mg} / \mathrm{kg}$

Sensitization: $\quad$ Prolonged/repeated contact may cause skin irritation and cause defatting thus rendering the skin more susceptible to damage by other substances.

\section{ECOLOGICAL INFORMATION}

Degradability: Avoid subsoil penetration. Prevent product from entering drains. Do not contaminate surface water.

Waste code number: in accordance with Federal Law Gazette [BGBI.] II No. 227/1997 (determination regulation) 55903 residual epoxy, not hardened

\section{DISPOSAL CONSIDERATIONS}

Product: $\quad$ Must be incinerated, when in compliance with local regulations.

Container: $\quad$ Empty containers can be landfilled after thorough cleaning, when in compliance with the Environmental Protection (Duty of Care) Regulations 1991.

\section{TRANSPORT INFORMATION}

Road Transport

$\begin{array}{lll}\text { ADR/RDD } & \text { Information applies to: } & \text { product } \\ \text { GGVS } & \text { Class: } & 9 \\ \text { GGVE } & \text { Hazard no: } & 90 \\ & \text { UN no: } & 3082 \\ & \text { TREM-CARD: } & 90 \text { GM6-III } \\ & \text { Proper shipping name: } & \text { Environmentally hazardous substance, liquid, N.O.S. } \\ & \text { Additional information } & \text { Bisphenol A-epoxy Resin and 1,2 -cresyl-glycidylether. }\end{array}$

\section{Maritime transport}

UN3082

Environmentally hazardous substance, liquid, N.O.S. (Bisphenol A-epoxy Resin mixture)

Class 9

Packing Group III

EMS F-A, S-F.

Marine Pollutant: No

\section{Air transport}

UN3082

Environmentally hazardous substance, liquid, N.O.S. (Bisphenol A-epoxy Resin mixture) Class 9

Packing Group III 


\section{REGULATORYINFORMATION}

Classification according to $\mathrm{EC}$ directives

Contains: BISPHENOL A-EPICHLORHYDRIN) \{REACTION PRODUCT

O-CRESYL GLYCIDYL ETHER

Symbol(s)
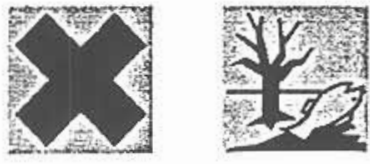

\section{$\mathrm{Xi}$-Irritant $\mathrm{N}$ - Hazardous to the Environment}

Classification:

Labelling required

Hazard labels:

Xi - Irritant N-Hazardous to the Environment

R36/38 Irritating to eyes and skin.

R43 May cause sensitization by skin contact

$\mathrm{R} 51 / 53$ Toxic to aquatic organisms, may cause long-term adverse effects in the aquatic environment

R68 Possible risk of irreversible effects.

P5 Contains epoxy constituents. See information supplied by the manufacturer

S24/25 Avoid contact with skin and eyes.

S26 In case of contact with eyes, rinse immediately with plenty of water and seek medical advice.

S36/37 Wear suitable protective clothing and gloves.

S51 Use only in well ventilated areas.

S57 Use appropriate containment to avoid environmental contamination.

S60 This material and/or its container must be disposed of as hazardous waste.

S61 Avoid release to the environment. Refer to special instructions/Safety data sheets

Contains Epoxy Resin

UNNO 3082 Environmentally Hazardous Substance, Liquid, N.O.S.

(Epoxy Resin Mixture (Number average $\mathrm{MW}<=700$ ))

\section{N.B. THIS MATERIAL IS NOT HAZARDOUS WHEN MIXED \& CURED}

\section{OTHER INFORMATION}

The provision of Safety Data Sheets comes under Regulation 6 of CHIP (CHIP is the recognised abbreviation for the Chemicals (Hazard Information and Packaging (Regulations). This is an addition to the Health and safety at Work Act 1974. Users of products supplied by Alocit Systems Ltd should take appropriate measures to ensure working practices are in accordance with the Control of Substances Hazardous to Health Regulations (COSHH).

All information is based on results gained from experience and tests and is believed to be accurate but is given without acceptance of liability for loss or damage attributable to reliance thereon as conditions of use lie outside our control. Users should always carry out sufficient tests to establish the suitability of any products for their intended applications. No statements shall be incorporated in any contract unless expressly agreed in writing nor construed as recommending the use of any product in conflict of any patent. All goods are supplied subject to Alocit Systems Ltd General Conditions of Sale. 


\title{
ALOCIT 28.15 EPOXY COATING FINISH
}

\section{STANDARD CRADE (All temps above water - undenwater below $17^{\circ} \mathrm{C} / 63^{\circ} \mathrm{F}$ )}

\author{
- Outstanding adhesion, on oily surfaces \& underwater \\ - Environmentally friendly - solvent free and no heavy metals \\ - Proven protection against corrosion, including A.L.W.C. \\ - An inexpensive solution to problem coating needs \\ - Abrasion resistant
}

\section{USAGE}

As a hygienic, easily cleaned finish for concrete, steel, ironwork providing a hard wearing attractive surface. For preservation of steel structures, industrial floors, cellars, bund areas, laundries, sheet pilings, locks and channels, docks, harbours, oil rigs, oil tanks, ships hulls and bilges, bridges, conduits, caverns, industrial plants for wet or oily surfaces, railway and subway tunnels, underpasses, swimming pools etc. Can also be used as self-priming coat on minimal surface prep.

- a protective coating resistant to many alkalis, some acids, oils, sewage, mechanical wear and chemical attack

- a coating that can be applied on dry, wet, or even on underwater surfaces

- a high build (200 - 400 microns $/ 8-16$ mil) per coat

\section{TECHNICAL DETAILS}

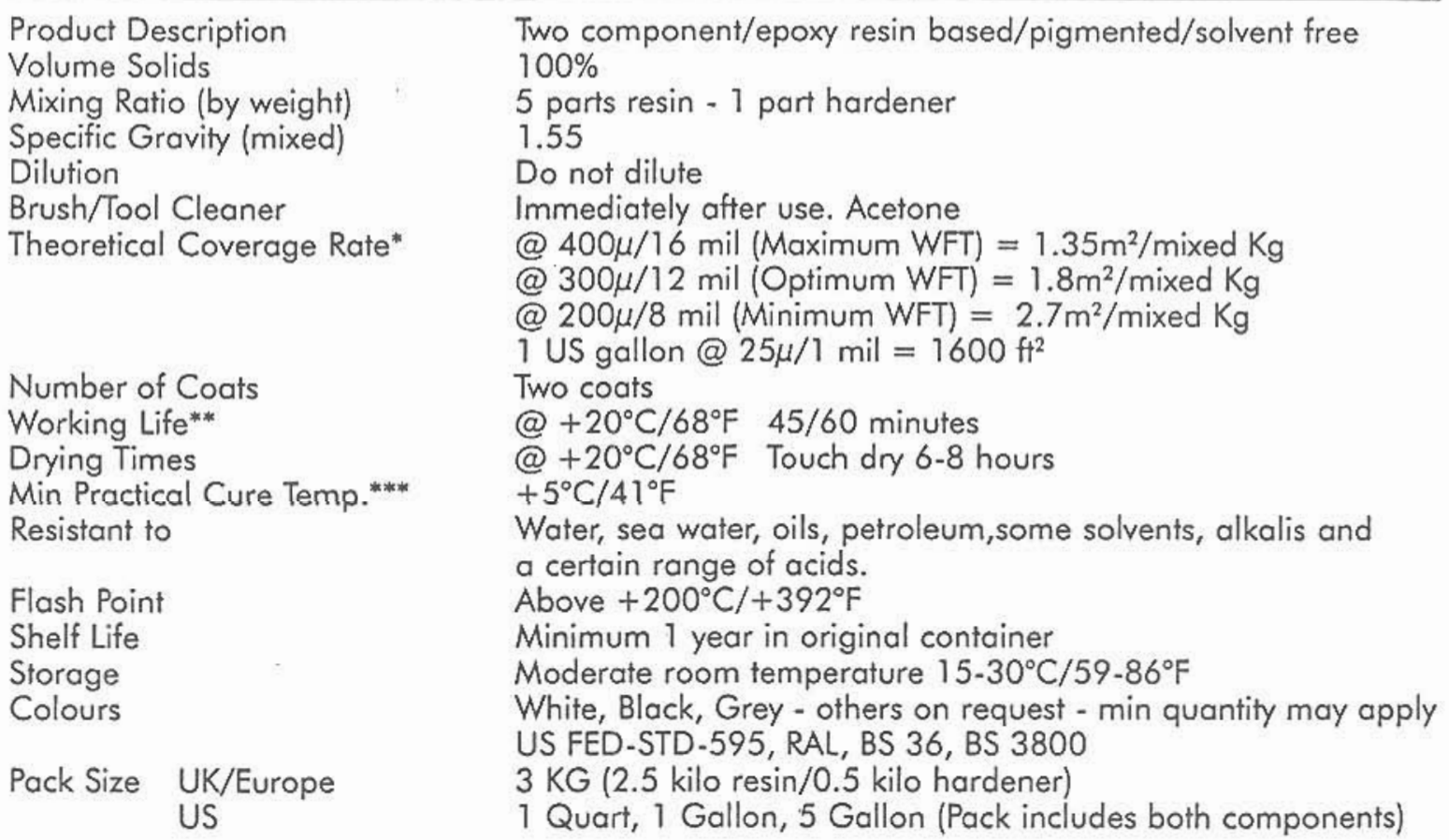

Notes * Underwater application can result in reduced coverage rates.

*** Working life is deperident on unit size, ambient/product temperature, mixing method and time, application speed relative to reduction in vol. of mixed product.

*** Curing will take place at lower temperatures but over an extended period. 
A) NEW STEEL

All millscale to be removed by abrasive blasting, check for rogue peaks and laminations, take remedial action. Remove dust and other contaminations. A blast profile of between 50 and $100 \mu(2.4 \mathrm{mil})$ is the aim, based on Swedish Pictorial Standards / ISO-8501-1/SSPC/NACE. We recommend SA2 (SP6, NACE 3) as a minimum, and SA 2.5 (SP10, NACE 2) as the optimum. A secondary choice for surface preparation is mechanical abrading to remove surface contamination before coating application.

\section{B) WEATHERED/EXPOSED/CORRODED STEEL}

Our basic aim is to remove surface contamination such as corrosion deposits, marine growths, chemical compounds etc., to revealing a clean steel substrate with a surface profile of a minimum 25 microns/1 mil (50 microns/2 mil underwater), various options are:-

1) Abrasive blasting, dry, in areas of low chemical contamination followed by optional high pressure water blast (15-20,000psi).

2) UHP hydroblasting (30/40,000psi) to remove all previous coatings etc and reveal original profile. Especially suitable for wet environments such as ships tanks, piers, jetties etc. Clean to an agreed standard and check soluble salts level.

3) UHP and High Pressure water blasting may sometimes be employed with added abrasive.

4) Mechanical cleaning (power) i.e. needle gunning, rotary wire brushing etc to remove all contamination/dust etc.

\section{Notes:}

1) Stains of rust, paint or mill scale remaining on the surface do not present a problem providing minimum surface profile criteria are met.

2) Alocit product range can be applied to both dry, wet and underwater surfaces, however whilst clean steel in saltwater is acceptable, steel heavily contaminated with salt and/or other chemicals above water is not acceptable. This type of steel requires decontamination, with chemical levels measured before and after.

\section{C) CONCRETE}

The substrate should be free from high levels of laitence, dust, oil contamination, large surface voids etc. Sometimes brush blasting (dry) or UHP hydroblasting are appropriate methods, especially for large areas, large cracks/surface voids should be repaired prior to coating.

\section{D) NON-FERROUS METALS}

Light surface abrading, remove dust etc. If there are any queries re surface preparation prior to applying the Alocit coating system, please contact our technical dept. for further advice.

\section{E) NON METALLIC}

If possible, surface abrading, then remove dust etc if in doubt, apply a test patch before coating. 


$\begin{array}{ll}\text { Atmospheric: } & \begin{array}{l}\text { Brush \& Roller } \\ \text { Airless spray - minimum 68:1, Tip size 21-23 thou. }\end{array} \\ & \text { Alocit brushes - use vigorous circular motion. } \\ \text { Sweating, damp } & \text { Alocit K1 underwater pump with round brush - use vigorous circular motion. } \\ \text { or underwater: } & \end{array}$

Notes:

1) Please contact our technical dept for specific details or if any doubt.

2) All equipment should be cleaned immediately after use with acetone.

3) Airless spray is not suitable for wet/damp surfaces

\section{PRODUCT APPLICATION - COATING SYSTEMS}

\section{STEEL Atmospheric and Underwater:}

Minimum - 1 coat Alocit 28.14 primer plus 1 coat Alocit 28.15.

Optimum - 1 coat Alocit 28.14 primer plus 2 coats Alocit 28.15

OR 2 coats Alocit 28.15

\section{CONCRETE}

Atmospheric: 1 coat Alocit 28.95 sealer plus 1 coat Alocit 28.15

OR 1 coat Alocit 28.95 sealer plus 2 coats Alocit 28.15

OR 2 coats Alocit 28.15

Underwater: 2 coats Alocit 28.15

Notes:

1) Use Alocit 28.15 of different colours in a multi-coat system.

2) Alocit 28.14 zinc primer is specially designed for application onto clean, rust-free profiled steel.

3) Alocit 28.95 primer sealer is for application onto wet, oily, concrete etc - not underwater.

\section{PRECAUTIONS}

Always use up the entire can. Product cannot be reused after working life expires.

Always empty the entire amount of hardener into the epoxy, because the proper mixing ratio must be maintained. Containers are pre-measured with most epoxy containers oversized to allow adding and mixing of the hardener.

Never dilute Alocit 28.15 with thinners.

Mix thoroughly by hand or with a mechanical mixer - avoid aeration of mixed product. Make sure that material is mixed well around the walls and the bottom of the can before mixing with hardener.

\section{IMPORTANT}

Alocit 28.15 must be brushed onto the surface with circular motions, using pressure on moist, wet, submerged, or oily surfaces. 2 nd coat must be applied as soon as the first coat is touch dry - not later.

\section{ALL INFORMATION IS GIVEN IN GOOD FAITH BUT WITHOUT WARRANTY}




\section{ocr-15-2003(TED) 12:09 somay pain? factory}

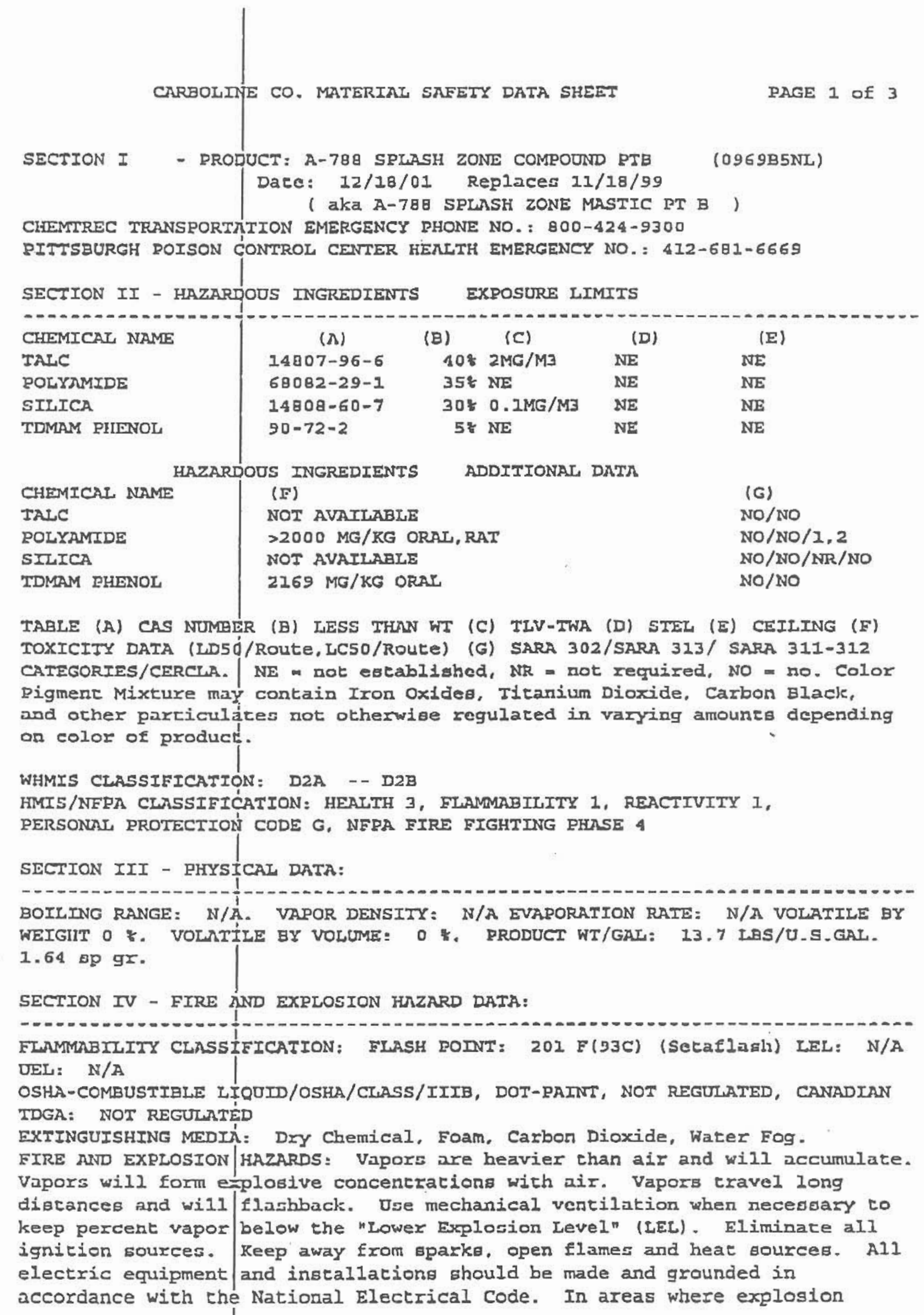




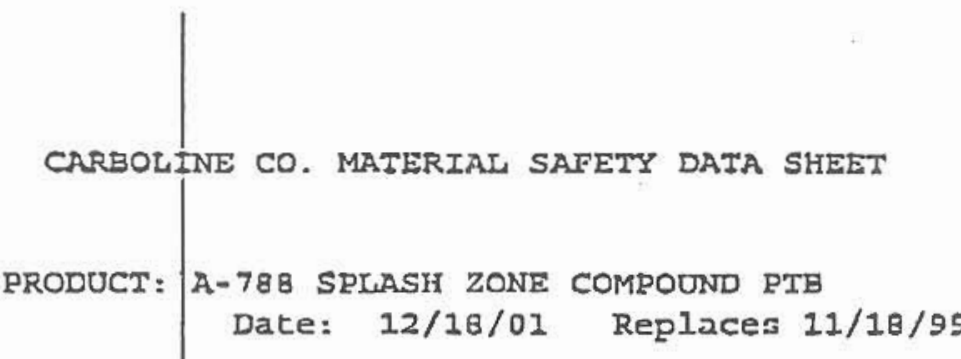

hazarda exist, workers should be required to use nonferroug coola and co wear conductive and non-sparking khoes.

SPECIAL FIRE FIGHTING PROCEDURES: Evacuate hazard arez of unprotected

personnel. Use a NIOSII approved self-contained breathing unte and complete body protection. Cool surrounding conthiners with water 1 n case of fire exposure.

SECIION V - HEALTH HAZARD DATA:

INIALATION: MaY cause nose and throat irxitation. May caugc lung irritation. May cause allergic respiratory reaction, cflecta may be permarene.

CONIRCT: May cause eye burms. May be hasmful $1 f$ absorbed through the skin. May cause skin burns. May cause allergic akin reaction.

NOTICE: Contring SIIICA which can cause cancer. Rigk of cancer depends on duration and level of exposure.

MEDICAL CONDITIONS PRONE TO AGGRAVATION BY EXPOSURE: If geNsicized to amines, epoxies or other chemicala do not use. See a phygician if a medical condicion exists.

PRTMARY ROUTE(S) AF ENTRY: Imhalation, Dermnl, Ingestion.

EMERGENCY FIRST AT PROCEDURES: When exposed always get medical attention. EYE CONTACT: Flush with water for 15 minutes.

SKIN CONTACT: Wagh with soap and water. Remove contaminated clothing and clean before reuse!.

INHALATION: Remove co Eresh air. provide oxygen if breaching ia difIicule. Une artificial respiratlon if not breathing. Get medical acrention. IF SWALLOWED: DO NOI INDUCE VOMITING!1 Rlways get medical aecention.

SECTION VI - REACITUITY DATA:

STARIIITY: ThIs product is stable under normal acorage conditions.

ILAZARDOUS DECOMPOSITION IRODUCTS: Carbon monoxide, nitrogen oxider, and unidentified organjic compounds. Consider all make and funeg from burning macerial as very hazardous. Welding, cucclng or abrasive grinding can create smolse and fumes. Do not breathe any fumes or smoke from thero operations. CONDITIONS TO AVOID: Heat, sparles, and open flumes.

INCOMPATIBIIITY: Avaid contact with strong oxidizing agents.

SECTION VII - SPIII OR LENK RROCEDURES:

STEPS TO BE TAKEN IN CASE OF SPILL: Eliminace all ignition sources.

Handling equipment must be grounded to prevent sparking. Evacuate the area of unprorecced perßonnel. Wear appropriate personal protection clotiving and equipment. Follow gaEe handling and use guidelines in Section vIII. Contain and soak up resldual with an absorbent (clay or aand). Take up absorbent material and seal tightly for proper disposal. Dispose of in accordance with local. state and federal regulations. Refer to section II for Saro Title III and CERCLA information. 


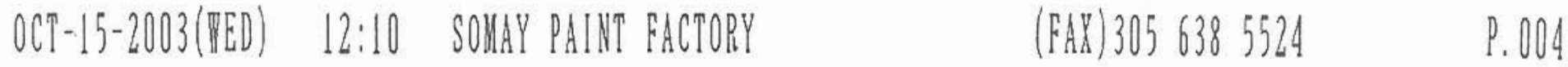

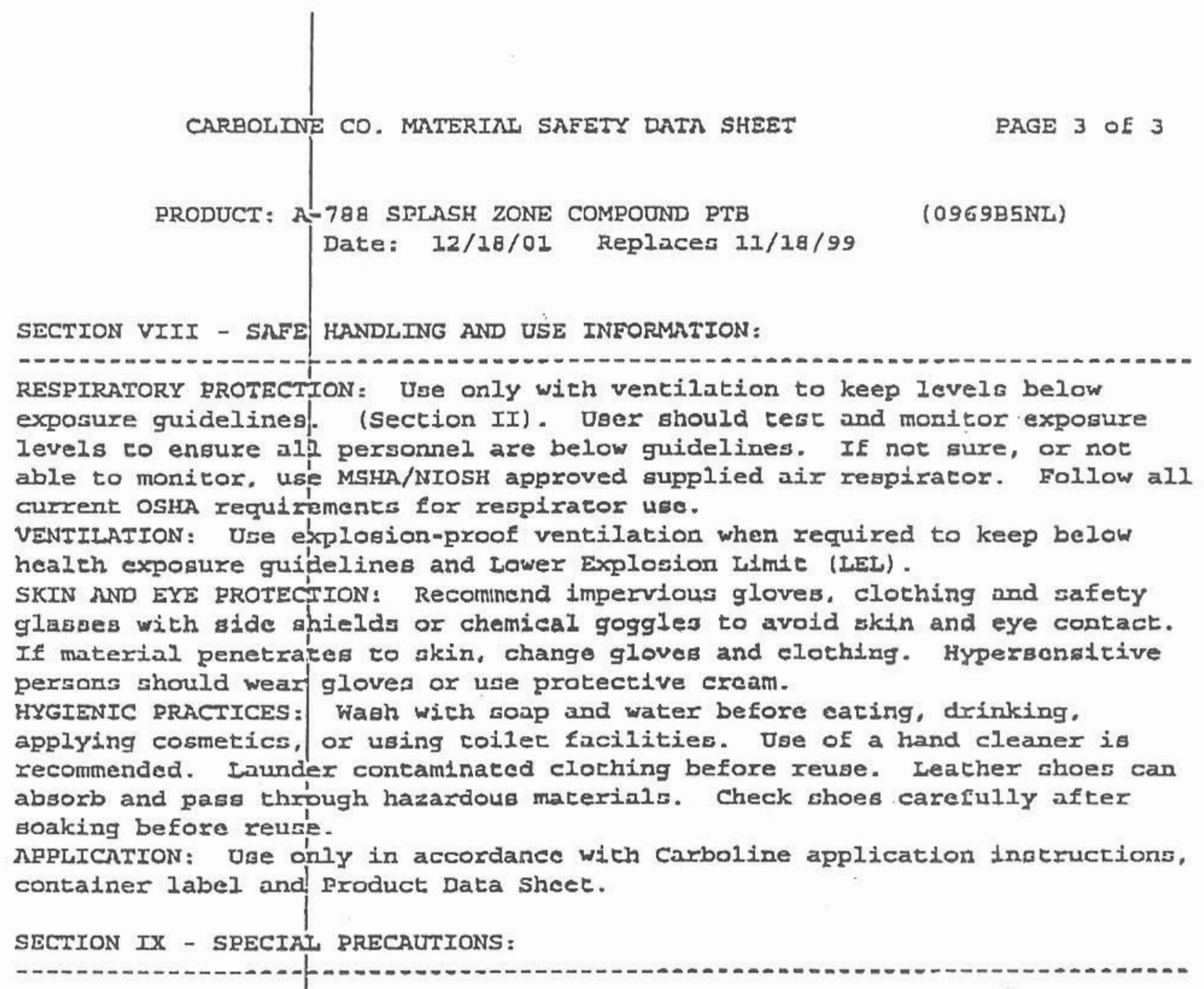

PRECAUIIONS TO BE TAAKEN IN HANDLING AND STORAGE: Reep away from heat, spurks, open flame, and strong oxidizing agents. Keep contaisers closed. store in cool, dry place with adoquate ventilation. If pouring or rxangferring materials. ground all containers and tools. OTHER PRECAUIIONS: Do not weld, heat, cue or drill on full or empey concafners.

The Infonnation contained herein is, to the beet of our knowledge and bellef accurate. Howeve=, stnce the conditions of handling. and use are beyond our control, we make no guarancee of resulfs, and assume no liability for damages incursed by use of this material. It is the responsibility of the user to comply with all applicable federal, state, and local laws and regulations.

Carboline Company 350 Hanley Ind. Cr. SE. Louia, Mo 63144

PHONE NO. 314-644-1000 FOR INDUSTRINL USE ONLY 
CARBOLIANE CO. MATERINL SAFETY DATA SHEET PRODUCT: Á-7B日 SPLASH ZONE COMPOUND PTB

Date: 12/18/01

(0969B5NL) SPECIFIC STATE REGUTATORY INFORMATION

Replaces 11/18/99

NEW JERSEY

PENNSYLVINIA

Non-Huzardous Materials above I Percent:

Name Pct

No materials meet bhis crlteria

\section{CALIFORNIA}

WARNING: This product containa a chemical(s)

known to the stace of Callformia to cause

cancer, and birth defects or other reproductive ham. 


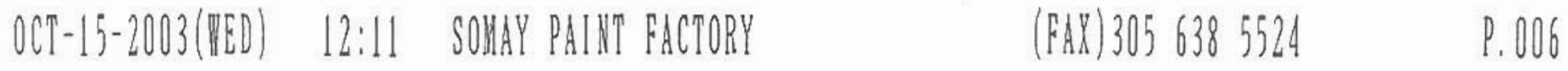

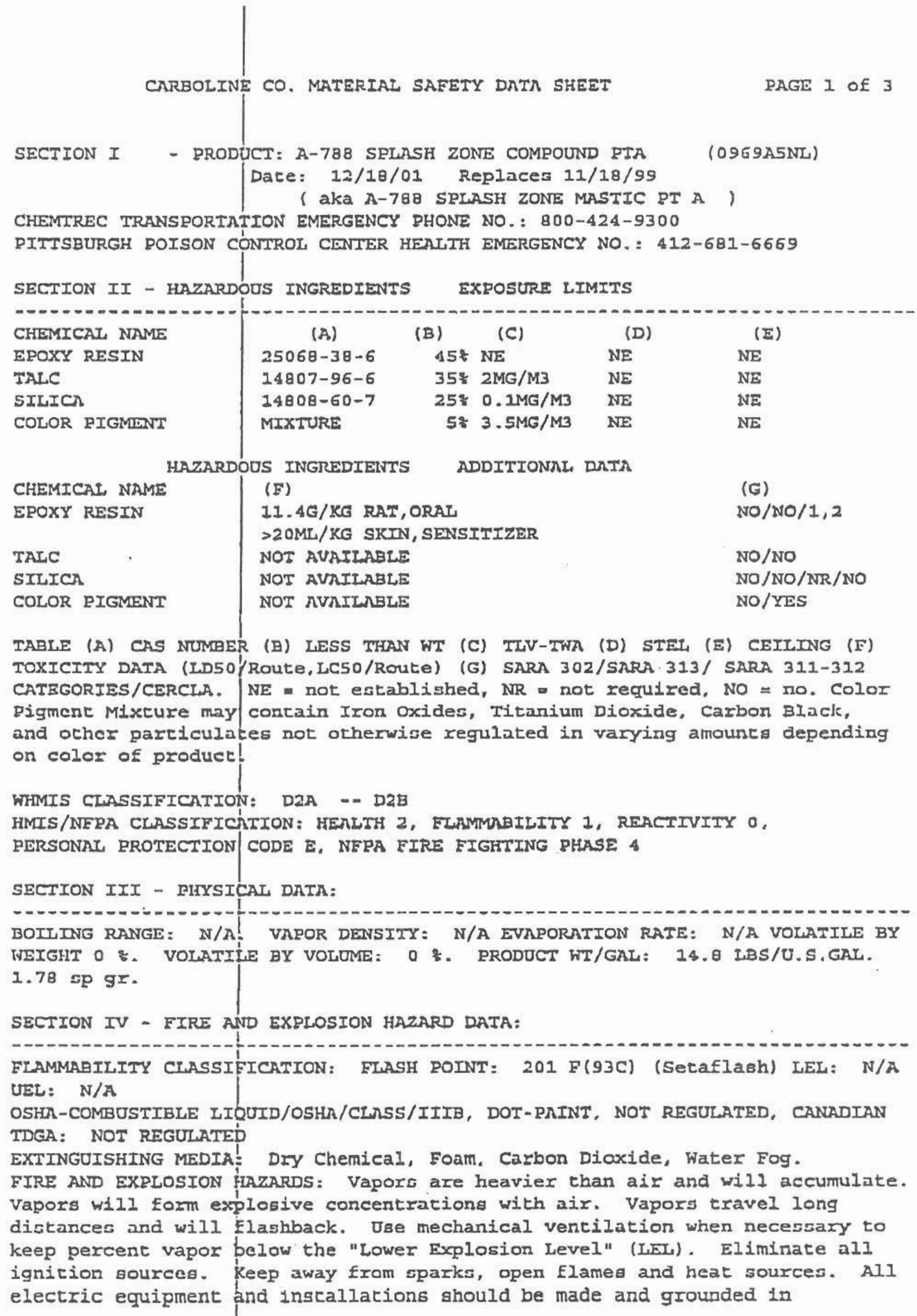




\section{oct-15-2003(med) 12:11 somay pain? ractory}

CARBOLINE CO. MATERIAL SAFETY DATA SHEET $\quad$ PAGE 20

accordance with the National tlectrtcal Code. In areas where explosion
hazards exist, workers should be required to use nonferrous coolo and to wear conductive and non-sparking shoe日.

SPECIAL FIRE FIGHTING PROCEDURES: Evacuate hazard aren of unprotected personnel. Use a Niosk approved self-contained breathing unit and complete body protection. Cpol surrounding containers with water in case of firo exposure.

SECTION $V$ - HEALTH HLAZARD DATA:

INHAthrIoN: May caluge nose and throat 1mrteacion.

CONTACT: May cause eye irritation. May eause slein irritetion. May caube allergic skin reaction.

NOTICE: Contains StrICA which can cause cancer. Risk of cancer depends on duration and level be exposure.

MEDICAL CONDITIONS 'PRONE TO AGGRAVATION BY EXPOSURE: If senEitized to amines, epoxies or bther chemicals do not use. See a physician if a medical condition exists. PRIMARY ROUTE(S) OR ENTRY: Inhalation, Dermal, Ingestion.

EMIRGENCY FIRST AID PROCEDURES: When exposed always get medical attention. EYE CONTACT: Flushl with water for 15 minute日.

SKIN CONTACT: wash/ with soup and water. Remove contaminated clothing and clean before reuse.

INHALATION: Remove to Eregh air. Provide oxygen if breathing $1 \mathrm{~s}$ difficult. Use artificial respiration if not breathing. Get medical attention. IF SWALLOWED: DO NOT INDUCE VOMITING!! RIwaya get medical attention.

SECIION VI - REACTIVITY DATA:

STREILITY: Thid prpduct is stable under normal gtorage conditions.

FAZARDOUS POLYMERIZATION: Will not occur under normal conditions.

FAZARDOUS DECOMPOSITION PRODUCTS: Curbon monoxide. nitrogen oxiden, and unidentifled organic compounds. Consider all emolse and funes from burning inaterial as very hozardous. Welding, cutting or abrastve grinding can create smoke and Iumes. Do not breathe any fumed or smoke from these operacions. CONDITIONS TO AVOID: Heat, sparks, and open flames.

INCOMPATIBILITY: Avoid contact with gtrong oxidizing agents.

SECTION VII - SRILL OR LEAK PROCEDURES:

STEPS TO BE IAKEN IN CASE OF SPILL: Eliminate all Ignition sOUrCes.

flandling equipment just be grounded to prevent sparking. Evacuate the area of unprorected personnel. Wear approprlate personal proteccion clothing and equipment. Follow safe handling and use guidelines in section vIII. Contain and soak up residuail wich an absorbent (clay or sand). Take up absorbent material and seal tightly for proper disposal. Diapose of in accordance with local, state and federal regulaciona. Refer to Section. II for Sara Iitle III and CERCLA information. 
SECIION VIII - SAFE| RESPIRATORY PROTECTION: Use only with ventilation to keep levels below levels to ensure all personnel are below guidelines. If not sure, or not able to manitor, uge MSHA/NIOSH approved supplted air respirator. Follow all current oSH requirements for respirator use.

VENTILATION: Use explosion-proof ventilation when required to keep below health exposure guildelines and Lower Explosion Limic (LEL).

SKIN AND EYE BROTECIION: Recommend impervious gloves, clothing and snfety glasee with gide ahields or chemical goggles to avoid akin and eye contnct. If material penetrate日 to skin, chunge gloves and clothing. Hypersensteive persons should weac gloves or use protecrive cream.

HYGIENIC PRACTICES: Wash with soap and water before eating, drinking.

applying cosmetics, or using toilet facllities. Use of a hand cleaner is recommended. Launder contaminated clothing before reuse. Leather shoen can absorb and pass through hazardous macerials. Check shoeg carefully after soaking before reuge.

APPLICATION: Use ány in accordance with Carboline applfcation instrucrions, containcr label and Product Data Sheet.

SECTION IX - SPECIRL PRECAUTIONS:

PRECAUTIONS TO BE TAREN IN HANDLING AND STORAGE: Keep aWOY from heßt,

sparks, open flame. and ttrong oxidizing agents. Keep containers closed.

store in cool. dry place with adequace ventilacton. IE pouring or transferring materials, ground all contalners and tools.

OTIIER PRECAUTIONS: Do not weld, heat, cut or drill on full or empty containers.

The information concained herein is, to the berc of our knowledge and belief accurate. However, since the conditions of handling and use are beyond our concrol, we make no guarankee of reaulks, and assume no liabilicy for damages incurred by use of this macerial. It is the responsibility of the user to comply with all applicable federal, state, and local laws and regulations.

Carboline Company 350 Hanley Ind. Ct. St. Louis, MO 63244 PHONE NO. 314-6A4-1000 FOR INDUSTRIAL USE ONLY 
CARBOLINE CO. MATERIAL SAFETY DATA SHEET RRODUCT: A'-78B SPLASH ZONE COMPOUND PTA Date: 12/18/01 Replaces 2I/18/99 SPECIFIC STATE REGULATORY INEORMATION

NEW JERSEY
PENNSYLUANIA

Non-Huzardous Materials above 1 Percent:

Name CAS

Det

No materials meet this criterla

CALIFORNIA

WARNING: Thig product contains a chemical(s)

known to che state of CaIifornia to caure

cancer, and birth defects or orher reproductive harm. 


\section{Carboguard $^{\otimes}$ A-78 product data (Carboline ${ }_{\odot}$ Splash Zone Mastic}

\section{Selection \& Specification Data}

Generic Type Epoxy Polyamide

Description Solventefree gatching compound used for repeiring pits. cracks and voids in steol repeiring pils, cracks and voids in steel, concrate, wood and other surfaces. Has the underwater.

Features - Designed for undenwater and other wot applications.

- Can be applied up to $2^{\prime \prime}$ in thickness

- Self-priming on most surfaces and over most generic types of coatings

- Rapid cure characteristices

- VOC compilant to current AIM regulations

Color

Olive Green

Finish

Flat

Primers

Topcoats

Seff-priming

Dry Film

Thicknes:

Epoxies, Polyurethanes if required

$1 / 8^{\circ}-2$ (3.1-50 mm) for most applications $1 / 4^{*}(6.4 \mathrm{~mm})$ is proctical meximum thickness for vertical and overhead applications.

Solids Contont

By Volume:

$99 \% \pm 1 \%$

Theorettcal

Coverage Rate

$1604 \mathrm{mll} \pi^{2}\left(24.5 \mathrm{~m}^{2} \mathrm{n}\right.$ al 25 microns)

Allow for loss in mixing and application.

Field experience has displayed a realiztic coverage rate of $8 \mathrm{~N}^{z} / \mathrm{gallon}\left(.2 \mathrm{~m}^{\mathrm{z} / 1}\right)$. This figure accounts for actual losses and the fact then the product is frequently applied at higher dry film thicknesses.

voc Values

As supptled: $\quad 0.00 \mathrm{lbs} / \mathrm{gal}(0 \mathrm{~g} / \mathrm{l})$ These are nominal values.

Dry Temp. Continuous: $\quad 200^{\circ} \mathrm{F}\left(93^{\circ} \mathrm{C}\right)$

Resistance Non-Continuous: $250^{\circ} \mathrm{F}\left(121^{\circ} \mathrm{C}\right)$

\section{Substrates \& Surface Preparation}

General

all oil or grease from the surface w Carboline Surface Cleaner 3 in accordan with SSPC-SP?.

Remove all oln, loose paint, spalling concret rotted wood, marine growth and oth contaminants by abrasive blasting or his pressure water blasting.

Hand or powrer tool cleaning methods may used but are of limited benefit and are tir consuming.

Abrastve blasting can be done undenwater the initial air blast will clear a path through of water for the abrasive/air mixture.

When working at the splash zone or in si water, cost deaned metal surfaces as soc as possible to minimize new corrosion. 


\section{Carboguard $^{\oplus}$ A-788}

\section{Tication Equipment}

General

Apply by hand, trowel or brosed knite. Spread matoriat smeothly onto the surface in a $1 / 8^{\circ}$ io $1 / 4^{\circ}$ (3. material $\mathrm{mm}$ ) Urick layer using onough persure (3.1 to 8.4 water and air bubbles. Smooth out the area by hand When slarsing another mix, stan spreading at and hand. from the orevibus appliod Film. Mris will help and trapped alr oubbles or leaving an area uncoelp prevo

If applying to dry surfaces in dry alr, periodically rewe hands or tools with water to keap the product sticking.

When used as a pateh or grour, fores the material into the hole or crack and smooth by hand to the thicknes needed. For larger porches greapar then ine tricknesa use a steol or fiberglass plate for adian th $^{2}(12.7 \mathrm{~mm})$. A.788 to the subetrate. (cut larger then the hols) and ombed the suppon plate

When applied undenwater or when watted wh during applicsion, the surtace of A 788 with weller emulsified lightor green "scumn" A-783er, will form an normal and facillutes apolication. Ther. This loyer ts "scum" layer remsins undistcalon. The film undar the The "scum" layer will cura and becond will cure property. when A-7BB is cured aboum bart of the finish will remain soh and uncured when the $A-78$. is layer underwater during curing.

\section{Mixing \& Thinning}

Mixlng

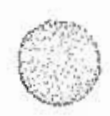

Thlnning

Mix one Pan A to one Pan B by volume. Mhx by hand "scooping" a quantivy of the " $A$ " component from the can and then "BCoop" the same quandly of the B components by hand unil the watlow and by have cornbined to mate a colons Apply this mixlure immediathy aher mive green color. time is is mixhro im hands and the materiels wet wing, weep the gloved hands and the

Not recommended. Use of thinnars other than thase supplied or recommended by Carboline may aoversely affect product performance and void product werrenty, whecher exprassed or implied.

Working times at $70^{\circ} \mathrm{F}\left(21^{\circ} \mathrm{C}\right)$, Below and above water, Golfoall size mix:
Beseball to Sotball size mix: $\quad 30$ minutes Baseball to Sotball size mix: $\quad 30$ minutas
Y/a galion mix: Working times ane reduced by ona-hali at temperatures Working times ane

Do not mix more melerial than can be applied in the working limes listed. The materlal may soll appear to be workable affor the time limit is oxcosded. but it will not propenty adhere to the substrate ather apolication and curing.

\section{Cleanup \& Safety}

\begin{tabular}{|c|c|}
\hline Cleanup & Use $\# 2$ Thinner or Acalone. \\
\hline Safery & 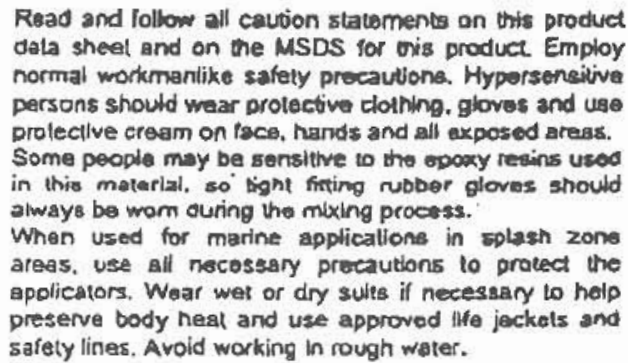 \\
\hline
\end{tabular}

\section{Application Conditions}

\begin{tabular}{|c|c|c|c|c|}
\hline Condivon & $\frac{\text { Moteria }}{65^{\circ}-75^{\circ} \mathrm{F}}$ & & Ambione & Mumidity \\
\hline Normal & $\left(18^{-}-24^{\circ} \mathrm{C}\right)$ & $\left(16^{\circ}-27^{\circ} \mathrm{C}\right)$ & $\begin{array}{c}60^{\circ}-80^{\circ} \mathrm{F} \\
\left(16^{\circ}-27^{\circ} \mathrm{C}\right)\end{array}$ & $30-70 \%$ \\
\hline Mlnimum & $\begin{array}{r}50^{\circ} \mathrm{F} \\
\left(10^{\circ} \mathrm{C}\right) \\
\end{array}$ & $\begin{array}{l}50^{\circ} \mathrm{F} \\
\left(10^{\circ} \mathrm{C}\right)\end{array}$ & $\begin{array}{c}50^{\circ} \mathrm{F} \\
\left(10^{\circ} \mathrm{C}\right)\end{array}$ & $0 \%$ \\
\hline Maximum & $\begin{array}{l}100^{\circ} \mathrm{F} \\
\left(38^{\circ} \mathrm{C}\right)\end{array}$ & $\begin{array}{l}110^{\circ} \mathrm{F} \\
\left(43^{\circ} \mathrm{C}\right)\end{array}$ & $\begin{array}{l}100^{\circ} \mathrm{F} \\
\left(30^{\circ} \mathrm{C}\right)\end{array}$ & $100 \%$ \\
\hline
\end{tabular}

apolication conations. Do nos map required above of below norma then $\mathrm{B}$ or greotert than g) or in solutions core in acidic or alkaline water (pH less

\section{Curing Schedule}

\begin{tabular}{|c|c|c|c|}
\hline $\begin{array}{l}\text { Surfaca } \\
\text { Tomp. a } \\
\text { sox Revlative } \\
\text { Humidis. }\end{array}$ & Dry to Touch & $\begin{array}{l}\text { Dry to Handle or } \\
\text { Topcoart }\end{array}$ & $\begin{array}{l}\text { Maximum } \\
\text { Recoat Time }\end{array}$ \\
\hline $50^{\circ} \mathrm{F}\left(10^{\circ} \mathrm{C}\right)$ & $8 \mathrm{HOW}$ & 38 Hourd & 72 Hours \\
\hline $60^{\circ} \mathrm{F}\left(16^{\circ} \mathrm{C}\right)$ & Thours & 18 Hours & J8'Hours \\
\hline $75^{\circ} \mathrm{F}\left(24^{\circ} \mathrm{C}\right)$ & 2 & a houn & 27 Hours \\
\hline $30^{\circ} \mathrm{F}\left(32^{\circ} \mathrm{C}\right)$ & 1 Hour & 6 Hours & 12 Hours \\
\hline
\end{tabular}

These tirnes are besed on a $1 / 8^{\circ}(3.1 \mathrm{~mm})$ dy film thickness. Higher silm thicknesses or cooler lemperstures will raquire langer cure timos, if the maximum recast times have been exceeded, the surface must be abraded by swerep blasking or sanding to produce a rough surface and to remove the "scum" layer 政

\section{Packaging, Handling \& Storage}

Shipping Waighe

(Approxlonato)

Flash Point (Setaflash)

Storage Temperature

3 Humidity

Shatf Life

\begin{tabular}{|c|c|}
\hline & $\frac{1 / 2 \text { Gollon Kat }}{10(4 \mathrm{~kg})} \quad \frac{2 \text { Gellon Kit }}{30 \mathrm{lbs}(13 \mathrm{~kg})}$ \\
\hline \multicolumn{2}{|c|}{$\begin{array}{ll}\text { Part A: } & >200^{\circ} \mathrm{F}\left(93^{\circ} \mathrm{C}\right) \\
\text { Pan B: } & >200^{\circ} \mathrm{F}\left(93^{\circ} \mathrm{C}\right)\end{array}$} \\
\hline \multicolumn{2}{|c|}{$\begin{array}{l}40^{\circ}-110^{\circ} \mathrm{F}\left(4^{\circ}-43^{\circ} \mathrm{C}\right) \text { Store indoors. } \\
0-100 \% \text { Redativa Hurmidity }\end{array}$} \\
\hline \multicolumn{2}{|c|}{4 monthes at $75^{\circ} \mathrm{F}\left(24^{\circ} \mathrm{C}\right)$} \\
\hline
\end{tabular}

4301 N.W. 35th Avenue Miami, FL 33142-4382

Tel.: (305) 633-6333

Fax: (305) 638-5524
SOMAY PRODUCTS, INC. 
Diver - cote $^{\mathrm{TM}}$

RA 5OOUW-HV

Epoxy Resin

\section{Q сheйico

\section{IDENTIFICATION OF PREPARATION \& OF COMPANY}

$\begin{array}{ll}\text { Product: } & \text { Epoxy Resin. } \\ \text { Manufacturer: } & \text { Chemco International Ltd } \\ & \text { East Shawhead Industrial Estate } \\ & \text { Coatbridge ML5 4XD } \\ & \text { Scotland } \\ & +44(0) 1236606060 \\ \text { Telephone No: } & \text { sales@chemcoint.com } \\ \text { Email: } & \text { www.chemcoint.com }\end{array}$

\section{COMPOSITION INFORMATION ON INGREDIENTS}

Blend of epoxy resin and reactive diluents.

$\begin{array}{llll} & \text { Chemicals } & \text { Classification } & \text { Risk phrases } \\ \text { Resin } & \text { Bisphenol A } & \text { Xi, N } & \text { R36/38-43-51/53 } \\ & \text { Bisphenol F } & \text { Xi, N } & \text { R36/38-43-51/53 } \\ & \text { Aliphatic diglycidylether } & \mathrm{Xi} & \mathrm{R} 36 / 38-43\end{array}$

The remaining $30 \%$ of the composition is a blend of proprietary, non-hazardous chemicals that are trade secret.

\section{HAZARDS IDENTIFICATION}

Irritating to eyes and skin.

May cause sensitisation by skin contact.

Toxic to aquatic organisms, may cause long term adverse effects in the aquatic environment.

\section{FIRST AID MEASURES}

Inhalation:

Ingestion:

Eyes:

Skin:

Remove to fresh air if effects occur. Seek medical attention. The decision of whether to induce vomiting or not should be made by an attending physician.

Irrigate with flowing water immediately and continuously for 15 minutes. Consult medical personnel.

Immediately flush with flowing water for at least 15 minutes while removing contaminated clothing. Removes residues with soap and water. Seek medical attention if irritation persists.

\section{FIRE-FIGHTING MEASURES}

Extinguishing media:

Hazardous combustion products:

Specific fire or explosion hazards: Special fire-fighting protection:
Carbon dioxide, dry chemical powder, alcohol foam. Under conditions for incomplete combustion or pyrolysis, phenolics and carbon oxides may evolve. The thermal decomposition products therefore should be treated as potentially hazardous substances and appropriate. Non-flammable product.

Wear positive pressure self-contained breathing apparatus and protective fire fighting clothing (includes fire-fighting helmet, coat, pants, boots and gloves). 
6. ACCIDENTAL RELEASE MEASURES

Personal precautions:

Environmental precautions:

Methods for cleaning up:

Wear adequate personal protective equipment

Prevent from entering soil, waterways and groundwater. Flushings and wash waters must be confined and prevented from entering into soil, waterways and ground water. Contain large spills with a dike. Soak up with absorbent material such as sand and collect in suitable, labelled containers. Solvents are not recommended for clean up unless the recommended exposure guidelines and safe handling procedures for the specific solvent is followed. Residual product may be removed using steam or hot soapy water.

7. HANDLING \& STORAGE

Handling:

Practice care and caution to avoid skin and eye contact. Avoid breathing vapours of heated material. Store in a cool, dry ventilated storage and in closed containers. Keep away from oxidisers, heat or flames.

\section{EXPOSURE CONTROLS / PERSONAL PROTECTION}

Engineering controls:

Adequate ventilation should be sufficient for most conditions. Local exhaust ventilation may be necessary for some operations.

Exposure controls:

Respiratory protection:

Not established.

Normally not required. If respiratory irritation is experienced, use an approved air purifying respirator. In misty atmospheres, use an approved mist respirator.

Eye protection: Chemical safety glasses, splash-proof eye goggles with a full face shield. Contact lenses should not be worn. Use protective clothing impervious to this material. Selection of specific items will depend on operation. Use impervious gloves when prolonged or frequently contact could occur. Remove contaminated clothing no later than at the end of the work period and launder before reuse.

Hand protection: Nitrile rubber gloves or butyl rubber gloves, gauntlet type.

\section{PHYSICAL \& CHEMICAL PROPERTIES}

Physical state:

Colour:

Odour:

Specific gravity:

$\mathrm{pH}$ :

Boiling point:

Flash point:

Water solubility:

Viscosity:
Liquid.

Pale yellow.

None.

1.33 - 1.51g. $\mathrm{cm}^{-3} @ 25^{\circ} \mathrm{C}$

Not applicable.

Decomposes prior to boiling.

$100^{\circ} \mathrm{C}$ (DIN 51758

$>1 \%$ wt $\left(25^{\circ} \mathrm{C}\right)$

25 - 47 Pa.s@ $25^{\circ} \mathrm{C}$ 


\section{STABILITY \& REACTIVITY}

Chemical stability:

Materials to avoid:

Conditions to avoid:

Hazardous polymerisation:
Stable under normal storage conditions.

Acids, amines, bases and oxidising agents.

Excessive heating over long periods of time degrades the product (causes discoloration).

Will not occur by itself, but masses of more than $0.5 \mathrm{~kg}$ of product, plus an aliphatic amine will cause

irreversible polymerisation with considerable heat build up.

\section{TOXICOLOGICAL INFORMATION}

\section{Acute toxicity \\ Ingestion:}

Skin contact:

Inhalation:

Irritation:

Sensitisation:
Single dose oral toxicity is low. Small amounts swallowed incidental to normal handling operations are not likely to cause injury.

Oral LD50 (rats) $=>2,000 \mathrm{mg} / \mathrm{kg}$

Single prolonged exposure is not likely to result in

material being absorbed through the skin in harmful amounts. At room temperature, exposures to vapours may generate vapour levels sufficient to cause adverse effects.

Skin - Prolonged or repeated exposure may cause slight skin irritation.

Eyes - May cause eye irritation (temporary corneal injury).

Has caused allergic skin reactions in humans.

\section{ECOLOGICAL INFORMATION}

Mobility and bioaccumulation potential: Partitioning from water to octanol is not applicable.

Degradation:

Aquatic toxicity:

Below detectable limits under aerobic conditions.

LC50 (fathead minow - pimephales promelas) $=3.1 \mathrm{mg} / 1$

\section{DISPOSAL CONSIDERATIONS}

Product:

Recommended procedure for disposing of waste products is burning under carefully controlled conditions. Burn in adequate incinerator or bury in an approved landfill site.

Contaminated packaging: unless all remaining product adhering to container wall has been removed. Washings must be disposed of safely in accordance with local regulations. 


\section{TRANSPORT INFORMATION}

Proper shipping name:

Road/rail

ADR/RID Class:

Hazard No:

UN No:

Sea

IMDG Class:

UN No:

Air

IATA/ICAO:

UN No:

Packing Instruction (Pass \& Cargo): 914

90

3082

9

3082
Environmentally hazardous substance, liquid, n.o.s. (Bisphenol A - epoxy resin)

ADR/RID Item No:

Trem Card:

$11 \mathrm{c}$

Packing Group:

Class:

Packing Group:

Packing Instruction (Cargo): 914

\section{REGULATORY INFORMATION}

Chemical name:

Labelling:

Symbols:

Risk phrases:

Safety phrases:
Contains hexanediol diglycydlether, epoxy resin.

According to Chemical Hazard Information and

Packaging for Supply (CHIP) legislation.

(Xi) Irritant

(N) Dangerous for the environment.

R36/38, Irritating to eyes and skin.

R43, May cause sensitisation by skin contact.

$\mathrm{R} 51 / 53$, Toxic to aquatic organisms, may cause long-

term adverse effects in the aquatic environment.

Please note that in the final cured film, the product is

non-hazardous and does not affect aquatic organisms.

$\mathrm{S} 28$, After contact with skin, wash immediately with

plenty of water.

S37/39, Wear suitable gloves and eye/face protection.

\section{OTHER INFORMATION}

The information contained in this data sheet is based on present state of knowledge and current national legislation. It provides guidance on health, safety and environmental aspects of the product and should not be construed as any guarantee of technical performance or suitability for the particular applications. 
Effective Date 01/06/2003

Diver - cote ${ }^{\text {TM }}$

RA 500UW-HV

Epoxy Resin

\section{IDENTIFICATION OF PREPARATION \& OF COMPANY}

Product:

Manufacturer:

Telephone No:

Email:

Web Site:
Epoxy Resin.

Chemco International Ltd

East Shawhead Industrial Estate

Coatbridge ML5 4XD

Scotland

$+44(0) 1236606060$

sales@chemcoint.com

www.chemcoint.com

\section{COMPOSITION INFORMATION ON INGREDIENTS}

Blend of epoxy resin and reactive diluents.

$\begin{array}{llll} & \text { Chemicals } & \text { Classification } & \text { Risk phrases } \\ \text { Resin } & \text { Bisphenol A } & \mathrm{Xi}, \mathrm{N} & \mathrm{R} 36 / 38-43-51 / 53 \\ & \text { Bisphenol F } & \mathrm{Xi}, \mathrm{N} & \mathrm{R} 36 / 38-43-51 / 53 \\ & \text { Aliphatic diglycidylether } & \mathrm{Xi} & \mathrm{R} 36 / 38-43\end{array}$

The remaining $30 \%$ of the composition is a blend of proprietary, non-hazardous chemicals that are trade secret.

\section{HAZARDS IDENTIFICATION}

Irritating to eyes and skin.

May cause sensitisation by skin contact.

Toxic to aquatic organisms, may cause long term adverse effects in the aquatic environment.

\section{4. $\quad$ FIRST AID MEASURES}

Inhalation:

Ingestion:

Eyes:

Skin:
Remove to fresh air if effects occur. Seek medical attention. The decision of whether to induce vomiting or not should be made by an attending physician.

Irrigate with flowing water immediately and continuously for 15 minutes. Consult medical personnel.

Immediately flush with flowing water for at least 15 minutes while removing contaminated clothing. Removes residues with soap and water. Seek medical attention if irritation persists.

\section{FIRE-FIGHTING MEASURES}

Extinguishing media:

Hazardous combustion products:
Carbon dioxide, dry chemical powder, alcohol foam. Under conditions for incomplete combustion or pyrolysis, phenolics and carbon oxides may evolve. The thermal decomposition products therefore should be treated as 
Specific fire or explosion hazards: Special fire-fighting protection: potentially hazardous substances and appropriate.

Non-flammable product.

Wear positive pressure self-contained breathing apparatus and protective fire-fighting clothing (includes fire-fighting helmet, coat, pants, boots and gloves).

\section{ACCIDENTAL RELEASE MEASURES}

Personal precautions:

Environmental precautions:

Methods for cleaning up:
Wear adequate personal protective equipment. Prevent from entering soil, waterways and groundwater. Flushings and wash waters must be confined and prevented from entering into soil, waterways and ground water. Contain large spills with a dike. Soak up with absorbent material such as sand and collect in suitable, labelled containers. Solvents are not recommended for clean up unless the recommended exposure guidelines and safe handling procedures for the specific solvent is followed. Residual product may be removed using steam or hot soapy water.

\section{HANDLING \& STORAGE}

Handling:

Storage:

Practice care and caution to avoid skin and eye contact. Avoid breathing vapours of heated material. Store in a cool, dry ventilated storage and in closed containers. Keep away from oxidisers, heat or flames.

\section{EXPOSURE CONTROLS / PERSONAL PROTECTION}

Engineering controls:

Exposure controls:

Respiratory protection:

Eye protection:

Skin protection

Hand protection:
Adequate ventilation should be sufficient for most conditions. Local exhaust ventilation may be necessary for some operations.

Not established.

Normally not required. If respiratory irritation is experienced, use an approved air purifying respirator. In misty atmospheres, use an approved mist respirator. Chemical safety glasses, splash-proof eye goggles with a full face shield. Contact lenses should not be worn. Use protective clothing impervious to this material. Selection of specific items will depend on operation. Use impervious gloves when prolonged or frequently contact could occur. Remove contaminated clothing no later than at the end of the work period and launder before reuse.

Nitrile rubber gloves or butyl rubber gloves, gauntlet type.

\section{PHYSICAL \& CHEMICAL PROPERTIES}

$\begin{array}{ll}\text { Physical state: } & \text { Liquid. } \\ \text { Colour: } & \text { Pale yellow. } \\ \text { Odour: } & \text { None. }\end{array}$


Specific gravity:

$\mathrm{pH}$ :

Boiling point:

Flash point:

Water solubility:

Viscosity:

10. STABILITY \& REACTIVITY

Chemical stability:

Materials to avoid:

Conditions to avoid:

Hazardous polymerisation:
$1.33-1.51 \mathrm{~g} \cdot \mathrm{cm}^{-3} @ 25^{\circ} \mathrm{C}$

Not applicable.

Decomposes prior to boiling.

$100^{\circ} \mathrm{C}$ (DIN 51758)

$>1 \% \mathrm{wt}\left(25^{\circ} \mathrm{C}\right)$

$25-47$ Pa.s@ $25^{\circ} \mathrm{C}$

Stable under normal storage conditions.

Acids, amines, bases and oxidising agents.

Excessive heating over long periods of time degrades the product (causes discoloration).

Will not occur by itself, but masses of more than $0.5 \mathrm{~kg}$ of product, plus an aliphatic amine will cause irreversible polymerisation with considerable heat build up.

\section{TOXICOLOGICAL INFORMATION}

Acute toxicity

Ingestion:

Skin contact:

Inhalation:

Irritation:

Sensitisation:
Single dose oral toxicity is low. Small amounts swallowed incidental to normal handling operations are not likely to cause injury.

Oral LD50 (rats) $=>2,000 \mathrm{mg} / \mathrm{kg}$

Single prolonged exposure is not likely to result in material being absorbed through the skin in harmful amounts.

At room temperature, exposures to vapours may generate vapour levels sufficient to cause adverse effects.

Skin - Prolonged or repeated exposure may cause slight skin irritation.

Eyes - May cause eye irritation (temporary corneal injury).

Has caused allergic skin reactions in humans.

\section{ECOLOGICAL INFORMATION}

Mobility and bioaccumulation potential: Partitioning from water to octanol is not applicable. Degradation: Aquatic toxicity: Below detectable limits under aerobic conditions. LC50 (fathead minow - pimephales promelas) $=3.1 \mathrm{mg} / \mathrm{l}$

\section{DISPOSAL CONSIDERATIONS}

Product:

Contaminated packaging:
Recommended procedure for disposing of waste products is burning under carefully controlled conditions. Burn in adequate incinerator or bury in an approved landfill site.

Empty container disposed of as hazardous waste unless all remaining product adhering to container wall has been removed. Washings must be disposed of safely in accordance with local regulations. 


\section{TRANSPORT INFORMATION}

Proper shipping name:

Road/rail

ADR/RID Class:

Hazard No:

UN No:

Sea

IMDG Class:

UN No:

Air

IATA/ICAO:

UN No:

Packing Instruction (Pass \& Cargo)
Environmentally hazardous substance, liquid, n.o.s. (Bisphenol A - epoxy resin)

$\begin{array}{lll}9 & \text { ADR/RID Item No: } & \text { 11c } \\ 90 & \text { Trem Card: } & 90 \mathrm{G} 01 \\ 3082 & & \\ 9 & & \\ 3082 & & \\ & & \\ \text { Packing Group: } & \text { III } \\ \text { DGR } & \text { Class: } & 9 \\ 3082 & \text { Packing Group: } & \text { III } \\ ): & 914 \quad \text { Packing Instruction (Cargo): } 914\end{array}$

\section{REGULATORY INFORMATION}

Chemical name:

Labelling:

Symbols:

Risk phrases:

Safety phrases:
Contains hexanediol diglycydlether, epoxy resin. According to Chemical Hazard Information and Packaging for Supply (CHIP) legislation.

(Xi) Irritant.

(N) Dangerous for the environment.

R36/38, Iritating to eyes and skin.

R43, May cause sensitisation by skin contact.

R51/53, Toxic to aquatic organisms, may cause longterm adverse effects in the aquatic environment.

Please note that in the final cured film, the product is non-hazardous and does not affect aquatic organisms. S28, After contact with skin, wash immediately with plenty of water.

$\$ 37 / 39$, Wear suitable gloves and eye/face protection.

\section{OTHER INFORMATION}

The information contained in this data sheet is based on present state of knowledge and current national legislation. It provides guidance on health, safety and environmental aspects of the product and should not be construed as any guarantee of technical performance or suitability for the particular applications. 
$\therefore \quad \cdots$

Diver - coterm

RA 500UW

Epoxy Solvent-Free System Incorporating COR-SANiM

Ciliner-cote m

\section{PRODUCT DESCRIPTION \& CHARACTERISTICS}

Diver-coterm is recommended for a wide range of applications including the protection of risers, pipes and structures below the splash zone. Repairs holes, leaks, cracks, chips and defects with minimum effort and downtime.

Specifically designed for application underwater or in very wet areas as a protective coating for poorly prepared metal and concrete substrates. Ideal for use on wet and saturated metal and concrete and for hand prepared or hydro-blasted surfaces. Compared to other underwater coating systems, the product offers minimal dispersion during application which in turn:-

- reduces potential contamination of the environment

- helps to keep expensive diving suits and equipment clean

- improves the controllability and accuracy of application as the diver's vision is clearer for a longer period of time.

It will help reduce the risk of M.I.C. (Microbiological Induced Corrosion) and S.R.B. (Sulphate Reducing Bacteria) because it does not contain the food ingredients contained in traditional solvent-borne systems that the bacteria thrive on.

Exhibits long-term resistance to the marine environment.

It is an ideal product for use with other underwater application products such as:-

- Diver-stix ${ }^{\mathrm{TM}}$

- Diver-fillerTM

Material can be supplied in two forms:-

- Diver-coterm RA 500UW-LV as a low viscosity coating for use on submerged or wet surfaces to produce a high gloss finish. Ideal for large areas to give an aesthetically pleasing finish.

- Diver-coterm RA 500UW-HV as a high viscosity coating for use on deep cracks, holes and large defects. Ideal as a repair compound for damaged surfaces.

\section{TECHNICAL FEATURES \& BENEFITS}

Unique coating system formulated for above and under water applications (by incorporating COR-SAN'M fibre technology). Ideal for protecting large areas under water. There is less paint film dispersion (a common problem with this type of application) instead, the coating forms a smooth, paint-like finish, enabling very high application rates to be achieved. The system exhibits excellent abrasion resistance and is able to withstand severe physical stresses caused by wave action.

\section{PRODUCT INFORMATION}

Typical applications:

Structural steelwork, GRP, splash zone (above and below tide level) tank repairs (internal and external). Ideal for underwater repairs (metal and concrete). Ship repair work, swimming pools and ponds etc. Repair of cracks, including worn, damaged and old concrete.

Colour: Standard white \& blue (other colours available on request). Volume solids: $100 \%$

DISCLAIMER. The information contained herein is to the best of our knowledge accurate and current and is given in good faith without warranty, Users are deemed to hove satisfied themselves independently as to the suitability of our products for their particular purpose. In no event shall Chemco International be liable for consequent or incidental damages. 
Density:

Mix ratio:

Thinner:

Cleaner:

Cure:

Pot life:

Touch dry:

Hard dry:

Full cure:
$1.21 \pm 0.01 \mathrm{~g} / \mathrm{cm}^{3} @ 20^{\circ} \mathrm{C}$

Mix part A (resin RA 500UW and part B (hardener HF 500) in proportionate weights as supplied.

No thinning agents required.

SIIA

$10^{\circ} \mathrm{C}-20^{\circ} \mathrm{C}$

$2 \mathrm{hrs} \quad 1 \mathrm{hr} 20 \mathrm{mins}$

$10 \mathrm{hrs} \quad 6 \mathrm{hrs}$

$24 \mathrm{hrs} \quad 12 \mathrm{hrs}$

14 days 3 days

\section{PRODUCT INFORMATION (cont'd)}

Recoating interval: Minimum:
Maximum:

Typical thickness range

Typical thickness range

Theoretical coverage

Theoretical coverage

Temperature resistance:

Method:

Above water:

$4-6$ hrs (†ouch dry)

unlimited.

(RA 500UW-LV): $200-400$ microns per coat.

(RA 500UW-HV): $1.0-5.0 \mathrm{~mm}$

(RA 500UW-LV): $\quad 3.1 \mathrm{~m}^{2} / \mathrm{kg} @ 250$ microns.

(RA 500UW-HV): $0.67 \mathrm{~m}^{2} / \mathrm{kg} @ 1.0 \mathrm{~mm}$

(Allow for application losses, surface irregularities, etc).

Maximum $60^{\circ} \mathrm{C}$ (immersed).

Airless spray, roller, brush or trowel. spatula, mitts.

Airless spray application: $\quad$ Pump (minimum 45:1 ratio) with a fluid twist tip: RA 500UW-LV $(23-31$ thou.)

\section{SURFACE PREPERATION}

Underwater repairs:

Above waterline:
Remove all loose contamination by wire brushing or scraping.

Remove any scale, dirt, grease with water-proof abrasive paper (wet \& dry paper)

Remove all loose contamination by wire brushing or scraping. For small areas roughen area with mechanical abrader. For larger areas a suitable angular metallic or non-metallic abrasive should be chosen to give a minimum profile of 50 microns. Abrasive blast the surface to ISO $8501-1$ SA2 $1 \frac{1}{2}$

\section{LIMITATIONS}

Pot life:

Vigilant care and attention to pot life is required during application. If gelling has started, do not apply.

\section{SAFETY PRECAUTIONS}

It is the policy of CHEMCO INTERNATIONAL (C.I.) to ensure that its products are handled and applied by professionally approved and skilled applicators.

Application shall be carried out in accordance with instructions contained in this data sheet and referenced to C.I. TECHNICAL SPECIFICATION MANUAL.

CHEMCO INTERNATIONAL management are intent on ensuring all work is carried out in accordance with company HEALTH \& SAFETY procedures and all materials are handled with due care to $\mathrm{COSHH}$ regulations and instructions.

DISCLAIMER The information contained herein is to the best of our knowledge accurate and current and is given in good faith without warranty. Users are deemed to hove satisfied themselves independently as to the suitability of our proctucts for their particular purpose. In no event shat Chemco intemctional be liable for consequent or incidental damages. 
r. ac

Effective Date 01/06/03

STORAGE

Store in cool, dry conditions (between $2-20^{\circ} \mathrm{C}$ ). Keep away from direct heat source and sunlight. When not using the material, always replace the lid on the container.

\section{SHELF LIFE}

At least 12 months when stored in sealed containers at temperatures of $20^{\circ} \mathrm{C}$ or below. At temperatures above, refer to manufacturer for advice.

DISCLAIMER. The information contained herein is to the best of our knowledge accurate and current and is given in good faith without warranty. Users are deemed to hove satisfied themselves independently as to the suitability of our products for their particular purpose. In no event shall Chemco Intemotiona be liable for consequent or incidental damages. 
Diver - cote $^{\mathrm{TM}}$

RA 50OUW-LV

Cenañe

Epoxy Resin

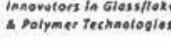

\section{IDENTIFICATION OF PREPARATION \& OF COMPANY}

Product:

Manufacturer:

Epoxy Resin.

Chemco International Ltd

East Shawhead Industrial Estate

Coatbridge ML5 4XD

Scotland

Telephone No:

+44 (0) 1236606060

Email:

sales@chemcoint.com

Web Site:

www.chemcoint.com

\section{COMPOSITION INFORMATION ON INGREDIENTS}

Blend of epoxy resin and reactive diluents.

$\begin{array}{llll} & \text { Chemicals } & \text { Classification } & \text { Risk phrases } \\ \text { Resin } & \text { Bisphenol A } & \mathrm{Xi}, \mathrm{N} & \mathrm{R} 36 / 38-43-51 / 53 \\ & \text { Bisphenol F } & \mathrm{Xi}, \mathrm{N} & \mathrm{R} 36 / 38-43-51 / 53 \\ & \text { Aliphatic diglycidylether } & \mathrm{Xi} & \mathrm{R} 36 / 38-43\end{array}$

The remaining 30\% of the composition is a blend of proprietary, non-hazardous chemicals that are trade secret.

\section{3. $\quad$ HAZARDS IDENTIFICATION}

Irritating to eyes and skin.

May cause sensitisation by skin contact.

Toxic to aquatic organisms, may cause long term adverse effects in the aquatic environment.

\section{FIRST AID MEASURES}

Inhalation:

Ingestion:

Eyes:

Skin:

\section{FIRE-FIGHTING MEASURES}

Extinguishing media:

Hazardous combustion products:

Specific fire or explosion hazards:

Special fire-fighting protection:
Remove to fresh air if effects occur. Seek medical attention. The decision of whether to induce vomiting or not should be made by an attending physician.

Irrigate with flowing water immediately and continuously for 15 minutes. Consult medical personnel.

Immediately flush with flowing water for at least 15 minutes while removing contaminated clothing. Removes residues with soap and water. Seek medical attention if irritation persists. 


\section{ACCIDENTAL RELEASE MEASURES}

Personal precautions:

Environmental precautions:

Methods for cleaning up:
Wear adequate personal protective equipment

Prevent from entering soil, waterways and groundwater. Flushings and wash waters must be confined and prevented from entering into soil, waterways and ground water. Contain large spills with a dike.

Soak up with absorbent material such as sand and collect in suitable, labelled containers. Solvents are not recommended for clean up unless the recommended exposure guidelines and safe handling procedures for the specific solvent is followed. Residual product may be removed using steam or hot soapy water.

\section{HANDLING \& STORAGE}

Handling:

Storage:
Practice care and caution to avoid skin and eye contact. Avoid breathing vapours of heated material. Store in a cool, dry ventilated storage and in closed containers. Keep away from oxidisers, heat or flames.

\section{EXPOSURE CONTROLS / PERSONAL PROTECTION}

\section{Engineering controls:}

Exposure controls:

Respiratory protection:

\section{Eye protection:}

Skin protection:

Hand protection:
Adequate ventilation should be sufficient for most conditions. Local exhaust ventilation may be necessary for some operations.

Not established.

Normally not required. If respiratory irritation is experienced, use an approved air purifying respirator. In misty atmospheres, use an approved mist respirator. Chemical safety glasses, splash-proof eye goggles with a full face shield. Contact lenses should not be worn. Use protective clothing impervious to this material. Selection of specific items will depend on operation. Use impervious gloves when prolonged or frequently contact could occur. Remove contaminated clothing no later than at the end of the work period and launder before reuse.

Nitrile rubber gloves or butyl rubber gloves, gauntlet type.

\section{PHYSICAL \& CHEMICAL PROPERTIES}

\section{Physical state:}

Colour:

Odour:

Specific gravity:

$\mathrm{pH}$ :

Boiling point:

Flash point:

Water solubility:

Viscosity:
Liquid.

Pale yellow.

None.

$1.28-1.35 \mathrm{~g} \cdot \mathrm{cm}^{-3} @ 25^{\circ} \mathrm{C}$

Not applicable.

Decomposes prior to boiling.

$100^{\circ} \mathrm{C}$ (DIN 51758)

$>1 \%$ wt $\left(25^{\circ} \mathrm{C}\right)$

14 - 35 Pa.s @ $25^{\circ} \mathrm{C}$ 
10. STABILITY \& REACTIVITY

Chemical stability:

Materials to avoid:

Conditions to avoid:

Hazardous polymerisation:
Stable under normal storage conditions.

Acids, amines, bases and oxidising agents.

Excessive heating over long periods of time degrades

the product (causes discoloration).

Will not occur by itself, but masses of more than $0.5 \mathrm{~kg}$

of product, plus an aliphatic amine will cause

irreversible polymerisation with considerable heat build up.

\section{TOXICOLOGICALINFORMATION}

Acute toxicity

Ingestion:

Skin contact:

Inhalation:

Irritation:

Sensitisation:
Single dose oral toxicity is low. Small amounts swallowed incidental to normal handling operations are not likely to cause injury.

Oral LD50 (rats) $=>2,000 \mathrm{mg} / \mathrm{kg}$

Single prolonged exposure is not likely to result in material being absorbed through the skin in harmful amounts.

At room temperature, exposures to vapours may generate vapour levels sufficient to cause adverse effects. Skin - Prolonged or repeated exposure may cause slight skin irritation.

Eyes - May cause eye irritation (temporary corneal injury). Has caused allergic skin reactions in humans.

\section{ECOLOGICAL INFORMATION}

Mobility and bioaccumulation potential:

Degradation:

Aquatic toxicity:
Partitioning from water to octanol is not applicable. Below detectable limits under aerobic conditions. LC50 (fathead minow - pimephales promelas) $=3.1 \mathrm{mg} / /$

\section{DISPOSAL CONSIDERATIONS}

Product:

Contaminated packaging:
Recommended procedure for disposing of waste products is burning under carefully controlled conditions. Burn in adequate incinerator or bury in an approved landfill site.

Empty container disposed of as hazardous waste unless all remaining product adhering to container wall has been removed. Washings must be disposed of safely in accordance with local regulations. 


\section{TRANSPORT INFORMATION}

Proper shipping name:

Road/rail

ADR/RID Class:

Hazard No:

UN No:

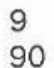

90

Sea

IMDG Class:

UN No:

3082

Air

IATA/ICAO:

UN No:

DGR

Packing Instruction (Pass \& Cargo):
Environmentally hazardous substance, liquid, n.o.s. (Bisphenol A - epoxy resin)

\section{ADR/RID Item No:}

Trem Card:

$11 c$

90G01

Packing Group:

III

Class:

Packing Group:

9

Packing Instruction (Cargo): 914

\section{REGULATORY INFORMATION}

Chemical name:

Labelling:

\section{Symbols:}

Risk phrases:

Safety phrases:
Contains hexanediol diglycydlether, epoxy resin. According to Chemical Hazard Information and Packaging for Supply (CHIP) legislation.

(Xi) Irritant.

(N) Dangerous for the environment.

R36/38, Irritating to eyes and skin.

$\mathrm{R} 43$, May cause sensitisation by skin contact.

$\mathrm{R} 51 / 53$, Toxic to aquatic organisms, may cause long. term adverse effects in the aquatic environment.

Please note that in the final cured film, the product is non-hazardous and does not affect aquatic organisms. S28, After contact with skin, wash immediately with plenty of water.

S37/39, Wear suitable gloves and eye/face protection.

\section{OTHER INFORMATION}

The information contained in this data sheet is based on present state of knowledge and current national legislation. It provides guidance on health, safety and environmental aspects of the product and should not be construed as any guarantee of technical performance or suitability for the particular applications. 
Effective Date 01/06/03

\section{Diver - cole ${ }^{T M}$ \\ RA 500UW-LV \\ Epoxy Resin}

\section{IDENTIFICATION OF PREPARATION \& OF COMPANY}

Product:

Manufacturer:

Telephone No:

Email:

Web Site:

\section{Epoxy Resin.}

Chemco International Ltd

East Shawhead Industrial Estate

Coatbridge ML5 4XD

Scotland

$+44(0) 1236606060$

sales@chemcoint.com

www.chemcoint.com

\section{COMPOSITION INFORMATION ON INGREDIENTS}

Blend of epoxy resin and reactive diluents.

$\begin{array}{llll} & \text { Chemicals } & \text { Classification } & \text { Risk phrases } \\ \text { Resin } & \text { Bisphenol A } & \mathrm{Xi}, \mathrm{N} & \mathrm{R} 36 / 38-43-51 / 53 \\ & \text { Bisphenol } \mathrm{F} & \mathrm{Xi}, \mathrm{N} & \mathrm{R} 36 / 38-43-51 / 53 \\ & \text { Aliphatic diglycidylether } \mathrm{Xi} & \mathrm{R} 36 / 38-43\end{array}$

The remaining $30 \%$ of the composition is a blend of proprietary, non-hazardous chemicals that are trade secret.

\section{HAZARDS IDENTIFICATION}

Irritating to eyes and skin.

May cause sensitisation by skin contact.

Toxic to aquatic organisms, may cause long term adverse effects in the aquatic environment.

\section{FIRST AID MEASURES}

Inhalation:

Ingestion:

Eyes:

Skin:
Remove to fresh air if effects occur. Seek medical attention. The decision of whether to induce vomiting or not should be made by an attending physician.

Irrigate with flowing water immediately and continuously for 15 minutes. Consult medical personnel.

Immediately flush with flowing water for at least 15 minutes while removing contaminated clothing. Removes residues with soap and water. Seek medical attention if irritation persists.

\section{FIRE-FIGHTING MEASURES}

Extinguishing media:

Hazardous combustion products:
Carbon dioxide, dry chemical powder, alcohol foam. Under conditions for incomplete combustion or pyrolysis, phenolics and carbon oxides may evolve. The thermal decomposition products therefore should be treated as 
Specific fire or explosion hazards: Special fire-fighting protection: potentially hazardous substances and appropriate. Non-flammable product.

Wear positive pressure self-contained breathing apparatus and protective fire fighting clothing (includes fire-fighting helmet, coat, pants, boots and gloves).

\section{ACCIDENTAL RELEASE MEASURES}

Personal precautions: Environmental precautions:

Methods for cleaning up:
Wear adequate personal protective equipment. Prevent from entering soil, waterways and groundwater. Flushings and wash waters must be confined and prevented from entering into soil, waterways and ground water. Contain large spills with a dike. Soak up with absorbent material such as sand and collect in suitable, labelled containers. Solvents are not recommended for clean up unless the recommended exposure guidelines and safe handling procedures for the specific solvent is followed. Residual product may be removed using steam or hot soapy water.

\section{HANDLING \& STORAGE}

Handling:

Practice care and caution to avoid skin and eye contact. Avoid breathing vapours of heated material. Store in a cool, dry ventilated storage and in closed containers. Keep away from oxidisers, heat or flames.

\section{EXPOSURE CONTROLS / PERSONAL PROTECTION}

Engineering controls:

Exposure controls:

Respiratory protection:

Eye protection:

Skin protection:

Hand protection:
Adequate ventilation should be sufficient for most conditions. Local exhaust ventilation may be necessary for some operations.

Not established.

Normally not required. If respiratory irritation is experienced, use an approved air purifying respirator. In misty atmospheres, use an approved mist respirator. Chemical safety glasses, splash-proof eye goggles with a full face shield. Contact lenses should not be worn. Use protective clothing impervious to this material. Selection of specific items will depend on operation. Use impervious gloves when prolonged or frequently contact could occur. Remove contaminated clothing no later than at the end of the work period and launder before reuse.

Nitrile rubber gloves or butyl rubber gloves, gauntlet type.

\section{PHYSICAL \& CHEMICAL PROPERTIES}

Physical state:

Colour:

Odour:
Liquid.

Pale yellow.

None. 
Specific gravity:

$\mathrm{pH}$ :

Boiling point:

Flash point:

Water solubility:

Viscosity:
$1.28-1.35 \mathrm{~g} . \mathrm{cm}^{-3} @ 25^{\circ} \mathrm{C}$

Not applicable.

Decomposes prior to boiling.

$100^{\circ} \mathrm{C}$ (DIN 51758)

$>1 \% \mathrm{wt}\left(25^{\circ} \mathrm{C}\right)$

$14-35$ Pa.s@ $25^{\circ} \mathrm{C}$

10. STABILITY \& REACTIVITY

Chemical stability:

Materials to avoid:

Conditions to avoid:

Hazardous polymerisation:
Stable under normal storage conditions.

Acids, amines, bases and oxidising agents.

Excessive heating over long periods of time degrades the product (causes discoloration).

Will not occur by itself, but masses of more than $0.5 \mathrm{~kg}$ of product, plus an aliphatic amine will cause irreversible polymerisation with considerable heat build up.

\section{TOXICOLOGICAL INFORMATION}

Acute toxicity

Ingestion:

Skin contact:

Inhalation:

Irritation:

Sensitisation:
Single dose oral toxicity is low. Small amounts swallowed incidental to normal handling operations are not likely to cause injury.

Oral LD50 (rats) $=>2,000 \mathrm{mg} / \mathrm{kg}$

Single prolonged exposure is not likely to result in material being absorbed through the skin in harmful amounts.

At room temperature, exposures to vapours may generate vapour levels sufficient to cause adverse effects.

Skin - Prolonged or repeated exposure may cause slight skin irritation.

Eyes - May cause eye irritation (temporary corneal injury).

Has caused allergic skin reactions in humans.

\section{ECOLOGICAL INFORMATION}

Mobility and bioaccumulation potential:

Degradation:

Aquatic toxicity:
Partitioning from water to octanol is not applicable.

Below detectable limits under aerobic conditions.

LC50 (fathead minow - pimephales promelas) $=3.1 \mathrm{mg} / 1$

\section{DISPOSAL CONSIDERATIONS}

Product:

Contaminated packaging:
Recommended procedure for disposing of waste products is burning under carefully controlled conditions. Burn in adequate incinerator or bury in an approved landfill site.

Empty container disposed of as hazardous waste unless all remaining product adhering to container wall 


\section{TRANSPORT INFORMATION}

Proper shipping name:

Road/rail

ADR/RID Class:

Hazard No:

UN No:

Sea

IMDG Class:

UN No:

Air

IATA/ICAO:

UN No:

Packing Instruction (Pass \& Cargo):

90

9 3082:
Environmentally hazardous substance, liquid, n.o.s.

(Bisphenol A - epoxy resin)

3082

3082

Packing Group:

III

$11 \mathrm{c}$

Trem Card: $90 \mathrm{GO}$

DGR 3082

\author{
Class: \\ Packing Group: III \\ 914 Packing Instruction (Cargo): 914
}

\section{REGULATORY INFORMATION}

Chemical name:

Labelling:

Symbols:

Risk phrases:

Safety phrases:
Contains hexanediol diglycydlether, epoxy resin. According to Chemical Hazard Information and Packaging for Supply (CHIP) legislation.

(Xi) Irritant.

(N) Dangerous for the environment.

R36/38, Irritating to eyes and skin.

R43, May cause sensitisation by skin contact.

$\mathrm{R} 51 / 53$, Toxic to aquatic organisms, may cause longterm adverse effects in the aquatic environment.

Please note that in the final cured film, the product is non-hazardous and does not affect aquatic organisms. S28, After contact with skin, wash immediately with plenty of water.

\$37/39. Wear suitable gloves and eye/face protection.

\section{OTHER INFORMATION}

The information contained in this data sheet is based on present state of knowledge and current national legislation. It provides guidance on health, safety and environmental aspects of the product and should not be construed as any guarantee of technical performance or suitability for the particular applications. 


\section{MATERIAL SAFETY DATA SHEET}

SUBMAR-EPOXX $570^{\circ}=$

HMIS: Health- 3 Fire-1 Reactivity-0

Date lssued: $11 / 18 / 91$ Supersedes: $03 / 21 / 91$

1. IDENTIFICATION \& PHYSICAL DATA

Product Name: ' GUBMAR-EROXY, 570 .

Product Class: Modified Alphatic Amine

Manufacturer's I.D. : 0326050

VOC: Not Applicable

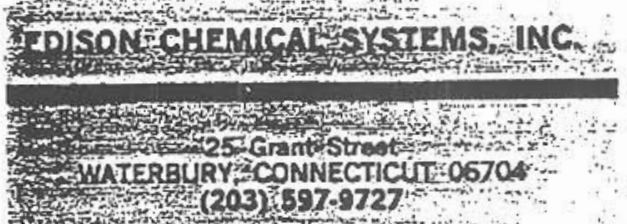

Percent Volaulle by Volume: $<1.0$

Bolling Range: >432 F

Vapor Density: No data

Welght Per Gallon: $\quad 8,1$ lbs.

Vapor Pressure at $20 \mathrm{C:}-1.0 \mathrm{~mm} \mathrm{Hg}$

Evaporatlon Rate: Not Applicable

Solubillty in Water: Partally Soluble

Appearance and Odor: Clear light colored viscous illquid with amine odor

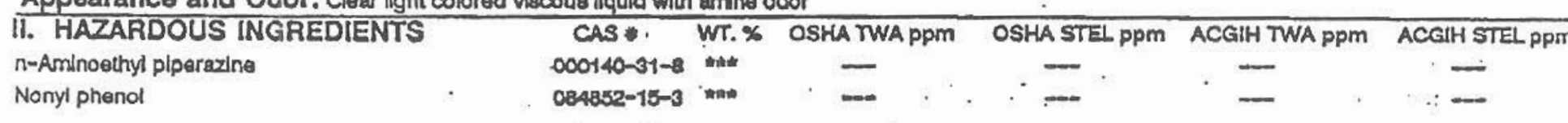

Nonyl phenol

-- Not establlshed

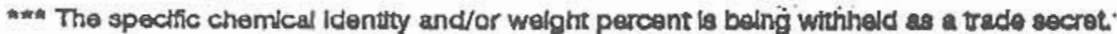

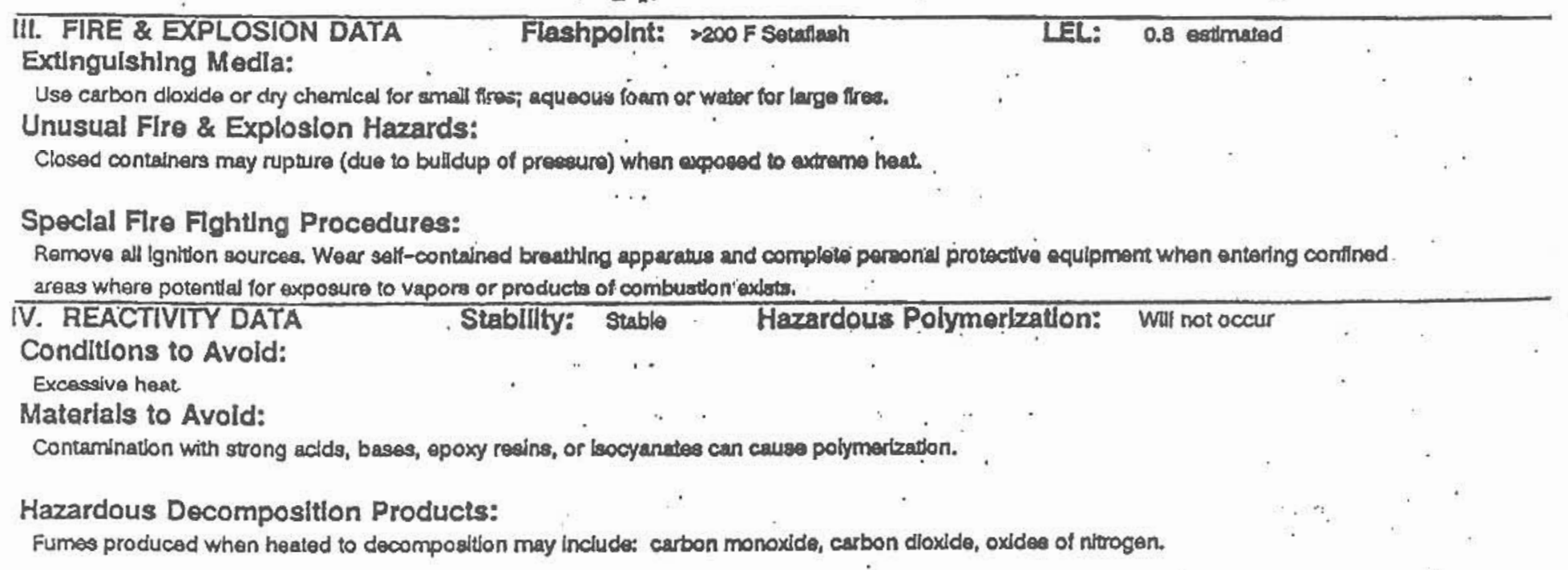

Fumes produced when heated to decomposition may include: carbon monoxide, carbon dioxide, oxjdes of nitrogen.

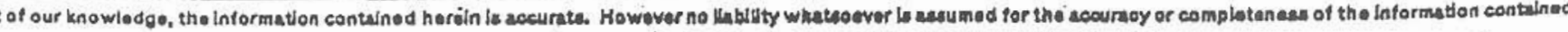
Al dotermination of suitablity of any material is tha sole rasponalbillty of the user. All matariale may presont unknown hesith hazardas and should be used with cautlon. tithoun cartain hazards are described herein, we cannot guaranteo that these are the enly hazarde that oxiat. 


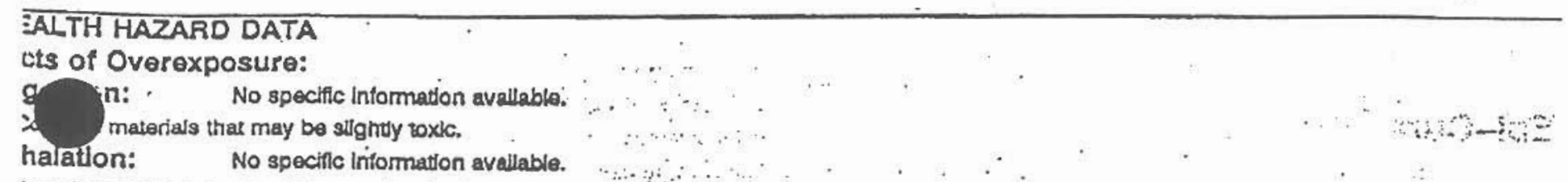

iontains materials that could cause headaches, neusea, qizziness, and respiratory lottation if inhaled. Senshtzer - may cause allergic aspiratory reaction.

dn Absorption: No specille information avallable.

iontains materials that may bo moderataly toxic.

in Contact:

$\cdots+\cdots \cdot \cdots$

fay cause chemical bum on skin. Sensittzer - may cajee allergle akin raection whlch can be severe In cartain Indlviduale.

to Contact: No specilic information avallable.

intalns materials that may cause chemical burn In eye - damage lrevenaible.

Ironlc Effects of Overexposure:

lo speciflc information available.

\section{rgency \& First Ald Procedures:}

- Contact:

lush with plenty of water for at least 15 minutes and seak madcal attention.

in Contact:

imove contaminated clothing and wash contact area with soap and water for 15 minutes.

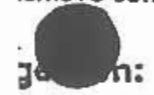

appreclable quantities are swallowed, seek medical attention.

ralation:

I case of exposure to a high concentration of vapor or mist, remove person to fresh alr. If breathing has stopped, administer artificial sspiration and soek medical attention.

\section{PILL OR LEAK PROCEDUAES}

$s$ to Be Taken in Case Material Is Released or Splliedi:...

ike spill. Absorb with inert matorial and collect for disposel. Fush aree with water. Prevverit washings from entaring waterways.

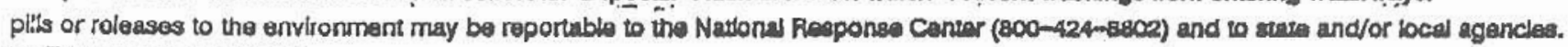

to Disposal Method:

Icinerate or use blologloal treatment in accordance wth federal, atate, and local regulations. Thls materleal bo not defined as a hazardous

aste under current RCRA regulations.

PECIAL PROTECTION INFORMATION

iratory Protectlon:

'ear a properly fitted NIOSH/MSHA approved respirator whenever exposure to vapor/mlat is Ukely untess levels are below appllicable limits.

\section{ilation:}

al Exhaust - Recommended when approprlate to control employes exposure.

thanical - Not recommended as the sole means of controlling employee exposure.

retlve Gloves:

roperations where contact can occur, wear impervious glovies (Neoprene).

Trotection: Chemical splash goggles.

Protective Equipment:

it ions where contact can occur, coveralls, apron and rubber foct covering are recommended. A sefety shower and eye wash faclity 10. avallable. 


\section{SPECIAL PRECAUTIONS}

Avoid contamination of skin. Remove and thoroughly launder comtaninated clothing before reuse. Dlscard contaminated shoes.

\section{IY OITIONAL R-T-K COMPOSITION INFORMATION}

formation is provided in conlunction with the ingredient intormation in Section if to meet varlous regulatory composition requirements.

Component

n-Aminoethyl piperazine
CAS \# UIsts

D0140-31-8 CN;MA1;NJ2;PA1;

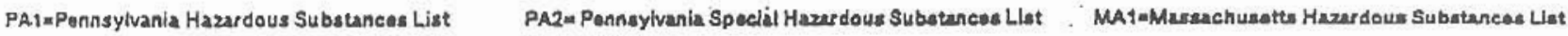
MA2*Massachusetts Extraordinary Hazardous Substances Lles NJ1-New Joracy Workplace Haurdous Subatances Liat NJawew Jersey Special Hearth Mazerds List

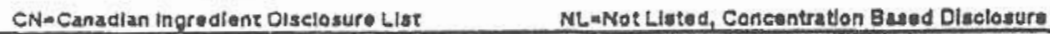

\section{SARA TItle III Information}

Supplier notification under SARA Tite III Section 313 not required for this product.

SARA Section 311 and 312 hazard classification(s) for this product ara listed below:

\section{Kl. RCRA Information}

immediate (acute) health hazard

Since this product is not sold as a waste, we have not lested it as a waste. Based on our knowledge of the product, its raw materlals and processes employed furing its manufacture, we belleve it is unlikely that this product ls a hazardous waste for foderal RCRA purposes. We recommend that you carry out your swn tests and ovaluations prior to discarding any materials.

U1.. CERCLA INFORMATION

Under EPA-CERCLA releases to air, land or water which exceed the reportable quantty must be reported to the National Response Center (800-424-8sc2). This product contains no materials with reportable quantitios.

UIII. Callfornia Proposition 65 Information

This product is not subject to California Propositon 65 notification requirements.

\section{Transportation Information}

).O.T. Shlpping Name: Polyalkylamines, n.o.s. (N-sminoethyl plperezine)

3.O.T. Hazard Class: Corrosive Material

2.O.T. Label(s):

Corrosive

D.O.T. UN/NA Number: UN 2735

\section{Other Information}

ains p-Nonyl phenol which is TSCA Section 12(b) reportable. If exported.

This product complles with all TSCA inventory reculrements. 


\section{MARINE-FLEX 570}

\section{Underwater Grade Epoxy Coatings}

\section{DESCRIPTION:}

Marine-FLEX 570 is a $100 \%$ solids, medium viscosity moisture insensitive epoxy coating intenc for heavy marine and wet industrial exposures.

Marine-FLEX 570 CAN BE APPLIED UNDERWATER, as well as on wet, damp or dry surface: concrete or steel exposed to air.

\section{PROPERTIES:}

\begin{tabular}{|l|l}
\hline Solids Content: & $100 \%$ \\
\hline Composition: & Epoxy/Amine \\
\hline Mix Ratio: & $1.5: 1$ \\
\hline Pot Life $\left(77^{0} \mathrm{~F}\right):$ & $20 \mathrm{~min}$. \\
\hline Tack-Free Time: & $4-10 \mathrm{hrs}$. \\
\hline VOC Content: & 0 \\
\hline
\end{tabular}

\section{CHEMICAL RESISTANCE:}

\begin{tabular}{|l|l}
\hline Sea Water & Distilled Water \\
\hline Ethanol & Detergent \\
\hline \hline $\mathrm{NaOH}$ & $\mathrm{H}_{2} \mathrm{SO}_{4}$ \\
\hline $\mathrm{HCl}$ & $\mathrm{HNO}_{3}$ \\
\hline
\end{tabular}

Not recommended for use in contact with strong organic solvents, acetic acid, or Skydrc APPLICATION:

Marine-FLEX 570 is supplied in preportioned units. Mix the two components thoroughly using $s$ speed paddle mixer, mixing for at least 4 minutes and avoiding incorporation of excess air.

Once blended the two surfaces will not separate or bleed if submerged, and application can be performed in calm, clean water or salt water. Note that pot life is reduced and reaction is accelerated underwater.

Product may also be applied in air, as with other $100 \%$ solids epoxy coatings. Submersion is acceptable at any point in the cure regime, but protect from mechanical damages until cured. 
Surface Preparation is comparable to other high quality, moisture insensitive epoxy coatings. Surfaces should be clean, sound, free of dirt, oil, grease, coatings or other contaminants which interfere with adhesion. Loose rust and scale should be removed by mechanical means from st surfaces. Abrasive blasting is not required, but will aid in maximizing system durability. Concret surfaces should be free of laitance, loose surface material or other contaminants.

Apply by brush or roller as required to provide a uniform, continuous coating. In hot weather, ol vertical surfaces, incorporation of upto $3 \%$ fumed silica is acceptable. if required to prevent sag! or maintain high film build. Do not apply when air, surface and/or water temperature is below $5 \mathrm{C}$

A second coat may be applied, if desired, at any time after the first coat has cured to a tack-fre $\epsilon$ state. Aged surfaces may be recoated by simply cleaning the existing coating surface and reapplying.

\section{SAFETY AND HANDLING:}

Read and observe the safety and handling guidelines as detailed in the Material Safety D sheets supplied with this product. Avoid skin and eye contact.

\section{Marine-FLEX 570 is non-flammable. Store at moderate temperatures, between 50 and $85^{\circ}$} Keep partially used containers tightly closed.

Shelf life is a minimum of 2 years from date of factory shipment in unopened, properly stored containers.

Used applicators may be disposed of upon curing of the residual coating as non-hazardous waste. Alternatively, clean up solvent is Xylene or SYSTEM 100 Read and observe the Materia Safety Data Sheets for solvents, as supplied by their manufacturers.

\section{FOR COMMERCIAL AND INDUSTRIAL USE ONLY.}

For additional information, contact EDISON COATINGS, INC. or your Edison Technical Service Representative.

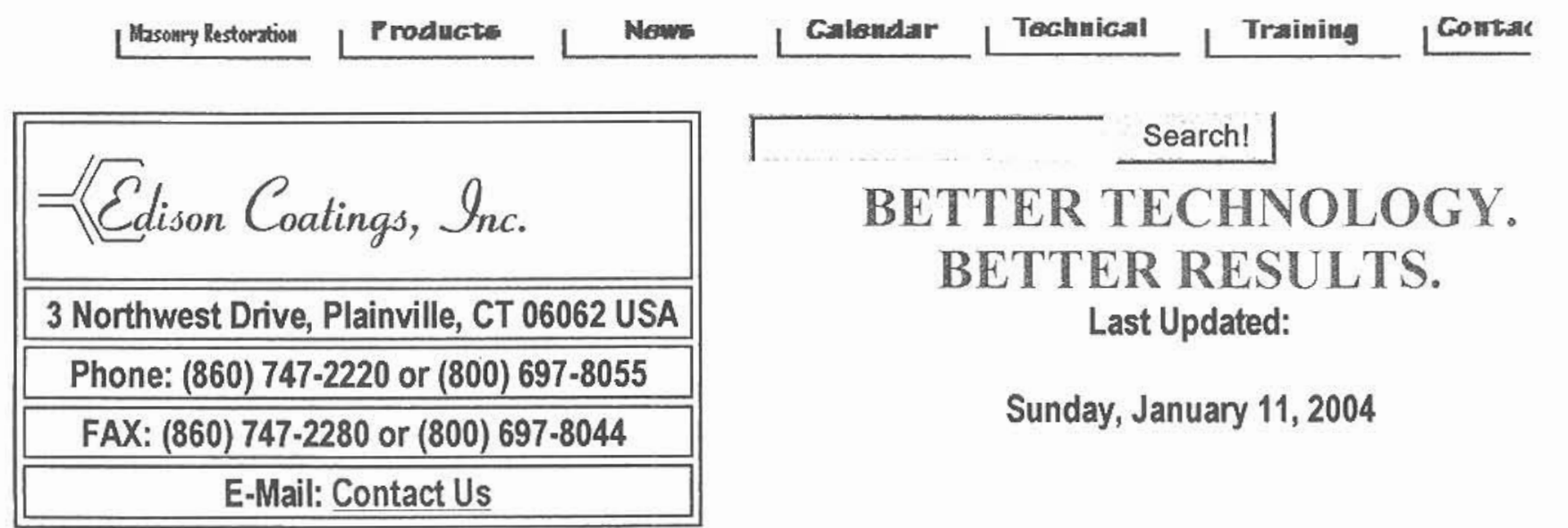

http://edisoncoatings.com/html/Marine-Flex 570100 Solids U/marine-flex $570 \begin{array}{lllll}100 & \text { s... } & \text { 1/12/04 }\end{array}$ 


\section{EURO-viny CV02 Material Safety Data Sheet}

1. DENTIFICATION OF THE SUBSTANCE/COMPANY

Product Name: $\quad$ EURO-vinyl CV02

Company Name: EURONAVY-Tintas Maritimas e Industriais S.A.

Address: $\quad$ Estrada Vale de Mulatas, Quinta de S. Francisco, 2914-516 Setúbal Portugal

Phone: $\quad 351265739440$

Fax: $\quad 351265702711$

Emergency Contact: $\quad 265265739440$

2. COMPOSITION/INFORMATION ON INGREDIENTS

Preparation Description: Underwater primer.

HAZ,ARDOUS INGREDIENTS

Ingredient name CAS number Concentration EC Symbol ECR-phrase

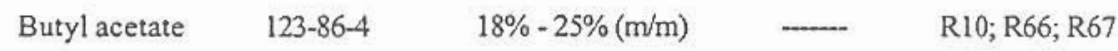

\section{HAZARDS IDENTIFICATION}

Flammable.

Irritating to respiratory system.

May cause skin dryness or cracking.

Vapors inhalation may cause dizziness. 


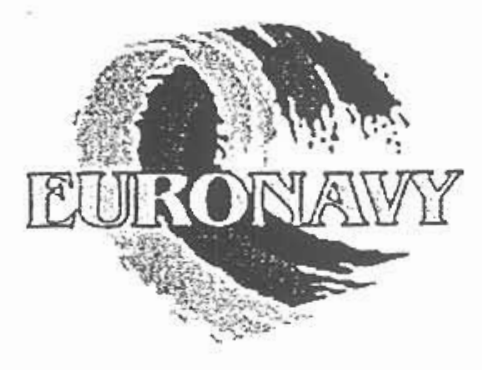

4. FIRST AID MEASURES

\begin{tabular}{|c|c|}
\hline EYE CONTACT & $\begin{array}{l}\text { For direct contact: Immediately flush eyes for } 15 \text { minutes, occasionally lifting eye- } \\
\text { lids. If victim wears contact lenses, remove lenses and continue rinsing. Cean } \\
\text { contact before reuse. If irritation or redness persists, seek medical attention. }\end{array}$ \\
\hline SKIN CONTACT & $\begin{array}{l}\text { : Remove contaminated clothing. Wash affected area with mild soap and water. If } \\
\text { irritation or redness develops and persists, seek medical attention. }\end{array}$ \\
\hline INGESTION & : Do not induce vomit and get medical attention, \\
\hline INHALATION & : Remove victim from affected area, if problem persists, get medical attention. \\
\hline
\end{tabular}

\section{FIRE-FIGHTING MEASURES}

Extinguishing Media:

Fire Fight Procedure: fighters.

Unusual Fire/Explosion Hazards: Keep adjacent containers cool by spraying water.

\section{ACCIDENTAL RELEASE MEASURES}

Personal protection:

Environmental precautions:

Use suitable personal protection equipment. Remove all ignition sources, do not produce sparks. Assure ventilation to affected areas. Avoid contact with skin.

Avoid the contamination of rivers, lakes and sea, absorb or contain with earth, sand or other suitable material. Sweep up and wash area clean with water.

\section{HANDLING AND STORAGE}

Handling: Do not breath the vapors, use ventilation, use personal protective equipment.

Keep containers closed and use only with adequate ventilation when not in use. Do not use or store near heat, sparks or flame. Use non-sparking tools. Ground and bond all containers when transferring liquid.

Storage: Keep away from heat and flames.

Keep the containers closed in a dry place. 


\section{EXPOSURE CONTROLS/PERSONAL PROTECTION}

n-Butyl acetate:

TLV/TWA: $710 \mathrm{mg} / \mathrm{m}^{3}$

Eyes protection: Safety glasses and available eye bath.

Respiratory protection: Mask or self breathig apparatus for high vapor concentration.

Hand protection: Rubber gloves.

\section{PHYSICAL AND CHEMUCAL PROPERTIES}

Physical state - Liquid

Flash Point $->23^{\circ} \mathrm{C}$ (Abel)

Density $-1.52 \mathrm{~g} / \mathrm{cm}^{3}$.

Solubility in water: Not soluble

\section{STABILITY AND REACTIVITY}

Stable under normal conditions

\section{TOXICOLOGICAL INFORMATION}

There are no information about the preparation.

\section{ECOLOGICAL INFORMATION}

There are no information about the preparation.

\section{DISPOSAL CONSIDERATIONS}

Depending the extend of the contamination reclaiming or incineration of the product by an officially authorized enterprise. 


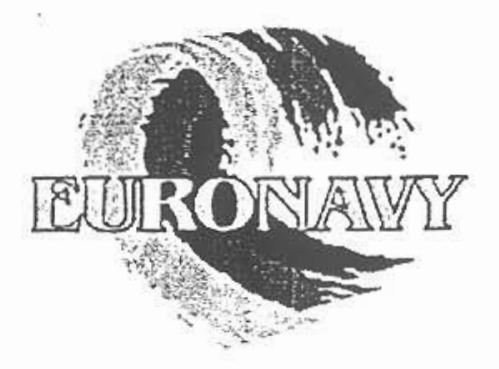

\section{TRANSPORT INFORMATION}

UN-No

ADR/RID

Class 3

Item $\quad 31^{\circ} \mathrm{C}$

IMO/IMDG

Class $\quad 3.3$

IMDG CODE PAGE $\quad 3345$

ICAO/ATA

Class 3

15. REGULATORY INFORMATION

$\begin{array}{cc}\text { EEC R-phrases } & \begin{array}{r}\text { R10- Flammable. } \\ \text { R37- Irritating to respiratory sy } \\ \text { R66- May cause skin } \\ \text { R67-Vapors inhalation }\end{array} \\ \text { EEC S-phrases } & \begin{aligned} \text { S23-Do not breathe vapors. } \\ \text { S24-Avoid contact with skin. } \\ \text { S25-Avoid contact with eyes. }\end{aligned}\end{array}$

\section{OTHER INFORMATION}

This Material Safety Data Sheet is in compliance with EEC 91/155/EEC directives.

Above informations have been made very carefully based on existing literatures, EURONAVY does not accept any liability whatsoever arising out of the use of this information. 


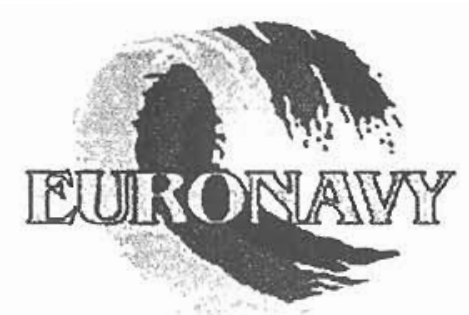

\section{EURO-viny| CVO2 \\ Underwater primer plum}

\section{Application guide}

\section{SURFACE PREPARATION}

EURO-vinyl CV02, is engineered for direct application on poorly prepared surfaces. Gently clean surface with pneumatic rotating machine over entire area to be treated. Remove all lose material, fouling, grease and lose coating. Before application of EURO-vinyl CV02 you MUST gently clean surface if any fouling or debris has settled on surface with rotating disc of SCOTCH BRITE or similar materials. NOTE: If surface has oil or grease contamination paint will bead and not adhere. Apply soap or degreaser to cleaning pad and clean surface. Contact your local Euronavy agent, for recommendations.

\section{MIXING AND THINNING}

EURO-vinyl CV02, is a one pack product. Mix coating to obtain an uniform consistency. The mixing should not take more than 2 to 3 minutes. The use of a speed adjustable power mixer is recommended.

\section{APTEICATION}

EURO-vinyl CV02, can be applied, by conventional, brush or roller. A power roller, is recommended for ease and speed. Use contrasting colours for each coat and stripe coating. However a regular solvent resistant brush or roller should be use. Use short bristle brush or medium nap roller working the material into all irregularities. Brush or lap marks may be visible. Be sure that proper film thickness is achieved by working the material. On sharp edges, boltheads, flanges, etc., a second coat would be better to "skips" or holidays. Product may be immersed in water during application on kept topside for power roller application.

Before any overall application is undertaken a small area should be coated and inspected for lifting, wrinkling or softening of the underfilm.

DO NOT THIN THIS PRODUCT

SसमसT

WARNING: Cause eye and skin irritation. The solvents may cause respiratory irritation in sensitive individuals. May cause allergic skin reaction. Avoid breathing the solvents. Do not get in eyes on skin or clothing. ear eye and skin protective equipment. Use appropriate respirator, it is recommended to avoid potential respiratory irritation. Wash skin thoroughly after use and water. Call a physician. Launder clothing before reuse. If not breathing give artificial respiration, preferably mouth-to-mouth, and call physician. FIRST AID: In case of eye contact immediately flush with plenty of water for at least 15 minutes while removing contaminated clothing and shoes. Wash skin contact area with soap.

DISCLAIMER: This is not a specification and all information is given in good faith. Every values presented as Theoretioal were calculated from the product formula, unless otherwise mentioned, and can deviate from laboratory measurements using standard methods that may be not applicable giving the nature of the products. If requested, Euronavy can inform any intemal measurement method used to determinate any given value presented. This Technical Data Sheet content can be changed without previous notice. Since conditions of use are beyond the manufacturers control information contained herein is without warranty, implied or otherwise, and final determination of the suitability of any information or material for the use contemplated, the manner of use and whether there is any infringement of patents is the sole responsibility of user. The product is intended for professional use only. Manufacturer does not assume any liability in connection with the use of the product relative to coverage, performance or injury. For application in special conditions please consult Euronavy for detailed recommendations.

EURO-vinyl CV02, last revised 31/07/2002

Manufactured by EURONAVY - Tintas Maritimas e Industriais, S.A - www.euronavy.net Estrada Vale de Mulatas, Quinta de S. Francisco, 2914-516 - Setúbal, Portugal Tel: +351.265.739440 .Fax: +351.265 .702711 .E-mail: sales@euronavy.net 


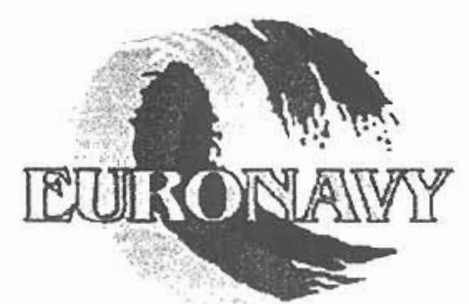

GENTRA I -
EURO-vinyl CV02, is a high
performance one pack product,
designed for application underwater
with conventional tools.
EURO-vinyl CV02, complies with
moden environmental regulations,
and can be applied, directly over on
steel and/or fibre glass surfaces free
of grease and loose matter.

\section{EURO-viny| CVO2 \\ Underwater primer plum}

\begin{tabular}{l}
\hline NDATIIRS \\
EXCELLENT ANTICORROSIVE \\
PROPERTIES \\
LOW TEMPERATURE \\
APPLICATION. \\
Can be applied in any temperature \\
water. Application less than $5^{\circ} \mathrm{C}$ \\
$\left(41^{\circ}\right.$ F), requires slightly longer to \\
dry. \\
EASY UNDERWATER \\
APPLICATION WITH \\
CONVENTIONAL TOOLS. \\
SINGLE PACK PRODUCT. \\
EXCELLENT ADHESION ON \\
POORLY TREATED SURFACES. \\
\end{tabular}

\begin{tabular}{l} 
RACONAMENDED USYS \\
\hline SHIPS, OFFSHORE \& \\
MARINE STRUCTURES \\
Great for protection of water lines \\
areas. \\
STRUCTURAL STEEL \\
EQUIPMENT \\
Provides anticorrosive protection \\
for steel structures underwater. \\
Since coating is renewable this \\
protection can be sustained with \\
periodic recoating. \\
PIPE COATINGS \\
Provides anticorrosive protection \\
for industrial water intakes lines. \\
NOT SUITABLE FOR \\
DIRECT APPLICATION \\
ON INTERIOR POTABLE \\
WATER PIPE LINES
\end{tabular}

\section{Specification Data}

\begin{tabular}{|l|}
\hline Binder Type / Pigment Type \\
\hline Colors \\
\hline Finish \\
\hline Mixing ratio \\
\hline Specific gravity \\
\hline Solids by Volume \\
\hline Flash point (Abel) \\
\hline Theoretical covering capacity \\
\hline Typical film thickness per coat \\
\hline Application method \\
\hline Thinner \\
\hline VoC (Volatile Organic Compound) \\
\hline Drying time \\
\hline Overcoating time \\
\hline Recommended primers \\
\hline Ambient temperature \\
\hline Substrate temperature \\
\hline Packing \\
\hline Storage and Shelf life \\
\hline Approvals \\
\hline
\end{tabular}

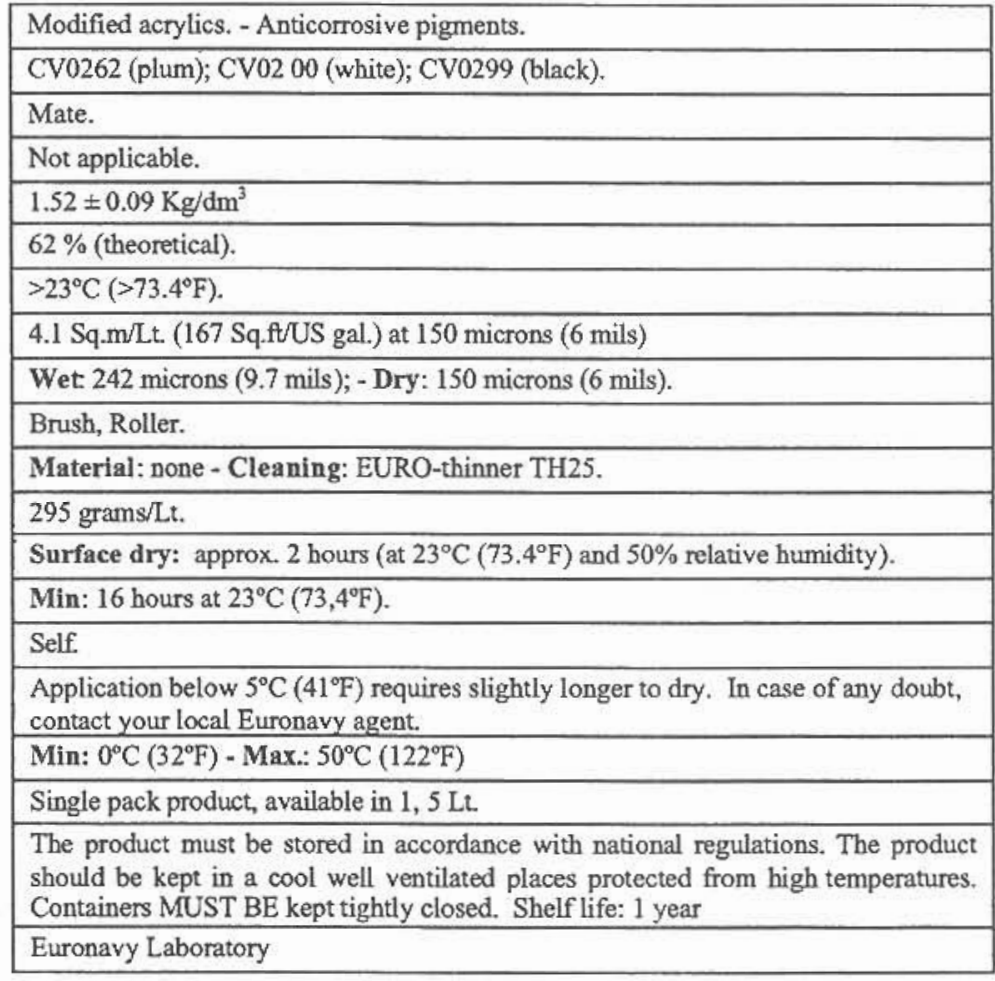

EURO-vinyl CV02, last revised 31/07/2002

Manufactured by EURONAVY - Tintas Maritimas e Industriais, S.A - www.euronavy.net Estrada Vale de Mulatas, Quinta de S. Francisco, 2914-516 - Setúbal, Portugal Tel: +351.265 .739440 . Fax: +351.265 .702711 . E-mail: sales@euronavy.net 


\section{EURO-paste ES326)(Base) \\ Material Safety Data Sheet}

1. IDENTIFICATION OF THE SUBSTANCE/COMPANY

Product Name: $\quad$ EURO-paste ES326(base)

Company Name: EURONAVY

Address: $\quad$ Estrada Vale de Mulatas, Quinta de S. Francisco, 2914-516 Setúbal Portugal

Phone: $\quad 351265739440$

Fax: $\quad 351265702711$

Emergency Contact: $\quad 351265739440$

2. COMPOSITION/INFORMATION ON INGREDIENTS

Preparation Description: $100 \%$ Solids Underwater Epoxy Filler.

HAZARDOUS INGREDIENTS

Ingredient name CAS number Concentration ECSymbol EC R-phrase

Liquid epoxy resin $\quad 25068-38-6 \quad 38 \%-48 \%(\mathrm{~m} / \mathrm{m}) \quad \mathrm{Xi} \quad \mathrm{R} 36 / \mathrm{R} 38 ; \mathrm{R} 43$

Benzyl alcohol $\quad 100-51-6 \quad 19 \%-24 \%(\mathrm{~m} / \mathrm{m}) \quad \mathrm{Xn} \quad \mathrm{R} 20 / \mathrm{R} 22$

Polymer with branched not available $20 \%-30 \%(\mathrm{~m} / \mathrm{m}) \quad \mathrm{Xi}$

branched ether and urethane

groups

\section{HAZARDS DENTIFICATION}

EYES : Causes irritation.

SKIN $\quad$ : Causes irritation. 


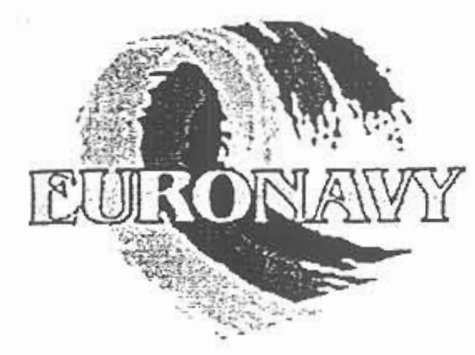

\section{4. $\quad$ FIRST AID MEASURES}

EYE CONTACT

SKIN CONTACT

INGESTION

INHALATION
: For direct contact: Immediately flush eyes for 15 minutes, occasionally lifting eyelids. If victim wears contact lenses, remove lenses and continue rinsing. Clean contact before reuse. If irritation or redness persists, seek medical attention.

: Remove contaminated clothing. Wash affected area with mild soap and water. If irritation or redness develops and persists, seek medical attention.

: Do not induce vomiting, if victim is conscious and able. Get immediate medical attention.

: No specific measures

\section{FIRE-FIGHTING MEASURES}

Extinguishing Media:

Fire Fight Procedure:

fighters.

Unusual Fire/Explosion Hazards:
Dry chemical powder, carbon dioxide, foam, sand. Do not use water.

The use of self-contained breathing apparatus's recommended for fire

Keep adjacent containers cool by spraying water.

\section{ACCIDENTAL RELEASE MEASURES}

Personal protection:

Environmental precautions: Prevent contamination of soil and water, prevent from spreading or entering into drains, ditches or rivers by using sand, earth, or other appropriate barriers. If material enters drains, it should be pumped out into an open vessel.

\section{HANDLING AND STORAGE}

Handling: Avoid contact with skin, eyes and clothing..

Storage: Keep containers tightly closed, in warm and dry conditions. 


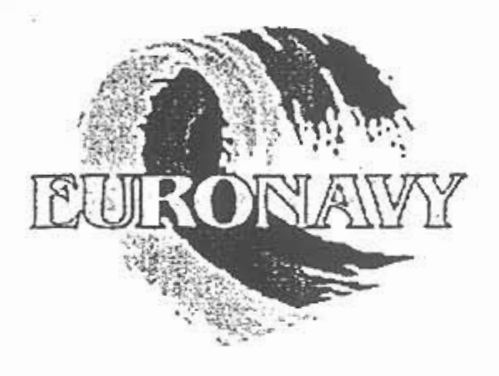

8. EXPOSURE CONTROLS/PERSONAL PROTECTION

Not established

Eyes protection: Safety glasses and available eye bath.

Respiratory protection: Not normally required.

Hand protection: Use chemical resistant type gloves.

\section{PHYSICAL AND CHEMICAL PROPERTIES}

Physical state - Liquid.

Flash Point $->100^{\circ} \mathrm{C}\left(212^{\circ} \mathrm{F}\right)$ (Abel)

Density $-1,34 \mathrm{~g} / \mathrm{cm}^{3}$.

Solubility in water: Not soluble

\section{STABILITY AND REACTIVITY}

Reacts with strong oxidizing agents, polymerizes exothermically with amines, mercaptans and lewis acids at ambient temperature and above.

\section{TOXICOLOGICAL INFORMATION}

There are no information about the preparation.

12. ECOLOGICAL INFORMATION

There are no information about the preparation.

\section{DISPOSAL CONSIDERATIONS}




\section{TRANSPORT INFORMATION}

Not dangerous according to IMO, ADR/RID and IATA/ICAO

\section{REGULATORY INFORMATION}

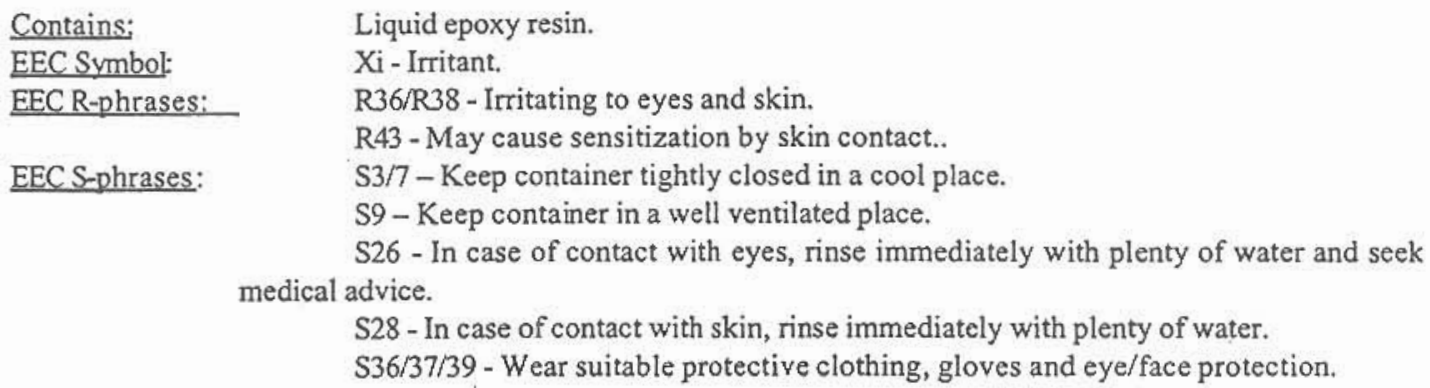

\section{OTHER INFORMATION}

This Material Safety Data Sheet is in compliance with EEC 91/155/EEC directives.

Above informations have been made very carefully based on existing literatures, EURONAVY does not accept any liability whatsoever arising out of the use of this information. 


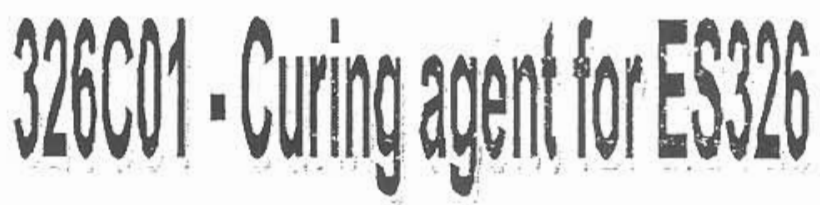 Material Safety Data Sheet}

1. DENTIFICATION OF THE SUBSTANCE/COMPANY

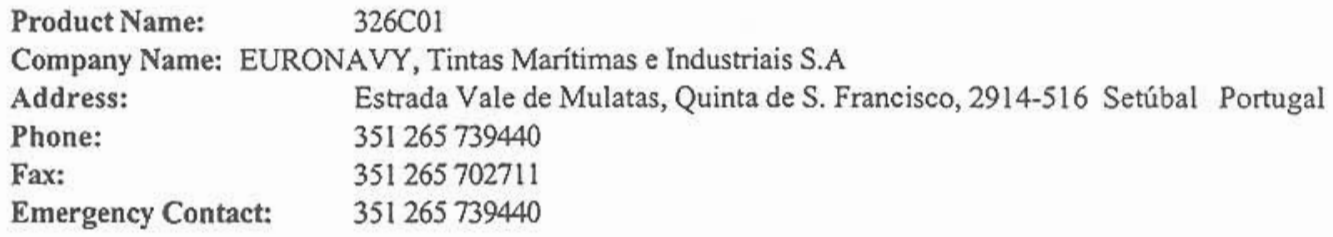

\section{COMPOSITION/INFORMATION ON INGREDIENTS}

\begin{tabular}{|c|c|c|c|c|}
\hline \multicolumn{5}{|c|}{ HAZARDOUS INGREDIENTS } \\
\hline Ingredient name & CAS number & Concentration & EC Symbol & EC R-phrase \\
\hline Isophoronediamine & $2855-13-2$ & $40 \%-50 \%(\mathrm{~m} / \mathrm{m})$ & C & $\mathrm{R} 21 / 22 ; \mathrm{R} 34 ; \mathrm{R} 43$ \\
\hline Benzyl alcohol & $100-51-6$ & $10 \%-15 \%(\mathrm{~m} / \mathrm{m})$ & $\mathrm{Xn}$ & $\mathrm{R} 20 / 22$ \\
\hline
\end{tabular}

\section{HAZARDS MENTIFICATION}

Harmful in contact with skin and by ingestion. May cause burns.

May cause sensitization by skin contact.

\section{4. $\quad$ FIRST AID MEASURES}

EYE CONTACT

SKIN CONTACT

INGESTION

: For direct contact: Immediately flush eyes for 15 minutes, occasionally lifting eyelids. If victim wears contact lenses, remove lenses and continue rinsing. Clean contact lenses before reuse. If irritation or redness persists, seek medical attention. : Remove contaminated clothing. Wash affected area with plenty of water and soap . If you feel unwell, seek medical attention.

: Do not induce vomiting. Show this document where possible. 


\section{an

\section{FIRE-FIGHTING MEASURES}

Extinguishing Media:

Special Fire Fight Procedure: used for cooling purposes.

6.

\section{ACCIDENTAL RELEASE MEASURES}

Personal protection:

Use suitable personal protection equipment.

Environmental precautions: Avoid the contamination of rivers, lakes and sea, absorb or contain with earth, sand or other suitable material. Sweep up and wash area clean with water.

\section{HANDLING AND STORAGE}

Handling:- Avoid contact with skin and eyes. Provide good ventilation.

Storage: Keep the containers in a cool, dry place.

\section{EXPOSURE CONTROLS/PERSONAL PROTECTION}

Eyes protection: Safety glasses and available eye bath.

Hand protection: Use suitable gloves.

Skin protection: Wear boot and industrial overalls, preferably disposable, of the impervious, multilayer type.

\section{PHYSICAL AND CHEMICAL PROPERTMES}

Physical state - Liquid

Flash Point $->100^{\circ} \mathrm{C}\left(212^{\circ} \mathrm{F}\right)$

Density $-1,0 \mathrm{~g} / \mathrm{cm}^{3}$.

Solubility in water: Not soluble 
Reacts with act đs.

It decomposes at temperatures above $260^{\circ} \mathrm{C}$, it produces ammonia as decomposition product.

\section{TOXICOLOGICAL INFORMATION}

There are no information about the preparation.

12. ECOLOGICAL INFORMATION

There are no information about the preparation.

13. DISPOSAL CONSWERATIONS

Depending the extend of the contamination reclaiming or incineration of the product by an officially authorized enterprise.

14. TRANSPORT INFORMATION

UN-NO

2735

ADR/RID

Class 8

IMO/IMDG

$53^{\circ} \mathrm{C}$

Clas

ICAO/IATA

Class 


\title{
an

15. REGULATORY INFORMATION

\author{
Contains: Isophorone diamine \\ EEC Symbol: $\quad$ C-Corrosive. \\ EEC R-phrases: $\quad \mathrm{R} 21 / \mathrm{R} 22$ - Harmful by skin contact and ingestion. \\ R34 - Causes burns \\ R43 - May cause sensitization by skin contact.
}

EEC S-phrases: $\quad S 1 / 2-$ Keep locked up and out of reach of children.

S26 - In case of contact with eyes, rinse immediately with plenty of water and seek medical advice.

S36/37/39 - Wear suitable protective clothing, gloves and eye/face protection.

S45 - In case of accident or if you feel unwell, seek medical advice immediately

(show the label where possible).

\section{OTHER INFORMATION}

This Material Safety Data Sheet is in compliance with EEC 91/155/EEC directives.

Above informations have been made very carefully based on existing literatures, EURONAVY does not accept any liability whatsoever arising out of the use of this information. 


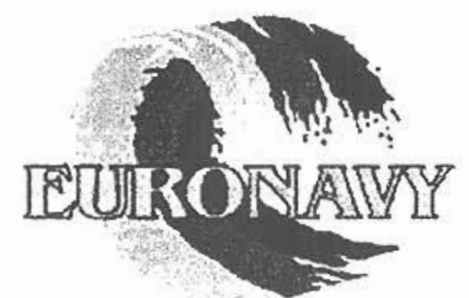

\section{GDNDRAL}

EURO-paste ES326, is an excellent $100 \%$ solids two components epoxy filler for application underwater with conventional tools.

EURO-paste ES326 is ecologically formulated and designed to be applied on steel, where high impact resistance and thickness are required, such as pitting, welding and anodic zinc areas.

EURO-paste ES326, can be applied directly over poorly treated surfaces

This product does not contain voC's.

\section{EURO-paste ES326}

$100 \%$ solids underwater epoxy filler

\section{FDATURA}

NO HARMFUL SOLVENT VAPOURS.

- Superior impact resistance.

- Good chemical resistance

- Cost savings on surface preparation.

- Excellent properties.

- High film build - up to 5000 microns (200 mils)

- Easy underwater application with conventional tools.

- Compatible with Cathodic protection.

\begin{tabular}{|} 
PICOMNUNDED USSGS \\
\hline SHIPS, OFFSHORE \& \\
MARINE STRUCTURES \\
STRUCTURAL STEEL \& \\
EQUIPMENT \\
PIPES \& GREY WATER \\
TANKS \\
STEEL WATER TANKS, \\
ETC. \\
\end{tabular}

\section{Specification Data}

\begin{tabular}{|l|}
\hline Binder Type / Pigment Type \\
\hline Colors \\
\hline Finish \\
\hline Mixing ratio \\
\hline Curing agent \\
\hline Specific gravity (mixture) \\
\hline Solids by Volume \\
\hline Pot Life \\
\hline Flash point (Abel) \\
\hline Theoretical covering capacity \\
\hline Typical film thickness per coat \\
\hline Application method \\
\hline Thinner \\
\hline VoC (Volatile Organic Compound) \\
\hline Drying time \\
\hline Overcoating time \\
\hline Recommended primers \\
\hline Ambient temperature \\
\hline Substrate temperature \\
\hline Packing \\
\hline Storage and Shelf life \\
\hline Approvals \\
\hline
\end{tabular}

\begin{tabular}{|c|c|}
\hline \multicolumn{2}{|c|}{$\begin{array}{l}\text { Modified epoxy - Chemical resistant pigments and extenders. } \\
\text { White }\end{array}$} \\
\hline \multicolumn{2}{|l|}{ Semi-Gloss } \\
\hline 5 (base) to 1 (curing agent) by weight. & 4.4 (base) to 1 (curing agent) by volume \\
\hline \multicolumn{2}{|l|}{$326 \mathrm{C} 01$} \\
\hline \multicolumn{2}{|l|}{$1.25 \pm 0.04 \mathrm{Kg} / \mathrm{dm}^{3}$} \\
\hline \multicolumn{2}{|l|}{$100 \%$. (theoretical). } \\
\hline \multicolumn{2}{|c|}{30 minutes at $23^{\circ} \mathrm{C}\left(73,4^{\circ} \mathrm{F}\right)$, (outside from the water). } \\
\hline \multicolumn{2}{|c|}{ Base: $>100^{\circ} \mathrm{C}\left(>212^{\circ} \mathrm{F}\right)$; Curing Agent: $>100^{\circ} \mathrm{C}\left(>212^{\circ} \mathrm{F}\right)$} \\
\hline \multicolumn{2}{|c|}{ Not applicable. } \\
\hline \multicolumn{2}{|l|}{ Not applicable. } \\
\hline \multicolumn{2}{|l|}{ Spatula. } \\
\hline \multicolumn{2}{|c|}{ Material: none - Cleaning: EURO-thinner TH03. } \\
\hline \multicolumn{2}{|c|}{ Does not contain. It is a $100 \%$ solids epoxy product. } \\
\hline \multicolumn{2}{|c|}{ Surface dry: approx. 24 hours (underwater application, $23^{\circ} \mathrm{C}$ aprox.). } \\
\hline \multicolumn{2}{|c|}{$\begin{array}{l}\text { Min: } 24 \text { hours at } 23^{\circ} \mathrm{C}\left(73,4^{\circ} \mathrm{F}\right) \text {. Max.: } 7 \text { days. If maximum overcoat time period } \\
\text { exceeded, rough up surface. }\end{array}$} \\
\hline \multicolumn{2}{|c|}{ Self. } \\
\hline \multicolumn{2}{|l|}{ Min: $5^{\circ} \mathrm{C}\left(41^{\circ} \mathrm{F}\right)$, Max.: $50^{\circ} \mathrm{C}\left(122^{\circ} \mathrm{F}\right)$} \\
\hline \multicolumn{2}{|c|}{ Min: $5^{\circ} \mathrm{C}\left(41^{\circ} \mathrm{F}\right)$, Max.: $50^{\circ} \mathrm{C}\left(122^{\circ} \mathrm{F}\right)$} \\
\hline \multicolumn{2}{|c|}{ Two pack product, available in I and $5 \mathrm{Kg}$., packs. } \\
\hline \multicolumn{2}{|c|}{$\begin{array}{l}\text { The product must be stored in accordance with national regulations. The product } \\
\text { should be kept in a cool well ventilated places protected from high temperatures. } \\
\text { Containers MUST BE kept tightly closed. Shelf life: } 1 \text { year }\end{array}$} \\
\hline Euronavy Laboratory. & \\
\hline
\end{tabular}

EURO-paste ES326, last revised 31/07/2002

Manufactured by EURONAVY - Tintas Maritimas e Industriais, S.A - www.euronavy.net Estrada Vale de Mulatas, Quinta de S. Francisco, 2914-516 - Setúbal, Portugal Tel: +351.265.739440.Fax: +351.265.70 2711 .E-mail: sales@euronavy.net 


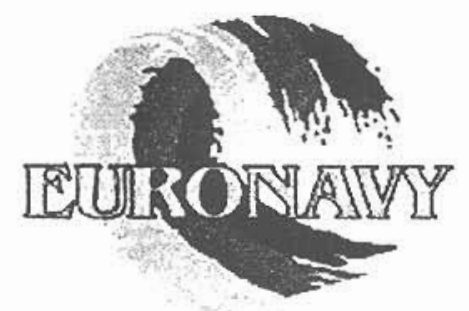

\section{EURO-paste ES326}

$100 \%$ solids undenwater epoxy filler

\section{Application guide}

\section{SURFACE PREPARATION}

EURO-paste ES326, is engineered for direct application on poorly prepared surfaces. Gently clean surface with pneumatic rotating machine over entire area to be treated. Remove all lose material, fouling, grease and lose coating. Before application of EURO-paste ES326, you MUST gently clean surface if any fouling or debris has settled on surface with rotating disc of SCOTCH BRITE or similar materials. NOTE: If surface has oil or grease contamination paint will bead and not adhere. Apply soap or degreaser to

cleaning pad and clean surface. Contact your local Euronavy agent, for recommendations.

\section{MIXING AND THINNING}

EURO-paste ES326, is a two pack $100 \%$ epoxy product., which contains the proper ratio of ingredients. Mix the product to obtain an uniform consistency. The mixing should not take more than 2 to 3 minutes. The use of a speed adjustable power mixer is recommended. The entire contents of each container must be mixed together, as supplied. Stir base first to obtain smooth homogenous condition not longer than 2 minutes. After obtaining a uniform base, add the curing agent slowly to the base under continuous stirring for 3 minutes. The use of a speed adjustable power mixer is recommended. Do not over agitate as this, will accelerate cure and lower life of product.

\section{DO NOT THIN THIS MATERIAI}

Higher temperatures will reduce pot life of the mixture. Lower temperatures will increase it.

ATHICAMION

EURO-paste ES326, can be applied, by spatula. Care should be taken that proper and uniform film thickness are obtained.

\section{SATEMY}

WARNING: Cause eye and skin irritation. Do not get in eyes on skin or clothing.

Be careful handling after mixing product. Use gloves.

FIRST AID: In case of eye contact immediately flush with plenty of water for at least 15 minutes, call a physician.

Wash skin contact areas with soap.

DISCLAIMER: This is not a specification and all information is given in good faith. Every values presented as Theoretionl were caloulated fiom the product formul unless otherwise mentioned and can deviate from laboratory measurements using standard methods that may be not applicable giving the nature of the products. If requested, Eurnavy can inform any intemal measurement method used to determinate any given value presented givis The

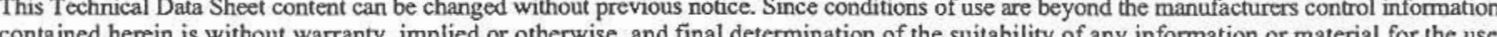
contained hereen is without was contemplated, de professional use only. Manufacturer does not assurne any liability in connection with the use of the product relative to coverage, performance or injury. For application in special conditions please consult Euronavy for detailed recommendations.

EURO-paste ES326, last revised 31/07/2002

Manufactured by EURONAVY - Tintas Maritimas e Industriais, S.A - www.euronavy,net Estrada Vale de Mulatas, Quinta de S. Francisco, 2914-516 - Setúbal, Portugal Tel: +351.265.739440 . Fax: +351.265 .702711 .E-mail: sales@euronavy.net 


\section{EURO-diver" TES323:(Base) \\ Material Safety Data Sheet}

1. IDENTIFICATION OF THE SUBSTANCE/COMPANY

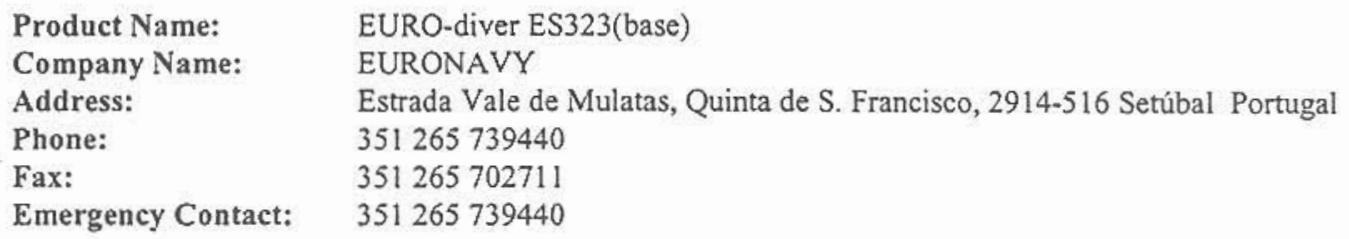

Emergency Contact: $\quad 351265739440$

\section{COMPOSITION/INFORMATION ON INGREDIENTS}

Preparation Description: 100\% Solids Underwater Epoxy Coating. HAZARDOUS INGREDIENTS

\begin{tabular}{|c|c|c|c|c|}
\hline Ingredient name & CAS number & Concentration & EC Symbol & EC R-phrase \\
\hline Liquid epoxy resin & $25068-38-6$ & $30 \%-40 \%(\mathrm{~m} / \mathrm{m})$ & $\mathrm{Xi}$ & R36/R38; R43 \\
\hline Benzyl alcohol & $100-51-6$ & $2 \%-5 \%(\mathrm{~m} / \mathrm{m})$ & $\mathrm{Xn}$ & $\mathrm{R} 20 / \mathrm{R} 22$ \\
\hline $\begin{array}{l}\text { lymer with branched } \\
\text { ranched ether and ureth } \\
\text { roups }\end{array}$ & $\begin{array}{l}\text { not available } \\
\text { ane }\end{array}$ & $20 \%-30 \%(\mathrm{~m} / \mathrm{m})$ & $\mathrm{Xi}$ & - \\
\hline $\begin{array}{l}\text { Glycidyl ester of } \\
\text { Neodecanoic acid }\end{array}$ & $26761-45-5$ & $5 \%-10 \%(\mathrm{~m} / \mathrm{m})$ & $\mathrm{Xi}$ & R36/R38; R43 \\
\hline
\end{tabular}

\section{HAZARDS IDENTIFICATION}

EYES : Causes irritation.

SKIN : Causes irritation. 


\section{m \\ EURORNAVY

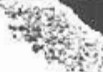 \\ $4 \operatorname{lin}^{2}$}

\section{4. $\quad$ FIRST AID MEASURES}

EYE CONTACT

SKIN CONTACT

INGESTION

INHALATION
: For direct contact: Immediately flush eyes for 15 minutes, occasionally lifting eye-lids. If victim wears contact lenses, remove lenses and continue rinsing. Clean contact before reuse. If irritation or redness persists, seek medical attention.

: Remove contaminated clothing. Wash affected area with mild soap and water. If irritation or redness develops and persists, seek medical attention.

: Do not induce vomiting, if victim is conscious and able. Get immediate medical attention.

: No specific measures.

\section{FIRE-FIGHTING MEASURES}

Extinguishing Media;

Fire Fight Procedure: fighters.

Unusual Fire/Explosion Hazards:
Dry chemical powder, carbon dioxide, foam, sand. Do not use water.

The use of self-contained breathing apparatus's recommended for fire

Keep adjacent containers cool by spraying water.

6. ACCIDENTAL RELEASE MEASURES

Personal protection

Environmental precautions:

se personal protection equipment. entering into drains, ditches or rivers by using sand, earth, or other appropriate barriers. If material enters drains, it should be pumped out into an open vessel.

\section{HANDLING AND STORAGE}

Handling: $\quad$ Avoid contact with skin, eyes and clothing..

Storage: $\quad$ Keep containers tightly closed, in warm and dry conditions. 


\section{EXPOSURE CONTROLS/PERSONAL PROTECTION}

Not established

Eyes protection: Safety glasses and available eye bath.

Respiratory protection: Not normally required.

Hand protection: Use chemical resistant type gloves.

\section{PHYSICAL AND CHEMICAL PROPERTIES}

\section{Physical state - Liquid.}

Flash Point $->200^{\circ} \mathrm{C}-392^{\circ} \mathrm{F}$ (Abel)

Viscosity - $104 \mathrm{KU}$ (mixture).

Density $-1,3 \mathrm{~g} / \mathrm{cm}^{3}$.

Solubility in water: Not soluble

\section{STABILITY AND REACTIVITY}

Reacts with strong oxidizing agents, polymerizes exothermically with amines, mercaptans and lewis acids at ambient temperature and above.

\section{TOXICOLOGICAL INFORMATION}

There are no information about the preparation.

\section{ECOLOGICAL INFORMATION}

There are no information about the preparation.

\section{DISPOSAL CONSIDERATIONS}

Depending the extend of the contamination reclaiming or incineration of the product by an officially authorized enterprise. 


\section{an EURRONAIVY

\section{TRANSPORT INFORMATION}

Not dangerous according to IMO, ADR/RID and IATA/ICAO

\section{REGULATORY INFORMATION}

Contains:

EEC Symbol:

EEC R-phrases:

EEC S-phrases:

Contains:

EEC Symbol:

EEC R-phrases:

EEC S-phrases:
Liquid epoxy resin and glycidyl ester of neodecanoic acid

$\mathrm{Xi}$ - Irritant.

R36/R38 - Irritating to eyes and skin

R43 - May cause sensitization by skin contact..

S24 - Avoid contact with skin.

S26 - In case of contact with eyes, rinse immediately with plenty of water and seek medical advice.

S28 - After contact with skin, wash immediately with plenty of soap and water S37/S39 - Wear suitable gloves and eye/face protection.

Benzyl Alcohol

$\mathrm{Xn}$ - Harmful.

R20/R22 - Harmfull by inhalation and ingestion.

S2 - Keep out of reach of children.

S26 - In case of contact with eyes, rinse immediately with plenty of water and seek medical advice.

\section{OTHER INFORMATION}

This Material Safety Data Sheet is in compliance with EEC 91/155/EEC directives.

Above informations have been made very carefully based on existing literatures, EURONAVY does not accept any liability whatsoever arising out of the use of this information. 


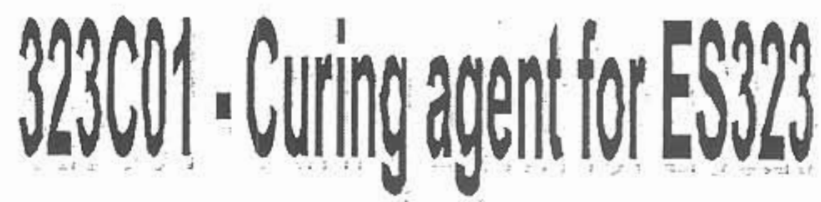 \\ Material Safety Data Sheet}

\section{DENTIFICATION OF THE SUBSTANCE/COMPANY}

$\begin{array}{ll}\text { Product Name: } & 323 \mathrm{C} 01 \\ \text { Company Name: } & \text { EURONAVY, Tintas Maritimas e Industriais S.A } \\ \text { Address: } & \text { Estrada Vale de Mulatas, Quinta de S. Francisco, 2914-516 Setúbal Portugal } \\ \text { Phone: } & 351265739440 \\ \text { Fax: } & 351265702711 \\ \text { Emergency Contact: } & 351265739440\end{array}$

\section{COMPOSITION/INFORMATION ON INGREDIENTS}

Preparation Description: Contains cycloaliphatic polyamine Curing agent for ES323.

HAZARDOUS INGREDIENTS

\begin{tabular}{ccccc}
\multicolumn{1}{c}{ Ingredient name } & CAS number & Concentration & EC Symbol & EC R-phrase \\
Cycloaliphatic polyamine & $2855-13-2$ & $40 \%-50 \%(\mathrm{~m} / \mathrm{m})$ & $\mathrm{C}$ & $\mathrm{R} 21 / 22 ; \mathrm{R} 34 ; \mathrm{R} 43$ \\
Benzyl alcohol & $100-51-6$ & $10 \%-15 \%(\mathrm{~m} / \mathrm{m})$ & $\mathrm{Xn}$ & $\mathrm{R} 20 / 22$
\end{tabular}

\section{HAZARDS IDENTIFICATION}

Harmful in contact with skin and by ingestion.

May cause burns.

May cause sensitization by skin contact. 


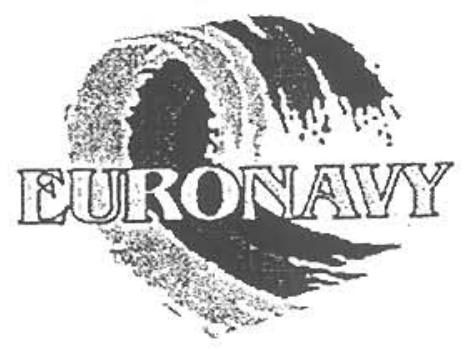

\section{FIRST AID MEASURES}

EYE CONTACT $\quad$ : For direct contact: Immediately flush eyes for 15 minutes, occasionally lifting eyelids. If victim wears contact lenses, remove lenses and continue rinsing. Clean contact lenses before reuse. If irritation or redness persists, seek medical attention.

SKIN CONTACT $\quad$ : Remove contaminated clothing. Wash affected area with plenty of water and soap . If you feel unwell, seek medical attention.

INGESTION

: Do not induce vomiting. Show this document where possible..

\section{FIRE-FIGHTING MEASURES}

Extinguishing Media:

Foam, dry chemical or water spray. Do not use water jet.

Special Fire Fight Procedure: The use of self-contained breathing apparatus's recommended for fire fighters. Water may be helpful in keeping adjacent containers cool. Avoid spreading burning liquid with after used for cooling purposes.

\section{ACCIDENTAL RELEASE MEASURES}

Personal protection:

Use suitable personal protection equipment.

Environmental precautions: $\quad$ Avoid the contamination of rivers, lakes and sea, absorb or contain with earth, sand or other suitable material. Sweep up and wash area clean with water.

\section{HANDLING AND STORAGE}

Handling: Avoid contact with skin and eyes. Provide good ventilation.

Storage: $\quad$ Keep the containers in a cool, dry place.

\section{EXPOSURE CONTROLS/PERSONAL PROTECTION}

Eyes protection: Safety glasses and available eye bath.

Hand protection: Use suitable gloves.

Skin protection: Wear boot and industrial overalls, preferably disposable, of the impervious, multilayer type.

$323 \mathrm{CO1}$, curing agent for ES323, last revised 20-06-2002 
9. PHYSICAL AND CHEMICAL PROPERTIES

Physical state - Liquid

Flash Point $->100^{\circ} \mathrm{C}$ (Abel)

Viscosity - > $140 \mathrm{KU}$.

Density $-1,0 \mathrm{~g} / \mathrm{cm}^{3}$

Solubility in water: Not soluble

\section{STABILITY AND REACTIVITY}

Reacts with acids.

It decomposes at temperatures above $260^{\circ} \mathrm{C}$, it produces ammonia as decomposition product.

11. TOXICOLOGICAL INFORMATION

There are no information about the preparation.

\section{ECOLOGICAL INFORMATION}

There are no information about the preparation.

\section{DISPOSAL CONSIDERATIONS}

Depending the extend of the contamination reclaiming or incineration of the product by an officially authorized enterprise.

\section{TRANSPORT INFORMATION}

UN-No

$323 \mathrm{CO} 1$, curing agent for ES323, last revised 20-06-2002
2735

Mod 60/01 
ICAO/IATA

15. REGULATORY INFORMATION

Contains:
EEC Symbol:
EECR-phrases:

EEC S-phrases: medical advice.

Contains:

EEC Symbo:

EEC R-phrases:

EEC S-phrases:

S26 - In case of contact with eyes, rinse immediately with plenty of water and seek medical advice.

Cycloaliphatic polyamine

C-Corrosive.

R21/R22 - Harmful by skin contact and ingestion.

R34 - Causes burns

R43 - May cause sensitization by skin contact.

Benzyl Alcoho

$\mathrm{X} n$ - Harmful.

R20/R22 - Harmfull by inhalation and ingestion.

S2 - Keep out of reach of children.
S26 - In case of contact with eyes, rinse immediately with plenty of water and seek

S36/37/39 - Wear suitable protective clothing, gloves and eye/face protection.

\section{OTHER INFORMATION}

This Material Safety Data Sheet is in compliance with EEC 91/155/EEC directives.

Above informations have been made very carefully based on existing literatures, EURONAVY does not accept any liability whatsoever arising out of the use of this information. 


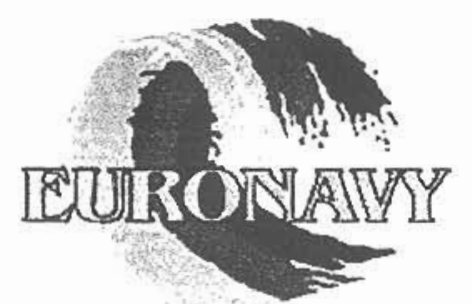

\section{CWNDRA:}

EURO-diver 1 ES323, is a $100 \%$ solids high performance two pack epoxy product, designed for application underwater with conventional tools.

EURO-diver 1 ES323, complies with modern environmental regulations (does not contain VOC's), and can be applied directly over steel.

Before any overall application is undertaken a small area should be coated and inspected for lifting, wrinkling or softening of the underfilm.

\section{EURO-WEer IES32] \\ $100 \%$ solids undenwater epoxy coating}

\section{FOATURAS}

- EXCELLENT ANTICORROSIVE PROPERTIES.

- EASY UNDERWATER APPLICATION WITH CONVENTIONAL TOOLS.

COMPATIBLE WITH CATHODIC PROTECTION.

- eXCELlent ADHESION ON POORLY TREATED SURFACES.

- EXCELleNT

WATER RESISTANCE
RDCOMMIDNMDUSES

SHIPS, OFFSHORE \& MARINE STRUCTURES

Great for protection of splash zones.

PIPE COATINGS

Provides anticorrosive protection for industrial water intakes lines.

STEEL WATER TANKS

\section{Specification Data}

\begin{tabular}{|l|}
\hline Binder Type / Pigment Type \\
\hline Colors \\
\hline Finish \\
\hline Mixing ratio \\
\hline Curing agent \\
\hline Specific gravity (mixture) \\
\hline Solids by Volume \\
\hline Pot Life \\
\hline Flash point (Abel) \\
\hline Theoretical covering capacity \\
\hline Typical film thickness per coat \\
\hline Application method \\
\hline Thinner \\
\hline VOC (Volatile Organic Compound) \\
\hline Drying time \\
\hline Overcoating time \\
\hline Recommended primers \\
\hline Ambient temperature \\
\hline Substrate temperature \\
\hline Packing \\
\hline Storage and Shelf life \\
\hline Approvals \\
\hline
\end{tabular}

\begin{tabular}{|c|c|}
\hline \multicolumn{2}{|c|}{ Modified epoxy/Amine composite - Chemical resistant pigments. } \\
\hline \multicolumn{2}{|l|}{ ES323 00 White, or custom request. } \\
\hline \multicolumn{2}{|l|}{ Mate. } \\
\hline 5 (base) to 1 (curing agent) by weight. & 4 (base) to 1 (curing agent) by volume \\
\hline \multicolumn{2}{|l|}{$323 \mathrm{C} 01}$. \\
\hline \multicolumn{2}{|l|}{$1.30 \pm 0.04 \mathrm{Kg} / \mathrm{dm}^{3}$} \\
\hline \multicolumn{2}{|l|}{$100 \%$. (theoretical). } \\
\hline \multicolumn{2}{|c|}{40 minutes at $23^{\circ} \mathrm{C}\left(73,4^{\circ} \mathrm{F}\right)$, (outside from the water). } \\
\hline \multicolumn{2}{|c|}{ Base: $>100^{\circ} \mathrm{C}\left(>212^{\circ} \mathrm{F}\right)$; Curing Agent: $>100^{\circ} \mathrm{C}\left(>212^{\circ} \mathrm{F}\right)$} \\
\hline \multicolumn{2}{|c|}{3,84 Sq.m/Kg. (18,8 Sq.fuLb) at 200 microns ( 8 mils). } \\
\hline \multicolumn{2}{|c|}{ Wet: 200 microns ( 8 mils); - Dry: 200 microns ( 8 mils). } \\
\hline \multicolumn{2}{|c|}{ Brush, Roller. A power roller is recommended for quickest application } \\
\hline \multicolumn{2}{|c|}{ Material: Not applicable - Cleaning: EURO-thinner TH03. } \\
\hline \multicolumn{2}{|c|}{ Does not contain. It is a $100 \%$ solids epoxy product. } \\
\hline \multicolumn{2}{|c|}{ Surface dry: approx. 24 hours (underwater application, $23^{\circ} \mathrm{C}$ aprox.). } \\
\hline \multicolumn{2}{|c|}{$\begin{array}{l}\text { Min: } 24 \text { hours at } 23^{\circ} \mathrm{C}\left(73,4^{\circ} \mathrm{F}\right) \text {. Max.: } 7 \text { days. If maximum overcoat time period } \\
\text { exceeded, rough up surface. }\end{array}$} \\
\hline \multicolumn{2}{|c|}{ Self. } \\
\hline \multicolumn{2}{|l|}{ Min: $5^{\circ} \mathrm{C}\left(41^{\circ} \mathrm{F}\right)$, Max: $50^{\circ} \mathrm{C}\left(122^{\circ} \mathrm{F}\right)$} \\
\hline \multicolumn{2}{|l|}{ Min: $5^{\circ} \mathrm{C}\left(41^{\circ} \mathrm{F}\right)$, Max.: $50^{\circ} \mathrm{C}\left(122^{\circ} \mathrm{F}\right)$} \\
\hline \multicolumn{2}{|c|}{ Two pack product, available in 1 and $5 \mathrm{Kg}$., packs. } \\
\hline \multicolumn{2}{|c|}{$\begin{array}{l}\text { The product must be stored in accordance with national regulations. The product } \\
\text { should be kept in a cool well ventilated places protected from high temperatures. } \\
\text { Containers MUST BE kept tightly closed. Shelf life: } 1 \text { year }\end{array}$} \\
\hline Euronavy Laboratory. & \\
\hline
\end{tabular}

EURO-diver 1 ES323, last revised 31/07/2002

Manufactured by EURONAVY - Tintas Maritimas e Industriais, S.A - www.euronavy.net Estrada Vale de Mulatas, Quinta de S. Francisco, 2914-516 - Setúbal, Portugal Tel: +351.265.739440. Fax: +351.265.702711.E-mail: sales@euronavy.net 


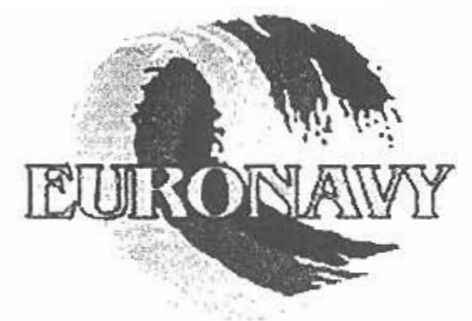

\title{
EUROdWer' IES323
}

Application guide

\author{
SURFACE PREPARATION
}

EURO-diver 1 ES323, is engineered for direct application on poorly prepared surfaces. Gently clean surface with pneumatic rotating machine over entire area to be treated. Remove all lose material, fouling, grease and lose coating. Before application of EURO-diver 1 ES323, you MUST gently clean surface if any fouling or debris has settled on surface with rotating disc of SCOTCH BRITE or similar materials. NOTE: If surface has oil or grease contamination paint will bead and not adhere. Apply soap or degreaser to cleaning pad and clean surface. Contact your local Euronavy agent, for recommendations.

\section{MIXING AND THINNING}

EURO-diver $1 \mathrm{ES} 323$, is a two pack $100 \%$ epoxy product., which contains the proper ratio of ingredients. Mix the product to obtain an uniform consistency. The mixing should not take more than 2 to 3 minutes. The use of a speed adjustable power mixer is recommended. The entire contents of each container must be mixed together, as supplied. Stir base first to obtain smooth homogenous condition not longer than 2 minutes. After obtaining a uniform base, add the curing agent slowly to the base under continuous stirring for 3 minutes. The use of a speed adjustable power mixer is recommended. Do not over agitate as this, will accelerate cure and lower life of product.

Higher temperatures will reduce pot life of the mixture. Lower temperatures will increase it.

APPICAMION

EURO-diver 1 ES323, can be applied by brush or roller. A power roller, is recommended for ease and speed. Use contrasting colours for each coat and stripe coating. However a regular solvent resistant brush or roller should be use. Use short bristle brush or medium nap roller working the material into all irregularities. Brush or lap marks may be visible. Be sure that proper film thickness is achieved by working the material. On sharp edges, boltheads, flanges, etc., a second coat would be better to "skips" or holidays. Product may be immersed in water during application on kept topside for power roller application.

WARNING: Cause eye and skin irritation. Do not get in eyes on skin or clothing.
Be careful handling after mixing product. Use gloves.
FIRST AID: In case of eye contact immediately flush with plenty of water for at least 15 minutes, call a physician.
Wash skin contact areas with soap.

DISCLAIMER: This is not a specification and all information is given in good faith. Every values presented as Theoretical were calloulated from the product formula, unless otherwise mentioned, and can deviate from laboratory measurements using standard methods that may be not applicable, giving the nature of the products. If requested, Euronavy can inform any intemal measurement method used to determinate any given value presented. This Technical Data Sheet content can be changed without previous notice. Since conditions of use are beyond the manufacturers control information contained herein is without warranty, implied or otherwise, and final determination of the suitability of any information or material for the use contemplated, the manner of use and whether there is any infringement of patents is the sole responsibility of user. The product is intended for professional use only. Manufacturer does not assume any liability in connection with the use of the product relative to coverage, performance or injury. For application in special conditions please consult Euronavy for detailed recommendations.

EURO-diver 1 ES323, last revised 31/07/2002

Manufactured by EURONAVY - Tintas Maritimas e Industriais, S.A - www.euronavy,net Estrada Vale de Mulatas, Quinta de S. Francisco, 2914-516 - Setúbal, Portugal Tel: +351.265.739440.Fax: +351.265.702711.E-mail: sales@euronavy.net 


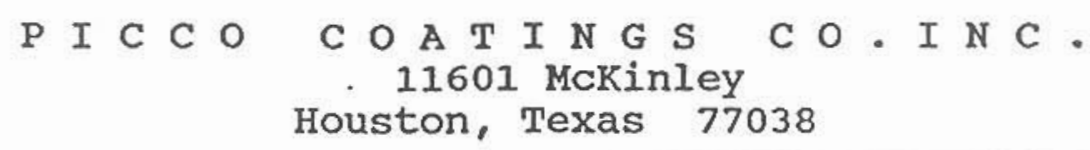

Section I -- PRODUCT IDENTIFICATION

\begin{tabular}{lrl}
\hline Product Class & EPOXY PRODUCTS & Emergency Tel.\#:(800) 633-8253 \\
Manufacturers Code: UT-15 A & Information \#: (281) 447-8877 \\
Trade Name & $:$ UNDERWATER EPOXY RESIN &
\end{tabular}

Trade Name

Section II -- HAZARDOUS INGREDIENTS

\begin{tabular}{|c|c|c|c|c|c|c|c|}
\hline Ingredients & CAS & $\#$ & : & Percent & : & TLV & : \\
\hline $\begin{array}{l}\text { BISPHENOL A/EPICHLOROHYDRIN } \\
\text { (EPOXY RESIN) }\end{array}$ & : 25068-3 & $8-6$ & $:$ & 100 & $\vdots$ & NE. & $=$ \\
\hline
\end{tabular}

1. Residual levels of Epichlorohydrin are controlled to 1 PPM maximum.

Section III -- PHYSICAL DATA

\begin{tabular}{ll}
\hline Diling Point : $>500$ deg. F & Evaporation Rate : N/A \\
oht/Gallon : $9.7 \#$ & o volatile by Vol. : $0 \%$ \\
ve : Pressure: N/A & Appearance and Odor : THICK CLEAR LIQUID \\
Vapor Density : N/A & Solubility in Water : NEGLIGIBLE
\end{tabular}

\section{Section IV -- FIRE AND EXPLOSION HAZARD DATA}

Flammability classification :OSHA-CLASS III-A

Extinguishing Media Use National Fire Protection Association (NFPA) C
Fire Extinguisher or dry chemical, foam or carbon
dioxide. Water fog may also be used.

Unusual Fire and Explosion Hazards: Keep containers tightly closed and away from heat, sparks, electrical equipment and open flame. Closed containers may explode when exposed to extreme heat and resultant pressure build up.

\section{Section V -- HEALTH AND HAZARD DATA}

THRESHOLD LIMIT VALUE: N.E.

EFFECTS OF OVER EXPOSURE

Acute: Inhalation- Because of its low volatility, this product is not likely to be an inhalation hazard.

Chronic: Repeated contact may cause dermatitis.

EMERGENCY AND FIRST AID PROCEDURES: Remove patient to fresh air. Flush eyes with clean water for 15 minutes. Wash skin thoroughly and remove saturated clothing. If symptoms persist, seek medical attention.

Ingestion: Keep person warm and quiet. Do not induce vomiting. Call physician immediately. 
SL...JLITY: Stable

INCOMPATIBILITY (MATERIALS TO AVOID); Avoid contact with strong oxidizing agents.

HAZARDOUS DECOMPOSITION PRODUCTS: Usual products of combustion - $\mathrm{CO}, \mathrm{CO} 2$ and possibly acrolein.

HAZARDOUS POLYMERIZATIONS: [ ] MAY OCCUR [X] WILL NOT OCCUR

CONDITIONS TO AVOID: Reaction with some curing agents may produce considerable heat. Run-a-way reactions may char and decompose the resin system, generating unidentified fumes and vapors which may be toxic.

Section VII -- SPILL OR LEAK PROCEDURES

STEPS TO BE TAKEN IN CASE MATERIAL IS RELEASED OR SPILLED: Remove sources Of ignition and provide ventilation. Large spills may be scooped up with

Wlatblade shovels. Provide personal protection. Small quantities may
be picked up with absorbent material. See disposal precautions below.
WASTE DISPOSAL METHOD: Place in closed containers. See other precautions

flatblade shovels. Provide personal protection. Small quantities may
be picked up with absorbent material. See disposal precautions below.
WASTE DISPOSAL METHOD: Place in closed containers. See other precautions below. Dispose of in accordance with local, state and federal regulations.

\section{Section VIII -- SPECIAL PROTECTION INFORMATION}

NGSPIRATORY PROTECTION: Not ordinarily required.

MmILATION: Designed and maintained to provide fresh air volume and pattern to prevent vapor concentration in excess of Threshold limit Value (TLV) or Lower Explosive Limit (LEL).

PROTECTIVE GLOVES: Neoprene rubber gloves. EYE PROTECTION: Goggles or side shield spectacles.

OTHER PROTECTIVE EQUIPMENT: EYe wash station and safety showers should be available.

\section{Section IX -- SPECIAL PRECAUTIONS}

PRECAUTIONS TO BE TAKEN IN HANDLING AND STORAGE: store in cOol, dry place. Keep away from open flames and high temperatures. Containers, even those that have been emptied, can contain hazardous product residues. Handle in accordance with the hazard potential of curing agent(s) used.

Transport Information: DOT: Resin Compound, Not Regulated

While PICCO COATINGS $C O$. believes that the data herein is accurate and derived from qualified sources, this data is not to be taken as a warrantee or representation of fact for which PICCO COATINGS CO. assumes legal responsibility. They are offered solely for your consideration, and investigation and verification. 


\section{P I C C O C O A T I N S CO. IN C. 11601 McKinley}

Houston, Texas 77038

Section I -- PRODUCT IDENTIFICATION

$\begin{array}{lrr}\text { Product Class } & : \text { EPOXY PRODUCTS } & \text { Emergency Tel. \#:(800) 633-825: } \\ \text { Manufacturers Code: UT-15B } & \text { Information \# : }(281) \text { 447-887: } \\ \text { Trade Name } & : \text { UNDERWATER EPOXY SYSTEM -HARDENER COMPONENT }\end{array}$

Section II -- HAZARDOUS INGREDIENTS

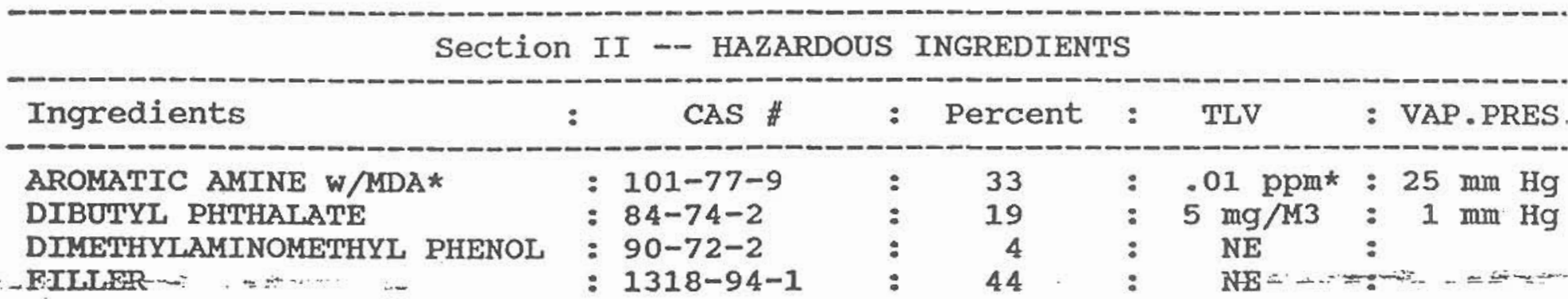

* Skin contact- This product contains trace quantities of Methylene Dianaline, which is a suspected carcinogen, and is therefore classified as "Extremely

Hazardous Substance" under SARA Title III. NE=NOT ESTABLISHED

$\mathrm{N} / \mathrm{A}=\mathrm{NOT}$ APPLICABLE

\section{Section III -- PHYSICAI DATA}

$\begin{array}{ll}\text { iling Point : }>200 \text { deg. C } & \text { Evaporation Rate : N/A } \\ \text { ht/Gallon : } 12.1 \# & \text { \% Volatile by Vol. : } 8 \% \\ \text { r Pressure: see above } & \text { Appearance and odor : THICK WHITE LIQUID } \\ \text { Vapor Density : N/A } & \text { Solubility in Water : SLIGHTLY SOLUBLE }\end{array}$

Section IV -- FIRE AND EXPLOSION HAZARD DATA

Flammability Classification :OSHA-CLASS III-A

Flash Point : $>250$ Deg. C

LEL: $N / A$

Extinguishing Media : Use National Fire Protection Association (NFPA) Class B Fire Extinguisher or dry chemical, foam or carbon dioxide. Water fog may also be used.

Unusual Fire and Explosion Hazards: Keep containers tightly closed and away from heat, sparks, electrical equipment and open flame. closed containers may explode when exposed to extreme heat and resultant pressure build up.

Section V -- HEALTH AND HAZARD DATA

THRESHOLD LIMIT VALUE: see section II

EFFECTS OF OVER EXPOSURE- Human liver toxin. Fever, chills, anorexia, jaundice, eye and respiratory tract irritation. Carcinogenic in laboratory test animals.

EMERGENCY AND FIRST AID PROCEDURES:

SKIN: Wash thoroughly with mild soap and water.

EYES: Immediately flush eyes with water for at least 15 minutes.

call a physician.

INGESTION: If conscious, give large quantities of water. Induce

vomiting. Call a physician.

INHALATION: Remove to fresh air. Give oxygen if breathing difficult.

OTHER: Promptly remove contaminated clothing and wash before reuse.

Destroy contaminated leather and absorbent shoes. 
BILITY: Stable

2.. LOMPATIBILITY (MATERIALS TO AVOID); Avoid contact with strong oxidizing agents.

HAZARDOUS DECOMPOSITION PRODUCTS: Usual products of combustion - $\mathrm{CO}, \mathrm{CO} 2$ and possibly acrolein.

HAZARDOUS POLYMERIZATIONS: [ ] MAY OCCUR [x] WILL NOT OCCUR

CONDITIONS TO AVOID: Reaction with some resin bases may produce considerable heat. Run-a-way reactions may char and decompose the resin system, generating unidentified fumes and vapors which may be toxic.

Section VII -- SPILI OR LEAK PROCEDURES

STEPS TO BE TAKEN IN CASE MATERIAL IS RELEASED OR SPILLED: Remove SOU Ces Of ignition and provide ventilation. Large spills may be scooped up with nonsparking tools. Provide respiratory protection if required. Small quantities may be picked up with absorbent material. - See disposal precautions below.

WASTE DISPOSAL METHOD: Place in closed containers. See other precautions below. Dispose of in accordance with loca?, state and federal regulations.

\section{Section VIII -- SPECIAI PROTECTION INFORMATION}

TSPIRATORY PROTECTION: NIOSH Or MSHA approved mask or respirator for organic 6 vapors.

v ILATION: Designed and maintained to provide fresh air volume and pattern to prevent vapor concentration in excess of Threshold Limit value (TLV) or Lower Explosive Limit (LEL).

RROTECTIVE GLOVES: Neoprene rubber gloves.

EYE PROTECTION: Goggles or side shield spectacles.

OTHER PROTECTIVE EQUIPMENT: Eye wash station and safety showers should be available.

\section{Section IX - SPECIAL PRECAUTIONS}

WARNING!! Harmful if absorbed through the skin, swallowed or inhaled. May cause irritation and sensitization.

Keep containers tightly closed when not in use. store away from food, food containers and clothing. Use clean clothing daily. A shower after work is recommended.

Transport Information: DOT: Environmentally Hazardous Substance, Liquid, Corrosive, n.o.s. (Polyaromatic Amine), 9, UN-3082, PG III PSN: Environmentally Hazardous Substance, Liquid, n.0.5. IMDG: Class 9 PA 09028 UN-3082 PGP III.

NOTE: This product is made exclusively for S.G. Pinney and Associates, Port St. Lucie, FI.

mile PICCO COATINGS $C O$. believes that the data herein is accurate and derived

Jm qualified sources, this data is not to be taken as a warrantee or

re zsentation of fact for which PICCO COATINGS CO. assumes legal

re. onsibility. They are offered solely for your consideration, and

investigation and verification. 


$$
\text { UT }-15
$$

\section{UNDERWATER EPOXY COATING}

\section{DESCRIPTION:}

PICCO COATINGS CO., INC. UT-15 caating is a twa component epoxy system designed ta be applied in underwater/splash zane environments. It chemically displaces water cin the surface being coated, effecting an excellent bond ta the substrate.

\section{RECOMMENDED APPLICATIONS:}

UT-15 Epoxy Coating is especially suited as a protective caating for use on of fshare oil rigs, dock pilings, cancrete reservairs, caoling towers, sewage treatment areas, and processing plant floors. UT-15 not only lowers maintenance costs, but extends the expected service 1 ife of equipment and structures. It provides a durable waterproof surface an a variety of materials such as metal, wood, concrete, and fiberglass.

\section{EEATURES:}

* $100 \%$ Sol ids

*Will not emulsify or float away during application.

* Lowers maintenance costs.

*Easily applied with a paint brush.

* Premeasured kits.

*Excellent resistance to mast acids, solvents, caustics, and ails.

PRODUCT CHARACTERISTICS:

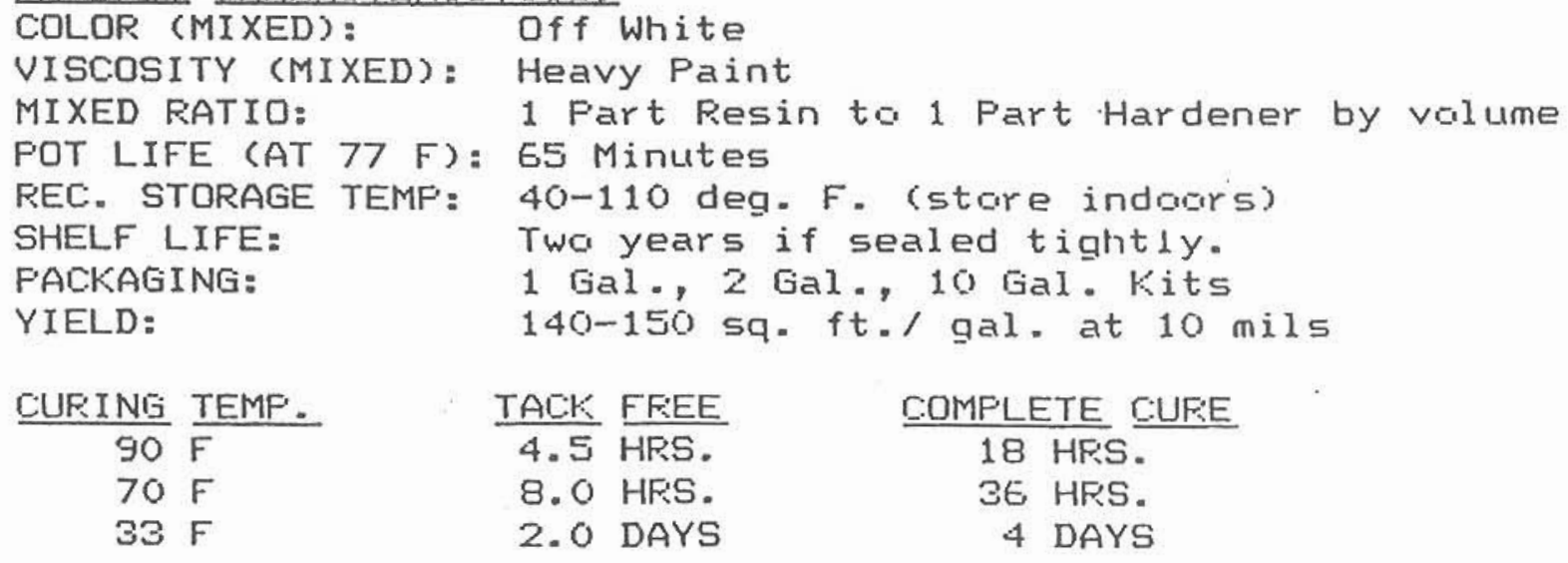


To recoat, allow caating to became task free. If caating is allowed to exceed the camplete cure periad, then mechanically abrade before recating. Although UT-15 will cure at $33 \mathrm{~F}$, normal recommended water temperature should not fall below $45 \mathrm{~F}$.

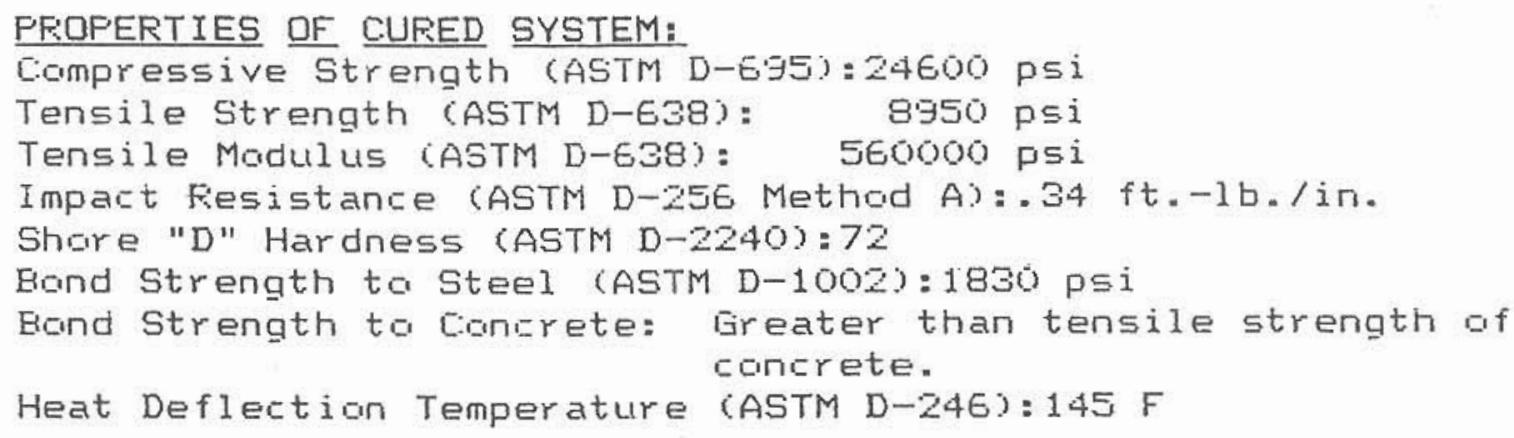

Abrasive blast or otherwise etch to remove surface 1 aitance and other cantaminants. Minimum cancrete strength must be 3,000 psi.

\section{Installation Procedures:}

1. Mix 1 parts Campanent $A$ to 1 part Campanent $B$ af the UT-15 for 2-3 minutes. Trowel apply this material.

2. Allow ta cure overnight.

\section{HANDLING AND SAFETY PRECAUTIONS:}

This bulletin does not accompany the product when sold. For First Aid instructions and Hazard warnings, refer to Material Safety Data Sheets, which are included with each shipment.

Ficca coatings C:a. Inc. Strangly recommends you read and fully understand handling and safety precautions prior to installation of materials. 
Fart A: Liquid Epa\%y Resin

Warning! causes eye and skin irritation. May cause allergic reaction. Harmful if swallowed. Avoid contact with eyes, skin and clathing. Wash thoroughly after handling. Avaid prolanged ar repeated contact with skin.

Fart B: Liquid Epoxy Hardener

Contains Alkaline Amines. Danger! Causes severe eye, and skin burns. May cause allergic skin and respiratory reaction. Harmful if swallowed, inhaled or absorbed through skin. Eontains trace quantities of MDA a suspected carcinogen and is therefore listed as "Extremely Hazardius Substance" by QSHA. Da not get in eyes, on skin or clothing. Avaid breathing vapor. Keep cantainer closed. Uise only adequate ventilation, wash after handling. Keep away from heat or open flame.

\section{DISCLAIMER:}

All technical data and recammendations herein are believed to be reliable to the best of our knowledge. Since PICCO COATINGS CO., INC. has no knowledge or cantral cancerning the purchaser's use of the product, no express warranty is made by FICCO COATINGS CO., INC. ar it's representatives and dealers with respect to results of any use of this product. No implied warranties, including but not limited to an implied warranty of merchantability, or an implied warranty of fitness for a particular purpose, are made with respect ta this product. Neither seller nor manufacturer assumes any liability for persanal injury, lass or damage resulting from the use of this praduct. 